\title{
SPATIAL AND TEMPORAL POPULATION GENETICS AT DEEP-SEA HYDROTHERMAL VENTS ALONG THE EAST PACIFIC RISE AND GALÁPAGOS RIFT
}

\author{
by \\ Abigail Jean Fusaro \\ B.S., University of Rhode Island, 2002 \\ Submitted in partial fulfillment of the requirements for the degree of \\ Doctor of Philosophy \\ at the \\ MASSACHUSETTS INSTITUTE OF TECHNOLOGY \\ and the \\ WOODS HOLE OCEANOGRAPHIC INSTITUTION \\ September 2008 \\ (C) 2008 Abigail J. Fusaro \\ All rights reserved. \\ The author hereby grants to MIT and WHOI permission to reproduce and \\ distribute publicly paper and electronic copies of this thesis document \\ in whole or in part in any medium now known or hereafter created.
}

Signature of Author

Joint Program in Oceanography/Applied Ocean Science and Engineering Massachusetts Institute of Technology and Woods Hole Oceanographic Institution July 7, 2008

Certified by

Timothy M. Shank Thesis Supervisor

Accepted by

Edward F. DeLong Chair, Joint Committee for Biological Oceanography

Massachusetts Institute of Technology and Woods Hole Oceanographic Institution 


\title{
Spatial and Temporal Population Genetics at Deep-Sea Hydrothermal Vents Along the East Pacific Rise and Galápagos Rift
}

\author{
by \\ Abigail Jean Fusaro \\ Submitted to the Department of Biology \\ on July 7, 2008, in partial fulfillment of the \\ requirements for the degree of \\ Doctor of Philosophy
}

\begin{abstract}
Ecological processes at deep-sea hydrothermal vents on fast-spreading mid-ocean ridges are punctuated by frequent physical disturbance. Larval dispersal among disjunct vent sites facilitates the persistence of sessile invertebrate species in these geologically and chemically dynamic habitats despite local extinction events. Regional population extension and rapid recolonization by the siboglinid tubeworm Riftia pachyptila have been well documented along the East Pacific Rise and the Galápagos Rift. To analyze spatial and temporal population genetic patterns and the processes governing them at ephemeral and disjunct habitats, a suite of 12 highly variable microsatellite DNA markers were developed for this species. Eight of these loci were used to assess the regional and within-ridge genetic structure of recent colonists and resident adults collected from nine sites in the eastern Pacific Ocean over period of three to seven years. A significant seafloor eruption during the seven-year sampling period allowed investigation into the role of local extinction in population genetic diversity at the Tica vent site at $9^{\circ} \mathrm{N}$ EPR, while collections within two and five years of an eruption that created the Rosebud vent field at $86^{\circ} \mathrm{W}$ GAR provided insights into genetic diversity input over population establishment.
\end{abstract}

For the first time, this thesis demonstrated significant genetic differences between Riftia populations on the East Pacific Rise and Galápagos Rift. Moreover, the separate treatment of colonist and resident subpopulations revealed a high potential for local larval retention at vent sites. This mechanism for recruitment likely sustains disjunct populations and supports the recolonization of locally extinct areas after disturbance events, while episodic long-distance dispersal maintains genetic coherence of the species. Temporal population genetic consideration at the Tica site on the East Pacific Rise suggests that the 2005-2006 seafloor eruption had little to no discernable effect on local population genetic composition. Yet local populations appear to exhibit a small degree of 
genetic patchiness, with a high degree of relatedness (half-sibs) among subsets of individuals within both colonist and resident cohorts. This thesis broadens the application of recently developed molecular techniques to study the effect of ridge-crest processes and offers new perspectives into marine dispersal, gene flow, and population differentiation.

Thesis Supervisor: Timothy M. Shank Title: Associate Scientist, Biology Department Woods Hole Oceanographic Institution 


\title{
Acknowledgments
}

\author{
"No man is an Island, entire of itself." John Donne, Meditation XVII
}

The journey I have been on these past several years would not have been possible had it not been for an enormous support system. I began the MIT/WHOI Joint Program in the Halanych lab, where Ken, Rob, Yale, Nan, and Annette led me into the world of molecular biology and genetics. Within months, Tim Shank graciously adopted me into his lab, and the adventures began in earnest. Tim has allowed me great freedom to explore, travel in several different (unfunded) research directions, and reconsider the routes that would lead to intellectual satisfaction. Together with my committee - Gabi Gerlach, Ron Etter, Adam Soule, Glenn Flierl-he has encouraged independence and ownership of my work. I take away from them the lessons of speculation and risk.

Many lab mates and classmates have coaxed me through the growing pains of grad school. Walter and Kate have provided a solid foundation as fellow students, always willing to lend an ear or a hand. I am also indebted to Amy and Diane for their previous work developing microsatellites for Riftia and Bathymodiolus and for being incredibly generous with their time and expertise. Rhian, Stace, and Breea have rounded out adventures at sea and in the lab with their experience and wherewithal. In addition, I have enjoyed working with and benefited from the manual support of many lab guests, including Taylor, Sara, Sarah, Carl, Alex, Aaron, Cory, and John.

My biology cohort of Kristen, Jonathan, Carly, and Ann has always been there as we leapfrogged through classes, generals preparations, thesis proposals, and defenses. Our thesis support dinners in the past year have nourished me not only with meals but also with food for thought. I also don't know how I would have survived (and in one piece) had it not been for Trish and Sharon. Leave it to two geologists to make me laugh the most and tolerate me at my worst. Together with Cory and Hunter, they are friends for life.

I gratefully acknowledge the opportunities for sample collection provided by S.C. Cary (NSF OCE-9714302), G. Luther (NSF OCE-9714302), R.A. Lutz (NSF OCE-9529819), and K.L. Von Damm (NSF OCE-9419156) during their expeditions, as well as the invaluable efforts of the captain, crew, and submersible pilots of the R/V Atlantis/Alvin. I would also like to thank A.M. "Ginger" Clark at the University of Florida, Gainesville for welcoming me into her lab and technical support for the development of microsatelliteenriched libraries. Special thanks to T. Paton, L. Timms, S. Russell, and J. Zhanqin at The Centre for Applied Genomics, Toronto, Canada for genotyping prepared samples and ensuring the highest quality control.

I was supported during my graduate tenure by a 2002 award from SEAPACE, a NSF 
Biocomplexity award to K. Halaynch (EAR-0120646), a 2004-2008 NOAA Dr. Nancy Foster Scholarship (Award No. NA04NOS4290253), and the Woods Hole Oceanographic Institution Academic Programs Office. Funding for my research was provided by the National Science Foundation (OCE-0327261 and OCE-0324232) and the National Oceanic and Atmospheric Administration's Office of Ocean Exploration and Research (Award Nos. NA03OAR4600110, NA16RP2390, and NA04OAR4600049) support to TMS.

Finally, I would like to thank my family for setting solid examples of integrity and hard work, for love and encouragement to do my best, and for believing in me through it all. Thank you for all the trips together to the seashore and for the inspiration to pursue my dreams, even when I was not entirely sure what they were. To my husband Vin, I cannot find words enough to express my gratitude. Thank you for the months endured at home while I was at sea, for keeping me going through late nights and early mornings, through tears and laughter, with constant companionship and faith. You have made sure that I get outdoors and take much-needed breaks, kept food in the house and dinner on the table, and given me perspective. This thesis is as much of your love and labor as it is of mine. 


\section{Table of Contents}

\begin{tabular}{|c|c|}
\hline \multicolumn{2}{|c|}{ 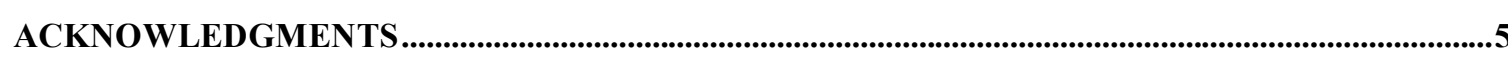 } \\
\hline \multirow{2}{*}{\multicolumn{2}{|c|}{ TABLE OF CONTENTS }} \\
\hline & LIST OF FIGURES \\
\hline \multicolumn{2}{|r|}{ LIST OF TABLES } \\
\hline \multicolumn{2}{|r|}{ 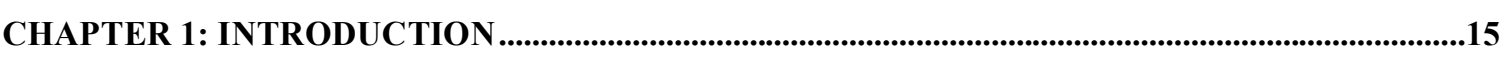 } \\
\hline & \\
\hline & \\
\hline & \\
\hline & \\
\hline & \\
\hline & \\
\hline & 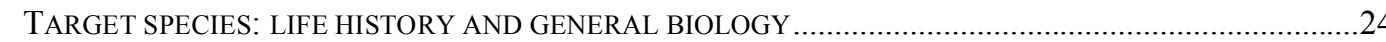 \\
\hline & RATIONALE FOR A DNA MICROSATELLITE APPROACH \\
\hline & ORGANIZATION OF THE CURRENT STUDY \\
\hline & 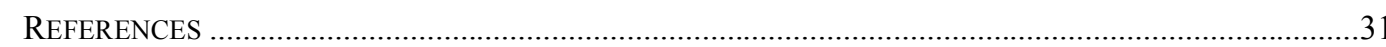 \\
\hline
\end{tabular}

\section{CHAPTER 2: DEVELOPMENT AND CHARACTERIZATION OF 12 MICROSATELLITE}

MARKERS FROM THE DEEP-SEA HYDROTHERMAL VENT SIBOGLINID RIFTIA

PACHYPTILA ............................................................................................................................................39

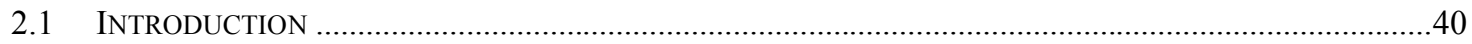

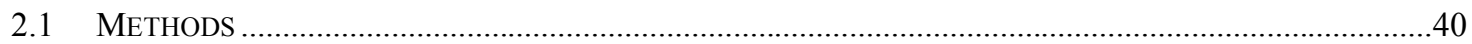

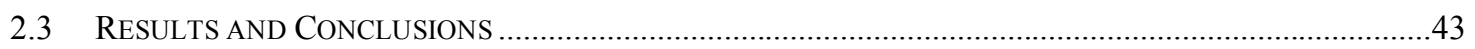

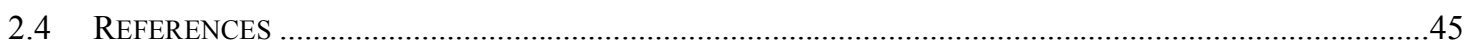

\section{CHAPTER 3: INFLUENCE OF LOCAL LARVAL RETENTION ON DEEP-SEA} HYDROTHERMAL VENT POPULATION STRUCTURE ..........................................................................47

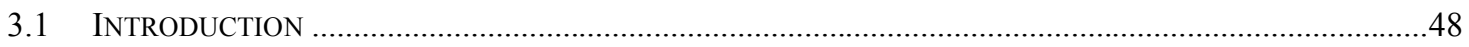

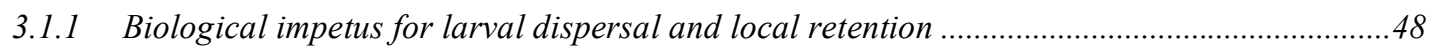

3.1.2 Proposed genetic barriers structuring eastern Pacific hydrothermal vent populations............50

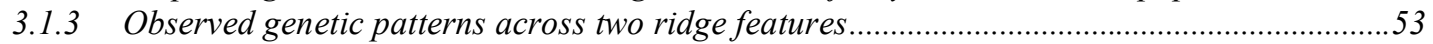

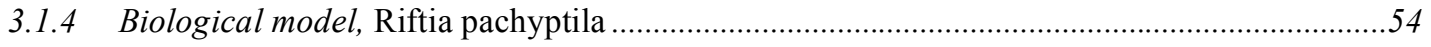

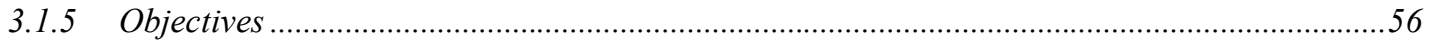

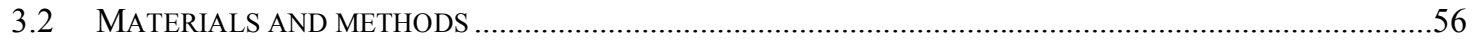

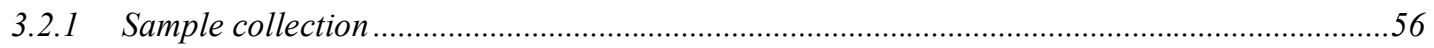

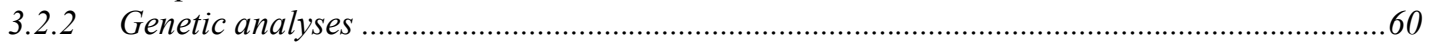

3.2.3 Single locus statistical analyses and conformance to Hardy-Weinberg equilibrium ...............61

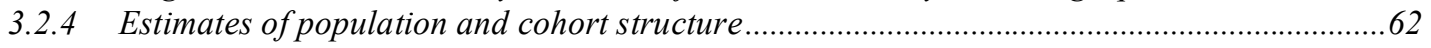

3.2.5 Effective migration, population bottlenecks, and colonist assignment ……............................64

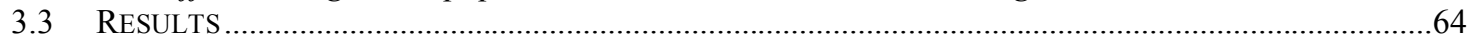

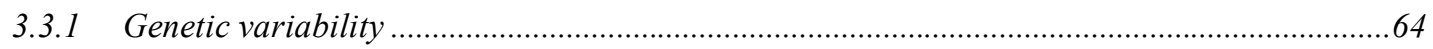

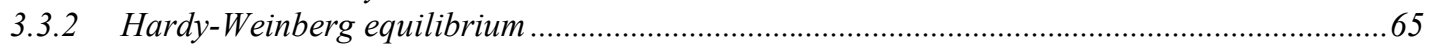

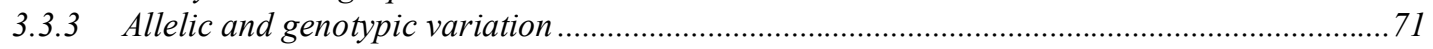

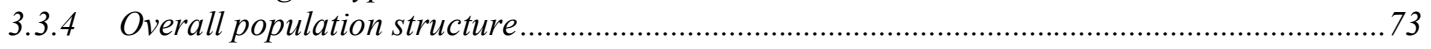

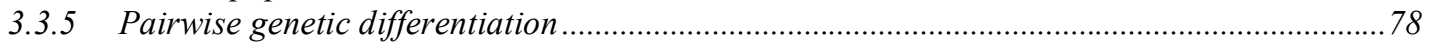




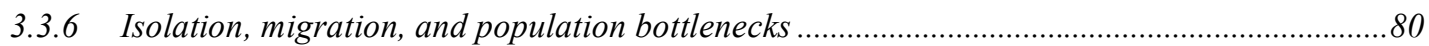

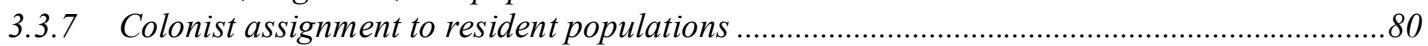

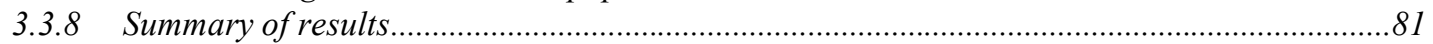

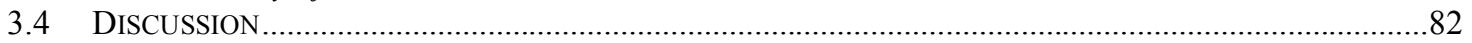

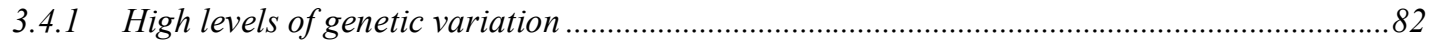

3.4.2 Excess homozygosity in relation to null alleles and Hardy-Weinberg equilibrium .................83

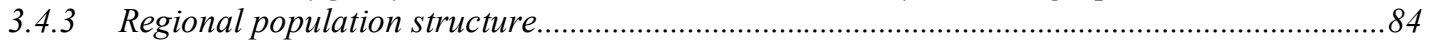

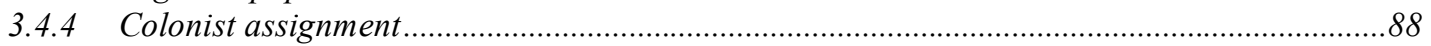

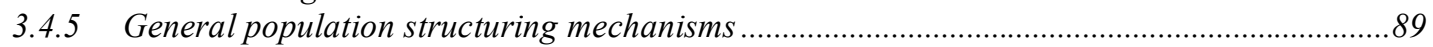

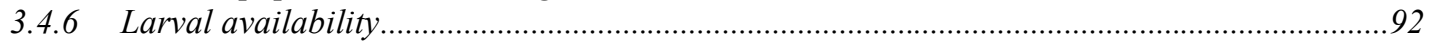

3.4.7 Consistency with previous vent population genetic patterns ..................................................93

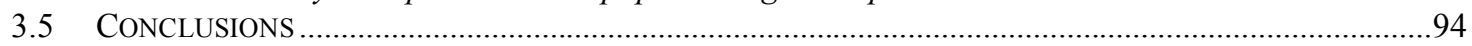

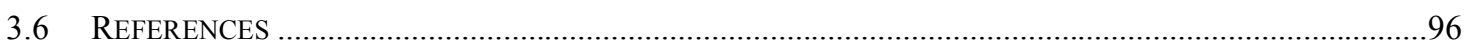

\section{CHAPTER 4: INTRA-RIDGE SEGMENT AND TEMPORAL POPULATION GENETIC} PATCHINESS AT HYDROTHERMAL VENTS.................................................................................109

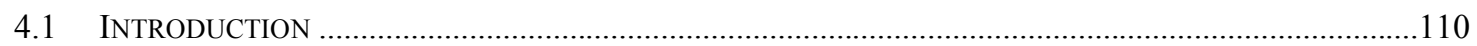

4.1.1 Fine-scale spatial and temporal population genetic variation ...............................................111

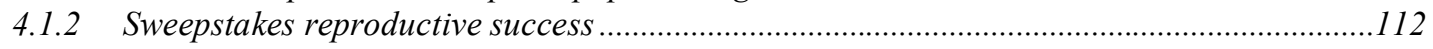

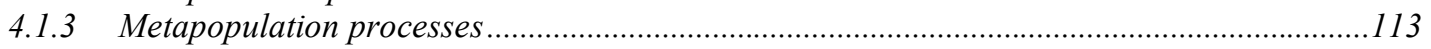

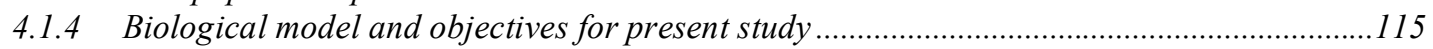

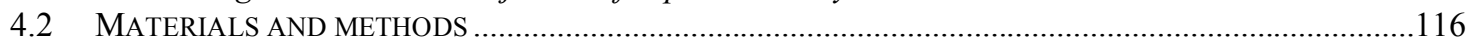

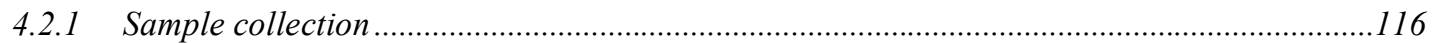

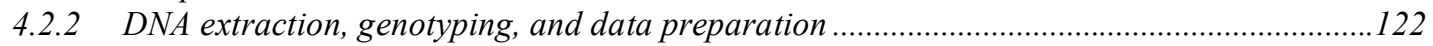

4.2.3 Single locus statistical analyses and conformance to Hardy-Weinberg equilibrium ..............123

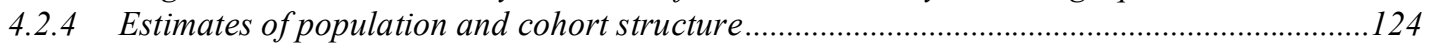

4.2.5 Effective migration, population bottlenecks, and cohort relatedness....................................126

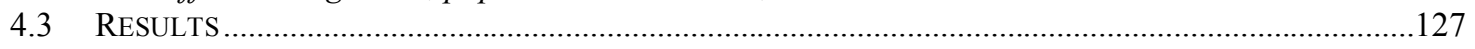

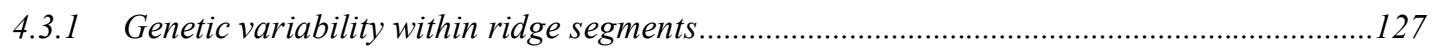

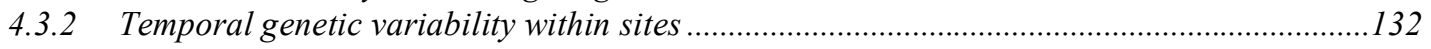

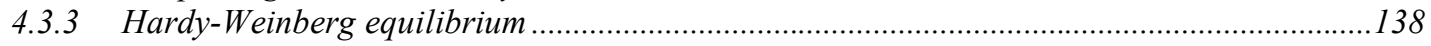

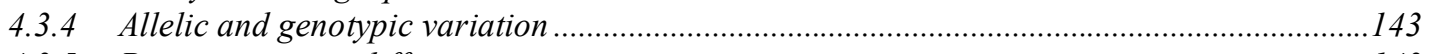

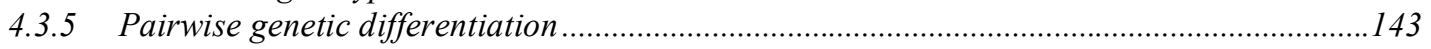

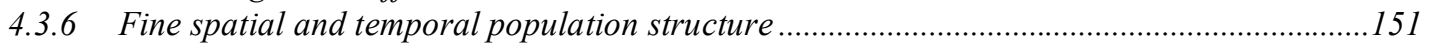

4.3.7 Isolation, migration, and population bottlenecks .............................................................151

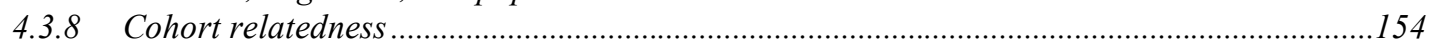

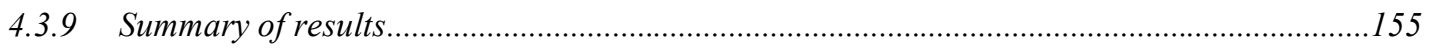

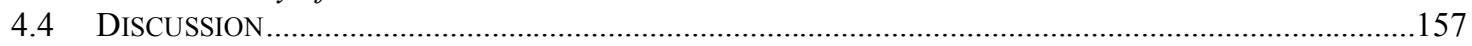

4.4.1 Higher genetic diversity on fast-spreading ridge ……........................................................15

4.4.2 Low level patchiness within ridge segments and among sampling years ............................157

4.4.3 Influence of seafloor eruptions and metapopulation dynamics ................................................160

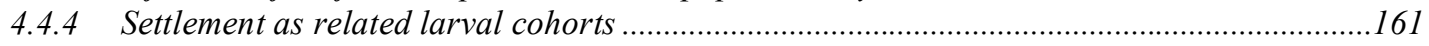

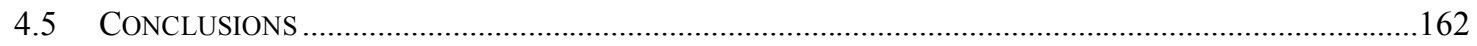

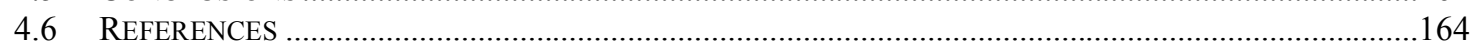

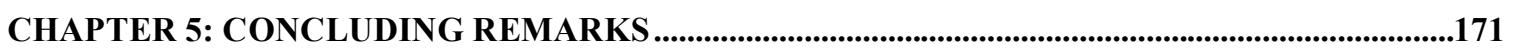

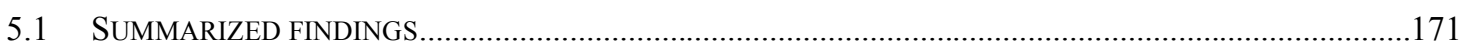

5.2 BARRIER TO GENE FLOW BETWEen THE EAST PACIFIC RISE AND GALÁPAGOS RIFT ...........................172

5.2.1 Influence of larval transport on oceanographic currents ..................................................... 174

5.2.2 Moderate migration rates versus non-equilibrium dynamics ................................................1.

5.3 LOCAL LARVAL RETENTION AND TRANSPORT WITH RELATED INDIVIDUALS ...................................176

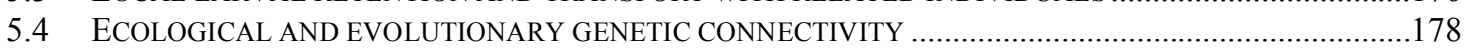

5.5 CONCEPTUAL MODEL OF RIFTIA DISPERSAL AND COLONIZATION ..................................................... 180 
5.6 COMPARISONS WITH HISTORICAL STUDY DESIGN AND PREVIOUS GENETIC PATTERNS IN RIFTIA ....180

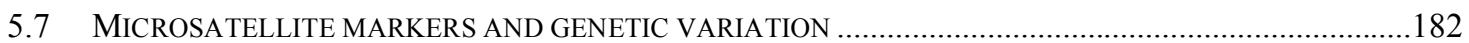

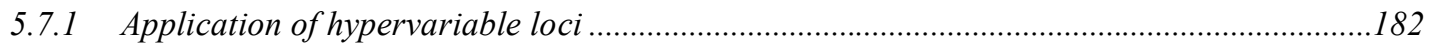

5.7 .2 Microsatellite variability in polychaetes ..............................................................................184

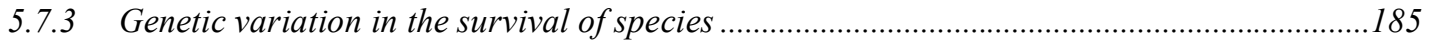

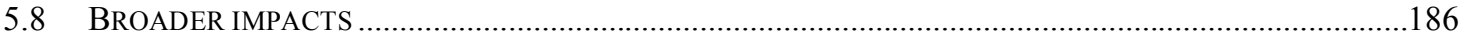

5.8.1 Consideration of fine spatial and temporal scale patterns ....................................................186

5.8.2 Multiple cohort perspective in population genetics.............................................................187

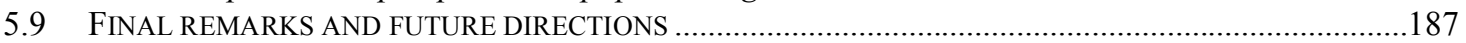

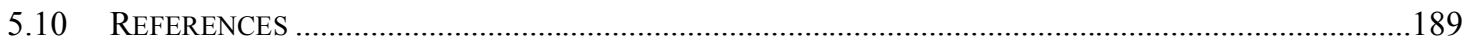

\section{APPENDIX A: MICROSATELLITE DEVELOPMENT IN BATHYMODIOLUS THERMOPHILUS}

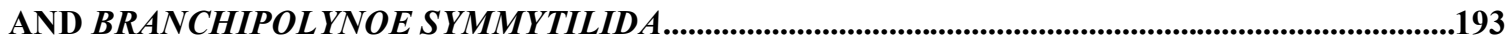

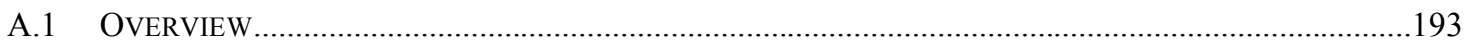

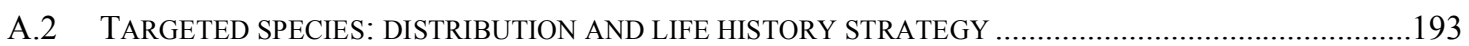

A.3 PREDICTED INFLUENCE OF LIFE HISTORY STRATEGIES ON POPULATION GENETIC PATTERNS..........196

A.4 PRELIMINARY MICROSATELLITE DEVELOPMENT ........................................................................198

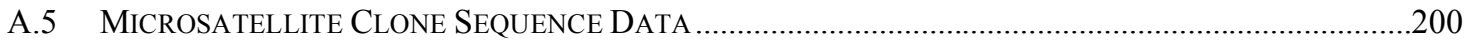

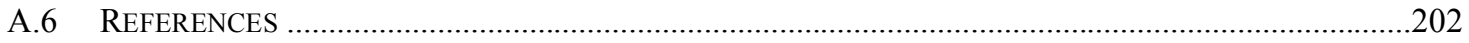

APPENDIX B: MICROSATELLITE LOCUS PROFILES............................................................205 


\section{List of Figures}

Figure 1.1 Timeline of select disturbances resulting in population and habitat turnover within the $9^{\circ} \mathrm{N}$ East Pacific Rise vent field.

Figure 3.1 Locations of sampling efforts on the East Pacific Rise $\left(1: 21^{\circ} \mathrm{N}, 2: 13^{\circ} \mathrm{N}\right.$, 3: $9^{\circ} \mathrm{N}$ ) and on the Galápagos Rift (4: Rosebud, 5: Garden of Eden).

Figure 3.2 Principal components analysis of genetic differentiation among nine Riftia subpopulations, showing significant isolation between the Galápagos Rift and East Pacific Rise.

Figure 3.3 Results from STRUCTURE with $\mathrm{K}=2$ populations $(20,000$ burnin, 20,000 MCMC reps, admixture model, correlated allele frequencies, no probability calculation for $\mathrm{K}$ ).

Figure 3.4 Genetic distance of residents $\left(F_{\mathrm{ST}} / 1-F_{\mathrm{ST}}\right)$ plotted against geographic distance $(\mathrm{km})$.

Figure 4.1 Location of 2000 sampling efforts at 9'N on the East Pacific Rise (East Wall, Tica, Choo Choo).

Figure 4.2 Location of 2005 sampling efforts at $86^{\circ} \mathrm{W}$ on the Galápagos Rift (Rosebud Markers J and N, Garden of Eden Marker Q).

Figure 4.3 Location of temporal efforts on the EPR and GAR (Tica: 2000, 2002, 2004, 2005, 2007; Rosebud: 2002, 2005).

Figure 5.1 Conceptual model of Riftia dispersal and colonization on the East Pacific Rise and Galápagos Rift.

Figure B.1 Microsatellite electropherogram profile for locus R2D12.

Figure B.2 Microsatellite electropherogram profile for locus R3B6.

Figure B.3 Microsatellite electropherogram profile for locus R3D3.

Figure B.4 Microsatellite electropherogram profile for locus Rpa10CA02.

Figure B.5 Microsatellite electropherogram profile for locus Rpa10CA06.

Figure B.6 Microsatellite electropherogram profile for locus Rpa10CA07. 
Figure B.7 Microsatellite electropherogram profile for locus Rpa10All01.

Figure B.8 Microsatellite electropherogram profile for locus C2D25.

Figure B.9 Microsatellite electropherogram profile for locus Bth06.

Figure B.10 Microsatellite electropherogram profile for locus Bth07. 


\section{List of Tables}

Table 1.1 Studies of gene flow, larval type, and inferred dispersal distances in eastern Pacific hydrothermal vent species.

Table 2.1 Characteristics of microsatellite markers in Riftia pachyptila.

Table 3.1 Riftia pachyptila sample and collection site characteristics.

Table 3.2 Allelic variability at eight microsatellite loci in Riftia pachyptila subpopulations.

Table 3.3 $\quad F_{\text {IS }}$ per locus and subpopulation.

Table 3.4 Differentiation over all populations.

Table 3.5 Analysis of molecular variance testing groupings: EPR $\left(21^{\circ} \mathrm{N}, 13^{\circ} \mathrm{N}, 9^{\circ} \mathrm{N}\right)$ and GAR ( $86^{\circ} \mathrm{W}$ Rosebud, Garden of Eden).

Table 3.6 $\quad F_{\text {ST }}$ per locus over all 5 populations.

Table 3.7 Genetic differentiation between populations $\left(F_{\mathrm{ST}}\right)$ and respective $P$ values.

Table 4.1 Riftia pachyptila within ridge-segment sample and collection site characteristics.

Table 4.2 Riftia pachyptila time series sample and collection site characteristics.

Table 4.3 Allelic variability at eight microsatellite loci in Riftia pachyptila populations within ridge segments.

Table 4.4 Allelic variability at eight microsatellite loci in Riftia pachyptila populations over time.

Table 4.5 Within ridge segment $F_{\text {IS }}$ per locus and cohort.

Table 4.6 Tica temporal $F_{\text {IS }}$ per locus and cohort.

Table 4.7 Rosebud temporal $F_{\text {IS }}$ per locus and subpopulation, with cohorts separated by marker $\mathrm{B}, \mathrm{J}=\mathrm{F}$, and $\mathrm{N}$.

Table 4.8 Rosebud temporal $F_{\text {IS }}$ per locus and subpopulation, with cohorts 
designated by year and sampling markers combined.

Table 4.9 Spatial differentiation over all populations.

Table 4.10 Differentiation over all temporal populations.

Table 4.11 $\quad F_{\text {ST }}$ per locus over all subpopulations.

Table 4.12a Genetic differences between populations at $9^{\circ} \mathrm{N}$ EPR $\left(F_{\mathrm{ST}}\right)$ and respective $P$ values.

Table 4.12b Genetic differences between populations at $86^{\circ} \mathrm{W}$ GAR $\left(F_{\mathrm{ST}}\right.$ or $\left.R_{\mathrm{ST}}\right)$ and respective $P$ values.

Table 4.12c Genetic differences between subpopulations at $86^{\circ} \mathrm{W}$ GAR $\left(F_{\mathrm{ST}}\right)$ and respective $P$ values.

Table 4.13 Temporal genetic differences between populations $\left(F_{\mathrm{ST}}\right)$ and respective $P$ values.

Table 4.14 $\quad F_{\mathrm{ST}}$-based analysis of molecular variance.

Table 4.15 Relatedness within subpopulations.

Table 5.1 Microsatellite markers variability in polychaetes.

Table A.1 Summary of microsatellite development and testing status for Branchipolynoe symmytilida and Bathymodiolus thermophilus.

Table A.2 Characteristics of microsatellite markers in Bathymodiolus thermophilus and Branchipolynoe symmytilida. 


\section{Chapter 1}

\section{Introduction}

\subsection{Overview}

This thesis addresses population genetic structure at deep-sea hydrothermal vents with new molecular tools and experimental design. Despite multiple attempts to reconcile the apparently homogenous population genetic structure of the siboglinid tubeworm Riftia pachyptila Jones, 1980 over more than $2000 \mathrm{~km}$ with inferences suggesting larval dispersal on the order of 100 to $200 \mathrm{~km}$ (Marsh et al. 2001), results from various genetic markers have been inconsistent (Bucklin 1988, Black et al. 1994, Hurtado et al. 2004). A recent pilot study explored the genetic diversity of $R$. pachyptila (a monospecific genus hereafter be referred to as Riftia) using amplified fragment length polymorphisms (AFLPs) at a range of spatial scales and found individuals clustered by sampling location (Shank \& Halanych 2007). As microsatellites have been useful in revealing high levels of genetic patchiness among siboglinids at cold hydrocarbon seeps in the Gulf of Mexico (McMullin 2003), the suggestion of discrete genetic groups in Riftia prompted the development of highly polymorphic microsatellite loci (Fusaro et al. 2008). Not only do I consider spatial scales of meters to thousands of kilometers, but I also incorporate multiyear sampling of populations and collections of recent colonist and resident adult cohorts in order to separate the genetic contribution of different generations. An archived timeseries collection of individuals at multiple vent sites along the East Pacific Rise and Galápagos Rift over the past decade provides the first opportunity for high-resolution genetic investigations of vent population structure, taking into account known disturbances in the vent environment. With these tools and samples, I address fundamental questions involving spatial and temporal processes that influence population genetic patterns in ephemeral and disjunct habitats. 


\subsection{Utility of population genetic studies}

The genetic structure of populations reflects the history of demographic and selective forces operating upon them, which ultimately determine their observed genetic configuration at a given locality and moment in time. The present composition of alleles within a population establishes its future course of persistence or extinction, adaptation and speciation, and its genetic influence on the species as a whole. Rather than focusing on any one stage in an organism's life, a dynamic view of its ecology, encompassing reproductive mode and dispersal scale through time and space in a particular environment, provides the means to predict future patterns (Hughes et al. 1999). As an example, documenting variation in recruitment among sites may not directly translate to levels of adult abundance at different locations due to different demographic processes (e.g., post-settlement mortality) acting upon them (Sale 1999). Moreover, if recruitment rates vary between years, inferences about the genetic diversity of a population may lead to over- or underestimates of its larval input, depending on the time of sampling. An integrated understanding of dispersal, recruitment, and reproductive success is required to accurately infer population genetic structure.

By examining the extent of allele exchange between populations, the consequent effects of balancing selection and genetic drift can be approximated (Balloux \& Lugon-Moulin 2002). In Nei's (1972) model of genetic differentiation, the number of genetic changes at a locus allows one to estimate genetic distance and in return (assuming constant substitution rates and/or certain migration models) is linearly related to geographic distance and divergence times between populations. Thus, understanding the makeup of a population at a single place and time and of collections of populations over their spatiotemporal existence can allow molecular ecologists to make inferences into the past and predictions of future population structure. 


\subsection{The metapopulation approach to temporal genetics}

In many marine systems, spatiotemporal genetic variation in larval cohorts has been used to investigate the variation observed in adult populations (Weinmayr et al. 2000, Gilg \& Hilbish 2003). Metapopulations can be generalized as a collection of local populations inhabiting discrete and recognizable habitat patches (Smith \& Green 2005). These patches are largely independent of each other but exhibit limited ties, as initially defined by Levins (1969). By definition, it can also be assumed that within a metapopulation, habitat patches support local breeding populations with limited dispersal of individuals such that no single population is large enough to ensure long-term local survival. Dispersal mode or realized dispersal distance may be inconsequential to metapopulation dynamics. Instead, the discrete nature of groups living an ephemeral existence plays a more important role than spatial patchiness when defining a metapopulation (Pannell \& Obbard 2003). Thus, it can be predicted that without continuous genetic contributions to ensure the survival of a patch, metapopulations are prone to local extinction. Furthermore, according to Levins' (1969) definition, patches within a metapopulation are not so geographically or genetically isolated as to prevent recolonization and local dynamics are sufficiently asynchronous that simultaneous extinction of all local populations is unlikely. In addition to physical habitat fluctuations over time, available habitat for colonizers may also be in flux due to the distributions of superior competitors through space and time (Keymer et al. 2000). Extinction and colonization throughout a metapopulation's range maintain its existence as a group of subdivided populations (Pannell \& Obbard 2003).

Metapopuluation approaches have been used to address fundamental ecological questions at deep-sea hydrothermal vents (Neubert et al. 2006, Jollivet et al. 1999). Vents provide spatially disjunct and temporally ephemeral habitats along mid-ocean ridges, separated by expanses of non-venting, and subject to interruptions and cessation of flow. Additionally, local vent populations have transient lifespans on the same timescale as faunal lifespans, resulting from frequent extinction and recolonization processes 
(Thiébaut et al. 2002). Geophysical and geochemical instability at vents may serve to (1) create population bottlenecks - increasing genetic drift and reducing metapopulation effective size - and to (2) increase genetic differentiation between vent populations towards the fixation of alleles. Given these characteristics, hydrothermal vents are likely candidates for metapopulation approaches. Additionally, existing population models do not explain inconsistencies in genetic structure/lack of structure and dispersal capabilities inferred for hydrothermal vent fauna (Jollivet et al. 1999). Metapopulation genetic models may offer alternative ways - to island, stepping-stone (Kimura \& Weiss 1964), or isolation by distance (Wright 1940) models - of explaining observed patterns and can be best studied on a range of spatial and temporal scales with high-resolution molecular markers (Vrijenhoek 1997, Pannell \& Obbard 2003, Freckleton \& Watkinson 2002, Segelbacher \& Storch 2002).

\subsection{Physical and biological setting}

Hydrothermal vents are ephemeral regions of geothermally heated and chemically altered seawater emitted from the seafloor along mid-ocean ridges, frequently venting highly toxic fluids at temperatures greater than $350^{\circ} \mathrm{C}$. These vents often support a large and endemic biomass dependent upon the chemosynthetic processes of bacteria and archaea converting chemical energy into fixed carbon. Biological processes at vents are intrinsically linked to the spreading systems on which they are found, including to the tectonic and magmatic instability of being located on an active spreading center, variable hydrothermal fluid flux and composition, and strong temperature and chemical gradients. It is assumed that if hydrothermal vents were continuously distributed along an unfractured mid-ocean ridge, fauna would be similar worldwide (Mironov et al. 1998). However, the global mid-ocean ridge system is constructed with faults and fractures that segment these seafloor mountain chains. A patchy distribution of venting habitats facilitates distinct biogeographic patterns in separate ocean basins and in different regions. Important questions remain regarding finer scale biogeographic patterns within a 
region that can help define the scale of disturbance (geographic or otherwise) impacting population genetic structure.

The East Pacific Rise (EPR), with its north-south orientation, northward currents along the eastern edge of the ridge, and strong eastward currents near the Equator extending out along the perpendicularly intersecting Galápagos Rift (GAR), was dubbed by Tunnicliffe (1988) a model setting in which to study clinal patterns of vent community development and genetic variance. This ridge became geographically isolated from the Juan de Fuca Ridge (once the mid-Tertiary Pacific-Farallon Ridge) about 35 Mya, while the Galápagos Rift began spreading from the EPR about 20-25 Mya (Hey 1977, Tunnicliffe 1988). In addition to differences in geologic age, the EPR has a faster maximum full spreading rate (up to $16 \mathrm{~cm} /$ year) than the GAR $(6.5-7.0 \mathrm{~cm} / \mathrm{yr})$; higher rates of spreading have been correlated to higher rates of disturbance and habitat turnover due to greater magmatic activity (Klaus et al. 1991, Ballard et al. 1982, Van Dover et al. 2002). Hydrothermal vents are also more abundant on the EPR than on the GAR (Baker \& German 2004).

As of 1997 , an $800 \mathrm{~km}$ area of the EPR between $7^{\circ}$ and $14^{\circ} \mathrm{N}$ had been explored, yielding the discovery of 198 vents, averaging 3-5 km between them, except in clusters at known as $9^{\circ} \mathrm{N}$ and $13^{\circ} \mathrm{N}$, where vents are spaced an average of $500 \mathrm{~m}$ apart (Chevaldonné et al. 1997). Between $12^{\circ} 38^{\prime}$ and $12^{\circ} 54^{\prime} \mathrm{N}$, a cluster of twenty-two vents occur within a linear stretch roughly $8 \mathrm{~km}$ long, with two additional vents separated by massive sulfides $7 \mathrm{~km}$ away. Fourteen active vents lie within a $30 \mathrm{~km}$ range around $21^{\circ} \mathrm{N}$, with a solitary black smoker $6.5 \mathrm{~km}$ afield (Grassle 1985). Additionally, thirty kilometers of the Galápagos Rift were surveyed in the late 1970s with the discovery of hydrothermal vents and revealed nine active vent areas, spread by a maximum distance of $8 \mathrm{~km}$, and three extinct vents identified by remnant shell debris (Grassle 1985). More recently, black smokers have been located on the GAR between $91^{\circ}$ and $95^{\circ} \mathrm{W}$ (Haymon et al. 2007). In general, vents on the GAR may be more geographically isolated than vents on the EPR but could provide more geochemically stable habitats for endemic populations. 


\subsection{History of local extinction, colonization, and succession on the East Pacific Rise and Galápagos Rift}

Since their discovery in 1977, local extinction and recolonization events have been recorded at hydrothermal vents (Haymon et al. 1993; Shank et al. 1998, 2003). On the EPR, the $21^{\circ} \mathrm{N}$ area has supported growing Riftia populations dating back to Clam Acres' discovery in 1979, including recovery from over-sampling in 1982 (Spiess et al. 1980, Hessler et al. 1985, Desbruyères 1998). This ridge segment has been active for at least 300 years with a spreading rate of $60 \mathrm{~mm} / \mathrm{yr}$, but a short shift in activity likely occurred over the past century, followed by several decades of continuous flow (Desbruyères 1998).

Vents at $13^{\circ} \mathrm{N}$ EPR were discovered in 1981 (Hekinian et al. 1983) and subject to fluid instabilities between 1982 and 1990 (Fustec et al. 1987, Desbruyères 1998). Since then, this region has experienced a resurgence of hydrothermal activity, with a large "sulfide mound" discovered in 2003 (Voight et al. 2004). It is believed that two centuries ago the $13^{\circ} \mathrm{N}$ segment was relatively stable, but more recently, the black smoker lifespan has been observed to be less than 5 to 10 years (Desbruyères 1998).

The $9^{\circ} \mathrm{N}$ vents were first observed from a towed camera system (ARGO) in 1989 (Fornari et al. 1990) and concentrated international efforts have monitored this area and tracked changes ever since (Figure 1.1). A 1992 Biologic-Geologic Transect along $1.37 \mathrm{~km}$ of the axial summit cauldera (ASC) between $9^{\circ} 49.61^{\prime} \mathrm{N}$ and $9^{\circ} 50.36^{\prime} \mathrm{N}$ at depths of $2500 \mathrm{~m}$, mapped the robust venting communities that arose after an eruptive event in 1991. This volcanic eruption disrupted the mature tubeworm and mussel communities observed in 1989 images of the region and provided a "zero" time point from which to follow the development of hydrothermal vent communities (Haymon et al. 1991, 1993). Photo- and videographic transects were subsequently established in March 1992, December 1993, 
1989 Discovery of $9^{\circ} 50^{\prime} \mathrm{N}$ venting areas

Tubeworm Pillar active

1991 Eruption

Dominance of snowblowers and mats

Dead Riftia at Tubeworm Barbeque

1992 Secondary eruption

Dominance of Tevnia

1993 Magmatic diking

Tubeworm Pillar black smoker

Dominance of Riftia

1994 Emergence of Bathymodiolus \& serpulids

1995 Cracking event

Serpulid worms \& brachyuran crabs

Overgrowth of Riftia by mussels

Rusty Riftia area

1997 Ty/lo black smokers emerge

Tica diffuse flow, few Riftia

2002 Rusty Riftia fauna absent

2003 Tica black smoker emerges

Tubeworm Pillar flow cessation

2004 Mussel Bed waning

Tubeworm Pillar inactive

2005 Eruption

2006 Extinction of Alvinellid Pillar, M Vent, Q Vent, \& Tica smoker New areas of diffuse flow

2007 Extensive Tevnia colonization

Limited Riftia presence

Figure 1.1 Timeline of select disturbances resulting in population and habitat turnover within the $9^{\circ} \mathrm{N}$ East Pacific Rise vent field.

October 1994, and November 1995 (Shank et al. 1998). Successional changes following the eruption were observed as follows:

1) initially, white bacterial mats blanketed the venting area;

2) within a year, mobile vent fauna colonized 17 newly-formed active vent 
areas, microbial mat coverage underwent significant reduction, and Tevnia jerichonana tubeworms began to settle in regions of intense diffuse flow;

3) over the subsequent months, Riftia tubeworms established hardy populations, fostering the arrival of additional vent-endemic species;

4) by the end of the second year following the eruption, sulfide chimneys developed and provided substrate for the colonization of alvinellid polychaetes;

5) a third year saw Bathymodiolus thermophilus mussels arrive on the scene;

6) within four years, galatheid crabs and serpulid polychaetes became more abundant and mussels started to recruit to Riftia tubes;

7) by year six, vesicomyid clams and enteropneusts entered the vent community.

Since that study, new high-temperature $\left(>360^{\circ} \mathrm{C}\right)$ vents formed and established areas declined (Von Damm et al. 2004). Lepetodrilid limpets heavily colonized the region and mussels overgrew previously robust Riftia aggregations as flow diminished. Seismic sensors also detected a major fracture event in 1995 that likely reinvigorated vents in the northern region of the Transect known as the Hole-to-Hell (Sohn et al. 1998). The Tica site became active with diffuse flow and a nascent Riftia population around 1997, with its high temperature black smoker emerging by 2003 (Fornari et al. 2004).

In 2005-2006, following a period of increased microseismicity another eruption at $9^{\circ} \mathrm{N}$ EPR devastated $18 \mathrm{~km}$ of vent communities (Tolstoy et al. 2006, Cowen et al. 2007, Soule et al. 2007). Where fauna had been paved over with fresh lava, new communities began to develop in the months thereafter as they did following the 1990-1991 eruptions, with $T$. jerichonana replacing microbial mats and subsequent settlement of solitary Riftia individuals (Shank et al. 2006). These events and recorded changes in community structure, coupled with extensive cross-disciplinary sampling since the 1991 eruption through to after the 2005-2006 eruption distinguish the $9^{\circ} \mathrm{N}$ EPR hydrothermal region from other less-studied vent fields and afford the opportunity for spatiotemporal studies. 
Colonization events have also been well documented along the Galápagos Rift at $86^{\circ} \mathrm{W}$ and $2470 \mathrm{~m}$ depth (Shank et al. 2003). Prior to the discovery of Galápagos vents, there was evidence of a 1972 eruption in the $86^{\circ} \mathrm{W}$ area (Macdonald \& Mudie 1974). The high flow Rose Garden site, thought to have originated in the early 1970s and last visited in 1990, was not found in 2002 (Childress 1988, Shank et al. 2003). Vent fluid flux at Rose Garden had been consistent across observations from 1979 to 1990; however, between 1979 and 1985, Riftia almost disappeared from this site, with a single cluster remaining atop a large mussel bed (Desbruyères 1998). Dives of the submersible Alvin in 2002 on what was once Rose Garden revealed that a recent volcanic eruption (no more than 2.5 years prior) had paved over the populations of tubeworms, mussels, and other vent fauna last seen thriving in a large fissure at that location in 1990 (Shank et al. 2003). While this flow of fresh seafloor eliminated a known, well-established community and changed the venting terrain and subsurface plumbing, a few hundred meters northwest, a new hydrothermal community was observed with juvenile tubeworms, mussels, and clams colonizing a nascent vent field-Rosebud, a low temperature $\left(24^{\circ} \mathrm{C}\right)$ site about $60 \mathrm{~m}$ by $50 \mathrm{~m}$ with four main venting areas. One remarkable finding in this young community was a deviation from previously hypothesized successional steps on the EPR - mussels, tubeworms, and clams of similar (young) ages and small size co-occurred in diffuse venting regions at Rosebud instead of transitioning gradually from early colonizing species (Riftia) to later vent stage inhabitants (Bathymodiolus and Calyptogena) (Shank et al. 2003). Also notable was the finding of roughly one-third of the species formerly sampled at Rose Garden thirteen years prior, suggesting a major shift in community composition occurred.

Rosebud and the surrounding area were visited again in May 2005 in an attempt to document changes to the community structure and water chemistry since its discovery. In three years, mussel and tubeworm communities had grown more robust and continued to inhabit discrete habitat patches while additional regions of diffuse flow remained 
available for colonization; the successional stages of vent organisms appeared to be developing simultaneously at this site (Nevala 2005).

The Garden of Eden vent site, last observed in the 1990s was also rediscovered in 2005. Its contemporary Riftia population can be assumed to have been present at least since the discovery of hydrothermal vents in 1977 (Corliss et al. 1979) and may have been unaffected by the eruption that created Rosebud $14 \mathrm{~km}$ distant. Extensive Riftia assemblages at Garden of Eden contained the largest documented tubeworms ( $>2 \mathrm{~m}$, pers. obs. T. Shank) in 2005, adding credence to their existence as part of a long-lived, robust population at this site.

Comparing the changes at vent fields in the eastern Pacific and the genetic structure of species found at both areas will provide insight into how physical dynamics translate to genetic signal. Ecological mechanisms structuring the development of the Galápagos vent communities are predicted to markedly differ from the faster spreading East Pacific Rise.

\subsection{Target species: life history and general biology}

It was expected in the early days of vent biology that in order to colonize new vents hundreds of kilometers away, vent fauna must undergo strong selection for high growth rates, high fecundity, and efficient dispersal (Grassle 1985). Larval behavior, as well as geographic barriers, may restrict long-distance dispersal that would otherwise connect populations (Darling et al. 2004). The details of life-history strategies at vents, although phylogenetically conservative (no common dispersal strategy, yet most appear to be subject to transport on ocean currents and/or vent plumes, Tunnicliffe 1988), may have evolved to deliver dispersive propagules to and ensure colonization of disjunct vent sites (Tyler \& Young 1999). From larval life-span investigations, hydrodynamic conditions, direct larval collection, and respiration research over the past few decades, some comparisons between species can now be made (Table 1.1). 
Table 1.1 Studies of gene flow, larval type, and inferred dispersal distances in eastern Pacific hydrothermal vent species. These studies were conducted at northern East Pacific Rise (NEPR) and Galápagos Rift (GAR). Modified from (Vrijenhoek 1997; Tyler \& Young 1999; Hurtado et al. 2004).

\begin{tabular}{|c|c|c|c|c|c|c|c|}
\hline Species & Ridge system & $\begin{array}{c}\text { Range } \\
\text { sampled }(\mathrm{km})\end{array}$ & $\begin{array}{l}\text { No. of } \\
\text { total loci* }\end{array}$ & $H_{T}$ & $\begin{array}{l}\text { Isolation } \\
\text { by } \\
\text { distance }\end{array}$ & Dispersal stage & $\begin{array}{l}\text { Inferred } \\
\text { dispersal } \\
\text { distance }\end{array}$ \\
\hline \multicolumn{8}{|l|}{ Amphipods } \\
\hline Ventiella sulfuris & NEPR, GAR & 3,340 & 14 & 0.296 & $\mathrm{Yes}^{1}$ & brooder $^{1}$ & short \\
\hline \multicolumn{8}{|l|}{ Vestimentiferans } \\
\hline Riftia pachyptila & NEPR, GAR & 3,960 & $17, \mathrm{n}, \mathrm{m}$ & 0.135 & $\mathrm{Yes}^{2}$ & trochophore $^{9}$ & moderate \\
\hline Tevnia jerichonana & NEPR & 340 & $15, \mathrm{n}, \mathrm{m}$ & 0.068 & $\mathrm{Yes}^{3}$ & $?$ & moderate \\
\hline Oasisia alvinae & NEPR & 1,330 & $15, \mathrm{n}, \mathrm{m}$ & 0.120 & $\mathrm{Yes}^{3}$ & $?$ & moderate \\
\hline \multicolumn{8}{|l|}{ Bivalves } \\
\hline $\begin{array}{l}\text { Bathymodiolus } \\
\text { thermophilus }\end{array}$ & NEPR, GAR & 2,370 & $26, \mathrm{n}, \mathrm{m}, \mathrm{c}$ & 0.017 & $\mathrm{No}^{4}$ & planktotrophic $^{10}$ & long \\
\hline Calyptogena magnifica & NEPR, GAR & 3,340 & $17, \mathrm{n}, \mathrm{c}$ & 0.016 & $\mathrm{No}^{5,6}$ & nonplanktotrophic $^{10}$ & short \\
\hline \multicolumn{8}{|l|}{ Gastropods } \\
\hline Eulepetopsis vitrea & NEPR, GAR & 3,340 & 10 & 0.059 & $\mathrm{No}^{7}$ & nonplanktotrophic ${ }^{10}$ & short \\
\hline Lepetodrilus pustulosus & NEPR, GAR & 2,370 & 16 & 0.046 & $\mathrm{No}^{7}$ & nonplanktotrophic ${ }^{10}$ & short \\
\hline Lepetodrilus elevatus & NEPR, GAR & 1,360 & 16 & 0.066 & Yes $^{7}$ & nonplanktotrophic ${ }^{10}$ & short \\
\hline Lepetodrilus galriftensis & NEPR & 1,360 & 16 & 0.051 & $\mathrm{Yes}^{7}$ & nonplanktotrophic ${ }^{10}$ & short \\
\hline \multicolumn{8}{|l|}{ Polychaetes } \\
\hline Paralvinella grasslei & NEPR & $\sim 4,000$ & 18 & $0.237 \dagger$ & $\mathrm{No}^{8}$ & lecithotrophic ${ }^{11}$ & short \\
\hline Alvinella caudata & NEPR & $\sim 900$ & 18 & $0.118 \dagger$ & $\mathrm{No}^{8}$ & lecithotrophic ${ }^{11}$ & short \\
\hline Alvinella pompejana & NEPR & $\sim 900$ & $18, \mathrm{~m}$ & $0.107 \dagger$ & $\mathrm{Yes}^{8}$ & lecithotrophic ${ }^{12}$ & short \\
\hline $\begin{array}{l}\text { Branchipolynoe } \\
\text { symmytilida }\end{array}$ & NEPR, GAR & $\mathrm{n} / \mathrm{a}$ & $\mathrm{m}$ & unk.t & Yes $^{13}$ & lecithotrophic ${ }^{14}$ & short \\
\hline
\end{tabular}

* Number of allozyme loci, followed by DNA-based markers: (m) mtDNA restriction haplotypes; (n) nDNA loci; and (c) cytochrome oxidase I mtDNA sequences. $H_{T}$ is a measure of total genetic diversity. $\dagger$, equivalent to the average observed heterozygosity per population. \$, not reported. References: (1) France et al. 1992; (2) Black et al. 1994; (3) Black et al. 1998; (4) Craddock et al. 1995b; (5) Vrijenhoek et al. 1994; (6) Karl et al. 1996; (7) Craddock et al. 1997; (8) Jollivet et al. 1995a (9) Marsh et al. 2001; (10) inferred from shell morphology (Lutz 1988); (11) Desbruyères \& Laubier 1986; (12) Chevaldonné \& Jollivet 1993; (13) Hurtado et al. 2004; (14) from congener B. seepensis in Tyler \& Young 1999.

Of these species, the siboglinid tubeworm Riftia is a dominant macrofaunal component of deep-sea hydrothermal vent communities in the eastern Pacific Ocean with a range of approximately $7000 \mathrm{~km}$. This species was selected as a focal species to address spatial and temporal population dynamics in ephemeral habitats for three main reasons: (1) its 
high occupancy at EPR and GAR vent sites, (2) extensive collections from throughout its species range over the past decade, (3) a rich but unresolved history of larval and genetic research.

Riftia has separate sexes (Jones 1980), with a nearly equal ratio of males to females (Thiébaut et al. 2002), and is highly fecund (Cary et al. 1989); up to 700,000 mature eggs have been observed in Riftia's ovisac (Young 2003). Eggs are small, yolky, lipid-rich (Cary et al. 1989), and near-neutrally buoyant (Marsh et al. 2001). Sperm released into the water column are then stored in ovarian spermatheca, and imperfect $(<100 \%)$ fertilization occurs internally before oocyte release (Hilário et al. 2005). Riftia embryos presumably undergo initial development at depth, as it has been demonstrated that they require ambient pressure in order to progress to the larval stage (Marsh et al. 2001).

This tubeworm species possesses a free-swimming, non-feeding (lecithotrophic) trochophore larvae believed to facilitate limited transport between disjunct areas of suitable habitat (Jones \& Gardiner 1989, Marsh et al. 2001). The larval lifespan of Riftia is estimated at about 38 days, including 3 weeks of embryonic development and 2 weeks of ciliary movement (Marsh et al. 2001). While the trochophore larva has no mouth, gut or anal opening, after settlement stage, juveniles may feed by ciliary action (Southward 1988). However, following horizontal endosymbiont transfer through the skin of newly settled tubeworms, Riftia develop a trophosome and lose their juvenile mouth and anal openings (Nussbaumer et al. 2006).

Natural and experimental colonization observations have been unable to determine the biotic or abiotic cue for Riftia settlement (Shank et al. 1998, Hunt et al. 2004, Mullineaux et al. 2000). As colonization occurs within a year or two of newly available habitat, it is considered likely that a pool of larvae is maintained in the water column above vents (Shank et al. 1998, Govenar et al. 2004). Recruitment lacks periodicity and is discontinuous, but settlement events can be frequent (e.g., 8 to 20 d) (Thiébaut et al. 
2002). Once established, tube growth rates may exceed 85 to $160 \mathrm{~cm} / \mathrm{yr}$ (Lutz et al. 1994, Thiébaut et al. 2002). While large worms may only inhabit one to two thirds of their total tube length (Govenar et al. 2004), Riftia is still considered one of the fastest growing organisms on Earth, out-competing or over-growing the smaller tubeworm species, Tevnia jerichonana, that is first to colonize new vents (Shank et al. 1998).

Despite multiple attempts to resolve Riftia's apparently homogenous population genetic structure with inferences suggesting limited larval dispersal, results from various genetic markers have been inconsistent (Bucklin 1988, Black et al. 1994, Hurtado et al. 2004). A recent pilot study explored the genetic diversity of Riftia using amplified fragment length polymorphisms (AFLPs) at a range of spatial scales and found individuals clustered by sampling location (Shank \& Halanych 2007). As microsatellites have been useful in revealing high levels of genetic patchiness among siboglinids at cold hydrocarbon seeps in the Gulf of Mexico (McMullin 2003), the suggestion of discrete genetic groups in Riftia prompted the development of highly polymorphic microsatellite loci (Fusaro et al. 2008).

\subsection{Rationale for a DNA microsatellite approach}

Examples of the application of molecular markers to determine population structure pervade marine, freshwater, estuarine, and terrestrial literature (Avise 2004). Each generation of population geneticists attempts to make use of a new technology, more sensitive to genetic differences than previous techniques, in order to reveal cryptic levels of genetic structure in populations. In the case of the intertidal copepod Tigriopus, allozyme data revealed strong genetic differentiation between populations, but mtDNA cytochrome oxidase subunit I (COI) sequences were able to resolve this structure to a phylogeographic break and define interpopulation relationships (Burton \& Lee 1994). Before the advent of affordable and reliable DNA sequencing, mtDNA was also analyzed using restriction endonuclease digests to reconstruct the ancestral history of intraspecific lineages (Avise et al. 1979). Since then, sequencing techniques have become accessible 
to investigators even in the smallest of labs. However popular, nuclear and mitochondrial DNA markers are considered to be better suited for intraspecific phylogeography and systematics than they are to population genetics (Sunnucks 2000). Methods continue to evolve and develop, such that it is now possible to isolate patterns in population arrays with more power and sensitivity.

Over the past decade, DNA microsatellites - rapidly evolving, tandemly repeated sequences of non-coding DNA randomly distributed throughout an organism's genomehave become another valuable tool in the population geneticist's toolbox (Selkoe \& Toonen 2006). Microsatellite markers are well-implemented in the fields of conservation biology, invasive species, disease mapping, and forensic science. As co-dominant Mendelian alleles with mutation rates of $10^{-2}$ to $10^{-6}$ per generation (up to 10,000 times that of other molecular markers), polymorphic microsatellite loci offer increased resolution to investigations of reproductive and recruitment success, current and historic gene flow, and population structure and persistence (Jarne \& Lagoda 1996, Balloux \& Lugon-Moulin 2002). At their inception, the characterization and isolation of microsatellites required extraction of large amounts of DNA, restriction enzyme digestion, gel fragment purification and vector insertion, DNA cloning, colony picking and sequencing. Today, more targeted methods are available, and microsatellites are becoming a primary tool in modern population genetics (Sunnucks 2000). Using magnetic beads bound with (TG) repeats, for example, DNA fragments can be enriched and cleaned for those containing complementary repeats only. Specific fragments are amplified in the polymerase chain reaction (PCR) using primers matching the flanking regions of these microsatellites, which can then be tested for polymorphism and adherence to expectations in the population of interest.

Microsatellites have been applied to populations where previous methods have yielded low levels of polymorphism, including marine studies on the slipper snail Crepidula fornicata (Dupont \& Viard 2003), the invasive brown mussel Perna perna (Holland 
2001), Atlantic salmon Salmo salar (Tessier \& Bernatchez 1999), and the tube-building polychaete Pectinaria koreni (Weinmayr et al. 2000); and to terrestrial populations in the case of the garden snail Helix aspersa (Arnaud \& Laval 2004). Highly polymorphic (i.e. having many alleles) and sensitive enough to amplify small amounts of source DNA from larvae and ethanol-preserved samples, microsatellites can also be applied to the study of cohort arrival and differential survival across the lifespan of individuals and populations (Weinmayr et al. 2000). They are often species-specific and can identify individuals in mixed plankton samples (Morgan \& Rogers 2001). However, their power of genetic resolution has seen only limited application to the study of deep-sea populations (gorgonian octocorals, Baco et al. 2006; hydrocarbon seep tubeworms, McMullin et al. 2004; and hydrothermal vent scale worms, Daguin \& Jollivet 2005, Plouviez et al. submitted), and in particular, of the effect ridge-crest processes have on vent-endemic species. The application of microsatellites to ecological questions in other environments suggests that these sensitive markers can be used to resolve conflicting larval and genetic results from previous vent studies.

\subsection{Organization of the current study}

This dissertation research begins by developing the tools necessary for multi-locus Mendelian population genetic analysis of ecological processes at deep-sea hydrothermal vents. Microsatellite loci are developed and characterized in Chapter 2 in order to facilitate further studies in the eastern Pacific. Chapter 3 incorporates these markers into a regional scale population genetic study of recent colonist and resident adult Riftia from five major vent fields on the East Pacific Rise and Galápagos Rift, comparing and contrasting these findings with those using a more traditional design. In Chapter 4, population genetic research is extended to fine-scale spatial comparisons within two ridge segments and temporal comparisons over two to seven years at sites on separate midocean ridge systems. The temporal population genetic study on the East Pacific Rise fortuitously spanned an eruption in 2005-2006, allowing inferences to be made about subsequent recolonization. Ultimately, this thesis demonstrates the added interpretive 
power that temporal genetic approaches contribute to understanding dispersal mechanisms. Moreover, it suggests that local larval retention dominates the settlement pool at deep-sea hydrothermal vents and encourages future researchers to design their studies in a manner that addresses this hypothesis. 


\subsection{References}

Arnaud J-F, Laval G (2004) Stability of genetic structure and effective population size inferred from temporal changes of microsatellite DNA polymorphisms in the land snail Helix aspersa (Gastropoda: Helicidae). Biological Journal of the Linnean Society, 82, 89-102.

Avise JC (2004) Molecular Markers, Natural History, and Evolution. Second Edition. Sinauer Associates, Sunderland, Massachusetts. 684 pp.

Avise JC, Lansman RA, Shade RO (1979) The use of restriction endonucleases to measure mitochondrial DNA sequence relatedness in natural populations. I. Population structure and evolution in the genus Peromyscus. Genetics, 92, 279-295.

Baco AR, Clark AM, Shank TM (2006) Six microsatellite loci from the deep-sea coral Corallium lauuense (Octocorallia: Coralliidae) from the islands and seamounts of the Hawaiian archipelago. Molecular Ecology Notes, 6, 147-149.

Ballard RD, van Andel TH, Holcomb RT (1982) The Galapagos Rift at $86^{\circ} \mathrm{W}: 5$. Variations in volcanism, structure, and hydrothermal activity along a 30-kilometer segment of the rift valley. Journal of Geophysical Research, 87, 1149-1161.

Balloux F, Lugon-Moulin N (2002) The estimation of population differentiation with microsatellite markers. Molecular Ecology, 11, 155-165.

Black MB, Lutz RA, Vrijenhoek RC (1994) Gene flow among vestimentiferan tube worm (Riftia pachyptila) populations from hydrothermal vents of the eastern Pacific. Marine Biology, 120, 33-39.

Black MB, Trivedi A, Maas PAY, Lutz RA, Vrijenhoek RC (1998) Population genetics and biogeography of vestimentiferan tube worms. Deep Sea Research II, 45, 365382.

Bucklin A (1988) Allozymic variability of Riftia pachyptila populations from the Galapagos Rift and $21^{\circ} \mathrm{N}$ hydrothermal vents. Deep-Sea Research, 35, 1759-1768.

Burton RS, Lee B-N (1994) Nuclear and mitochondrial gene genealogies and allozyme polymorphism across a major phylogeographic break in the copepod Tigriopus californicus. Proceedings of the National Academy of Sciences of the United States of America, 91, 5197-5201.

Cary SC, Felbeck H, Holland ND (1989) Observations on the reproductive biology of the hydrothermal vent tube worm Riftia pachyptila. Marine Ecology Progress Series, 52, 89-94.

Chevaldonné P, Jollivet D (1993) Videoscopic study of deep-sea hydrothermal vent alvinellid polychaete populations: biomass estimations and behaviors. Marine Ecology Progress Series, 95, 251-262. 
Chevaldonné P, Jollivet D, Vangriesheim A, Debruyères D (1997) Hydrothermal-vent alvinellid polychaete dispersal in the eastern Pacific. 1. Influence of vent site distribution, bottom currents, and biological patterns. Limnology and Oceanography, 42, 67-80.

Childress JJ (1988) Biology and chemistry of a deep-sea hydrothermal vent on the Galapagos Rift; the Rose Garden in 1985. Introduction. Deep-Sea Research, 35, 1677-1680.

Corliss JB, Dymond J, Gordon LI, et al. (1979) Submarine thermal springs on the Galápagos Rift. Science, 203, 1073-1083.

Cowen JP, Fornari DJ, Shank TM, et al. (2007) Volcanic eruptions at East Pacific Rise Near $9^{\circ} 50^{\prime}$ N. Eos, 88, 81, 88.

Craddock C, Hoeh WR, Lutz RA, Vrijenhoek RC (1995) Extensive gene flow among mytilid (Bathymodiolus thermophilus) populations from hydrothermal vents of the Eastern Pacific. Marine Biology, 124, 137-146.

Craddock C, Lutz RA, Vrijenhoek RC (1997) Patterns of dispersal and larval development of archaeogastropod limpets at hydrothermal vents in the eastern Pacific. Journal of Experimental Marine Biology and Evolution, 210, 37-51.

Daguin C, Jollivet D (2005) Development and cross-amplification of nine polymorphic microsatellite markers in the deep-sea hydrothermal vent polychaete Branchipolynoe seepensis. Molecular Ecology Notes, 5, 780-783.

Darling JA, Reitzel AM, Finnerty JR (2004) Regional population structure of a widely introduced estuarine invertebrate: Nematostella vectensis Stephenson in New England. Molecular Ecology, 13, 2969-2981.

Desbruyères D (1998) Temporal variations in the vent communities on the East Pacific Rise and Galápagos Spreading Centre: a review of present knowledge. Cahiers de Biologie Marine, 39, 241-244.

Desbruyères D, Laubier L (1986) Les Alvinellidae, une famille nouvelle d'annélides polychètes inféodées aux sources hydrothermales sous-marines: systématique, biologie et écologie Alvinellidae a new family of Polychaeta (Annelida) collected from hydrothermal vents: systematics, biology and ecology. Canadian Journal of Zoology, 64, 2227-2245.

Dupont L, Viard F (2003) Isolation and characterization of highly polymorphic microsatellite markers from the marine invasive species Crepidula fornicata (Gastropoda: Calyptraeidae). Molecular Ecology Notes, 3, 498-500.

Fornari D, Tivey M, Schouten H, et al. (2004) Submarine lava flow emplacement at the East Pacific Rise $9^{\circ} 50^{\prime} \mathrm{N}$ : implications for uppermost ocean crust stratigraphy and hydrothermal fluid circulation. In: Mid-Ocean Ridges: Hydrothermal Interactions Between the Lithosphere and Oceans (eds. German CR, Lin J, Parsons LM), pp. 187-217 (of 318). American Geophysical Union, Washington, DC. 
Fornari DJ, Haymon RM, Edwards M, Macdonald KC (1990) Volcanic and tectonic characteristics of the East Pacific Rise Crest $9^{\circ} 09^{\prime} \mathrm{N}$ to $9^{\circ} 54^{\prime} \mathrm{N}$ : implications for finescale segmentation of the plate boundary. Eos, 71, 625.

France SC, Hessler RR, Vrijenhoek RC (1992) Genetic differentiation between spatiallydisjunct populations of the deep-sea, hydrothermal vent-endemic amphipod Ventiella sulfuris. Marine Biology, 114, 551-559.

Freckleton RP, Watkinson AR (2002) Large-scale spatial dynamics of plants: metapopulations, regional ensembles and patch populations. Journal of Ecology, 90, 419-434.

Fusaro AJ, Baco AR, Gerlach G, Shank TM (2008) Development and characterization of 12 microsatellite markers from the deep-sea hydrothermal vent siboglinid Riftia pachyptila. Molecular Ecology Resources, 8, 132-134.

Fustec A, Desbruyères D, Juniper SK (1987) Deep-sea hydrothermal vent communities at $13^{\circ} \mathrm{N}$ on the East Pacific Rise: microdistribution and temporal variations. Biological Oceanography, 4, 121-161.

Gilg MR, Hilbish TJ (2003) Spatio-temporal patterns in the genetic structure of recently settled blue mussels (Mytilus spp.) across a hybrid zone. Marine Biology, 143, 679690.

Govenar B, Freeman M, Bergquist DC, Johnson GA, Fisher CR (2004) Composition of a one-year-old Riftia pachyptila community following a clearance experiment: insight to succession patterns at deep-sea hydrothermal vents. Biological Bulletin, 207, 177 182.

Grassle JF (1985a) Hydrothermal vent animals: distribution and biology. Science, 229, 713-717.

Grassle JP (1985b) Genetic differentiation in populations of hydrothermal vent mussels (Bathymodiolus thermophilus) from the Galapagos Rift and $13^{\circ} \mathrm{N}$ on the East Pacific Rise. Bulletin of the Biological Society of Washington, 6, 429-442.

Haymon RM, Baker ET, Resing JA, et al. (2007) Hunting for hydrothermal vents along the Galápagos Spreading Center. Oceanography, 20, 100-107.

Haymon RM, Fornari DJ, Damm KLV, et al. (1993) Volcanic eruption of the mid-ocean ridge along the East Pacific Rise crest at $9^{\circ} 45-52^{\prime} \mathrm{N}$ : Direct submersible observations of seafloor phenomena associated with an eruption event in April, 1991. Earth and Planetary Science Letters, 119, 85-101.

Haymon RM, Fornari DJ, Edwards MH, Carbotte S, Wright D, MacDonald KC (1991) Hydrothermal vent distribution along the East Pacific Rise crest $\left(9^{\circ} 09^{\prime}-54^{\prime} \mathrm{N}\right)$ and its relationship to magmatic and tectonic processes on fast-spreading mid-ocean ridges. Earth and Planetary Science Letters, 104, 513-534.

Hekinian R, Fevrier M, Avedik F, et al. (1983) East Pacific Rise near $13^{\circ} \mathrm{N}$ : geology of new hydrothermal fields. Science, 219, 1321-1324. 
Hessler RR, Smithey WM, Jr., Keller CH (1985) Spatial and temporal variation of giant clams, tube worms and mussels at deep-sea hydrothermal vents. Bulletin of the Biological Society of Washington, 6, 411-428.

Hey R (1977) Tectonic evolution of the Cocos-Nazca spreading center. Geological Society of America Bulletin, 88, 1404-1420.

Hilário A, Young CM, Tyler PA (2005) Sperm storage, internal fertilization, and embryonic dispersal in vent and seep tubeworms (Polychaeta: Siboglinidae: Vestimentifera). Biological Bulletin, 208, 20-28.

Holland BS (2001) Invasion without a bottleneck: microsatellite variation in natural and invasive populations of the brown mussel Perna perna (L). Marine Biotechnology, 3, 407-415.

Hughes AR, Inouye BD, Johnson MT, Underwood N, Vellend M (2008) Ecological consequences of genetic diversity. Ecology Letters, 11, 609-623.

Hunt HL, Metaxas A, Jennings RM, Halanych KM, Mullineaux LS (2004) Testing biological control of colonization by vestimentiferan tubeworms at deep-sea hydrothermal vents (East Pacific Rise, 950'N). Deep-Sea Research I, 51, 225-234.

Hurtado LA, Lutz RA, Vrijenhoek RC (2004) Distinct patterns of genetic differentiation among annelids of eastern Pacific hydrothermal vents. Molecular Ecology, 13, 26032615.

Jarne P, Lagoda PJL (1996) Microsatellites, from moleculaes to populations and back. Trends in Ecology and Evolution, 11, 424-429.

Jollivet D, Chevaldonné P, Planque B (1999) Hydrothemal-vent alvinellid polychaete dispersal in the eastern Pacific. 2. A metapopulation model based on habitat shifts. Evolution, 53, 1128-1142.

Jollivet D, Debruyéres D, Bonhomme F, Moraga D (1995) Genetic differentiation of deep-sea hydrothermal vent alvinellid populations (Annelida: Polychaeta) along the East Pacific Rise. Heredity, 74, 376-391.

Jones ML (1980) Riftia pachyptila, new genus, new species, the vestimentiferan worm from the Galápagos Rift geothermal vents (Pogonophora). Proceedings of the Biological Society of Washington, 93, 1295-1313.

Jones M, Gardiner SL (1989) On the early development of the vestimentiferan tube worm Ridgeia sp. and observations on the nervous system and trophosome of Ridgeia sp. and Riftia pachyptila. Biological Bulletin, 177, 254-276.

Karl SA, Schutz S, Debruyéres D, Lutz R, Vrijenhoek RC (1996) Molecular analysis of gene flow in the hydrothermal vent clam (Calyptogena magnifica). Molecular Marine Biology and Biotechnology, 5, 193-202. 
Keymer JE, Marquet PA, Velasco-Hernández JX, Levin SA (2000) Extinction thresholds and metapopulation persistence in dynamic landscapes. American Naturalist, 156, 478-494.

Kimura M, Weiss G (1964) The stepping stone model of population structure and the decrease of genetic correlation with distance. Genetics, 49, 561-576.

Klaus A, Icay W, Naar D, Hey R (1991) SeaMARC II survey of a propagating limb of a large nontransform offset near $29^{\circ} \mathrm{S}$ along the fastest spreading East Pacific Rise segment. Journal of Geophysical Research, 96, 9985-9998.

Levins R (1969) Some demographic and genetic consequences of environmental heterogeneity for biological control. Bulletin of the Entomological Society of America, 15, 237-240.

Lutz RA, Shank TM, Fornari DJ, et al. (1994) Rapid growth at deep-sea vents. Nature, 371, 663-664.

Macdonald KC, Mudie JD (1974) Microearthquakes on the Galapagos Spreading Centre and the seismicity of fast-spreading ridges. Geophysical Journal International, 36, 245-257.

Marsh AG, Mullineaux LS, Young CM, Manahan DT (2001) Larval dispersal potential of the tubeworm Riftia pachyptila at deep-sea hydrothermal vents. Nature, 411, 7780.

McMullin ER (2003) Phylogeography of deep-sea vestimentiferans and a population genetics study of two species, Lamellibrachia luymesi and Seepiophila jonesi, from the Gulf of Mexico, Pennsylvania State University.

McMullin ER, Wood J, Hamm S (2004) Twelve microsatellites for two deep sea polychaete tubeworm species, Lamellibrachia luymesi and Seepiophila jonesi, from the Gulf of Mexico. Molecular Ecology Notes, 4, 1-4.

Mironov AN, Gebruk AV, Moskalev LI (1998) Biogeographical patterns of the hydrothermal vent fauna: a comparison with "non-vent biogeography." Cahiers de Biologie Marine, 39, 367-368.

Morgan TS, Rogers AD (2001) Specificity and sensitivity of microsatellite markers for the identification of larvae. Marine Biology, 139, 967-973.

Mullineaux LS, Fisher CR, Peterson CH, Schaeffer SW (2000) Tubeworm succession at hydrothermal vents: use of biogenic cues to reduce habitat selection error?

Oecologia, 123, 275-284.

Nei M (1972) Genetic distances between populations. The American Naturalist, 106, 283-292.

Neubert MG, Mullineaux LS, Hill MF (2006) A metapopulation approach to interpreting diversity at deep-sea hydrothermal vents. In Kritzer JP, Sale PF (Eds) Marine Metapopulations. Academic Press, Amsterdam, pp. 321-350. 
Nevala AE (2005) On the seafloor, a parade of roses. Oceanus 44, 6.

Nussbaumer AD, Fisher CR, Bright M (2006) Horizontal endosymbiont transmission in hydrothermal vent tubeworms. Nature, 441, 345-348.

Pannell JR, Obbard DJ (2003) Probing the primacy of the patch: what makes a metapopulation? Journal of Ecology, 91, 485-488.

Plouviez S, Dauguin-Thiébaut C, Hourdez S, Jollivet D (submitted) Genetic relatedness between newly settled juveniles and adults of the hydrothermal vent scale-worm Branchipolynoe seepensis (Polychaeta: Polynoidae). Marine Ecology Progress Series.

Sale PF (1999) Coral reefs: recruitment in space and time. Nature, 397, 25-27.

Segelbacher G, Storch I (2002) Capercaillie in the Alps: genetic evidence of metapopulation structure and population decline. Molecular Ecology, 11, 1669-1677.

Selkoe KA, Toonen RJ (2006) Microsatellites for ecologists: a practical guide to using and evaluating microsatellite markers. Ecology Letters, 9, 615-629.

Shank T, Fornari D, Yoerger D, et al. (2003) Deep submergence synergy: Alvin and ABE explore the Galápagos Rift at $86^{\circ} \mathrm{W}$. Eos, 84, 425, 432-433.

Shank T, Govenar B, Buckman K, et al. (2006) Initial biological, chemical, and geological observations after the 2005-6 volcanic eruption on the East Pacific Rise. Eos Transactions, $A G U, \mathbf{8 7}$, Fall Meeting Supplement, Abstract V13C-04.

Shank TM, Fornari DJ, Von Damm KL, et al. (1998) Temporal and spatial patterns of biological community development at nascent deep-sea hydrothermal vents $\left(9^{\circ} 50^{\prime} \mathrm{N}\right.$, East Pacific Rise). Deep-Sea Research II, 45, 465-515.

Shank TM, Halanych KM (2007) Towards a mechanistic understanding of larval dispersal: insights from genomic fingerprinting of the deep-sea hydrothermal vent tubeworm Riftia pachyptila. Marine Ecology, 28, 25-35.

Smith MA, Green DM (2005) Dispersal and the metapopulation paradigm in amphibian ecology and conservation: are all amphibian populations metapopulations?

Ecography, 28, 110-128.

Sohn RA, Fornari DJ, Von Damm KL, Hildebrand JA, Webb SC (1998) Seismic and hydrothermal evidence for a cracking event on the East Pacific Rise crest at $9^{\circ} 50^{\prime} \mathrm{N}$. Nature, 396, 159-161.

Soule SA, Fornari DJ, Perfit MR, Rubin KH (2007) New insights into mid-ocean ridge volcanic processes from the 2005-2006 eruption of the East Pacific Rise, $9^{\circ} 46^{\prime} \mathrm{N}$ $9^{\circ} 56^{\prime}$ N. Geology, 35, 1079-1082.

Spiess FN, Macdonald KC, Atwater T, et al. (1980) East Pacific Rise: hot springs and geophysical experiments. Science, 207, 1421-1433. 
Sunnucks P (2000) Efficient genetic markers for population biology. Trends in Ecology and Evolution, 15, 199-203.

Tessier N, Bernatchez L (1999) Stability of population structure and genetic diversity across generations assessed by microsatellites among sympatric populations of landlocked Atlantic salmon (Salmo salar L.) Molecular Ecology, 8, 169-179.

Thiébaut E, Huther X, Shillito B, Jollivet D, Gaill F (2002) Spatial and temporal variations of recruitment in the tube worm Riftia pachyptila on the East Pacific Rise $\left(9^{\circ} 50^{\prime} \mathrm{N}\right.$ and $\left.13^{\circ} \mathrm{N}\right)$. Marine Ecology Progress Series, 234, 147-157.

Tolstoy M, Cowen JP, Baker ET, et al. (2006) A sea-floor spreading event captured by seismometers. Science, 314, 1920-1922.

Tunnicliffe V (1988) Biogeography and evolution of hydrothermal-vent fauna in the Eastern Pacific. Proceedings of the Royal Society of London B, 233, 347-366.

Tyler PA, Young CM (1999) Reproduction and dispersal at vents and cold seeps. Journal of the Marine Biological Association of the United Kingdom, 79, 193-208.

Voight J, Zierenberg R, McClain J, and the Science Party (2004) FIELD cruise to the northern EPR: discoveries made during biological investigations from $8^{\circ} 37^{\prime} \mathrm{N}$ to $12^{\circ} 48^{\prime} \mathrm{N}$. In: Ridge 2000 Events.

Von Damm K, Parker C, Beers K, et al. (2004) Update on the hydrothermal and biological status of the EPR ISS "Bull's Eye" at $9^{\circ} 50^{\prime} \mathrm{N}$. Ridge 2000 Events, April 2004, 25-26.

Van Dover CL, German CR, Speer KG, Parson LM, Vrijenhoek RC (2002) Evolution and biogeography of deep-sea vent and seep invertebrates. Science, 295, 1253-1257.

Vrijenhoek RC (1997) Gene flow and genetic diversity in naturally fragmented metapopulations of deep-sea hydrothermal vent animals. Journal of Heredity, 88, 285-293.

Vrijenhoek RC, Schutz SJ, Gustafson RG, Lutz RA (1994) Cryptic species of deep-sea clams (Mollusca: Bivalvia: Vesicomyidae) from hydrothermal vent and cold-water seep environments. Deep-Sea Research I, 41, 1171-1189.

Weinmayr G, Vautrin D, Solignac M (2000) Isolation and characterization of highly polymorphic microsatellites from the polychaete Pectinaria koreni. Marine Biotechnology, 2, 92-99.

Wright S (1940) Breeding structure of populations in relation to speciation. The American Naturalist, 74, 232-248. 


\title{
Chapter 2
}

\section{Development and characterization of 12 microsatellite markers from the deep-sea hydrothermal vent siboglinid Riftia pachyptila}

Reprinted with permission from:

Fusaro AJ, Baco AR, Gerlach G, Shank TM (2008) Development and characterization of 12 microsatellite markers from the deep-sea hydrothermal vent siboglinid Riftia pachyptila. Molecular Ecology Resources, 8, 132-134.

(C) 2007 The Authors

Journal compilation (C) 2007 Blackwell Publishing Ltd

\begin{abstract}
Ecological processes at deep-sea hydrothermal vents on fast-spreading mid-ocean ridges are punctuated by frequent physical disturbance, often accompanied by a high occurrence of population turnover. To persist through local extinction events, sessile invertebrate species living in these geologically and chemically dynamic habitats depend on larval dispersal. We characterized 12 polymorphic microsatellite loci from one such species, the siboglinid tubeworm Riftia pachyptila. All loci conformed to Hardy-Weinberg expectations without linkage (mean $H_{\mathrm{E}}=0.9405$, mean $N_{\mathrm{A}}=20.25$ ). These microsatellites are being employed in the investigation of spatial and temporal population genetic structure in the eastern Pacific Ocean.
\end{abstract}

Keywords: deep sea, hydrothermal vent, microsatellite, polychaete annelid, Riftia pachyptila, vestimentiferan tubeworm 


\subsection{Introduction}

The sessile siboglinid tubeworm Riftia pachyptila Jones, 1980 is a dominant megafaunal component of eastern Pacific Ocean deep-sea hydrothermal vent communities spanning approximately $7000 \mathrm{~km}$ of mid-ocean ridge (Hurtado et al. 2004). Riftia pachyptila disperses via a free-swimming trochophore larva that, when coupled with hydrodynamic models, is predicted to be retained within a ridge segment (Marsh et al. 2001). However, allozyme and mitochondrial DNA studies to assess population genetic structure in relation to larval dispersal potential in this species have not observed segment-scale structure among ephemeral, disjunct vent habitats (Bucklin 1988; Black et al. 1994; Hurtado et al. 2004). Using genomic fingerprinting to explore genetic diversity, a recent pilot study (Shank \& Halanych 2007) suggested the potential for previously undetected genetic structure in R. pachyptila populations. We report the isolation and characterization of 12 highly polymorphic microsatellite loci for R. pachyptila, intending to capitalize upon genome-wide genetic signal in the resolution of spatiotemporal population dynamics.

\subsection{Methods}

Four microsatellite loci were obtained using enriched genomic libraries created from two R. pachyptila individuals following the protocol outlined in Baco et al. (2006). Eight additional loci were developed from a third $R$. pachyptila individual. For the latter, approximately $10 \mu \mathrm{g}$ of genomic DNA was digested with DPNII (New England Biolabs) enzyme to construct $\mathrm{CA}$ and $\mathrm{CA}, \mathrm{AAC}$, and AGAT repeat-enriched libraries as described in the Molecular Markers: Tools for Developing Enriched Microsatellite Libraries handbook (Interdisciplinary Center for Biotechnology Research 2004). For these, the whole-genome polymerase chain reaction (PCR) libraries were denatured and hybridized to biotinylated $\mathrm{CA}$ or $\mathrm{CA} / \mathrm{AAC} / \mathrm{AGAT}$ probes, respectively. The hybridized repeatcontaining fragments were recovered with a 2-mL preparation of Dynabeads M-280 Streptavidin (Dynal Biotech) and a Dynal MPC-S magnetic particle concentrator. 
Positive clones from the TOPO TA Cloning Kit (Invitrogen) were identified using the Phototope-Star Chemiluminescent Detection Kit (New England Biolabs).

A total of $257 \mathrm{CA}$ and $38 \mathrm{CA} / \mathrm{AAC} / \mathrm{AGAT}$ repeat-containing plasmid inserts were sequenced using the M13F primer on an ABI 3730xl DNA Analyzer (Applied Biosystems). Reverse M13R sequences were later generated for 98 of these plasmid inserts. Manual (SEQUENCHER version 4.6, Gene Codes; SEQUENCING ANALYSIS, Applied Biosystems) and automated (MSATCOMMANDER, Faircloth 2007) examination of the resulting sequence data revealed 31 inserts containing tandem repeats with sufficient flanking regions for primer design. Primer pairs were developed using PRIMER3 (Rozen \& Skaletsky 2000).

In total, 12 variable microsatellite loci were used in genotyping. Genomic DNA was isolated from the vestimentum of 30 R. pachyptila individuals larger than $10 \mathrm{~cm}$ from the Tica hydrothermal vent site $\left(9^{\circ} 50.41^{\prime} \mathrm{N}, 104^{\circ} 17.50^{\prime} \mathrm{W}\right)$ on the East Pacific Rise using either the DNeasy Tissue (Qiagen) extraction kit or a Chelex 100 protocol (as used in Roy \& Sponer 2002). Amplification conditions were optimized for each locus, and forward primers were labelled on the 5' end with FAM, TAMRA, or HEX fluorophores, allowing for the pooling of similarly sized PCR products before capillary electrophoresis (see Table 1). PCRs carried out in a volume of $25 \mu \mathrm{L}$ consisted of 50-200 ng of DNA, 1× GeneAmp PCR buffer (Applied Biosystems) with final concentration of $1.5 \mathrm{mM} \mathrm{MgCl}_{2}$, $0.25 \mu \mathrm{M}$ each of a forward and a reverse primer (MWG Biotech), $0.2 \mathrm{mM}$ of each dNTP (Eppendorf), and 0.625 U of AmpliTaq Gold (Applied Biosystems). The thermal profile on Mastercycler ep gradient, Mastercycler personal (Eppendorf), and GeneAmp PCR System 9700 (Applied Biosystems) thermocyclers included an initial denaturation at $95^{\circ} \mathrm{C}$ for 10 min followed by 30 cycles ( 40 cycles for R2E14) of $95^{\circ} \mathrm{C}$ for $45 \mathrm{~s}$, a primerspecific annealing temperature (Table 1) for $30 \mathrm{~s}$, and $72^{\circ} \mathrm{C}$ for $45 \mathrm{~s}$, with a final extension of $72^{\circ} \mathrm{C}$ for $30 \mathrm{~min}$ to favor complete addition of a plus-A tail. PCR products were pooled before capillary electrophoresis as in Table 1. Products labelled with 6-FAM 
Table 1 Characteristics of microsatellite markers in Riftia padtyptila: locus name and GenBank Accession no., repeat array from clone, primer sequences, annealing temperature, size of the sequenced clone in base pairs, allele size range in base pairs, number of alleles determined from 30 individuals from the Tica vent site at $9^{\circ} 50^{\prime} \mathrm{N}$ on the East Pacific Rise, observed heterozygosity, unbiased expected heterozygosity, inbreeding coefficient, and $P$ value from Hardy-Weinberg equilibrium test

\begin{tabular}{|c|c|c|c|c|c|c|c|c|c|c|}
\hline $\begin{array}{l}\text { Locus } \\
\text { (GenBank } \\
\text { Accession no.) }\end{array}$ & Repeat array & Primers $5^{\prime}-3^{\prime}$ & $T_{\mathrm{a}}$ & $\begin{array}{l}\text { Cloned } \\
\text { allele } \\
\text { size }\end{array}$ & $\begin{array}{l}\text { Allele } \\
\text { size } \\
\text { range }\end{array}$ & $N_{a}(n)$ & $H_{\mathrm{O}}$ & $H_{\mathrm{E}}$ & $F_{\text {IS }}$ & $P_{\text {HW }}$ \\
\hline $\begin{array}{l}\text { R2D121 } \\
\text { (EF586194) }\end{array}$ & $(\mathrm{TG})_{27}$ & $\begin{array}{l}\text { F: *GCAGCAGAATTGAAGGTCGT } \\
\text { R: GCCTAGCATCTGTCTCTTATTGA }\end{array}$ & 50 & 240 & $213-278$ & $24(30)$ & 0.9667 & 0.9520 & -0.016 & 0.7875 \\
\hline $\begin{array}{l}\text { R2E142 } \\
\text { (EF586195) }\end{array}$ & $(\mathrm{AC})_{26} \mathrm{GC}(\mathrm{AC})_{3}$ & $\begin{array}{l}\text { F: *AATACCATGCTOGGTGGAAC } \\
\text { R: GCTGAAATTGGTCTCTTCGTG }\end{array}$ & $46 \S$ & 210 & $187-232$ & $20(30)$ & 1.0000 & 0.9508 & -0.053 & 1.0000 \\
\hline $\begin{array}{l}\text { R3B62 } \\
\text { (EF586196) }\end{array}$ & $\begin{array}{l}(\mathrm{AT})_{4}(\mathrm{GT})_{9} \mathrm{TT} \\
(\mathrm{GT})_{26}\end{array}$ & $\begin{array}{l}\text { F: †GQGATTCTTPGGATGA.AAACCA } \\
\text { R: ATTGTGAGTTCAAGCACACCTG }\end{array}$ & 53.3 & 240 & $163-235$ & $24(28)$ & 0.8571 & 0.9545 & 0.104 & 0.0188 \\
\hline $\begin{array}{l}\text { R3D33 } \\
(\mathrm{EF586197)}\end{array}$ & $(G T)_{15}(G C G T)_{15}$ & $\begin{array}{l}\text { F: †CATACAA@GGCAACAACGTTTA } \\
\text { R: ATACCGOGTAATTTGQCTAAGA }\end{array}$ & 60 & 232 & $215-269$ & $23(29)$ & 0.8621 & 0.9510 & 0.095 & 0.0563 \\
\hline $\begin{array}{l}\text { Rpa10CA024 } \\
\text { (EF586198) }\end{array}$ & $(\mathrm{CAA})_{4} \mathrm{CGA}(\mathrm{CAA})_{42}$ & $\begin{array}{l}\text { F: *ACGGTGGATACGTOCAACTACT } \\
\text { R: CTCOCGATTCTGACGTTTGT }\end{array}$ & 60 & 171 & $145-265$ & $23(30)$ & 0.9833 & 0.9508 & 0.019 & 0.4500 \\
\hline $\begin{array}{l}\text { Rpa10CA035 } \\
\text { (EF586199) }\end{array}$ & $\begin{array}{l}(\mathrm{AC})_{5} \mathrm{CC}(\mathrm{AC})_{7} \mathrm{AT} \\
(\mathrm{ACC})_{16}\end{array}$ & $\begin{array}{l}\text { F: *TGTTTCACTGCTCCGTGATT } \\
\text { R: TOGACGTCAGCTTAGCAATG }\end{array}$ & 51.2 & 236 & $255-338$ & $29(29)$ & $\mathrm{n} / \mathrm{a}$ & $\mathrm{n} / \mathrm{a}$ & $\mathrm{n} / \mathrm{a}$ & $\mathrm{n} / \mathrm{a}$ \\
\hline $\begin{array}{l}\text { Rpa10CA055 } \\
\text { (EF586200) }\end{array}$ & $\begin{array}{l}(\mathrm{TG})_{29}(\mathrm{OG})_{2} \mathrm{TGT} \\
(\mathrm{TG})_{5} \mathrm{AG}(\mathrm{TG})_{3}\end{array}$ & $\begin{array}{l}\text { F: *CACAGTACATACGAAAQCCATGT } \\
\text { R: TGCACACTCACATCAATGCT }\end{array}$ & 51.2 & 183 & $140-204$ & $24(29)$ & $\mathrm{n} / \mathrm{a}$ & $\mathrm{n} / \mathrm{a}$ & $\mathrm{n} / \mathrm{a}$ & $\mathrm{n} / \mathrm{a}$ \\
\hline $\begin{array}{l}\text { Rpa10CA065 } \\
\text { (EF586201) }\end{array}$ & $(\mathrm{AC})_{15}$ & $\begin{array}{l}\text { F: †GGCAAGGAATGCAGTGAGAT } \\
\text { R: GAGTGCGTGAAGATGAGTGC }\end{array}$ & 60 & 248 & $225-254$ & $12(25)$ & 0.8400 & 0.8865 & 0.054 & 0.2563 \\
\hline $\begin{array}{l}\text { Rpa10CA073 } \\
\text { (EF586202) }\end{array}$ & $(\mathrm{ACC})_{38}$ & $\begin{array}{l}\text { F: *GATCGAACCACCTGTTAGATGTT } \\
\text { R: GTCCTCAA.AGTCGCAAACAGA }\end{array}$ & 60 & 250 & $147-231$ & $23(28)$ & 0.9643 & 0.9468 & -0.019 & 0.8125 \\
\hline $\begin{array}{l}\text { Rpa10CA083 } \\
\text { (EF586203) }\end{array}$ & $\begin{array}{l}(\mathrm{TG})_{10} \mathrm{TTT}(\mathrm{GC})_{2} \\
(\mathrm{GT})_{3}(\mathrm{TC})_{2}\end{array}$ & $\begin{array}{l}\text { F: *TOCTGATGTGTTACOCCAAA } \\
\text { R: COCOGTACAATACTCOCAAT }\end{array}$ & 53.3 & 221 & $243-271$ & $10(28)$ & $\mathrm{n} / \mathrm{a}$ & $\mathrm{n} / \mathrm{a}$ & $\mathrm{n} / \mathrm{a}$ & $\mathrm{n} / \mathrm{a}$ \\
\hline $\begin{array}{l}\text { Rpa10CA094 } \\
\text { (EF586204) }\end{array}$ & $\begin{array}{l}(\mathrm{TG})_{22}(\mathrm{TOCG})_{9}(\mathrm{TG})_{22} \\
(\mathrm{CG})_{4} \mathrm{CATGCA}(\mathrm{TG})_{3}\end{array}$ & $\begin{array}{l}\text { F: †TGATGCAGGTTTCAGCATTG } \\
\text { R: AGGGACGTCTTAATGGGAATG }\end{array}$ & 60 & 180 & $200-288$ & $37(30)$ & $\mathrm{n} / \mathrm{a}$ & $\mathrm{n} / \mathrm{a}$ & $\mathrm{n} / \mathrm{a}$ & $\mathrm{n} / \mathrm{a}$ \\
\hline $\begin{array}{l}\text { Rpa10All011 } \\
\text { (EF586205) }\end{array}$ & $(C G)_{5}(\mathrm{CA})_{19} \mathrm{AA}(\mathrm{CA})_{11}$ & $\begin{array}{l}\text { F: †TAAAACCTGTTTGAAGCGTGTG } \\
\text { R: ATTAACOGCTCTTTGCTGATGT }\end{array}$ & 60 & 227 & $196-248$ & $17(30)$ & 0.9667 & 0.9316 & -0.038 & 0.8750 \\
\hline
\end{tabular}

* $¥$ Primersequence labelled with the fluorescent dye $* F A M,+H E X$, or $¥ T A M R A$ on the 5 'end, respectively. Numerical superscripts indicate PCR products pooled before electrophoresis. $T_{a^{\prime}}$, annealing temperature; $\S$, locus for which the cycle number is 40 instead of $30 ; N_{a^{\prime}}$ number of alleles; $n$, number of individuals successfully genotyped; $H_{\mathrm{O}}$, observed heterozygosity; $H_{\mathrm{E}}$, unbiased expected heterozygosity; $F_{\mathrm{IS}}$ inbreeding coefficient within populations; $P_{\mathrm{HW}}$, probability of observing at least as extreme a result given that genotype proportions conform to Hardy-Weinberg equilibrium; $\mathrm{n} / \mathrm{a}$, not analysed (see text). The adjusted value for significance (5\%) following Bonferroni correction for multiple comparisons is 0.00625 . The sequences were submitted to GenBank.

and TAMRA were pooled in equivalent volumes, while HEX-labelled products were pooled in a 2:1 volume ratio with FAM-labelled products to account for differences in signal intensity.

Fragment length was analysed on an ABI PRISM 3730 DNA Analyzer using the GeneScan-500 LIZ standard and GENEMAPPER version 3.7 (Applied Biosystems) with manual electropherogram inspection. PCR products from the same individuals were replicated between separate runs to monitor and control for genotyping inconsistencies. Raw allele sizes were binned using the automated FLEXIBIN (Amos et al. 2007) program and manually reviewed for ambiguities. Because of nonconformity to stepwise bins of 
allele lengths according to the sequenced repeat motif, four loci were excluded from subsequent analyses (Rpa10CA03, Rpa10CA05, Rpa10CA08, Rpa10CA09). The remaining loci were screened for the presence of null alleles using MICRO-CHECKER (van Oosterhout et al. 2004). Nonbiased expected and observed values for heterozygosity were determined using GENETIX (Belkhir et al. 2004), while tests for deviation from HardyWeinberg equilibrium and genotypic linkage were performed in FSTAT (Goudet 2001) (Table 1).

\subsection{Results and Conclusions}

All twelve loci were highly variable; the total number of alleles sampled from 30 individuals ranged from 10 to 37 . Null alleles were not detected among any of the loci, nor were heterozygote deficiencies significant for any locus. There was no evidence for linkage disequilibrium at the $5 \%$ significance level. A test for cross-genus amplification at Riftia-optimized PCR conditions for the 12 loci in the most closely-related sister taxon Tevnia jerichonana (based on COI sequence phylogeny; Black et al. 1997) yielded no products.

These loci are currently being applied to a spatiotemporal investigation of population genetic structure of R. pachyptila in the eastern Pacific Ocean. 


\section{Acknowledgements}

We gratefully acknowledge the opportunities provided by S.C. Cary (NSF OCE9714302), G. Luther (NSF OCE-9714302), R.A. Lutz (NSF OCE-9529819), and K. Von Damm (NSF OCE-9419156) during their expeditions, as well as the invaluable efforts of the captain, crew, and submersible pilots of the R/V Atlantis/Alvin. We thank A.M. Clark at the University of Florida, Gainesville for technical support and facilities in the development of microsatellite-enriched libraries. Special thanks to T. Paton, L. Timms, S. Russell, and J. Zhanqin at The Centre for Applied Genomics, Toronto, Canada for genotyping prepared samples. We also thank W. Amos at the University of Cambridge for his consultation following the release of FlexiBin.

This study was made possible by National Science Foundation (OCE-0327261 and OCE0324232) and National Oceanic and Atmospheric Administration's Office of Ocean Exploration (Award Nos. NA03OAR4600110 and NA16RP2390) support to TMS. AJF was supported by a NOAA Dr. Nancy Foster Scholarship (Award No.

NA04NOS4290253) and the Woods Hole Oceanographic Institution Academic Programs Office. Support to ARB was provided by a NOAA-WHOI Cooperative Institute for Climate and Ocean Research postdoctoral fellowship. TMS was also supported in part by the Ocean Life Institute and the Deep Ocean Exploration Institute at WHOI. 


\subsection{References}

Amos W, Hoffman JI, Frodsham A et al. (2007) Automated binning of microsatellite alleles: problems and solutions. Molecular Ecology Notes, 7, 10-14.

Baco AR, Clark AM, Shank TM (2006) Six microsatellite loci from the deep-sea coral Corallium lauuense (Octocorallia: Coralliidae) from the islands and seamounts of the Hawaiian archipelago. Molecular Ecology Notes, 6, 147-149.

Belkhir K, Borsa P, Goudet J, Chikhi L, Bonhomme F (2004) GENETIX 4.05, logiciel sous Windows TM pour la génétique des populations. Laboratoire Génome et Populations, CNRS UPR 5000, Université Montpellier II, Montpellier.

Black MB, Lutz RA, Vrijenhoek RC (1994) Gene flow among vestimentiferan tube worm (Riftia pachyptila) populations from hydrothermal vents of the Eastern Pacific. Marine Biology, 120, 33-39.

Black MB, Halanych KM, Maas PAY et al. (1997) Molecular systematics of vestimentiferan tubeworms from hydrothermal vents and cold-water seeps. Marine Biology, 130, 141-149.

Bucklin A (1988) Allozyme variability of Riftia pachyptila populations from the Galapagos Rift and $21^{\circ} \mathrm{N}$ hydrothermal vents. Deep-Sea Research Part A, 35, 17591768 .

Faircloth BC (2007) MSATCOMMANDER: detection of microsatellite repeat arrays and automated, locus-specific primer design. Molecular Ecology Resources, 8, 92-94.

Goudet J (2001) FSTAT, A Program to Estimate and Test Gene Diversities and Fixation Indices (version 2.9.3). Available from URL:

http://www2.unil.ch/popgen/softwares/fstat.htm. Updated from Goudet (1995).

Hurtado LA, Lutz RA, Vrijenhoek RC (2004) Distinct patterns of genetic differentiation among annelids of eastern Pacific hydrothermal vents. Molecular Ecology, 13, 26032615 .

Interdisciplinary Center for Biotechnology Research (2004) Molecular Markers: Tools for Developing Enriched Microsatellite Libraries, University of Florida.

Marsh AG, Mullineaux LM, Young CM, Manahan DT (2001) Larval dispersal potential of the tubeworm Riftia pachyptila at deep-sea hydrothermal vents. Nature, 411, 7780 .

van Oosterhout C, Hutchinson WF, Wills DPM, Shipley P (2004) MICRO-CHECKER: software for identifying and correcting genotyping errors in microsatellite data. Molecular Ecology Notes, 4, 535-538.

Roy MS, Sponer R (2002) Evidence of a human-mediated invasion of the tropical western Atlantic by the 'world's most common brittlestar.' Proceedings of the Royal Society London B, 269, 1017-1023. 
Rozen S, Skaletsky HJ (2000) PRIMER3 on the WWW for general users and for biologist programmers. In: Bioinformatics Methods and Protocols: Methods in Molecular Biology (eds Krawetz S, Misener S), pp. 365-386. Humana Press, Totowa, New Jersey.

Shank TM, Halanych KM (2007) Toward a mechanistic understanding of larval dispersal: insights from genomic fingerprinting of the deep-sea hydrothermal vent tubeworm Riftia pachyptila. Marine Ecology, 28, 25-35. 


\title{
Chapter 3
}

\section{Influence of local larval retention on deep-sea hydrothermal vent population structure}

\begin{abstract}
Organisms in disjunct and ephemeral habitats rely on various dispersal strategies to maintain genetic connectivity with other populations and persist as a species. In species with sessile adults, dispersal often occurs during a pelagic larval phase. Traditionally, the extent of larval dispersal is inferred from the genetic structure of adult populations, but such studies do not account for processes occurring on timescales relevant to individual life spans. Hydrothermal vents present a model environment in which the contributions of different cohorts to discrete populations may be measured with high-resolution genetic markers. This study employs eight polymorphic DNA microsatellite loci to population genetic considerations of the dominant tubeworm Riftia pachyptila at five hydrothermal vent regions in the eastern Pacific. Small but significant differences were found between Riftia populations on the East Pacific Rise and Galápagos Rift. The importance of considering cohorts in population genetic studies becomes apparent, as colonist subpopulations were most similar to residents sampled at the same and next proximate site. Within a ridge system, colonists were also more like other colonists than residents were to other residents. These results suggest that local larval retention plays a key role in establishing and maintaining Riftia populations, while limited gene flow exists on longer timescales between ridge systems in the eastern Pacific. Genetic comparisons of populations must therefore not only consider adults but also be mindful of larval and early juvenile stages, which can lead to different inferences about recruitment and gene flow.
\end{abstract}




\subsection{Introduction}

There is a biological need in all species that dispersal be balanced with retention. Below, various strategies for evaluating this balance are presented, the experimental setting is described, and key attributes of the model organism chosen for this study are discussed.

\subsubsection{Biological impetus for larval dispersal and local retention}

Organisms with sessile adults often rely upon a larval or juvenile phase to disperse and colonize new areas. This phase in a complex life history is important for coping with crowding and resource limitation, locating a mate outside of kin groups, and persisting as a species beyond local disturbance events. The movement of individuals from one location and subsequent development into successful reproductive adults in another location facilitates the exchange of genetic material. The extent of this exchange or gene flow determines both the genetic connectivity among populations and the range potential of a species.

In the marine environment, both biological and physical features influence larval dispersal potential and species realized gene flow. For example, unless there are mechanisms that occasionally allow for exchange, geographically isolated populations of species that brood or otherwise retain their young locally may diverge and speciate over evolutionary time. On the other hand, species with planktonic larvae may be able to travel far from their natal population before settlement (Thorson 1950). This strategy is especially useful for maintaining genetic connectivity across patchily distributed habitats.

Recent evidence from oceanographic models on scales of 10-100 km (e.g, Cowen et al. 2006) and direct observations (e.g., Swearer et al. 1999, Thorrold et al. 2002, Becker et al. 2007) suggests recruitment of planktonic larvae from local populations rather than long-distance larval dispersal (Thorson 1950, Scheltema 1986, Caley et al. 1996) may dominate marine population dynamics. While retention of larvae on small scales (e.g., < 
$1 \mathrm{~km}$ ) may be advantageous for population maintenance in disjunct habitats by ensuring the seeding of new progeny in a suitable location, it also makes a population more vulnerable to local extinction by limiting dispersal to an isolated location (Wood \& Gardner 2007). In coastal systems, year to year mean current variability has been shown to increase retention of iteroparous species by oscillating between conditions that favor short- and long-distance larval dispersal (Byers \& Pringle 2006). Species must balance along-current transport with remaining close to their natal population in order to persist in a region. The advantages of larval retention (e.g., reduced predation, ensured food availability) may be afforded irrespective of larval duration in the water column and without significant ecological tradeoffs (Strathmann et al. 2002, Levin 2006, Teske et al. 2007).

With rare exceptions (e.g., Annis 2005), larvae are difficult to locate and track in open marine systems. Scientists often rely upon multigenerational genetic comparisons of realized species dispersal reflected in adult populations. Classically, dispersal has been described in two ways - via the island model of discrete populations contributing to a mixed gene pool that is redistributed to those populations irrespective of their spatial arrangement (Wright 1931), or by the stepping-stone model, in which migration is more likely to occur between neighboring populations along a linear path (Kimura \& Weiss 1964, Wright 1940). These approaches overlook the actual mechanisms of dispersal, focusing on patterns that resulted from many generations of genetic exchange.

High-resolution molecular markers (e.g., microsatellites) have been more recently employed to identify important links among adults, juveniles, and larvae of marine populations and to ascertain the genetic influence of each cohort on the population at large (Morgan \& Rogers 2001). As an established cohort ages, mortality and selection can have a cumulative effect and significantly shrink genetic effective population sizes of recent colonists (Cassista \& Hart 2007). Age classes may become differentiated from each other (Planes \& Lenfant 2002). Genetic variation in larval cohorts can be then used 
to investigate the genetic mixture observed in adult populations (Weinmayr et al. 2000, Gilg \& Hilbish 2003). Not all individuals in a population may contribute uniformly to the next generation and not all local populations exchange individuals on contemporary timescales (Jehle et al. 2005). As a result, integrated adult-colonist genetic studies have the power to provide a more mechanistic understanding and to consider the effects of larval retention, demographic bottlenecks, and chaotic genetic patchiness (e.g., Hedgecock et al. 2007). The challenge is to implement population genetic comparisons within rather than across generations (Levin 2006).

\subsubsection{Proposed genetic barriers structuring eastern Pacific hydrothermal vent populations}

Deep-sea hydrothermal vents provide an ideal setting at which to examine larval dispersal and retention. Vents occur primarily along mid-ocean ridge spreading centers, giving them a roughly linear distribution. Biological processes at vents are intrinsically linked to the spreading systems on which they are found, including ties to the tectonic and magmatic instability of active spreading centers, variable hydrothermal fluid flux and composition, and strong temperature and chemical gradients. The chemosynthetic communities hosted at sites on fast-spreading ridges are particularly subject to frequent disturbance and local extinction (Haymon et al. 1993, Shank et al. 1998, Shank et al. 2003). Tectonic and volcanic events not only disrupt conduits for hydrothermal fluids but may also pave over existing vents and their associated fauna. Without reinvigoration, mineralization of particular vents will change their chemical composition and eventually block fluid flow completely. The cessation of flow and the chemical depletion of hydrogen sulfide have both been implicated in vent community death (Shank et al. 1998). Moreover, the global mid-ocean ridge system is ridden with faults and fractures, breaking up ridge chains into segments and isolating venting habitats by $10 \mathrm{~s}$ to $100 \mathrm{~s}$ of $\mathrm{km}$. Because of these environmental features, vent-endemic fauna must be able to colonize distant habitat in order to persist as coherent species. 
Processes controlling dispersal and colonization at vents have been inferred primarily from patterns of species distribution. Early research turned from larval shell proxies (summarized in Lutz et al. 1986) to genetic tools, typically generalizing gene flow as being high along mid-ocean ridge systems. Given the topographically influenced hydrodynamic mechanisms inferred for the ridge axis, larval retention may well be promoted at vents; this remains a fertile area for research (Ridge2000 2008 Program Review). Judging from recent and historical genetic studies (including France et al. 1992, Jollivet et al. 1995, Craddock et al. 1997, Won et al. 2003, Matabos et al. 2008), five bathymetric or hydrographic features (discussed below) are potentially important to vent population genetic structure in the eastern Pacific (Hurtado et al. 2004). In particular, the East Pacific Rise (EPR), a seafloor mountain chain stretching north to south along the divergent tectonic boundary of the Pacific plate with the Cocos and Nazca plates, is broken up into over a dozen segments by ridge offsets. Extending perpendicular to the EPR, the east-west Galápagos Rift (GAR) marks the spreading region between the Nazca and Cocoas plates; the region in which these two plates meet the Pacific plate is referred as the Galápagos Triple Junction. The Easter Microplate interrupts the EPR at its southern end, south of which the Pacific-Antarctic Ridge begins.

1) Flanked between $18^{\circ}$ and $20^{\circ} \mathrm{N}$, the Rivera Fracture Zone (RFZ) is the longest transform fault on the EPR. An east-west ridge offset $240 \mathrm{~km}$ long, the RFZ lacks hydrothermal venting and is thus a major discontinuity to the EPR ridge system. Species with short larval lives and dependent upon intermediate habitat may not be able to cross by this feature. A strong westward current runs through the RFZ (Reid 1997), capable of transporting pelagic larvae from southern vents along the ridge to those north of the fracture. However, this current could also prevent northern originating larvae from dispersing to vents to the southeast.

2) The Galápagos Triple Junction occurs at the intersection two mid-ocean ridges (EPR and GAR), bounded by three tectonic plates: the Pacific Plate to the west, 
the Cocos Plate to the northeast, and the Nazca Plate to the southeast. Hess Deep extends as a $5.4 \mathrm{~km}$ deep, $25 \mathrm{~km}$ long, $15 \mathrm{~km}$ wide depression at the propagating tip of the GAR (Searle \& Francheteau 1986, Lonsdale 1988) and may trap or impede larvae from transport between the EPR and GAR.

3) Aside from Hess Deep, the $5^{\circ} \mathrm{N}$ region of the East Pacific Rise is associated with oceanic gyres and deep eastward currents from the passage of an equatorial countercurrent (Reid 1997). Surface gyres spin north and south of the triple junction, potentially entraining buoyant larvae and advecting them away from the ridge crest. However, eastward currents could facilitate transport from the EPR to the GAR system or deter passage between the northern and southern EPR.

4) The region from $17^{\circ}$ to $23^{\circ} \mathrm{S}$ along the Southern East Pacific Rise (SEPR) is marked by an ultra-fast spreading rate (Sinton et al. 2002). Habitat turnover may be especially great in this region due to heightened seismic and volcanic activity, increasing the occurrence of local extinctions and genetic bottlenecks. The SEPR is also intersected by cross-axis currents at $15^{\circ} \mathrm{S}$. Together, high turnover and a boundary current could interrupt along-axis gene flow from populations north and south of these features.

5) The Easter Microplate between $23^{\circ}$ and $27^{\circ} \mathrm{S}$ on the EPR is flanked by transform faults on the north and south and seamount chains on the east and west (Searle et al. 1989). Cross-axis currents are entrained across the plate (Fujio \& Imasato 1991), which may create a barrier across which planktonic larvae are limited or unable to navigate. This region is also coincident with a biogeographic boundary defined by the Antarctic Circumpolar Current as recent as 20 Mya (Mironov et al. 1998, Vinogradova 1979) and therefore may represent historical species isolation. 


\subsubsection{Observed genetic patterns across two ridge features}

With concentrated sampling efforts in the northern EPR and GAR, this study is well poised to explore the first two postulated barriers in the context of recent colonist arrival and resident populations. Two species that occur on either side of the RFZ, the tubeworm Oasisia alvinae and amphipod Ventiella sulfuris, have also been demonstrated to exhibit restricted gene flow across this region (France et al. 1992). Species diversification across the Rivera Fracture Zone may also be present in several limpets, including lepetodrilids (Lepetodrilus and Gorgoleptis McLean 1988, Neolepetopsis McLean 1990) and peltospirids (McLean 1989; Warén \& Bouchet 1989, 1993, 2001). The RFZ marks the northern extent for Tevnia jerichonana tubeworms (Black et al. 1998), Bathymodiolus thermophilus mussels (Grassle 1985, Craddock et al. 1995, Van Dover 2000, Won et al. 2003), and Branchipolynoe symmytilida scaleworms (Hurtado et al. 2004). While collections are limited, various molluscs have also not been reported north of this major ridge discontinuity (Desbruyères et al. 2006), including the coiled snail Bathymargarites symplector (Warén \& Bouchet 1989), limpets Lepetodrilus pustulosus (Craddock et al. 1997), several neomphalids (Hickman 1984, Warén \& Bouchet 1993), and predatory snail Phymorhynchus major (Warén \& Bouchet 2001), as well as the scallop Bathypecten vulcani (Schein-Fatton 1985).

The Galápagos Rift Triple Junction and Hess Deep are associated with limited dispersal between the GAR and EPR not only in B. symmytilida, and potentially B. thermophilus (Grassle 1985, though not according to Craddock et al. 1995 and Won et al. 2003), but also in Calyptogena magnifica (Hurtado et al. 2003), V. sulfuris (France et al. 1992), and Paralvinella grasslei (Jollivet et al. 1995). Alvinella pompejana, T. jerichonana, and two species of bythograeid crabs are not found on the GAR (Guinot \& Hurtado 2003). A third bythograeid species as well as many copepods are endemic to the GAR (Guinot \& Hurtado 2003, Huys \& Conroy-Dalton 1997, Conroy-Dalton \& Huys 1999, Ivanenko \& Ferrari 2003, Desbruyères et al. 2006). 


\subsubsection{Biological model, Riftia pachyptila}

To examine the role of physical oceanographic barriers to the dispersal of vent organisms along the northern EPR and GAR, I turned my attention to the well studied siboglinid tubeworm Riftia pachyptila Jones, 1980 (a monospecific genus hereafter referred to as Riftia), a dominant macrofaunal component of deep-sea hydrothermal vent communities in the eastern Pacific Ocean. This species has separate sexes (Jones 1980), with roughly equal ratio of males to females (Thiébaut et al. 2002), and is highly fecund (Cary et al. 1989); up to 700,000 mature eggs have been observed in Riftia's ovisac (Young 2003). Eggs are small, yolky, lipid-rich (Cary et al. 1989), and near-neutrally buoyant on the seafloor (Marsh et al. 2001). Sperm released into the water column are then stored in ovarian spermatheca, and imperfect $(<100 \%)$ fertilization occurs internally prior to oocyte release (Hilário et al. 2005). Riftia embryos develop at depth (Marsh et al. 2001).

This tubeworm species possesses a free-swimming, non-feeding (lecithotrophic) trochophore larvae believed to facilitate limited transport between disjunct areas of suitable habitat (Jones \& Gardiner 1989, Tyler \& Young 1999, Marsh et al. 2001). Both along-axis currents and entrainment into the buoyant hydrothermal plume (Kim \& Mullineaux 1998) may disperse Riftia larvae during its larval lifespan of about 38 days (Marsh et al. 2001); this dispersive phase includes 3 weeks of embryonic development and 2 weeks of ciliary movement before settlement and symbiont acquisition (Southward 1988, Nussbaumer et al. 2006). Natural and experimental colonization observations have been unable to determine the biotic or abiotic cue for Riftia settlement (Shank et al. 1998, Hunt et al. 2004, Mullineaux et al. 2000). As colonization occurs within a year or two of newly available habitat, it is considered likely that a pool of larvae is maintained in the water column above vents (Shank et al. 1998, Govenar et al. 2004). Recruitment lacks periodicity and is discontinuous, but settlement events can be frequent (e.g., 8 to $20 \mathrm{~d}$ ) (Thiébaut et al. 2002). Once established, Riftia grows quickly and out-competes or overgrows the smaller tubeworm species, Tevnia jerichonana, first to colonize new vents (Lutz et al. 1994, Thiébaut et al. 2002, Shank et al. 1998). 
As measured by traditional genetic markers (allozymes, mtDNA), Riftia has been found to lack population genetic structure along much of its $7000 \mathrm{~km}$ range, with the exception of subdivision across the Easter Microplate in the southern Pacific (Bucklin 1988, Black et al. 1994, Hurtado et al. 2004). This pattern is similar to that found in bathymodiolid mussels across the same region (Won et al. 2003). North of this plate, dispersal appears to be unimpeded. Riftia's low mitochondrial DNA variability suggests the influence of metapopulation processes: a strong bottleneck or selective sweep, likely maintaining this species out of mutation-drift equilibrium as a result of continuous population reductions and expansions. However, Hurtado and colleagues (2004) recommended that further assessment be conducted to determine the extent such phylogeographic patterns are reflected genome-wide. A recent pilot study explored the genetic diversity of Riftia using amplified fragment length polymorphisms (AFLPs) at a range of spatial scales and found individuals clustered by sampling location (Shank \& Halanych 2007), prompting the development of highly polymorphic microsatellite loci (Fusaro et al. 2008), also useful in resolving genetic patchiness in siboglinids of other habitats (McMullin 2003).

In addition to genetic inferences of population structure, scientists have recently modeled oceanographic current interactions with the neutrally buoyant hydrothermal plume in order to understand how discrete populations may exchange individuals (Marsh et al. 2001, Won et al. 2003, Young et al. 2008). Coupling Riftia metabolic larval lifespan estimates of about 38 days with in situ measurements of current flow at two regions on the northern East Pacific Rise predicts maximum potential dispersal of 100 to $200 \mathrm{~km}$ without larvae being lost off the ridge axis (Marsh et al. 2001). However, given frequent flow reversals, it is much more likely for larvae to be retained within a few tens of kilometers of their source population (Marsh et al. 2001). Local retention of Riftia larvae would limit gene flow among distant locations, but metapopulation processes may serve to maintain apparent genetic homogeneity. The discrepancies in population genetic patterns, larval life history, and modeled dispersal potentials remain to be resolved. 


\subsubsection{Objectives}

Limited transport potential, metapopulation processes, and contrasting patterns of juvenile and adult population structure in other systems have led to the present examination of new microsatellite DNA evidence for local retention in Riftia. To capture the consequences of variable reproductive success and settlement, this research extends genetic comparisons of adults to earlier stages by including collections of recent colonists and resident adults (as in Hedgecock et al. 2007). The specific objectives of this study are to: 1) evaluate the consistency of proposed larval barriers across the Rivera Fracture Zone and Galápagos Triple Junction with fine scale genetic markers, 2) analyze variation between discrete cohorts within a site to consider intergenerational population genetic structure at vents, and 3) examine processes of recruitment to provide insights into population homogeneity observed with traditional markers.

\subsection{Materials and methods}

\subsubsection{Sample collection}

Riftia individuals were collected using the submersible DSV Alvin operating from the $R / V$ Atlantis on the East Pacific Rise (EPR) and Galápagos Rift (GAR) (Figure 3.1). Attempts were made to sample sites within the same year (2002) to avoid confounding results that can arise from temporal genetic variance (Gilg \& Hilbish 2003, Pedersen et al. 2000). After preliminary screening of sites through time revealed stable patterns of population structure at a single site through time (see Chapter 4 for details), the decision was made to include a third EPR site visited in 2003 and a second GAR site sampled in 2005 in order to increase sample number and provide additional power to hierarchical AMOVA groups. Within each site, specimens were collected within several days of each other. 


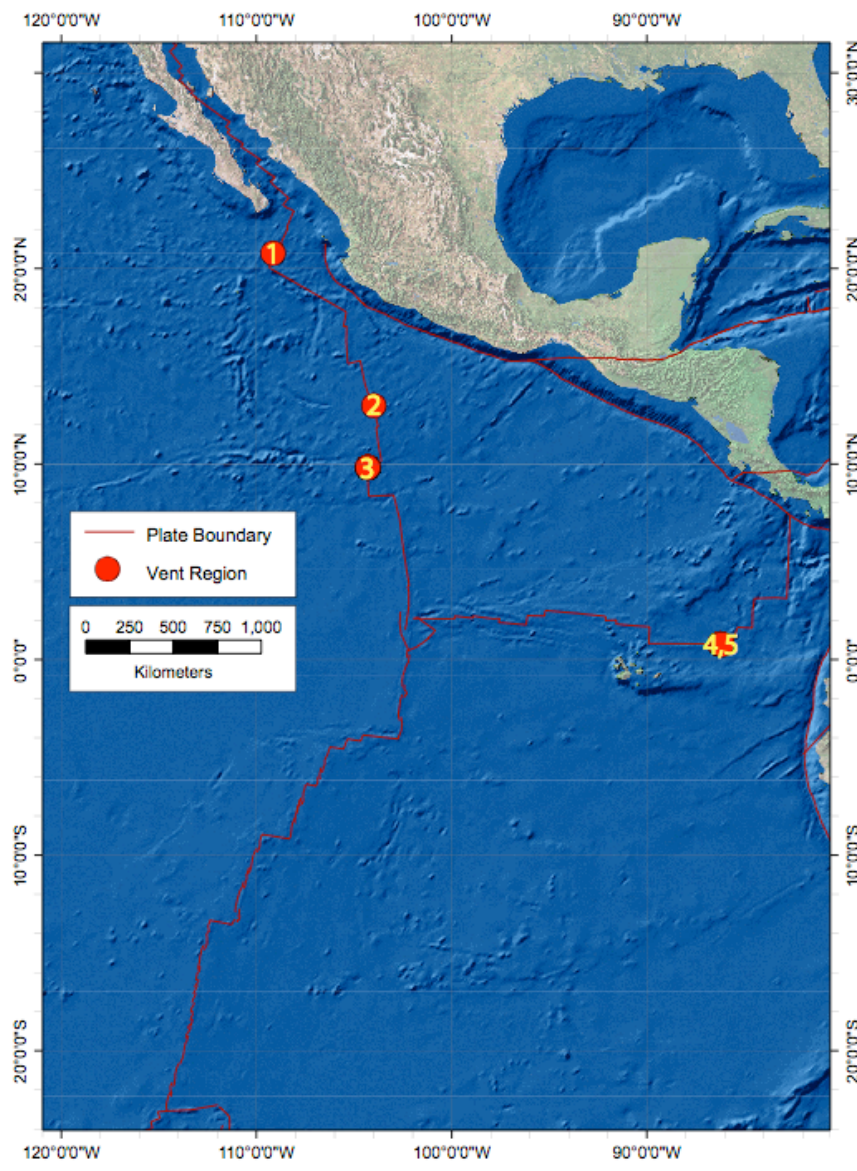

Figure 3.1 Locations of sampling efforts on the East Pacific Rise $\left(1: 21^{\circ} \mathrm{N}\right.$, 2: $13^{\circ} \mathrm{N}, 3: 9^{\circ} \mathrm{N}$ ) and on the Galápagos Rift (4: Rosebud, 5: Garden of Eden).

Tubeworms from specific assemblages within sites along these mid-ocean ridges were placed in sealed, insulated boxes until Alvin recovery. Within hours, individual specimens were removed from their chitinous tubes and measured for total body length (tip of plume to tip of opisthosome) to the nearest $0.5 \mathrm{~cm}$ or estimated when the body was severed (e.g., $>250 \mathrm{~mm},>500 \mathrm{~mm},<5 \mathrm{~mm},<20 \mathrm{~mm}$ ). Worms were categorized and sorted either as "recent colonists" (body length $<30 \mathrm{~mm}$ ) or as "resident adults" (body length > $100 \mathrm{~mm}$ ), ignoring intermediate size classes (with the exception of $13^{\circ} \mathrm{N}$ EPR, see below). Whole animals or individual tissues were frozen at $-80^{\circ} \mathrm{C}$ and transported on dry ice. Further molecular processing was conducted in a shore-based laboratory at Woods Hole Oceanographic Institution. 
Recent colonists were inferred to be less than one year old, while resident adults likely spanned many years of recruitment (as in Grassle 1985). This body length binning scheme was selected to ensure the sampling of discrete recruitment events, maximizing differences in age between the two "cohorts" and avoiding "short, fat" morphologies whose relative age would be difficult to assign. In addition to providing a more holistic sample of populations, the inclusion of different size classes facilitates tests of "generational stability" in population genetic structure (as in Purcell et al. 2006). Moreover, in a genomic fingerprint cluster analysis, Shank \& Halanych (2007) found that Riftia individuals smaller than $100 \mathrm{~mm}$ grouped in unresolved polytomies by sample site, suggesting that these small individuals comprised recent settlement cohorts.

Recent colonists and resident adults were collected in 2002 on expedition AT7-06 from the $21^{\circ} \mathrm{N}$ EPR Clam Acres site ( $21^{\circ} 51^{\prime} \mathrm{N}, 109^{\circ} 7^{\prime} \mathrm{W}, 2615 \mathrm{~m}$ deep) during Dive 3747 and from the $9^{\circ} \mathrm{N}$ EPR Tica site $\left(9^{\circ} 50^{\prime} \mathrm{N}, 104^{\circ} 18^{\prime} \mathrm{W}, 2511 \mathrm{~m}\right.$ deep) during Dives 3754 and 3769 (Table 3.1). The $86^{\circ} \mathrm{W}$ GAR Rosebud site $\left(0^{\circ} 48^{\prime} \mathrm{N}, 86^{\circ} 14^{\prime} \mathrm{W}, 2451 \mathrm{~m}\right.$ deep) was also sampled in 2002 on expedition AT7-13 during Dives 3789 and 3790. A fourth hydrothermal vent region, $13^{\circ} \mathrm{N}$ EPR "sulfide mound" $\left(12^{\circ} 43^{\prime} \mathrm{N}, 103^{\circ} 55^{\prime} \mathrm{W}, 2573 \mathrm{~m}\right.$ deep), was sampled in late 2003 on expedition AT11-01 during Dive 3957. No individuals within the "recent colonist" size class were available from the $13^{\circ} \mathrm{N}$ site; therefore, to increase sample size, the resident population at $13^{\circ} \mathrm{N}$ EPR includes individuals $>70 \mathrm{~mm}$. A second $86^{\circ} \mathrm{W}$ GAR site $10 \mathrm{~km}$ away from Rosebud, the Garden of Eden site ( $0^{\circ} 48^{\prime} \mathrm{N}, 86^{\circ} 8^{\prime} \mathrm{W}, 2489 \mathrm{~m}$ deep), was visited in 2005 on expedition AT11-27 during dives 4120 and 4121.

For the purpose of this paper, samples collected at a site are collectively referred to as a pooled population, while recent colonists and resident adults from each site are designated as a particular subpopulation or cohort. 


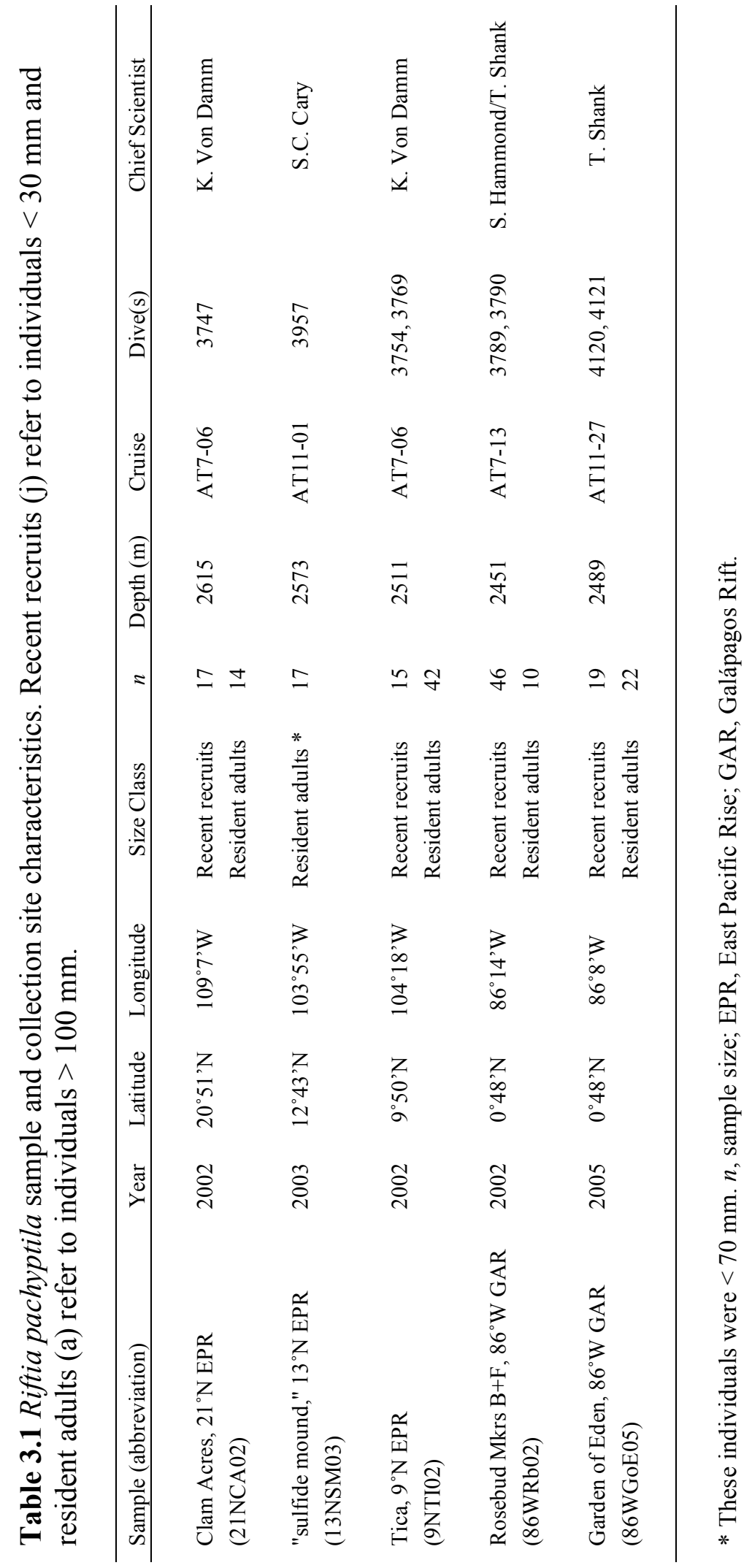




\subsubsection{Genetic analyses}

Genomic DNA was isolated from the frozen vestimentum (and from one opisthosome) of 202 Riftia individuals using either the DNeasy Tissue (Qiagen) extraction kit or the Chelex 100 procedure (Roy \& Sponer 2002). The polymerase chain reaction (PCR) was used to amplify these samples at eight highly polymorphic microsatellite loci (R2D12, R2E14, R3B6, R3D3, Rpa10CA02, Rpa10CA06, Rpa10CA07, Rpa10A1101) previously developed for genotyping (Fusaro et al. 2008). Allele fragment length was analyzed on an ABI 3730 DNA Analyzer using the GeneScan 500 LIZ standard and GENEMAPPER version 3.7 (Applied Biosystems) with manual electropherogram inspection. PCR products from a subset of individuals were replicated between separate runs to monitor and control for genotyping inconsistencies. Raw allele sizes were binned into whole number allele lengths (number of base pairs) using the automated FLEXIBIN (Amos et al. 2007) program and manually reviewed for ambiguities. Allele lengths were then translated to number of repeats based on sequenced clones from Fusaro et al. (2008).

Input files for analyses were created from a MS Excel spreadsheet in the 3-digit MICROCHECKER version 2.2.3 (van Oosterhout et al. 2004) and 6-digit GENETIX version 4.05.2 (Belkhir et al. 2004) formats. Data from the latter file-type were reformatted by GENETIX to create input files for FSTAT version 2.9.3.2 (Goudet 2001), ARLEQUIN version 3.11 (Excoffier et al. 2005), and GENEPOP ON THE WEB version 3.4 (Raymond \& Rousset 1995). The GENEPOP file format was implemented in BOTTLENECK version 1.2.02 (Cornuet \& Luikart 1996). The FSTAT file format was used in PCA-GEN version 1.2 (Goudet 1999). These data were formatted for 2-digit allele length (FSTAT, GENEPOP, BOTTLENECK), 3-digit allele length (MICRO-CHECKER, GENETIX), and repeat number (ARLEQUIN). The 3-digit allele length data were manually formatted for subsequent analyses in STRUCTURE version 2.2 (Pritchard et al. 2000; Falush et al. 2003, 2007). 


\subsubsection{Single locus statistical analyses and conformance to Hardy- Weinberg equilibrium}

MICRO-CHECKER was used to screen loci in each subpopulation for scoring errors-null alleles, large allele dropout, and stuttering - that would result in departure from HardyWeinberg equilibrium expectations (run at the default 95\% CI, 1000 permutations). The probabilities for observed homozygote size-class frequencies were calculated by a cumulative binomial distribution (Weir 1996) and by ranking the observed frequency in a distribution of randomized genotypes (van Oosterhout et al. 2004). These $P$ values were then combined to identify deviations from Hardy-Weinberg proportions (van Oosterhout et al. 2004). Once alleles were established to be reliably scored, the number of alleles, allelic richness (normalized to the smallest subpopulation size; El Mousadik \& Petit 1996), allele size range, and size and frequency of the most common allele(s) were calculated per subpopulation and across all subpopulations in the programs GENETIX and FSTAT.

Nonbiased expected and observed heterozygosity values were determined in ARLEQUIN following Nei (1987). Fisher-type exact tests of HWE per locus per cohort, comparing $\mathrm{H}_{\mathrm{E}}$ and $\mathrm{H}_{\mathrm{O}}$, were also conducted in ARLEQUIN with a recommended Markov chain of 2,000,000 steps and 200,000 dememorization steps for reproducibility (L. Excoffier, Genetic Software Forum pers. comm.). To assess locus conformance to HWE expectations of random mating, $F_{\text {IS }}$-based estimates were calculated in the program FSTAT (Weir \& Cockerham 1984) using 2000 permutations (recommended value for $<10$ loci $=1000$ permutations; however, it took 2000 randomizations to result in little variation in significant values among multiple runs). The data were analyzed for linkage disequilibrium (Weir 1996) using a probability test on all locus-specific contingency tables under the null hypothesis of independence (Cockerham \& Weir 1979). Parameter values in GENEPOP ON THE WEB consisted of 5000 dememorization steps, 500 batches, and 2000 iterations per batch - at which level variation in $P$ value magnitude among multiple runs did not alter the level of pairwise significance. In order to correct for multiple 
comparisons, all significance tests were run at a nominal alpha level of 0.05 with sequential Bonferroni correction (Rice 1989).

\subsubsection{Estimates of population and cohort structure}

In order to detect heterogeneity among and between pooled populations and cohorts, exact tests of differentiation in allele (genic) and genotype (genotypic) distributions between sample pairs were conducted in GENEPOP ON THE WEB using 5000 dememorization steps, 500 batches, and 2000 iterations per batch, as described for tests of linkage disequilibrium. A principal components analysis (PCA) based on $F_{\mathrm{ST}}$ comparisons was used to identify clusters of subpopulations from genotypic data using PCA-GEN. Significance of each axis in the PCA was determined using 10,000 randomizations.

Overall population structure was estimated using hierarchical analysis of molecular variance (AMOVA, ARLEQUIN) with 20,000 permutations. This allowed quantification of the magnitude of genetic variation (by partitioning total variance into covariance components) among geographic regions $\left(\Phi_{\mathrm{CT}}\right)$ relative to other sources of genetic variation among populations $\left(\Phi_{\mathrm{SC}}\right)$, within cohorts $\left(\Phi_{\mathrm{IS}}\right)$, and within individuals $\left(\Phi_{\mathrm{IT}}\right)$. Significant differences from zero in Wright's fixation indices at these four levels were tested for departure from HWE by comparing observed values to a null distribution estimated by randomly permuting the populations, individuals, or haplotypes among groups of populations defined by ridge system (EPR or GAR), cohorts, or individuals, respectively.

All samples were further explored for underlying genetic structure among one another and between ridge systems using an admixture model of ancestry and correlated allele frequencies in STRUCTURE (burnin of 20000, followed by 20000 MCMC replicates; tested for $K=1$ through $K=5$ ). This algorithm assigns individuals to groups assuming that loci 
are at HWE within each group and estimates the population of origin for each individual from the observed genotypes (Pritchard et al. 2000). The calculated membership coefficient $(Q)$ for each individual displays its estimated affinity to a given group. The posterior probability of the data (PPD) was plotted as in Garnier et al. (2004) to determine the best number of population groups $(K)$ given the results. In order to determine the origin of overall population structure, among-colonist and among-resident subpopulation structure was explored using the same parameters.

Estimates of Weir \& Cockerham's (1984) allele frequency-based $\theta_{\mathrm{WC}}$ (estimates Wright's $1951 F_{\mathrm{ST}}$ ), assuming the infinite alleles model of mutation, and Slatkin's (1995) allele repeat-based $R_{\mathrm{ST}}$, assuming the stepwise model of microsatellite mutation, were calculated between population and cohort pairs in ARLEQUIN. Significance was tested using 20,000 permutations - pairwise significance levels were consistent among runs at this number of permutations - with a sequential Bonferroni correction for multiple tests. $F_{\text {ST }}$ was also calculated and tested for significance per locus over all populations in FSTAT. These $F_{\mathrm{ST}}$-based comparisons considered genetic variability within and between populations, while the previous tests of genic and genotypic differentiation were based on contingency tables of the distribution of alleles or genotypes among populations.

Genetic isolation by geographical distance was evaluated for significance using the Mantel test implemented in GENEPOP ON THE WEB (500,000 permutations). As recommended when the distance between populations is greater than habitat width, Slatkin's (1995) linearized $F_{\mathrm{ST}}, F_{\mathrm{ST}} /\left(1-F_{\mathrm{ST}}\right)$ or $R_{\mathrm{ST}} /\left(1-R_{\mathrm{ST}}\right)$, was plotted against geographical distance to determine the significance of the relationship (Rousset 1997). The linear distance between sites was calculated as the shortest route between given coordinates of latitude and longitude using a great circle calculator with the WGS84 model (available at http://williams.best.vwh.net/gccalc.htm). 


\subsubsection{Effective migration, population bottlenecks, and colonist assignment}

The effective number of migrants among populations or cohorts $(\mathrm{Nm})$ was estimated using the rare alleles method implemented in GENEPOP ON THE WEB (Slatkin 1985, Barton \& Slatkin 1986). This overall estimate of gene flow is based on the average frequency of alleles found in only one population.

Populations and cohorts were tested for the presence of a recent genetic bottleneck using the program BOTTLENECK with the two-phased mutation model parameters of $30 \%$ variance and 70\% SMM (Di Rienzo et al. 1994), 10000 iterations, and a Wilcoxon signtest, recommended for suites of more than 4 loci and any sample size ( $n=15-40$ has most power).

The program WHICHRUN version 4.1 (Banks \& Eichert 2000) was used to assign colonists to populations of resident adults. Because the both colonists and residents were sampled at three different locations in 2002,78 colonists from $9^{\circ} \mathrm{N} E P R, 21^{\circ} \mathrm{NEPR}$, and $86^{\circ} \mathrm{W}$ GAR were chosen for assignment to one of those three resident adult populations. The base 10 logarithm of odds (LOD score) - the $\log _{10}$ of the ratio of the likelihood of assignment to the most likely population to the second most likely population-was used to discriminate among assigned and unassigned individuals.

\subsection{Results}

\subsubsection{Genetic variability}

Two-hundred and two Riftia individuals were analyzed from five populations (nine subpopulations) at eight polymorphic microsatellite loci. Within subpopulations, the number of individuals genotyped at each locus ranged from 10 to 46 , due to sampling effort and specimen availability at specific vent sites. All except three individuals were genotyped at all loci. A subset of individuals was replicated per plate and between runs to promote consistent allele scoring. Among subpopulations, the number of alleles per locus 
varied from 7 (Rpa10CA06) to 28 (Rpa10CA02), with a mean allele count of 16.25; over all populations, the total number of alleles per locus showed high variability, ranging from 18 to 38 (same loci respectively). Allelic richness normalized to a minimum of 10 individuals per sample ranged from 6.8 (Rpa10CA06, 86WMQ05j) to 16.7 (R3B6, 13NSM03) per locus and population (mean =12). In addition, allelic richness on the EPR was significantly greater than that on the GAR in an unpaired $t$-test $(P=0.0023)$, particularly in locus Rpa10CA06. Allele lengths ranged from $146 \mathrm{bp}$ (Rpa10CA02) to 277 bp (R2D12). Most common alleles and their frequencies within subpopulations are provided in Table 3.2 .

\subsubsection{Hardy-Weinberg equilibrium}

Non-biased expected heterozygosities (gene diversity) were also high and ranged from 0.7895 (Rpa10CA06, 86WRb02a) to $0.9804(\mathrm{R} 3 \mathrm{~B} 6,13 \mathrm{NSM} 03)($ mean $=0.9289)$ across subpopulations. Observed heterozygosity ranged from 0.5714 (Rpa10CA06, 21NCA02a) to 1.000 (numerous). MICRO-CHECKER suggested the potential excess of homozygotes due to null alleles at three loci (R3D3, Rpa10CA06, Rpa10CA07) in some subpopulations (seven of 72 tests), but significant departure from HWE in single locus exact tests in ARLEQUIN only supported three heterozygote-deficient subpopulations at a Bonferronicorrected nominal significance level of 0.05 (Table 3.2). In FSTAT, all except one (Rpa10CA06, 21NCA02j) single locus $F_{\mathrm{IS}}$-based exact test with Bonferroni correction were consistent with Hardy-Weinberg equilibrium expectations in the absence of inbreeding (Table 3.3). $F_{\text {IS }}$ values calculated over all loci were significantly different from Hardy-Weinberg expectations for $21^{\circ} \mathrm{N}$ EPR colonists and resident adults and for $9^{\circ} \mathrm{N}$ EPR resident adults ( $F_{\mathrm{IS}}=0.068,0.094$, and 0.040 , respectively). Resident adults at $13^{\circ} \mathrm{N}$ EPR and Garden of Eden GAR also could be suspected of inbreeding, at $P=$ 0.0069 .

All pairs of loci were found to be in genotypic equilibrium. 


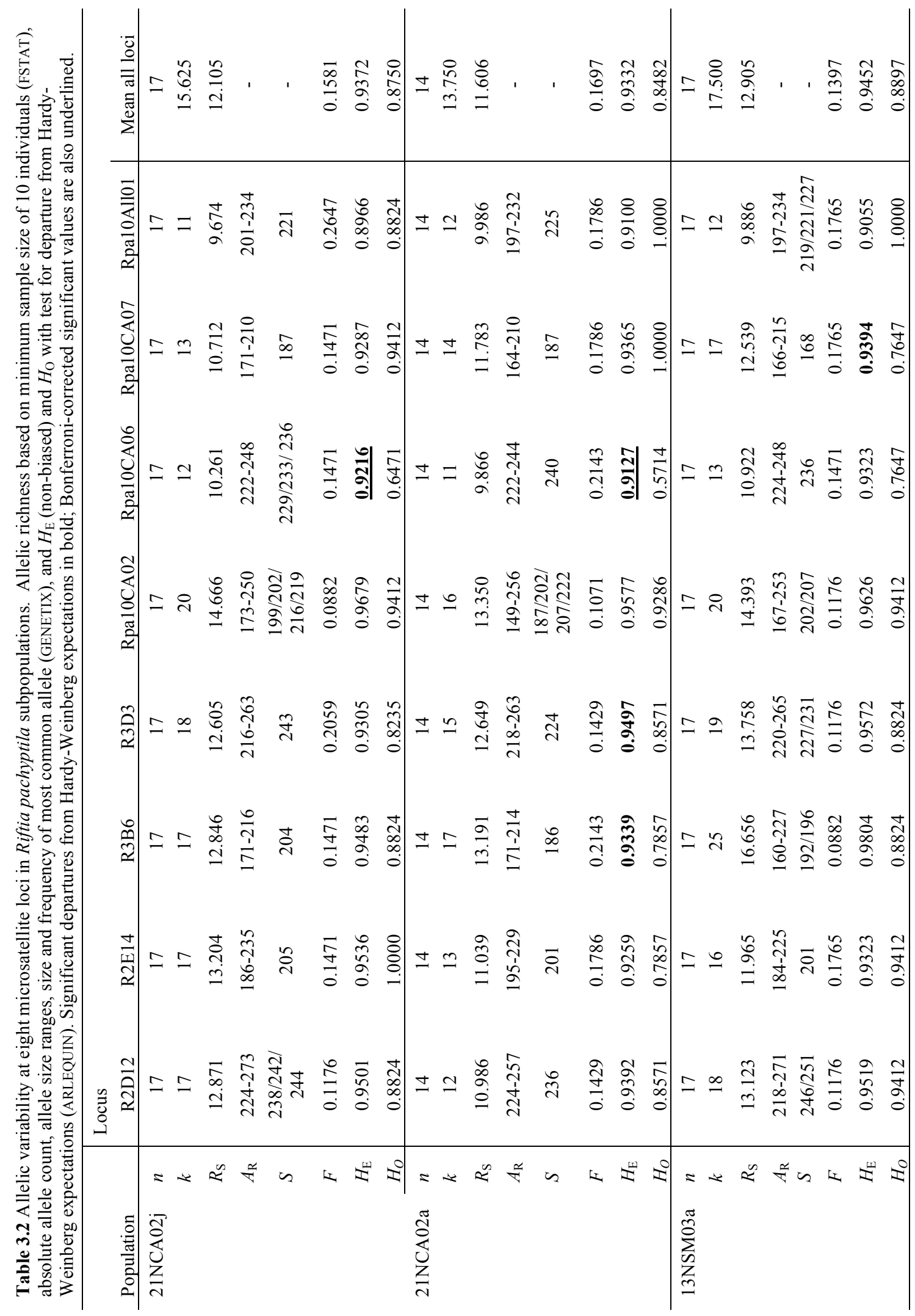




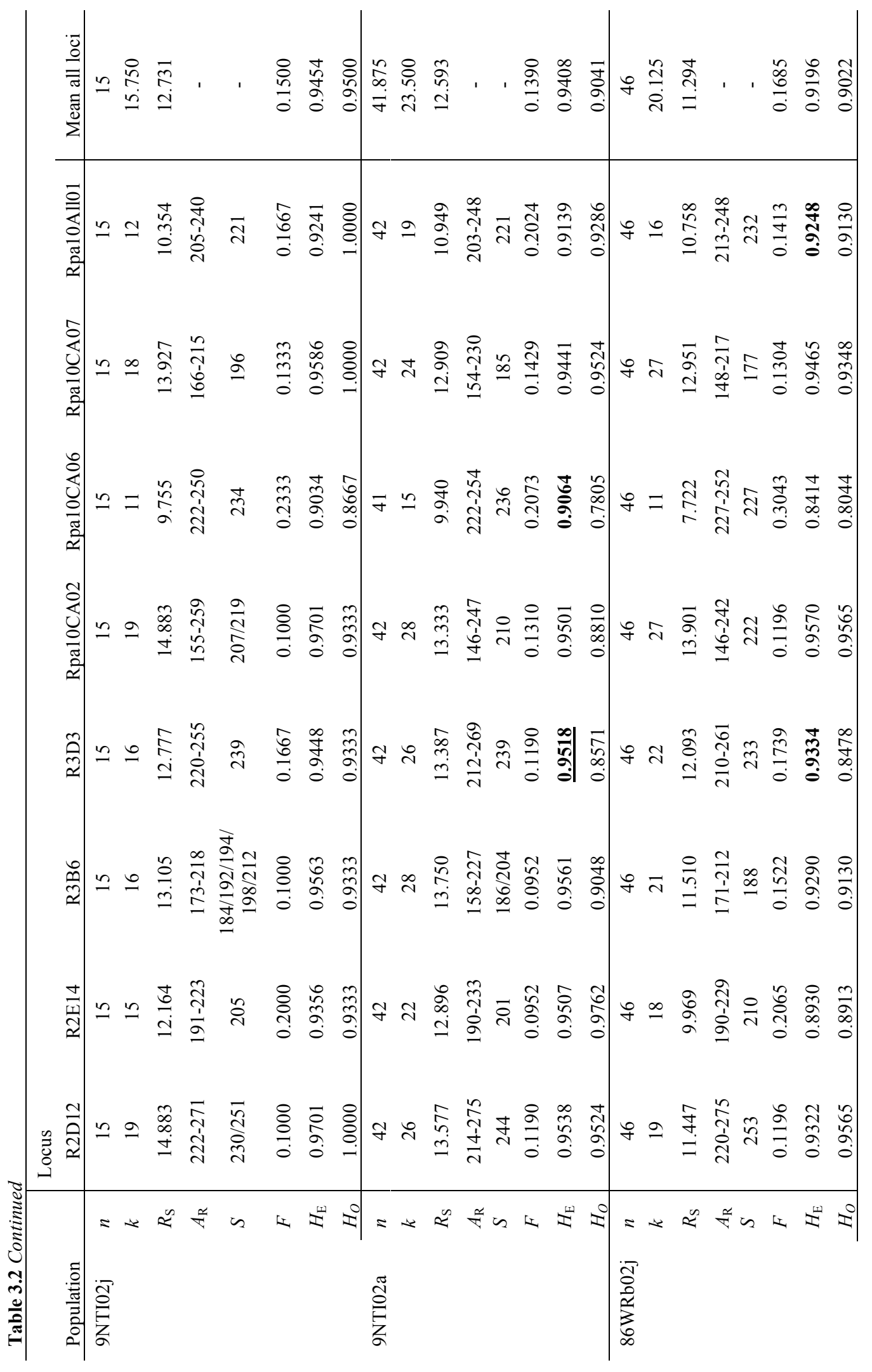




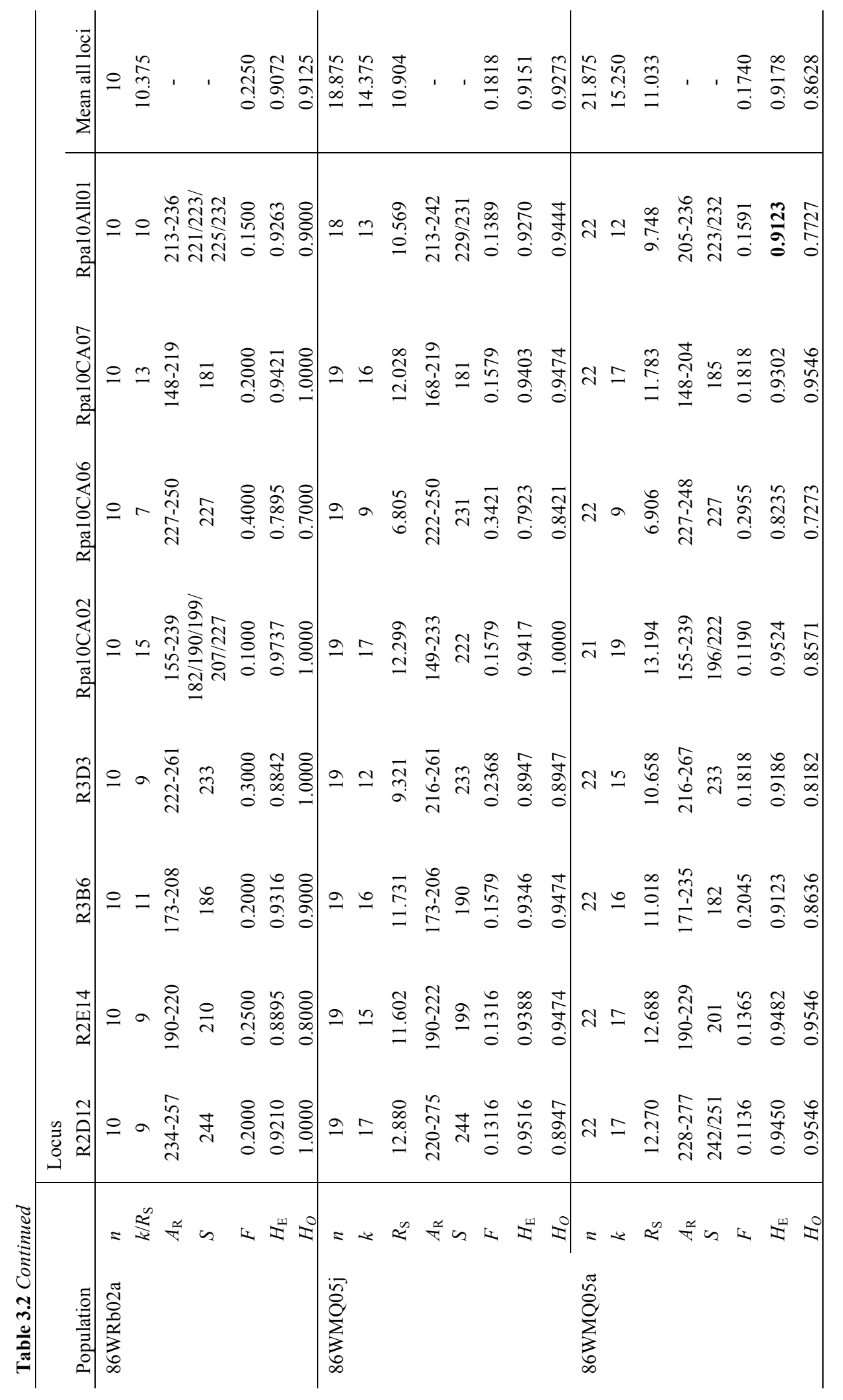




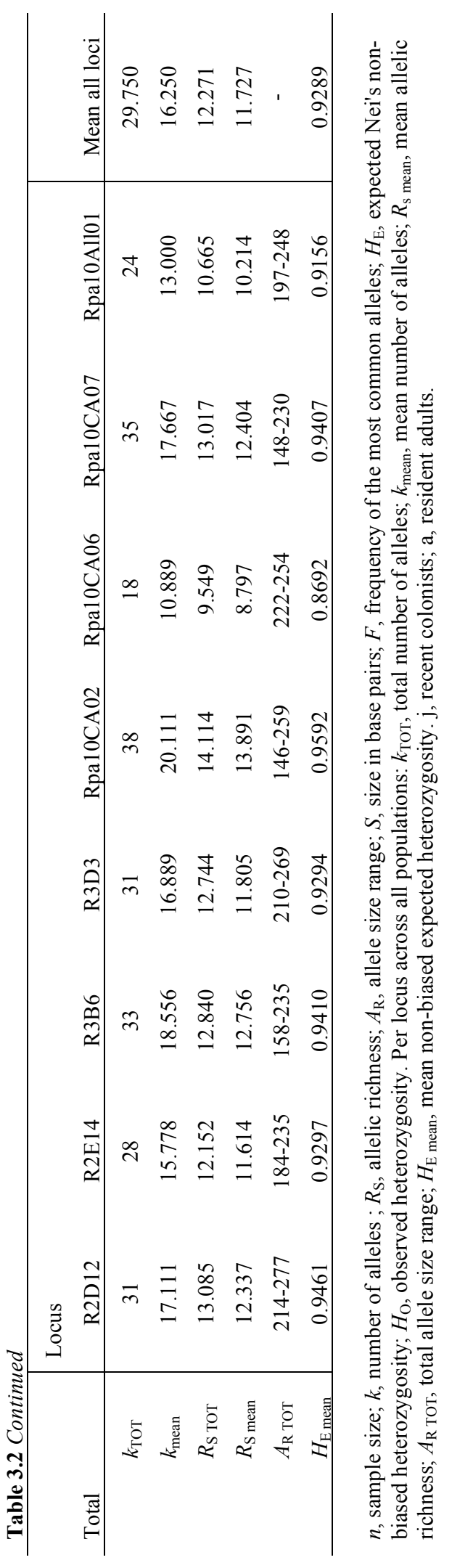


Table 3.3 $F_{\text {IS }}$ per locus and subpopulation (FSTAT). $P$ values in parentheses (1440 randomizations). Significant values are italicized and bolded values are significant with sequential Bonferroni-correction.

\begin{tabular}{|c|c|c|c|c|c|c|c|c|c|c|}
\hline \multicolumn{11}{|c|}{ Subpopulation } \\
\hline Locus & $21 \mathrm{~N} 02 \mathrm{j}$ & $21 \mathrm{~N} 02 \mathrm{a}$ & $13 \mathrm{~N} 03 \mathrm{a}$ & $9 \mathrm{~N} 02 \mathrm{j}$ & $9 \mathrm{~N} 02 \mathrm{a}$ & $86 \mathrm{~W} 02 \mathrm{j}$ & $86 \mathrm{~W} 02 \mathrm{a}$ & $86 \mathrm{~W} 05 \mathrm{j}$ & $86 \mathrm{~W} 05 \mathrm{a}$ & All \\
\hline \multirow[t]{2}{*}{ D12 } & 0.073 & 0.090 & 0.012 & -0.032 & 0.002 & -0.026 & -0.091 & 0.061 & -0.010 & 0.003 \\
\hline & $(0.2028)$ & $(0.2111)$ & $(0.5785)$ & $(1.0000)$ & $(0.5611)$ & $(0.8236)$ & $(1.0000)$ & $(0.2375)$ & $(0.7028)$ & \\
\hline \multirow[t]{2}{*}{ E14 } & -0.050 & 0.156 & -0.010 & 0.003 & -0.027 & 0.002 & 0.106 & -0.009 & -0.007 & 0.004 \\
\hline & (1.0000) & $(0.0764)$ & $(0.7083)$ & $(0.6472)$ & $(0.8729)$ & $(0.5813)$ & $(0.2951)$ & $(0.7201)$ & $(0.6722)$ & \\
\hline \multirow[t]{2}{*}{ R3B6 } & 0.072 & 0.164 & 0.103 & 0.025 & 0.054 & 0.017 & 0.036 & -0.014 & 0.055 & 0.050 \\
\hline & $(0.2090)$ & $(0.0424)$ & $(0.0361)$ & $(0.4896)$ & $(0.1083)$ & $(0.4118)$ & $(0.4938)$ & $(0.7396)$ & $(0.3021)$ & \\
\hline \multirow[t]{2}{*}{ R3D3 } & 0.118 & 0.101 & 0.080 & 0.013 & 0.101 & 0.093 & -0.139 & 0.000 & 0.112 & 0.073 \\
\hline & $(0.0958)$ & $(0.1514)$ & $(0.1618)$ & $(0.5813)$ & $(0.0090)$ & $(0.0250)$ & $(1.0000)$ & $(0.6306)$ & $(0.0819)$ & \\
\hline \multirow[t]{2}{*}{ CA02 } & 0.028 & 0.032 & 0.023 & 0.039 & 0.074 & 0.001 & -0.029 & -0.064 & 0.102 & 0.028 \\
\hline & $(0.4569)$ & $(0.4688)$ & $(0.5049)$ & $(0.3632)$ & $(0.0521)$ & $(0.6083)$ & $(1.0000)$ & $(1.0000)$ & $(0.0813)$ & \\
\hline \multirow[t]{2}{*}{ CA06 } & 0.304 & 0.383 & 0.184 & 0.042 & 0.140 & 0.044 & 0.119 & -0.065 & 0.119 & 0.127 \\
\hline & $(0.0007)$ & $(0.0014)$ & $(0.0299)$ & $(0.4521)$ & $(0.0132)$ & $(0.2799)$ & $(0.3500)$ & $(0.8188)$ & $(0.1694)$ & \\
\hline \multirow[t]{2}{*}{ CA07 } & -0.014 & -0.071 & 0.191 & -0.045 & -0.009 & 0.013 & -0.065 & -0.008 & -0.027 & 0.001 \\
\hline & $(0.7236)$ & $(1.0000)$ & $(0.0104)$ & (1.0000) & $(0.7069)$ & $(0.4528)$ & $(1.0000)$ & $(0.6958)$ & $(0.7993)$ & \\
\hline \multirow[t]{2}{*}{ All01 } & 0.016 & -0.103 & -0.108 & -0.085 & -0.016 & 0.013 & 0.030 & -0.019 & 0.156 & -0.005 \\
\hline & $(0.5528)$ & (1.0000) & $(1.0000)$ & $(1.0000)$ & $(0.7243)$ & $(0.4451)$ & $(0.5069)$ & $(0.7340)$ & $(0.0278)$ & \\
\hline \multirow[t]{2}{*}{ All loci } & $0.068^{*}$ & $0.094^{*}$ & 0.060 & -0.005 & 0.040 & 0.019 & -0.006 & -0.014 & 0.061 & 0.035 \\
\hline & $(0.0035)$ & $(0.0021)$ & $(0.0069)$ & $(0.6549)$ & $(0.0021)$ & $(0.1174)$ & $(0.6111)$ & $(0.7299)$ & $(0.0069)$ & \\
\hline
\end{tabular}

*These populations' over all loci $F_{\text {IS }}$ are significant in ARLEQUIN with 20022 permutations and Bonferroni correction 


\subsubsection{Allelic and genotypic variation}

Exact tests of genic and genotypic variation in pairwise population comparison (GENEPOP) detected limited genetic exchange between Galápagos Rift and East Pacific Rise subpopulations, with 16 of 36 tests of genic and genotypic differentiation significant, respectively (not shown). Loci R2D12, R2E14, R3D3, Rpa10CA06, and Rpa10CA07 contributed with Bonferroni-corrected significance to both types of differentiation over all subpopulations when colonists and residents were considered separately, while almost all loci contributed to differentiation when samples were pooled by location (Table 3.4a-b). The Rpa10CA06 locus was most likely to have null alleles in MICRO-CHECKER, was least variable and least heterozygous, had the strongest per locus $F_{\text {ST }}$ over all populations, and resulted in the highest $F_{\text {IS }}$ value. When this anomalous locus was excluded, pairwise comparisons with the $86^{\circ} \mathrm{W}$ GAR Rosebud recent colonist subpopulation emerged as having the greatest number of significant genic and genotypic differentiation tests. Overall allelic and genotypic tests of population differentiation were significant both with and without the Rpa10CA06 locus. Using all loci but with Rosebud colonist subpopulation excluded, the exact test for overall population differentiation was still significant at $P<0.001$, although Bonferroni-corrected significance at the 5\% nominal level across loci was lost for R2D12, R2E14, and Rpa10CA07. Among the pooled EPR populations alone (i.e. GAR Rosebud and Garden of Eden populations excluded), there is significant overall genic (but not genotypic) evidence of population differentiation; however, this stems primarily from the Rpa10CA07 locus and disappears when colonists and residents were considered separately. Galápagos subpopulations do not significantly differ from each other in genic and genotypic comparisons (despite locus-specific differentiation in six loci). 
Table 3.4 Differentiation over all populations (GENEPOP ON THE WEB: 5000 dememorization steps, 500 batches, 2000 iterations per batch). Bold $P$ values are significant with sequential Bonferroni correction for 8 tests at a level of $5 \%$.

a. Pooled populations

\begin{tabular}{lccccc}
\hline & \multicolumn{2}{c}{ Genic (allelic) } & & \multicolumn{2}{c}{ Genotypic } \\
\cline { 2 - 3 } \cline { 5 - 6 } Locus & $P$ value & S.E. & & $P$ value & S.E. \\
\hline R2D12 & $\mathbf{0 . 0 0 1 3 1}$ & 0.00045 & & $\mathbf{0 . 0 0 0 5}$ & 0.0003 \\
R2E14 & $<\mathbf{0 . 0 0 0 0 1}$ & 0.00000 & & $<\mathbf{0 . 0 0 0 1}$ & 0.0000 \\
R3B6 & $\mathbf{0 . 0 0 0 6 8}$ & 0.00027 & & 0.0127 & 0.0022 \\
R3D3 & $<\mathbf{0 . 0 0 0 0 1}$ & 0.00000 & & $\mathbf{0 . 0 0 0 1}$ & 0.0001 \\
CA02 & $\mathbf{0 . 0 0 1 3 2}$ & 0.00054 & & $\mathbf{0 . 0 0 4 7}$ & 0.0012 \\
CA06 & $<\mathbf{0 . 0 0 0 0 1}$ & 0.00000 & & $<\mathbf{0 . 0 0 0 1}$ & 0.0000 \\
CA07 & $\mathbf{0 . 0 0 0 0 1}$ & 0.00001 & & $<\mathbf{0 . 0 0 0 1}$ & 0.0000 \\
All01 & $\mathbf{0 . 0 0 4 7 1}$ & 0.00075 & & $\mathbf{0 . 0 0 1 9}$ & 0.0006 \\
\hline All loci & highly sig & & & $<\mathbf{0 . 0 0 0 0}$ \\
\hline
\end{tabular}

b. Separate colonists and residents cohorts

\begin{tabular}{lccccc}
\hline & \multicolumn{2}{c}{ Genic (allelic) } & & \multicolumn{2}{c}{ Genotypic } \\
\cline { 2 - 3 } \cline { 5 - 6 } Locus & $P$ value & S.E. & & $P$ value & S.E. \\
\hline R2D12 & $\mathbf{0 . 0 0 3 5 8}$ & 0.00084 & & $\mathbf{0 . 0 0 2 6}$ & 0.0016 \\
R2E14 & $\mathbf{0 . 0 0 0 5 9}$ & 0.00034 & & $\mathbf{0 . 0 0 0 9}$ & 0.0006 \\
R3B6 & 0.06931 & 0.00601 & & 0.2912 & 0.0147 \\
R3D3 & $\mathbf{0 . 0 0 0 4 2}$ & 0.00027 & & $\mathbf{0 . 0 0 2 0}$ & 0.0010 \\
CA02 & 0.02229 & 0.00284 & & 0.0481 & 0.0062 \\
CA06 & $<\mathbf{0 . 0 0 0 0 1}$ & 0.00000 & & $<\mathbf{0 . 0 0 0 1}$ & 0.0000 \\
CA07 & $\mathbf{0 . 0 0 1 6 3}$ & 0.00083 & & $\mathbf{0 . 0 0 2 2}$ & 0.0010 \\
All01 & 0.07436 & 0.00563 & & 0.0304 & 0.0052 \\
\hline All loci & highly sig & & & $<\mathbf{0 . 0 0 0 1}$ & \\
\hline
\end{tabular}




\subsubsection{Overall population structure}

PCA of pairwise $F_{\text {ST }}$ values was used to determine how colonist and resident subpopulations clustered with one another (Figure 3.2). The first two axes of the PCA explained $42 \%$ and $11 \%$ of the variation in $F_{\mathrm{ST}}$, respectively, differentiating the EPR subpopulations from the GAR subpopulations. Variation along the first axis of the PCA (PC1) was significant $(P=0.0001)$, but not along the remaining 7 axes $(P>0.05)$. Visually apparent were the close clustering of colonists with residents from the same sampling location (except at $21^{\circ} \mathrm{N} \mathrm{EPR}$ ), and the more distant arrangement of $13^{\circ} \mathrm{N}$ from $21^{\circ} \mathrm{N}$ EPR subpopulations.

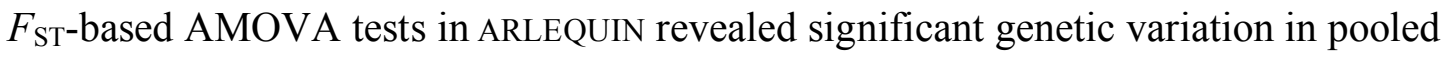
populations at the within populations and within individuals levels $\left(\Phi_{\mathrm{IS}}=3.2 \%, \Phi_{\mathrm{IT}}=\right.$ 5.0\%; Table 3.5). When colonists and residents were treated as separate cohorts, significant covariance components were detected from comparisons among subpopulations, within cohorts, and within individuals in the $F_{\mathrm{ST}}$-based tests $\left(\Phi_{\mathrm{CT}}=\right.$ $\left.1.4 \%, \Phi_{\mathrm{IS}}=3.2 \%, \Phi_{\mathrm{IT}}=4.3 \%\right) \cdot R_{\mathrm{ST}}$-based AMOVA tests also supported significant genetic structure at the among subpopulations level $\left(\Phi_{\mathrm{CT}}=2.7 \%\right)$. The majority of microsatellite allele frequency variation was found within populations or cohorts and within individuals $(>95 \%)$. 


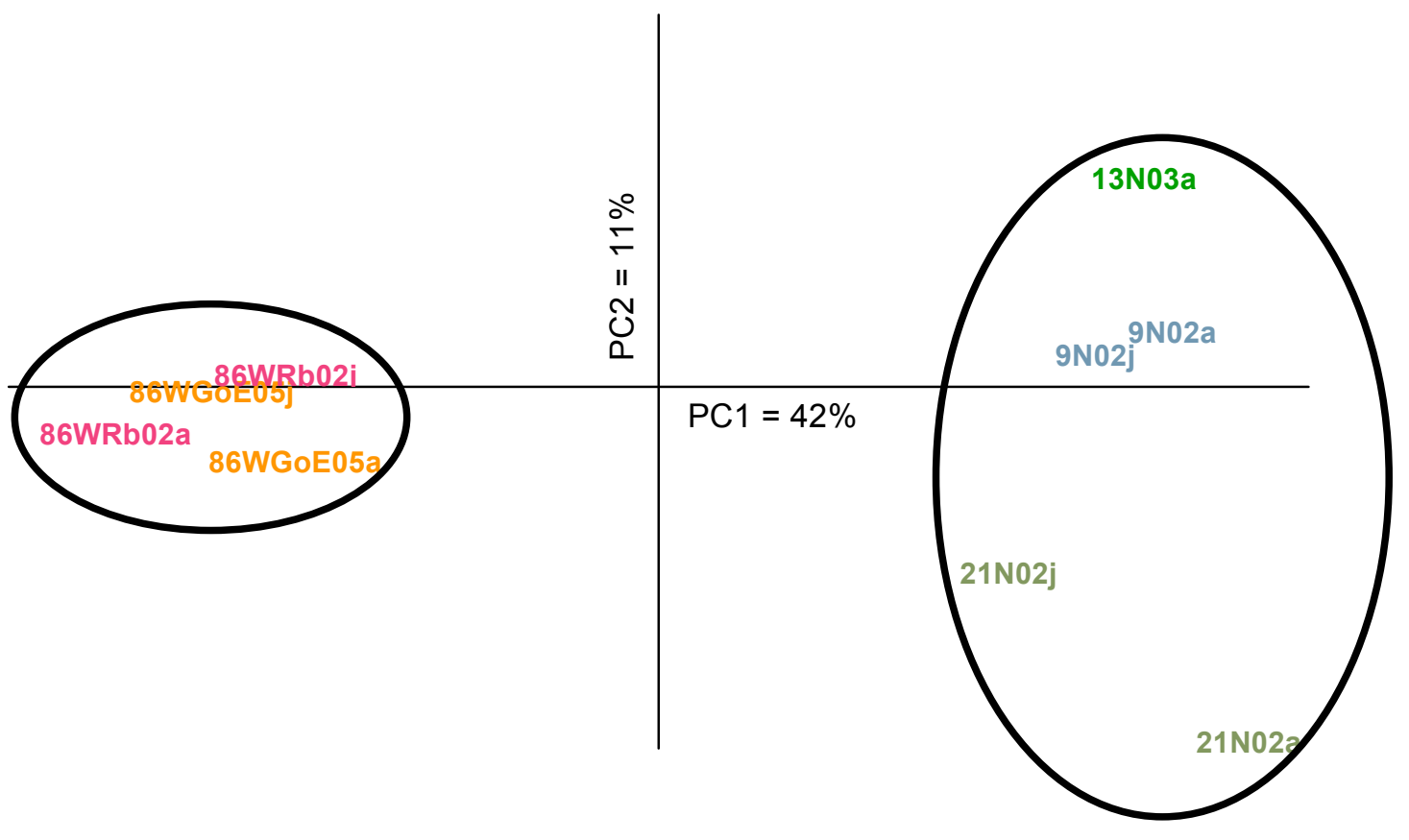

Figure 3.2 Principal components analysis of genetic differentiation among nine Riftia subpopulations, showing significant isolation between the Galápagos Rift and East Pacific Rise (encircled when $F_{\text {ST }}$ comparisons were not significantly different). PC1 and PC2 explain $42 \%$ and $11 \%$ of the genetic variation among samples, respectively. 
Table 3.5 Analysis of molecular variance testing groupings: EPR $\left(21^{\circ} \mathrm{N}\right.$, $\left.13^{\circ} \mathrm{N}, 9^{\circ} \mathrm{N}\right)$ and GAR $\left(86^{\circ} \mathrm{W}\right.$ Rosebud, Garden of Eden). Bold values are significant at 5\% nominal alpha level (ARLEQUIN: 20022 permutations)

\begin{tabular}{ccccc}
\hline Source of Variation & $d f$ & Variance & $\%$ & $F$ \\
\hline Among regions & 1 & 0.06901 & 1.83 & $F_{\mathrm{CT}}=0.01830$ \\
$\begin{array}{c}\text { Among populations } \\
\text { within regions }\end{array}$ & 3 & 0.00081 & 0.02 & $F_{\mathrm{SC}}=0.00022$ \\
Within populations & 197 & 0.11720 & 3.11 & $F_{\mathrm{IS}}=\mathbf{0 . 0 3 1 6 6}$ \\
Within individuals & 202 & 3.58416 & 95.04 & $F_{\mathrm{IT}}=\mathbf{0 . 0 4 9 5 9}$ \\
Total & 403 & 3.77117 & - & - \\
\hline
\end{tabular}


Figure 3.3 (opposing page) Results from STRUCTURE with $K=2$ populations $(20,000$ burnin, 20,000 MCMC reps, admixture model, correlated allele frequencies, no probability calculation for $\mathrm{K}$ ). Each individual, scored at 8 microsatellite loci, is represented by a vertical line broken into two segments representing the estimated proportion of the individual's genome originating from each inferred cluster. Two clusters were clearly evidenced among the East Pacific Rise and Galápagos pooled populations and resident cohorts, but not among the colonist cohorts. Top $=$ all individuals, middle $=$ residents only, bottom $=$ colonists only.

When treated as components of two groups, STRUCTURE showed that EPR and GAR individuals were well defined by ridge (Figure 3.3). However, STRUCTURE was unable to resolve samples into five distinct groups according to specific sampling locations $\left(21^{\circ} \mathrm{N}\right.$, $13^{\circ} \mathrm{N}, 9^{\circ} \mathrm{N}$ EPR; Rosebud, Garden of Eden $86^{\circ} \mathrm{W}$ GAR). Plotting the posterior probabilities of the data for $K=1$ through $K=5$ confirmed that the maximum $\ln (\mathrm{PPD})$ was reached when individuals were constrained to two populations. When colonists and residents were analyzed separately, the colonists displayed no genetic structure between ridges or among populations, while the residents were partitioned into two distinct groups as in the pooled population. A second optimum was occasionally found in this analysis, but the two-group optimum had a better (less negative) likelihood score. Removal of the Rpa10CA06 locus resulted in a similar pattern, though not as visually striking as with all eight loci. Analysis using one locus at a time revealed variation in only the Rpa10CA06 locus but no clear separation into two groups. 

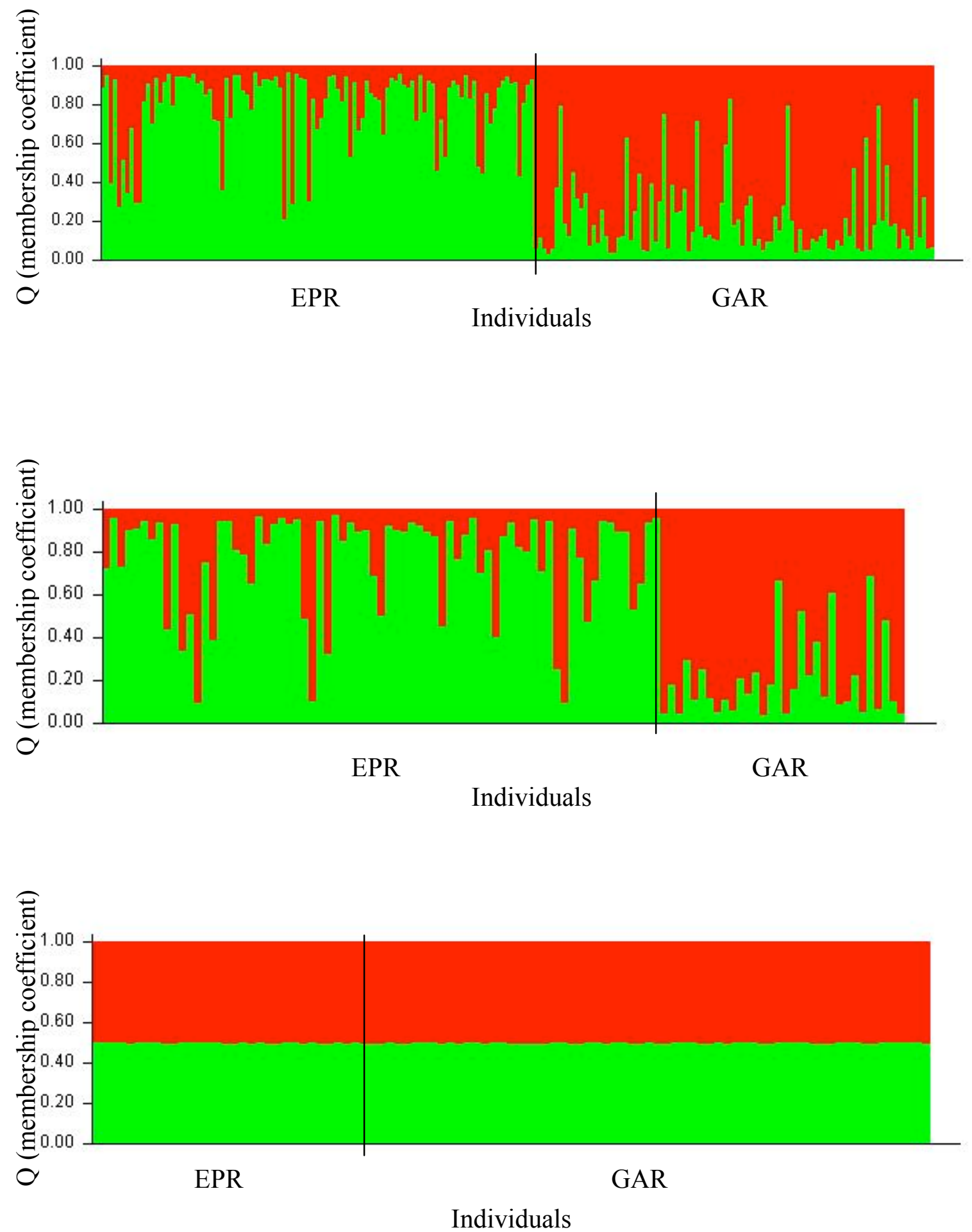


\subsubsection{Pairwise genetic differentiation}

Per locus $F_{\mathrm{ST}}$ values over all populations were greatest at the Rpa10CA06 locus (4\%), with an over all loci and all populations $F_{\mathrm{ST}}$ of $1 \%$ (no significance test available; Table 3.6). Pairwise $F_{\mathrm{ST}}$ and $R_{\mathrm{ST}}$ estimates in ARLEQUIN were as great as $3 \%$ and $8 \%$, respectively. Tests of multi-locus estimates of $F_{\mathrm{ST}}(\theta)$ found significant differences, with sequential Bonferroni correction, between the pooled Galápagos Rift and East Pacific Rise colonist and resident subpopulations (Table 3.7a). Multi-locus estimates of pairwise population $R_{\mathrm{ST}}\left(\rho^{\wedge}\right)$ trended in the same direction, with significant differences found between the GAR and EPR populations.

When recent colonists and resident adults at a given location were treated as separate cohorts, the basic pattern of small but significant genetic structure between the two ridge systems as measured by $F_{\mathrm{ST}}$ and $R_{\mathrm{ST}}$ is upheld without correction for multiple comparisons (Table 3.7b). When a sequential Bonferroni correction is applied to the nominal alpha value of 0.05 , the Rosebud GAR resident adult subpopulation differs significantly in $F_{\mathrm{ST}}$ from the $21^{\circ} \mathrm{N}$ and $9^{\circ} \mathrm{N}$ EPR resident adult subpopulations. In contrast, the Garden of Eden GAR resident and $21^{\circ} \mathrm{N}$ EPR colonist cohorts were not different when subpopulations were considered. Colonists did not differ from residents when comparisons were restricted to single locations and represented the smallest degree

of pairwise $F_{\mathrm{ST}}$ estimates (range $=-0.00727$ to 0.00134 , mean $=-0.00258$ ). Within a ridge system, colonists were more similar to one another (mean colonist $F_{\mathrm{ST}}=-0.00172$ ) than residents were to other residents (mean resident $\left.F_{\mathrm{ST}}=0.00104\right)$. Using a nonparametric van der Waerden (1956) test to compare mean colonist $F_{\mathrm{ST}}$ values with local (same location and next nearest, $F_{\mathrm{ST} \text { mean }}=0.00065$ ) versus more distant (three furthest, $F_{\mathrm{ST} \text { mean }}$ $=0.0129$ ) resident source populations, colonists were further evidenced to be most similar to nearby residents $(Z=3.2, \mathrm{df}=1, P=0.0013)$.

Removing the Rpa10CA06 locus from pairwise $F_{\mathrm{ST}}$ estimations had no effect on the significant pattern of population structure between the EPR and GAR pooled populations 
Table 3.6 $F_{\text {ST }}$ per locus over all 5 populations (FSTAT). Significant values are italicized with bolded values significant at sequential Bonferroni-correction.

\begin{tabular}{ccccccccc}
\hline R2D12 & R2E14 & R3B6 & R3D3 & CA02 & CA06 & CA07 & Al101 & All loci \\
\hline 0.003 & 0.008 & 0.004 & 0.010 & 0.002 & 0.035 & 0.009 & 0.005 & 0.009 \\
\hline
\end{tabular}

Table 3.7 Genetic differentiation between populations ( $F_{\mathrm{ST}}$, above diagonal) and respective $P$ values (below diagonal). Sequential Bonferroni corrected significant values are bolded (ARLEQUIN, 20022 permutations)

a. Pooled populations

\begin{tabular}{r|ccccc}
\hline & $21 \mathrm{~N} 02$ & $13 \mathrm{~N} 03$ & $9 \mathrm{~N} 02$ & $86 \mathrm{~W} 02$ & $86 \mathrm{~W} 05$ \\
\hline 21N02 & - & 0.00476 & 0.00105 & $\mathbf{0 . 0 1 9 0 7}$ & $\mathbf{0 . 0 1 8 3 2}$ \\
13N03 & 0.15108 & - & 0.00009 & $\mathbf{0 . 0 1 9 9 1}$ & $\mathbf{0 . 0 2 0 4 7}$ \\
9N02 & 0.36218 & 0.57868 & - & $\mathbf{0 . 0 1 8 5 7}$ & $\mathbf{0 . 0 1 8 9 0}$ \\
86W02 & $<0.00001$ & $<0.00001$ & $<0.00001$ & - & -0.00044 \\
86W05 & $<0.00001$ & $<0.00001$ & $<0.00001$ & 0.62513 & - \\
\hline
\end{tabular}

b. Colonist and resident subpopulations separated

\begin{tabular}{r|ccccccccc}
\hline & $21 \mathrm{~N} 02 \mathrm{j}$ & $21 \mathrm{~N} 02 \mathrm{a}$ & $13 \mathrm{~N} 03 \mathrm{a}$ & $9 \mathrm{~N} 02 \mathrm{j}$ & $9 \mathrm{~N} 02 \mathrm{a}$ & $86 \mathrm{~W} 02 \mathrm{j}$ & $86 \mathrm{~W} 02 \mathrm{a}$ & $86 \mathrm{~W} 05 \mathrm{j}$ & $86 \mathrm{~W} 05 \mathrm{a}$ \\
\hline 21N02j & - & 0.00134 & 0.00389 & -0.00310 & -0.00098 & $\mathbf{0 . 0 1 3 4 7}$ & 0.01012 & $\mathbf{0 . 0 1 5 4 5}$ & 0.00722 \\
$21 \mathrm{~N} 02 \mathrm{a}$ & 0.59487 & - & 0.00636 & 0.00171 & 0.00440 & $\mathbf{0 . 0 2 4 9 1}$ & $\mathbf{0 . 0 2 5 8 3}$ & $\mathbf{0 . 0 2 9 2 6}$ & $\mathbf{0 . 0 2 5 0 9}$ \\
$13 \mathrm{~N} 03 \mathrm{a}$ & 0.30820 & 0.17780 & - & -0.00268 & 0.00028 & $\mathbf{0 . 0 1 8 9 7}$ & 0.01712 & $\mathbf{0 . 0 2 1 8 2}$ & $\mathbf{0 . 0 1 7 8 1}$ \\
9N02j & 0.84513 & 0.46696 & 0.83074 & - & -0.00277 & $\mathbf{0 . 0 1 4 3 4}$ & 0.01394 & $\mathbf{0 . 0 1 6 0 6}$ & $\mathbf{0 . 0 1 3 9 6}$ \\
9N02a & 0.75119 & 0.15892 & 0.57764 & 0.88808 & - & $\mathbf{0 . 0 1 7 2 7}$ & $\mathbf{0 . 0 2 1 1 8}$ & $\mathbf{0 . 0 2 1 0 4}$ & $\mathbf{0 . 0 1 7 1 4}$ \\
$86 \mathrm{~W} 02 \mathrm{j}$ & 0.00005 & $<0.00001$ & $<0.00001$ & 0.00015 & $<0.00001$ & - & -0.00727 & -0.00034 & -0.00075 \\
$86 \mathrm{~W} 02 \mathrm{a}$ & 0.08990 & 0.00025 & 0.00654 & 0.01044 & 0.00005 & 0.97228 & - & -0.01031 & -0.00686 \\
86W05j & 0.00055 & $<0.00001$ & $<0.00001$ & 0.00010 & $<0.00001$ & 0.55192 & 0.96544 & - & -0.00163 \\
$86 \mathrm{~W} 05 \mathrm{a}$ & 0.08480 & $<0.00001$ & 0.00010 & 0.00190 & $<0.00001$ & 0.67857 & 0.93492 & 0.70314 & - \\
\hline
\end{tabular}


(not shown). However, exclusion of this locus resulted in the loss of significant population differentiation between the $21^{\circ} \mathrm{N}$ EPR resident cohort and both GAR resident cohorts, between the $21^{\circ} \mathrm{N}$ EPR and Garden of Eden GAR colonist cohorts, between the $9^{\circ} \mathrm{N}$ EPR colonist cohort and all GAR cohorts, and between the $9^{\circ} \mathrm{N}$ EPR and Rosebud GAR resident cohorts.

\subsubsection{Isolation, migration, and population bottlenecks}

The resident subpopulations exhibited weak isolation-by-distance in $F_{\mathrm{ST}}$ data as shown in the plotted trendline (Figure 3.4), but this trend was not apparent among the pooled populations or the colonist subpopulations. Isolation by distance eroded when the Galápagos populations were excluded (not shown). When the Rpa10CA06 locus was excluded, however, the observed pattern of IBD among residents was upheld.

Estimation of the number of migrants per generation $(\mathrm{Nm})$ using the private allele method implemented by GENEPOP ON THE WEB and corrected for sample size suggested moderate gene flow of approximately 11 migrants per generation when populations consisted of individuals pooled by location. The estimated number of colonist migrants per generation was lower $(\sim 6)$ than that of the resident adults $(\sim 9)$; greater estimated migration in the adult subpopulation is consistent with what would be expected from combining the ecological history of multiple generations and colonizing cohorts.

BOTTLENECK analyses revealed heterozygosity excess across all subpopulations except $21^{\circ} \mathrm{N}$ EPR colonists, suggesting recent demographic bottlenecks. These excesses were limited to 5 loci (R2D12, R2E14, Rpa10CA02, Rpa10CA06, Rpa10A1101).

\subsubsection{Colonist assignment to resident populations}

To explore the possible assignment of colonists to resident adult populations 78 colonists from $21^{\circ} \mathrm{N}$ EPR $(n=17), 9^{\circ} \mathrm{N}$ EPR $(n=15)$, and $86^{\circ} \mathrm{W}$ GAR $(\mathrm{n}=46)$ were used. Two 


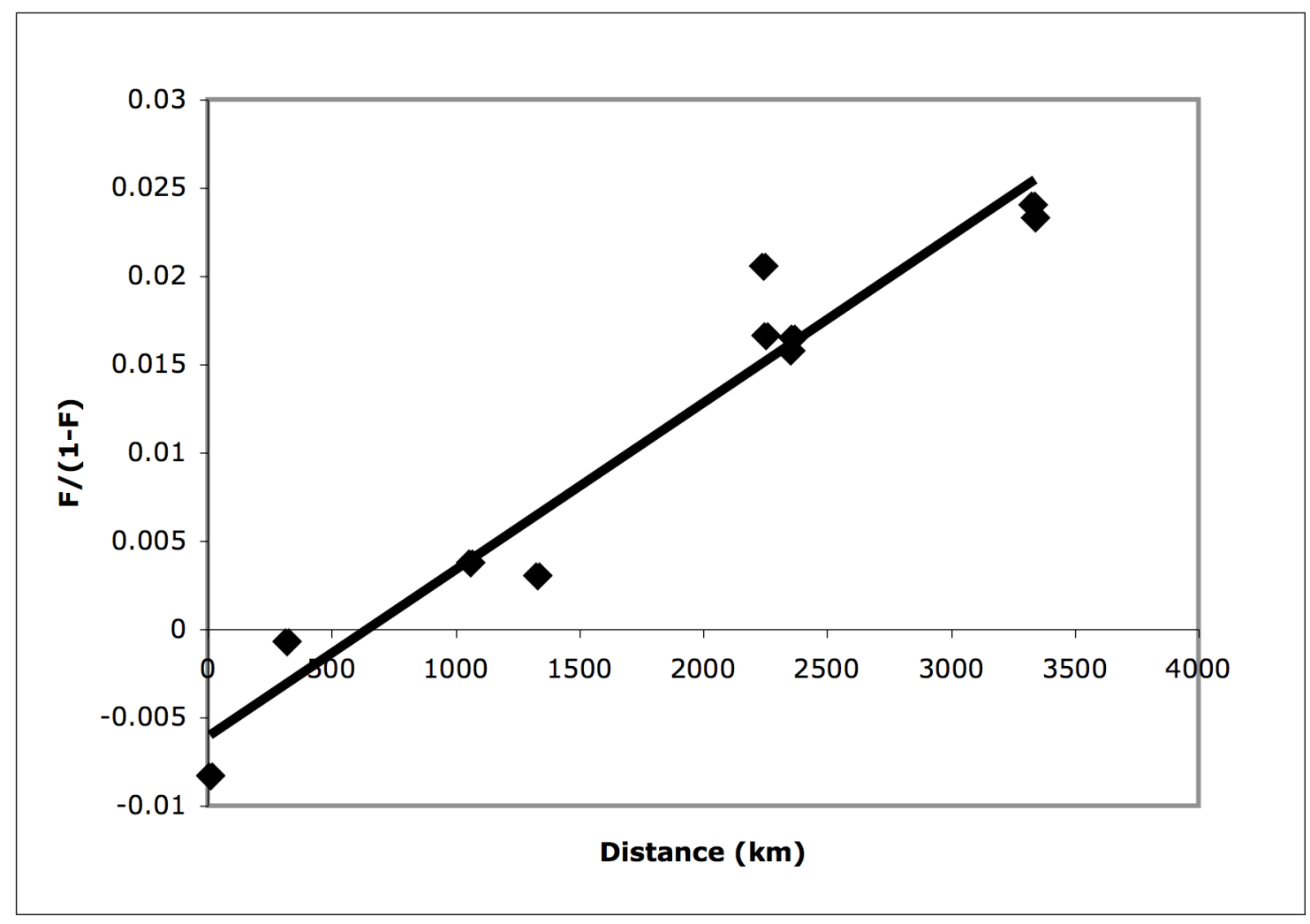

Figure 3.4 Genetic distance of residents $\left(F_{\mathrm{ST}} / 1-F_{\mathrm{ST}}\right)$ plotted against geographic distance $(\mathrm{km})($ GENEPOP ON THE WEB: 500000 permutations; $y$-intercept $=-0.0060993$, slope $=$ $0.00000946, P=0.03294)$

colonists from $21^{\circ} \mathrm{N}, 0$ from $9^{\circ} \mathrm{N}$ but 40 from $86^{\circ} \mathrm{W}$ were correctly assigned with a probability threshold of $1 \%$ (i.e, an LOD score $\geq 2$ ) to their resident adult population; therefore, despite low genetic differences among locations, $53.8 \%$ of colonists could rightly be assigned to the resident population at the same location. Individuals with an LOD score of less than two were considered "unassigned."

\subsubsection{Summary of results}

In summary, using highly variable loci, I found high heterozygosity within and among Riftia populations on the East Pacific Rise and Galápagos Rift. There were more alleles represented on the EPR than on the GAR. Few locus-specific homozygous excesses were 
detected for any subpopulation, but over all loci, inbreeding could be suspected in several resident populations. No locus or subpopulation controlled the marked population differentiation observed between the EPR and GAR. Allelic distribution is similar among GAR populations but not among pooled EPR populations.

When considering all subpopulations included in this study, the EPR and GAR fall as two entities, with the signal differentiating the two groups stemming from resident genetic structure. There may be stepping stone dispersal further creating weak isolation by distance, but the observed trend was not conclusive. Migration is moderate and sufficient for gene flow to counter genetic drift at local populations. Recent bottlenecks were detected in all but the $21^{\circ} \mathrm{N}$ EPR colonist cohort.

Colonists were most similar to residents sampled at the same and next proximate location. Within a ridge system, colonists were also more similar to other colonists than residents were to other residents. Furthermore, colonists were correctly assigned to their co-sampled resident population on the GAR but not at $9^{\circ} \mathrm{N}$ EPR.

\subsection{Discussion}

\subsubsection{High levels of genetic variation}

The level genetic variation observed within and among populations was greater in these microsatellite data than previously reported for Riftia (Bucklin 1988, Black et al. 1994, Hurtado et al. 2004, Shank \& Halanych 2007). Three plausible explanations for this genetic diversity can be proposed. First, high genetic variability has been attributed to increased fitness for invasive marine species in spatially and temporally heterogeneous habitats (e.g., Holland 2001). The same advantage could be conferred upon Riftia's gregarious settlement and overgrowth of other hydrothermal vent species soon after new habitat becomes available. Second, while many species experiencing frequent bottlenecks exhibit few rare alleles (discussed in Spencer et al. 2000), successful metapopulation 
properties (recolonization after extinction and habitat creation) have been suggested to influence the retention of genetic diversity more than extensive migration (Vrijenhoek et al. 1998, Born et al. 2008). In that context, Riftia's ability to rapidly establish itself as an early colonizer and continue to persist at new vents may maintain high genetic diversity. Lastly, species occurring at a large percentage of sampled sites, as is Riftia, are also predicted to have higher levels of genetic diversity than more rare species (Vrijenhoek 1997). Although it is not possible to discriminate between them, the genetic diversity found in this study is consistent with conditions predicted by all three of these hypotheses.

\subsubsection{Excess homozygosity in relation to null alleles and Hardy- Weinberg equilibrium}

It is unlikely that null alleles were present in this data set. Of all the individuals analyzed, only three locus-specific genotypes were missing, most likely due to errors in electrophoresis. If null alleles were present, one would expect to have a substantial proportion of null homozygotes (in the form of unamplified products) at a given locus. This not being the case, the potential for population admixture (Wahlund effect) can be considered. If deviations from HWE were the result of population substructure or inbreeding, heterozygote deficits should be present across all or most loci. However, heterozygote deficiency is limited to two of the eight loci considered herein and spread between three subpopulations. Elevated $F_{\text {IS }}$ values were unlikely the result of initial Wahlund effects that may be created by rapid colonization from several divergent source populations, as those effects would be eliminated at individual loci after one generation of random mating (Vrijenhoek 1997). It is possible that differential selection for homozygotes in resident or colonist cohorts could be the cause of heterozygote deficiencies (Zouros \& Foltz 1984, Raymond et al. 1997). Though not all elevated $F_{\text {IS }}$ values were statistically significant, four of the five subpopulations with heterozygote deficiencies were resident cohorts, potentially suggesting that homozygous residents confer elevated fitness over more heterozygous colonists. As neither null alleles nor 
Wahlund effects alone explain these departures from HWE, it is possible that a combination of effects and perhaps selection or nonrandom mating may be the cause (Dupont et al. 2007).

\subsubsection{Regional population structure}

Multi-locus estimates of $F_{\mathrm{ST}}$ and $R_{\mathrm{ST}}$ for population and cohort pairs were small but displayed significant structure over broad spatial scales. Low pairwise estimates of population differentiation are typical of highly polymorphic markers applied to questions of genetic structure in many large marine populations. In fact, estimates of $F_{\mathrm{ST}}$ in most marine invertebrates and fishes fall well below the theoretical maximum of 1 for completely genetically isolated populations, owing more to microsatellite allele homoplasy than to the level of locus polymorphism (O'Reilly et al. 2004). High rates of extinction and colonization at vents have also been predicted to reduce pairwise levels of $F_{\text {ST }}$ by shrinking the overall effective population size (Vrijenhoek 1997). Moreover, if the number of Riftia's reproductively successful individuals was limited, the absolute magnitude of genetic differentiation may be low among and between populations as observed. Therefore, though maximum differention between populations was on the order of a few percent, this could still indicate significant ecological isolation.

The present study provides the first evidence for a dispersal barrier between the EPR and GAR Riftia populations. However, the level of individual resolution to distinct EPR subpopulations found when Shank \& Halanych (2007) employed AFLP fingerprinting was not observed. Using multilocus microsatellite markers, gene flow instead appeared to be extensive within a ridge system, with non-significant but roughly $1 \%$ genetic differentiation (patchiness) between $21^{\circ} \mathrm{N}$ EPR and more southern EPR populations. Gene flow between ridges was less pronounced, with significant differentiation between the majority of established resident subpopulations on the East Pacific Rise and Galápagos Rift. While the $13^{\circ} \mathrm{N}$ EPR and Rosebud GAR residents were not significantly different at the nominal level adjusted for multiple comparisons, allele frequencies in 
these populations indicated some level of differentiation. Vents at $13^{\circ} \mathrm{N}$ experienced instabilities in fluid flux between 1982 and 1990 (Fustec et al. 1987, Desbruyères 1998) and a resurgence of hydrothermal activity in the 1990s (Voight et al. 2004), but it is hypothesized that two centuries ago the $13^{\circ} \mathrm{N}$ segment was relatively stable. Less punctuated disturbance could have prevented the settlement of early colonists like Riftia, thus precluding significant gene flow from other areas. The remaining signal may be weak because of more recent black smoker turnover less than every 5 or 10 years (Desbruyères 1998).

Colonist cohorts were also distinct between ridge systems, as were EPR residents from GAR colonists. However, EPR colonists were less distinct from GAR residents (with the exception of $9^{\circ} \mathrm{N}$ EPR colonists and Garden of Eden GAR residents), potentially suggesting unidirectional gene flow in establishing historical populations. The lack of significance in some of these tests may be due to loss of power to discriminate among small sample sizes (e.g., Rosebud residents) as in O'Reilly et al. (2004; see also Ruzzante 1998). All the same, small sample sizes and large numbers of alleles do not reduce the $F_{\text {ST }}$ estimates themselves (Ruzzante 1998). Moreover, low $F_{\text {ST }}$ values do not necessarily imply high gene flow, as they may be characteristic of loci with high allele counts or of recently founded populations (Ruzzante et al. 2001).

Considering processes in the geological past, the EPR became geographically isolated from the Juan de Fuca Ridge (once the mid-Tertiary Pacific-Farallon Ridge) about 35 Mya, while the GAR began spreading about 20-25 Mya (Hey 1977, Tunnicliffe 1988). Greater allelic richness in the EPR populations than in GAR populations coupled with significant differentiation between these two regions suggests that there may be relict geological isolation between these ridges. Recently, it has been proposed that the NEPR is the center of historical vent dispersal (Bachraty et al. 2008). Bachraty and colleagues (2008) suggest that species on the fast-spreading EPR in the oldest extant ocean benefit from increased dispersal capabilities and higher diversity. 
However, contemporary population demographics and gene flow may be more relevant. Broad spatial homogeneity and significant differentiation at only on the largest geographic scale has also been found in surf clams (Cassista \& Hart 2007). In that case, however, the level of migration between populations needed to homogenize allele frequencies between them is much lower than that needed to replenish exploited populations by dispersal. Likewise, Riftia populations that experience contraction or local extinction may be able to be recolonized by small larval input. Historical population expansion can also mask low levels of migration and give an upward bias to gene flow estimates. Thus, a lack of regional population genetic differentiation does not necessarily mean that the number of migrants is high.

Galápagos Rift hydrothermal vent sites may occasionally be colonized by long-distance larvae originating from the East Pacific Rise, but these populations are primarily selfseeding. The Rosebud GAR site was first observed as a nascent Riftia population in 2002, when the nearby Rose Garden site could not be located; it is presumed that the 2000 eruptive event that created Rosebud also wiped out the older Rose Garden community (Shank et al. 2003). A young population such as Rosebud may be founded by a stochastic dispersal event from an EPR-like population - and perhaps one that was not sampled or was otherwise undetected-leaving that signal in the original residents; recent colonists will more likely arrive from nearby GAR populations, with a genetic signal distinct from the EPR. Vents on these two ridge systems provide a similar chemical milieu, though focused black smoker flow is not present in the $86^{\circ} \mathrm{W}$ GAR region. As such, the cue for larval settlement may be weaker and more localized at the GAR than at the EPR, favoring recruits from nearby (undetected) vents.

Meanwhile, the Garden of Eden population has had time to assemble itself and differentiate from the EPR. In 2005, extensive Riftia assemblages at Garden of Eden contained the largest recorded tubeworms ( $>2 \mathrm{~m}$, pers. obs. T. Shank), suggesting they 
might be part of a long-lived, robust population, first observed at this site in 1977 (Corliss et al. 1979). Garden of Eden's similarity to $21^{\circ} \mathrm{N}$ EPR colonists may be the residual effect from a subset of individuals of similar origin or suggest back-seeding from the GAR to the EPR. Vents at $21^{\circ} \mathrm{N}$ EPR have also supported growing Riftia populations dating back to Clam Acres' discovery in 1979, including recovery from over-sampling in 1982 (Spiess et al. 1980, Hessler et al. 1985, Desbruyères 1998). This ridge segment has been active for at least 300 years with a spreading rate of $60 \mathrm{~mm} / \mathrm{yr}$, but a short shift in activity likely occurred over the past century, followed by several decades of continuous flow (Desbruyères 1998). As such, there has been time to receive limited input from distant vent populations to the south, though genetic similarity to other populations on the EPR could also be a relict of historic dispersal processes predating the Rivera Fracture Zone.

Stepping-stone dispersal has often been invoked for hydrothermal vent species (Black et al. 1994, Jollivet et al. 1995, Matabos et al. 2008). In Riftia, I found that the pattern of genetic isolation by geographical distance hinges upon inclusion of the distant Galápagos populations. It is expected that some IBD to be retained on the EPR if distance was a dominant factor in population structure, especially if larvae tend to recruit to their natal population, but it is also important to note that less than half of Riftia's known range has been considered. Stepping-stone dispersal does not seem to be the mechanism for maintaining genetic cohesiveness across northern EPR and GAR Riftia populations over evolutionary time but may be responsible for biologically important genetic differences with ecological significance (as in Purcell et al. 2006). The absence of significant IBD could also be attributed to bottleneck/non-equilibrium dynamics or insignificant statistical power with too few populations and loci (Jehle et al. 2005). Future studies should consider the complete range of Riftia from $27^{\circ} \mathrm{N}$ to $32^{\circ} \mathrm{S}$ EPR in order to test the remaining proposed genetic barriers, namely the equatorial region, $17-23^{\circ} \mathrm{S} E P R$, and the Easter Microplate. 


\subsubsection{Colonist assignment}

Assignment tests for the source populations of individuals were performed despite low population differentiation ( $\sim 2 \%)$, where assignment may not be appropriate (pers. comm. G. Gerlach). Assignment tests revealed that about $54 \%$ of colonists could be assigned to the resident adults from the same location where the colonists were sampled. This suggests that the majority of colonist cohorts originated from the same populations where they settled and is of the same magnitude as predicted in other marine habitats (Cowen et al. 2006, Becker et al. 2007). The majority of self-assigned colonists were found in the GAR population, suggesting particular fidelity at the Rosebud site. The $21^{\circ} \mathrm{N}$ and $9^{\circ} \mathrm{N}$ EPR assignments were less dramatic, perhaps owing to mesoscale eddy mixing, but suggest that some recruits are nevertheless retained. All the same, colonists at each location were found to be most similar to the closest sampled resident populations, further supporting the case for local larval retention (Gilg et al. 2007). If this moderate level of self-recruitment is observed in multiple samples over time, it could lead to stable genetic patchiness among populations (Wood \& Gardner 2007).

Had this study found evidence for significantly divergent adult and juvenile cohorts (e.g., Hedgecock et al. 2007), such differences would have been consistent with "sweepstakes" reproductive success, whereby successful colonists originate from only a few adults despite large reproductive output. While this mechanism is consonant with the observed excess heterozygosity, neither reduced allelic diversity among colonists as compared to residents nor gametic phase disequilibrium was found. Therefore, the possibility of reproductive sweepstakes cannot entirely be discounted, though it is remarkable that genetic diversity remains high within populations given local retention.

The low genetic differentiation observed within ridge systems, with significant isolation between ridges, is consistent with the predominance of local retention and periodic among "island" migration (Rivera et al. 2004). In fact, most recent evidence for selfrecruitment comes from island populations (Johnson \& Black 2006), and the vent 
environment appears to provide another example. These results demonstrated that realized larval dispersal cannot necessarily be inferred from life history characteristics, as is often proposed (Kinlan \& Gaines 2003, Grantham et al. 2003, P. Krug 2008 OSM). Currents and environmental discontinuities ultimately have more of a structuring effect on regional lineages (Teske et al. 2007). Larval behavior may also promote retention within an oceanographic regime (North et al. 2008). It will be important to determine whether colonist input is similar over a period of multiple years in order to evaluate the retention hypothesis with more certainty.

\subsubsection{General population structuring mechanisms}

Understanding the processes behind population maintenance and new habitat colonization has proven to be one of the most challenging aspects of vent biology (Tyler \& Young 2003). Several mechanisms may be implicated in the observed between-ridge Riftia population structure. These factors include metapopulation dynamics, large-scale oceanographic currents, along-axis flow reversals, periodic mesoscale eddy passage, buoyant plume entrainment, and larval behavior, and are discussed below.

Due to a slower tectonic plate spreading rate, eruptions are expected to be less frequent on the Galápagos Rift than on the East Pacific Rise, perhaps facilitating longer-lived and more stable populations (Fouquet 1997). Stochastic events (e.g., eruptions, rearrangement of subsurface plumbing, clogging of conduits, instability of hydrothermal convection), especially at $13^{\circ} \mathrm{N}$ and $9^{\circ} \mathrm{N}$ EPR, constrain the temporal evolution of these vent communities and favor fast-growing species like Riftia (Desbruyères 1998). Higher spreading rates have also been implicated in accelerated loss of genetic diversity in other vent populations (Young et al. 2008), though that is not seen here. Support for recent population bottlenecks across all Riftia populations in the present study may result from recent foundation of populations, but immigration could confound this interpretation (Cornuet \& Luikart 1996). Because many hydrothermal vent sites are influenced by local 
extinctions and recolonizations, it is likely that Riftia populations are not at migrationdrift equilibrium (Jollivet et al. 1999).

Hydrographic regimes may be a main isolating force between present day East Pacific Rise and Galálpagos Rift populations. In general, flow is anticyclonic crossing the EPR around $11-13^{\circ} \mathrm{N}$ and vertically rather uniform with depth (Fujio \& Imasato 1991). While the trade winds cause currents to flow westward at about $20^{\circ} \mathrm{N}$ on the eastern side of the Pacific, imbedded in between are the equatorial counter currents (ECC) flowing eastward (Sverdrup 1941, 1947). The countercurrent is located north of the equator and further to the north in the summer than in the winter. It should be sufficient to act as a barrier between the ridge systems, but it will be important to include populations from the southern EPR to discriminate between a current- or ridge-created (e.g., Hess Deep) discontinuity.

Deep current models on the East Pacific Rise have predicted that along-ridge flow reversals likely retain most larvae within tens of kilometers of their source population, while larvae that remain longer in the water column have a greater likelihood of being swept off-axis and lost to the ridge system (Marsh et al. 2001, Thiébaut et al. 2002, Mullineaux et al. 2002). Larvae that remain near the EPR's ridge axis may be dispersed by tidal reversals on the order of $100 \mathrm{~km}$ (SSE, half as much to NNW) along axis, except for at $13^{\circ} \mathrm{N}$, where sustained SSE flows and a longer larval lifespan could extend Riftia's potential dispersal up to $245 \mathrm{~km}$ (Marsh et al. 2001, Mullineaux et al. 2002). Outside the axial rift valley, larvae are likely transported away from their natal vents by tidal currents, in which mixing could homogenize larval abundance on scale of 100s m (Mullineaux et al. 2005). However, recent tracer experiments have followed plume advection $80 \mathrm{~km}$ offaxis and subsequently returned to the ridge crest (Jackson et al. in prep).

Correlations of strong along-axis flow with daily larval supply support the prediction of primary larval supply from local sources (1-2 km) in other hydrothermal vent taxa, while 
entrainment by mesoscale eddies (apparently generated along distant storm tracks; Palacios \& Bograd 2005) may facilitate transport between vents hundreds of kilometers apart two to three times a year (Adams 2007, Adams \& Mullineaux 2008). At vents in the northeast Pacific (on the Juan de Fuca, Explorer, and Gorda ridges), strong flow enables larger population sizes, greater genetic diversity, and greater immigration into downstream populations (Young et al. 2008). Mesoscale eddies have also been predicted to be important to stochastic dispersal in other marine systems (Siegel et al. 2008). For instance, Halanych et al. (OSM 2008) attribute some Antarctic invertebrates' lack of range limits across major circumpolar currents to entrainment and transport in mesoscale eddies. Therefore, the combined factors of along-axis flow with periodic reversal and stochastic eddy passage could primarily retain larvae at a local scale while preserving high genetic heterozygosity in the eastern equatorial Pacific, as evidenced by the present Riftia microsatellite results.

Observed and modeled current entrainment have been coupled with biological samples in the field in order to test these predictions. Using larval collection observations and plume model data, Kim et al. (1994) estimated mean vertical flux at EPR black smokers to be 100-1000 vent larvae/hour, translating into an expected mean abundance of 2 to 10 vent larvae $/ 1000 \mathrm{~m}^{3}$ in the neutrally buoyant plume. This could also provide a mechanism for vertical transport and long-range horizontal advection, as vent larvae have been reported within and outside of buoyant hydrothermal plumes (Mullineaux et al. 1995). Plumelevel dispersal of vent larvae could be important for initial colonization and the maintenance of species between distant vent habitats, while local recruitment from nearby populations may be more important to the growth of new populations and the maintenance of those already in existence (Kim \& Mullineaux 1998, Mullineaux et al. 2005). As the populations included in the present study were established years before the time of sampling, it is unlikely that larval inputs stemming exclusively from plumes were sampled. 
Lastly, species-specific processes - such as discontinuous spawning, differential survival, aggregative behavior, or interrupted dispersal - may drive variation and heterogeneity in larval supply, such that non-uniform delivery of colonists may represent only a subset of regional genetic diversity (Mullineaux et al. 2005). Settlement events at vents may be frequent, but larval supply in Riftia has been demonstrated to vary spatially (Thiébaut et al. 2002). The present genetic results are consistent with the hypothesis of local colonist retention dominating settlement within a site, but it is apparent that some genetic exchange occurs along the ridge system. In the case of large effective populations in which even a large number of migrants is proportionately small, local dynamics are likely to be independent and favor self-seeding within most populations (Purcell et al. 2006).

\subsubsection{Larval availability}

Vents are irregularly spaced along the mid-ocean ridge axis, differ in fluid chemistries that may provide weak or strong settlement cues, and produce larval outputs relative to local population size. These characteristics may explain why the flux of larvae to specific sites varies with respect to input from proximate source vents (Adams 2007, Adams \& Mullineaux 2008). Colonization studies have previously attributed differences in vestimentiferan composition at a vent to changes in the regional larval pool or sitespecific temporal colonization patterns (Hunt et al. 2004 but not Mullineaux 2000). Given that larval supply is not uniform, it was expected that colonist cohorts would differ among distant sites and from their co-sampled resident populations. However, the smallest degree of genetic differentiation $\left(F_{\mathrm{ST}} \sim 0\right)$ was found between colonists and residents collected at the same site, and colonists within a ridge were very similar to one another as compared to residents to other residents. The similarity of populations on the northern EPR is especially surprising.

An alternative explanation to local larval retention could be that post-settlement selection is acting on colonists so that they most represent the genetic composition of their resident population of collection. Differential mortality of settlers can select against immigrants 
from outside populations, as evidenced in high self-recruitment of estuarine fish (Bradbury et al. 2008). In contrast, an overall high level of genetic diversity in Riftia might be linked to selection for living in a heterogeneous environment (Vrijenhoek 1997). Previous authors (Thiébaut et al. 2002) have suggested that there may be high post-settlement mortality (e.g., predation or competition, physical instabilities of environment/low individual survivorship) in Riftia that could also explain the subsequent genetic differentiation observed among adult populations.

There is little evidence for selection at the loci considered in this study, even though this process is unlikely to reduce diversity at all loci (Hedgecock et al. 2007). The results presented here are unlike those of Planes and Lenfant (2002), who found significant divergence of cohorts of young individuals due to random larval genetic drift and initial family structure, and homogeneity among older developmental stages resulting from random adult movement. Instead, the consistency of Riftia's allelic distribution with localized genetic heterogeneity might reflect different rates of population turnover and

degrees of patchiness, with genetically homogeneous cohorts and recruits encompassing less variation than adults among sites (Watts et al. 1990). These processes could support the case for local retention presented earlier, in that larvae tend to settle at their natal population but occasionally travel longer distances, as observed in the heterogeneity of adult cohorts.

\subsubsection{Consistency with previous vent population genetic patterns}

This study had the capacity for comparison with two previously proposed larval barriers: 1) Rivera Fracture Zone, and 2) the Galápagos Rift Triple Junction. My findings were consistent with the structure associated with these features, specifically among populations of polychaetes and bivalves across the RFZ (Hurtado et al. 2004) and other vestimentiferans and a common vent endemic amphipod (France et al. 1992) across the Galápagos Triple Junction. Additional Riftia samples will be needed from the southern 
EPR in order to consider the remaining three potential genetic barriers using microsatellite loci.

Grassle (1985) presented the only other known vent genetic study in the Eastern Pacific to consider different size classes separately. In contrast to Riftia colonists, she found that small mussels on GAR exhibited significant heterozygote deficiencies (Grassle 1985). Rose Garden and Mussel Bed mussels within a given size class were highly similar, but different cohorts collected within a single vent site had low genetic similarity; large mussels between the GAR and $13^{\circ} \mathrm{N}$ EPR were even less similar. Grassle (1985) concluded that small RG and MB mussels likely came from multiple distinct source populations, providing consistent genetic diversity to the vents over time, but the contribution of recruits from most populations are infrequent or low. In the case of Riftia, the evidence presented above suggests that cohorts are well mixed within a ridge system and constant through time. This remains to be explicitly tested with multiple years of colonists collected at single site.

\subsection{Conclusions}

In summary, using highly variable loci and multi-cohort sampling, genetic differentiation was observed between Riftia populations on the East Pacific Rise and Galápagos Rift. Stepping stone dispersal may create weak isolation by distance, but the observed trend was not conclusive. Migration is likely moderate and sufficient for gene flow to counter genetic drift at local populations. Recent bottlenecks were detected in most subpopulations as is consistent with their ephemeral environment.

Colonist subpopulations were most similar to local and neighboring residents, suggesting that although limited gene flow exists on longer timescales between ridge systems in the eastern Pacific, local larval retention plays a key role in establishing and maintaining Riftia populations. The importance of considering cohorts in population genetic studies becomes apparent, as this signal of retention would not have been detected if samples had 
been pooled irrespective of size or if only large individuals had been considered. If local selection instead of retention were to create the observed patterns, the adult genetic baseline might have been able to be simulated (e.g., via a mixture analysis); this method is suitable for populations of low divergence (I. Bradbury, OSM 2008).

This study has demonstrated that future studies of population genetics at hydrothermal vents will have to consider both juvenile and adult cohorts in order to understand dispersal and local processes more completely. For instance, census estimates would provide insights into Riftia's population density and mean dispersal distances (O. Puebla, OSM 2008). Models of dispersal in all marine habitats should integrate larval retention by local currents as well as occasional long-distance transport. A simulation of larval dispersal coupled with circulation would be useful to further infer the number of migrants and number of genetic groups from these and future data (e.g., GENELAND, J. Watson, OSM 2008). To further test temporal stability of larval supply in the presence of metapopulation dynamics (Jollivet et al. 1999), colonists collected at multiple years at a given site will need to be considered. In light of the high probability for local retention in Riftia, especially on the GAR, this process should be examined in other vent species and types of mid-ocean ridges by including rigorous adult and juvenile sampling. 


\subsection{References}

Adams DK (2007) Influence of hydrodynamics on the larval supply to hydrothermal vents on the east Pacific Rise. PhD Thesis, MIT/WHOI Joint Program, Massachusetts Institute of Technology/Woods Hole Oceanographic Institution, MA.

Adams DK, Mullineaux LS (2008) Supply of gastropod larvae to hydrothermal vents reflects transport from local larval sources. Limnology and Oceanography, in press.

Amos W, Hoffman JI, Frodsham A et al. (2007) Automated binning of microsatellite alleles: problems and solutions. Molecular Ecology Notes, 7, 10-14.

Annis ER (2005) Temperature effects on the vertical distribution of lobster postlarvae (Homarus americanus). Limnology and Oceanography, 50, 1972-1982.

Bachraty C, Legendre P, Desbruyères (2008) Biogeographic relationships among deepsea hydrothermal vent faunas at global scale. Available from Nature Proceedings http://hdl.handle.net/10101/npre.2008.1823.1 .

Banks MA, Eichert W (2000) whichrun (version 3.2): a computer program for population assignment of individuals based on multilocus genotype data. Heredity, 91, 87-89.

Barton NH, Slatkin M (1986) A quasi-equilibrium theory of the distribution of rare alleles in a subdivided population. Heredity, 56, 409-416.

Becker BJ, Levin LA, Fodrie FJ, McMillan AP (2007) Complex larval connectivity patterns among marine invertebrate populations. Proceedings of the National Academy of Sciences of the United States of America, 104, 3267-3272.

Belkhir K, Borsa P, Goudet J, Chikhi L, Bonhomme F (2004) GENETIX 4.05, logiciel sous Windows TM pour la génétique des populations. Laboratoire Génome et Populations, CNRS UPR 5000, Université Montpellier II, Montpellier.

Black MB, Lutz RA, Vrijenhoek RC (1994) Gene flow among vestimentiferan tube worm (Riftia pachyptila) populations from hydrothermal vents of the Eastern Pacific. Marine Biology, 120, 33-39.

Black MB, Trivedi A, Maas PAY, Lutz RA, Vrijenhoek RC (1998) Population genetics and biogeography of vestimentiferan tube worms. Deep Sea Research II, 45, 365382.

Born C, Kjellberg F, Chevallier M-H, et al. (2008) Colonization processes and the maintenance of genetic diversity: insights from a pioneer rainforest tree. Proceedings of the Royal Society B, FirstCite doi:10.1098/rspb.2008.0446.

Bradbury IR, Campana SE, Bentzen P (2008) Estimating contemporary early life-history dispersal in an estuarine fish: integrating molecular and otolith elemental approaches Molecular Ecology 17, 6, 1438-1450. 
Bradbury IR (2008) Estimating contemporary larval dispersal and connectivity in an estuaring fish: integrating molecular and otilith elemental approaches. Ocean Science Meeting, Orlando, Florida.

Bucklin A (1988) Allozyme variability of Riftia pachyptila populations from the Galapagos Rift and $21^{\circ} \mathrm{N}$ hydrothermal vents. Deep-Sea Research Part A, 35, 17591768.

Byers JM, Pringle JM (2006) Going against the flow: retention, range limits and invasions in advective environments. Marine Ecology Progress Series, 313, 27-41.

Caley MJ, Carr MH, Hixon MA, Hughes TP, Jones GP, Menge BA (1996) Recruitment and the local dynamics of open marine populations. Annual Review of Ecology and Systematics, 27, 477-500.

Cary, S. C., H. Felbeck, et al. (1989). Observations on the reproductive biology of the hydrothermal vent tube worm Riftia pachyptila. Marine Ecology Progress Series, 52, 89-94.

Cassista MC, Hart MW (2007) Spatial and temporal genetic heterogeneity in the Arctic surfclam (Mactromeris polynyma). Marine Biology, 152, 569-579.

Cockerham CC, Weir BS (1979) Estimation of linkage disequilibrium in randomly mating populations. Heredity, 42, 105-111.

Conroy-Dalton S, Huys R (1999) A new genus of Aegisthidae (Copepoda, Harpacticoida) from hydrothermal vents on the Galapagos Rift. Journal of Crustacean Biology, 19, 408-431.

Corliss JB, Dymond J, Gordon LI, et al. (1979) Submarine thermal springs on the Galápagos Rift. Science, 203, 1073-1083.

Cornuet JM, Luikart G (1996) Description and power analysis of two tests for detecting recent population bottienecks from allele frequency data. Genetics, 144, 2001-2014.

Cowen RK, Paris CB, Srinivasan A (2006) Scaling of connectivity in marine populations. Science, 311, 522-527.

Craddock C, Hoeh WR, Lutz RA, Vrijenhoek RC (1995) Extensive gene flow among mytilid (Bathymodiolus thermophilus) populations from hydrothermal vents of the Eastern Pacific. Marine Biology, 124, 137-146.

Craddock C, Lutz RA, Vrijenhoek RC (1997) Patterns of dispersal and larval development of archaeogastropod limpets at hydrothermal vents in the eastern Pacific. Journal of Experimental Marine Biology and Evolution, 210, 37-51.

Desbruyères D (1998) Temporal variations in the vent communities on the East Pacific Rise and Galápagos Spreading Centre: a review of present knowledge. Cahiers de Biologie Marine, 39, 241-244.

Desbruyèyes D, Segonzac M, Bright M (2006) Handbook of Deep-Sea Hydrothermal Vent Fauna. Second completely revised edition. In: Denisia, 544 pp. 
Di Rienzo A, Peterson AC, Garza JC, Valdes AM, Slatkin M, Freimer NB (1994) Mutational processes of simple-sequence repeat loci in human populations Proceedings of the National Academy of Sciences, 91, 3166-3170.

Dupont L, Ellien C, Viard F (2007) Limits to gene flow in the slipper limpet Crepidula fornicata as revealed by microsatellite data and a larval dispersal model. Marine Ecology Progress Series 349, 125-138.

El Mousadik A, Petit RJ (1996) High level of genetic differentiation for allelic richness among populations of the argan tree [Argania spinosa (L.) Skeels] endemic to Morocco. Theoretical and Applied Genetics, 92, 832-839.

Excoffier L, Laval G, Schneider S (2005) Arlequin (version 3.0): an integrated software package for population genetic analysis. Evolutionary Bioinformatics Online, 1, 4750.

Falush D, Stephens M, Pritchard JK (2003) Inference of population structure using multilocus genotype data: linked loci and correlated allele frequencies. Genetics, 164, 1567-1587.

Falush D, Stephens M, Pritchard JK (2007) Inference of population structure using multilocus genotype data: dominant markers and null alleles. Molecular Ecology Notes, 7, 574-578.

Fouquet Y (1997) Where are the large hydrothermal sulphide deposits in the oceans? Philosophical Transactions of the Royal Society of London A, 355, 427-441.

France SC, Hessler RR, Vrijenhoek RC (1992) Genetic differentiation between spatiallydisjunct populations of the deep-sea, hydrothermal vent-endemic amphipod Ventiella sulfuris. Marine Biology, 114, 551-559.

Fujio S, Imasato N (1991) Diagnostic calculation for circulation and water mass movement in the deep Pacific. Journal of Geophysical Research, 96, 759-774.

Fusaro AJ, Baco AR, Gerlach G, Shank TM (2008) Development and characterization of 12 microsatellite markers from the deep-sea hydrothermal vent siboglinid Riftia pachyptila Molecular Ecology Resources, 8, 132-134.

Fustec A, Desbruyères D, Juniper SK (1987) Deep-sea hydrothermal vent communities at $13^{\circ} \mathrm{N}$ on the East Pacific Rise: microdistribution and temporal variations. Biological Oceanography, 4, 121-161.

Garnier S, Alibert P, Audiot P, Prieur B, Rasplus J-Y (2004) Isolation by distance and sharp discontinuities in gene frequencies: implications for the phylogeography of an alpine insect species, Carabus solieri. Molecular Ecology, 13, 1883-1897.

Gilg MR, Kirby SE, Sullivan R, Knapp LW, Hilbish TJ (2007) Dispersal vs. retention: correspondence of species-specific reproductive cycles and settlement periods in a blue mussel hybrid zone. Marine Ecology Progress Series, 351, 151-161. 
Gilg MR, Hilbish TJ (2003) Spatio-temporal patterns in the genetic structure of recently settled blue mussels (Mytilus spp.) across a hybrid zone. Marine Biology, 143, 679690.

Goudet J (1999) PCA-GEN for Windows, V. 1.2. Distributed by the author, Institute of Ecology, Univ. of Lausanne.

Goudet J (2001) FSTAT, a program to estimate and test gene diversities and fixation indices (version 2.9.3). Available from

http://www2.unil.ch/popgen/softwares/fstat.htm. Updated from Goudet J (1995). FSTAT (Version 1.2): a computer program to calculate F-statistics. The Journal of Heredity, 86, 485-486.

Govenar B, Freeman M, Bergquist DC, Johnson GA, Fisher CR (2004) Composition of a one-year-old Riftia pachyptila community following a clearance experiment: insight to succession patterns at deep-sea hydrothermal vents. Biological Bulletin, 207, 177182.

Grantham BA, Eckert GL, Shanks AL (2003) Dispersal potential of marine invertebrates in diverse habitats. Ecological Applications, 13, S108-S116.

Grassle JP (1985) Genetic differentiation in populations of hydrothermal vent mussels (Bathymodiolus thermophilus) from the Galapagos Rift and $13^{\circ} \mathrm{N}$ on the East Pacific Rise. Bulletin of the Biological Society of Washington, 6, 429-442.

Guinot D, Hurtado LA (2003) Two new species of hydrothermal vent crabs of the genus Bythograea from the southern East Pacific Rise and from the Galapagos Rift (Crustacea Decapoda Brachyura Bythograeidae) Comptes Rendus Biologies, 326, 423-439.

Halanych KM (2008) Phylogeography and larval connectivity of Antarctic shelf fauna. Ocean Sciences Meeting, Orlando, Florida.

Haymon RM, Fornari DJ, Damm KLV, et al. (1993) Volcanic eruption of the mid-ocean ridge along the East Pacific Rise crest at $9^{\circ} 45-52^{\prime} \mathrm{N}$ : Direct submersible observations of seafloor phenomena associated with an eruption event in April, 1991. Earth and Planetary Science Letters, 119, 85-101.

Hedgecock D, Launey S, Pudovkin AI, Naciri Y, Lapègue S, Bonhomme F (2007) Small effective number of parents $(\mathrm{Nb})$ inferred for a naturally spawned cohort of juvenile European flat oysters Ostrea edulis. Marine Biology, 150, 1173-1182.

Hessler RR, Smithey WM, Jr., Keller CH (1985) Spatial and temporal variation of giant clams, tube worms and mussels at deep-sea hydrothermal vents. Bulletin of the Biological Society of Washington, 6, 411-428.

Hey R (1977) Tectonic evolution of the Cocos-Nazca spreading center. Geological Society of America Bulletin, 88, 1404-1420.

Hickman CS (1984) A new archaeogastropod (Rhipidoglossa, Trochacea) from hydrothermal vents on the East Pacific Rise. Zoologica Scripta, 13, 19-25. 
Hilário A, Young CM, Tyler PA (2005) Sperm storage, internal fertilization, and embryonic dispersal in vent and seep tubeworms (Polychaeta: Siboglinidae: Vestimentifera). Biological Bulletin, 208, 20-28.

Holland BS (2001) Invasion without a bottleneck: microsatellite variation in natural and invasive populations of the brown mussel Perna perna (L). Marine Biotechnology, 3, 407-415.

Hunt HL, Metaxas A, Jennings RM, Halanych KM, Mullineaux LS (2004) Testing biological control of colonization by vestimentiferan tubeworms at deep-sea hydrothermal vents (East Pacific Rise, 9 50'N). Deep-Sea Research I, 51, 225-234.

Hurtado LA, Mateos M, Lutz RA, Vrijenhoek RC (2003) Coupling of bacterial endosymbiont and host mitochondrial genomes in the hydrothermal vent clam Calyptogena magnifica. Applied and Environmental Microbiology, 69, 2058-2064.

Hurtado LA, Lutz RA, Vrijenhoek RC (2004) Distinct patterns of genetic differentiation among annelids of eastern Pacific hydrothermal vents. Molecular Ecology, 13, 26032615.

Huys R, Conroy-Dalton S (1997) Discovery of hydrothermal vent Tantulocarida on a new genus of Argestidae (Copepoda: Harpacticoida). Cahiers de Biologie Marine, 38, 235-249.

Ivanenko VN, Ferrari FD (2003) A new genus andspecies of the family Dirivultidae (Copepoda, Siphonostomatoida) from a deep-sea hydrothermal vent at the Juan de Fuca Ridge (Pacific Ocean) and comments of dirivultid distribution. Arthropoda Selecta, 11, 177-185.

Jackson PR, Ledwell JR, Thurnherr AM (in prep) Dispersion of a tracer on the East Pacific Rise $\left(9^{\circ} \mathrm{N}\right.$ to $\left.10^{\circ} \mathrm{N}\right)$, including the influence of hydrothermal plumes.

Jehle R, Wilson GA, Arntzen JW, Burke T (2005) Contemporary gene flow and the spatio-temporal genetic structure of subdivided newt populations (Triturus cristatus, T. marmoratus). Journal of Evolutionary Biology, 18, 619-628.

Johnson MS, Black R (2006) Islands increase genetic subdivision and disrupt patterns of connectivity of intertidal snails in a complex archipelago. Evolution, 60, 2498-2506.

Jollivet D, Debruyéres D, Bonhomme F, Moraga D (1995) Genetic differentiation of deep-sea hydrothermal vent alvinellid populations (Annelida: Polychaeta) along the East Pacific Rise. Heredity, 74, 376-391.

Jollivet D, Chavaldonné P, Planque B (1999) Hydrothemal-vent alvinellid polychaete dispersal in the eastern Pacific. 2. A metapopulation model based on habitat shifts. Evolution, 53, 1128-1142.

Jones ML (1980) Riftia pachyptila, new genus, new species, the vestimentiferan worm from the Galápagos Rift geothermal vents (Pogonophora). Proceedings of the Biological Society of Washington, 93, 1295-1313. 
Jones M, Gardiner SL (1989) On the early development of the vestimentiferan tube worm Ridgeia sp. and observations on the nervous system and trophosome of Ridgeia sp. and Riftia pachyptila. Biological Bulletin, 177, 254-276.

Kim S, Mullineaux LS (1998) Distribution and near-bottom transport of larvae and other plankton at hydrothermal vents. Deep-Sea Research, 45, 423-440.

Kim SL, Mullineaux LS, Helfrich KR (1994) Larval dispersal via entrainment into hydrothermal vent plumes. Journal of Geophysical Research, 99, 12655-12665.

Kimura M, Weiss GH (1964) The steppig stone model of population structure and the decrease of genetic correlation with distance. Genetics, 49, 561-576.

Kinlan BP, Gaines SD (2003) Propagule dispersal in marine and terrestrial environments: a community perspective. Ecology, 84, 2007-2020.

Krug PJ (2008) Do biophysical coupling models predict Caribbean population connectivity? A test with six gastropod specis that vary in dispersal potential. Ocean Sciences Meeting, Orlando, Florida.

Levin LA (2006) Recent progress in understanding larval dispersal: new directions and digressions. Integrative and Comparative Biology, 46, 282-297.

Lonsdale P (1988) Structural pattern of the Galapagos microplate and evolution of the Galapagos triple junctions. Journal of Geophysical Research, 93, 13551-13574.

Lutz RA, Bouchet P, Jablonski D, Turner RD, Warén A (1986) Larval ecology of mollusks at deep-sea hydrothermal vents. American Malacological Bulletin, 4, 4954 .

Lutz RA, Shank TM, Fornari DJ, et al. (1994) Rapid growth at deep-sea vents. Nature, 371, 663-664.

Marsh AG, Mullineaux LM, Young CM, Manahan DT (2001) Larval dispersal potential of the tubeworm Riftia pachyptila at deep-sea hydrothermal vents. Nature, 411, 7780.

Matabos M, Thiébaut E, Le Guen D, et al. (2008) Geographic clines and stepping-stone patterns detected along the East Pacific Rise in the vestigastropod Lepetodrilus elevatus reflects species crypticism. Marine Biology, 153, 545-563.

McLean JH (1988) New archaeogastropod limpets from hydrothermal vents; superfamily Lepetodrilacea. I. Systematic description. Philosophical Transactions of the Royal Society of London B, 319, 1-32.

McLean JH (1989) New archaeogastropod limpets from hydrothermal vents: new family Peltospiridae, new superfamily Peltospiracea. Zoologica Scripta, 18, 49-66.

McLean JH (1990) Neolepetopsidae, a new docoglossate limpet family from hydrothermal vents and its relevance to patellogastropod evolution. Journal of Zoology, 222, 485-528. 
McMullin ER (2003) Phylogeography of deep-sea vestimentiferans and a population genetics study of two species, Lamellibrachia luymesi and Seepiophila jonesi, from the Gulf of Mexico, Pennsylvania State University.

Mironov AN, Gebruk AV, Moskalev LI (1998) Biogeographical patterns of the hydrothermal vent fauna: a comparison with "non-vent biogeography". Cahiers de Biologie Marine, 39, 367-368.

Morgan TS, Rogers AD (2001) Specificity and sensitivity of microsatellite markers for the identification of larvae. Marine Biology, 139, 967-973.

Mullineaux LS, Fisher CR, Peterson CH, Schaeffer SW (2000) Tubeworm succession at hydrothermal vents: use of biogenic cues to reduce habitat selection error?

Oecologia, 123, 275-284.

Mullineaux LS, Mills SW, Sweetman AK, et al. (2005) Vertical, lateral and temporal structure in larval distributions at hydrothermal vents. Marine Ecology Progress Series, 293, 1-16.

Mullineaux LS, Speer KG, Thurnherr AM, Maltrud ME, Vangriesheim A (2002) Implications of cross-axis flow for larval dispersal along mid-ocean ridges. Cahiers de Biologie Marine, 43, 281-284.

Mullineaux LS, Wiebe PH, Baker ET (1995) Larvae of benthic invertebrates in hydrothermal vent plumes over Juan de Fuca Ridge. Marine Biology, 122, 585-596.

Nei M (1987) Molecular Evolutionary Genetics, Columbia University Press, New York. $512 \mathrm{pp}$.

North, EW, Schlag Z, Hood RR, Li M, Zhong L, Gross T, Kennedy VS (2008) Vertical swimming behavior influences the dispersal of simulated oyster larvae in a coupled particle-tracking and hydrodynamic model of Chesapeake Bay. Marine Ecology Progress Series, in press.

Nussbaumer AD, Fisher CR, Bright M (2006) Horizontal endosymbiont transmission in hydrothermal vent tubeworms. Nature, 441, 345-348.

van Oosterhout C, Hutchinson WF, Wills DPM, Shipley P (2004) MICRO-CHECKER: software for identifying and correcting genotyping errors in microsatellite data. Molecular Ecology Notes, 4, 535-538.

O'Reilly PT, Canino MF, Bailey KM, Bentzen P (2004) Inverse relationship between Fst and microsatellite polymorphism in the marine fish, walleye pollock (Theragra chalcogramma): implications for resolving weak population structure. Molecular Ecology, 13, 1799-1814.

Palacios DM, Bograd SJ (2005) A census of Tehuantepec and Papagayo eddies in the northeastern tropical Pacific. Geophysical Research Letters, 32, L23606. 
Pedersen EM, Hunt HL, Scheibling RE (2000) Temporal genetic heterogeneity within a developing mussel (Mytilus trossulus and M. edulis) assemblage. Journal of the Marine Biological Association of the United Kingdom, 80, 843-854.

Planes S, Lenfant P (2002) Temporal change in the genetic structure between and within cohorts of a marine fish, Diplodus sargus, induced by a large variance in individual reproductive success. Molecular Ecology, 11, 1515-1524.

Pritchard JK, Stephens M, Donnelly P (2000) Inference of population structure using multilocus genotype data. Genetics, 155, 945-959.

Puebla O (2008) Genetic signature of the spatial scale of dispersal mediated by coral reef fish larvae. Ocean Sciences Meeting, Orlando, Florida.

Purcell JFH, Cowen RK, Hughes CR, Williams DA (2006) Weak genetic structure indicates strong dispersal limits: a tale of two coral reef fish. Proceedings of the Royal Society of London B, 273, 1483-1490.

Raymond M, Rousset F (1995) GENEPOP (version 1.2): population genetics software for exact tests and ecumenicism. Journal of Heredity, 86, 248-249.

Raymond M, Vaanto RL, Thomas F, Rousset F, de Meeus T, Renaud F (1997) Heterozygote deficiency in the mussel Mytilus edulis species complex revisited. Marine Ecology Progress Series, 156, 225-237.

Reid JL (1997) On the total geostrophic circulation of the Pacific Ocean: flow patterns, tracers, and transports. Progress in Oceanography, 39, 263-352.

Rice WR (1989) Analyzing tables of statistical tests. Evolution, 43, 223-225.

Ridge 2000 (2008) 2008 Program Review. Available at http://www.ridge2000.org/science/program_review_2008/ .

Rivera MAJ, Kelley CD, Roderick GK (2004) Subtle population genetic structure in the Hawaiian grouper, Epinephelus quernus (Serranidae) as revealed by mitochondian DNA analyses. Biological Journal of the Linnean Society, 81, 449-468.

Rousset F (1997) Genetic differentiation and estimation of gene flow from F-statistics under isolation by distance. Genetics, 145, 1219-1228.

Roy MS, Sponer R (2002) Evidence of a human-mediated invasion of the tropical western Atlantic by the 'world's most common brittlestar.' Proceedings of the Royal Society London B, 269, 1017-1023.

Ruzzante DE (1998) A comparison of several measures of genetic distance and population structure with microsatellite data: bias and sampling variance. Canadian Journal of Fisheries and Aquatic Sciences, 55, 1-14.

Ruzzante DE, Taggert CT, Doyle RW, Cook D (2001) Stability in the historical pattern of genetic structure of Newfoundland cod (Gadus morhua) despite the catastrophic decline in population size from 1964-1994. Conservation Genetics, 2, 257-269. 
Schein-Fatton E (1985) A new Pectinidae (Bivalvia, Pteromorphia) with Paleozoic affinities discovered on the East Pacific Rise at $13^{\circ} \mathrm{N}$. Comptes rendus de l'Académie des sciences. Série 3, Sciences de la vie, 301, 491-496.

Scheltema RS (1986) On dispersal and planktonic larvae of benthic invertebrates: An eclectic overview and summary of problem. Bulletin of Marine Science, 39, 290322.

Searle RC, Francheteau J (1986) Morphology and tectonics of the Galapagos Triple Junction. Marine Geophysical Researches, 8, 95-129.

Searle RC, Rusby RI, Engeln J, et al. (1989) Comprehensive sonar imaging of the Easter microplate. Nature, 341, 701-705.

Shank T, Fornari D, Yoerger D, et al. (2003) Deep submergence synergy: Alvin and ABE explore the Galápagos Rift at $86^{\circ} \mathrm{W}$. Eos, 84, 425, 432-433.

Shank TM, Fornari DJ, Von Damm KL, et al. (1998) Temporal and spatial patterns of biological community development at nascent deep-sea hydrothermal vents $\left(9^{\circ} 50^{\prime} \mathrm{N}\right.$, East Pacific Rise). Deep-Sea Research II, 45, 465-515.

Shank TM, Halanych KM (2007) Toward a mechanistic understanding of larval dispersal: insights from genomic fingerprinting of the deep-sea hydrothermal vent tubeworm Riftia pachyptila. Marine Ecology, 28, 25-35.

Siegel, DA, Mitarai S, Costello CJ, Gaines SD, Kendall BE, Warner RR, Winters KB (2008) Connectivity among nearshore marine populations: the stochastic nature of larval transport. Proceedings of the National Academy of Sciences, 105, 8974-8979.

Sinton J, Bergmanis E, Rubin K, et al. (2002) Volcanic eruptions on mid-ocean ridges: New evidence from the superfast spreading East Pacific Rise, $17^{\circ}-19^{\circ} \mathrm{S}$. Journal of Geophysical Research, 107, ECV3-1-3-19.

Slatkin M (1985) Rare alleles as indicators of gene flow. Evolution, 39, 53-65.

Slatkin M (1995) A measure of population subdivision based on microsatellite allele frequencies. Genetics, 139, 457-462.

Southward EC (1988) Development of the gut and segmentation of newly settled stages of Ridgea (Vestimentifera): implications for relationship between Vestimentifera and Pogonophora. Journal of the Marine Biological Association of the United Kingdom, 68, $465-487$.

Spencer CC, Neigel JE, Leberg PL (2000) Experimental evaluation of the usefulness of microsatellite DNA for detecting demographic bottlenecks. Molecular Ecology, 9, 1517-1528.

Spiess FN, Macdonald KC, Atwater T, et al. (1980) East Pacific Rise: hot springs and geophysical experiments. Science, 207, 1421-1433. 
Strathmann RR, Hughes TP, Kuris AM, et al. (2002) Evolution of local recruitment and its consequences for marine populations. Bulletin of Marine Science, 70 Supplement, 377-396.

Sverdrup HU (1941) The Gulf of California: Preliminary discussion of the cruise of the E. W. Scripps in February and March of 1939. Proceedings of the $6^{\text {th }}$ Pacific Scientific Congress, 161-166.

Sverdrup HU (1947) Wind-driven currents in a baroclini ocean with application to the equatorial currents in the eastern Pacific. Proceedings of the National Academy of Sciences, 33, 318-326.

Swearer SE, Caselle JE, Lea DW, Warner RR (1999) Larval retention and recruitment in an island population of coral reef fish. Nature, 402, 799-802.

Teske PR, Papadopoulos I, Zardi GI, et al. (2007) Implications of life history for genetic structure and migration rates of southern African coastal invertebrates: planktonic, abbreviated and direct development. Marine Biology, 152, 697-711.

Thiébaut E, Huther X, Shillito B, Jollivet D, Gaill F (2002) Spatial and temporal variations of recruitment in the tube worm Riftia pachyptila on the East Pacific Rise $\left(9^{\circ} 50^{\prime} \mathrm{N}\right.$ and $\left.13^{\circ} \mathrm{N}\right)$. Marine Ecology Progress Series, 234, 147-157.

Thorrold SR, Jones GP, Hellberg ME, et al. (2002) Quantifying larval retention and connectivity in marine populations with artificial and natural markers. Bulletin of Marine Science, 70, 291-308.

Thorson G (1950) Reproductive and larval ecology of marine bottom invertebrates. Biological Reviews, 25, 1-45.

Tunnicliffe V (1988) Biogeography and evolution of hydrothermal-vent fauna in the Eastern Pacific. Proceedings of the Royal Society of London B, 233, 347-366.

Tyler PA, Young CM (1999) Reproduction and dispersal at vents and cold seeps. Journal of the Marine Biological Association of the United Kingdom, 79, 193-208.

Tyler PA, Young CM (2003) Dispersal at hydrothermal vents: a summary of recent progress. Hydrobiologia, 503, 9-19.

Van Dover CL (2000) The Ecology of Deep-Sea Hydrothermal Vents. Princeton University, Princeton, NJ. 424 pp.

Vinogradova NG (1979) The geographical distribution of the abyssal and hadal (ultraabyssal) fauna in relation to the vertical zonation of the ocean. Sarsia, 64, 41-50.

Voight JR, Zierenberg RA, McClain J, and the Science Party (2004) FIELD cruise to the northern EPR: discoveries made during investigations from $8^{\circ} 37^{\prime} \mathrm{N}$ to $12^{\circ} 48^{\prime} \mathrm{N}$. Ridge 2000 Events, April.

Vrijenhoek RC (1997) Gene flow and genetic diversity in naturally fragmented metapopulations of deep-sea hydrothermal vent animals. Journal of Heredity, 88, 285-293. 
Vrijenhoek RC, Shank T, Lutz RA (1998) Gene flow and dispersal in deep-sea hydrothermal vent animals. Cahiers de Biologie Marine, 39, 363-366.

Warén A, Bouchet P (1989) New gastropods from East Pacific hydrothermal vents. Zoological Scripta, 18, 67-102.

Warén A, Bouchet P (1993) New records, species, genera, and a new family of gastropods from hydrothermal vents and hydrocarbon seeps. Zoological Scripta, 22, $1-90$.

Warén A, Bouchet P (2001) Gastropoda and Monoplacophora from hydrothermal vents and seeps, new taxa and records. The Veliger, 44, 116-231.

Watson J (2008) Simulating the impact of El Nino on the gene flow of marine species in the Southern California Bight. Ocean Sciences Meeting, Orlando, Florida.

Watts RJ, Johnson MS, Black R (1990) Effects of recruitment on genetic patchiness in the urchin Echinometra mathaei in Western Australia. Marine Biology, 105, 145 151.

Weinmayr G, Vautrin D, Solignac M (2000) Isolation and characterization of highly polymorphic microsatellites from the polychaete Pectinaria koreni. Marine Biotechnology, 2, 92-99.

Weir BS, Cockerham CC (1984) Estimating $F$-Statistics for the analysis of population structure. Evolution, 38, 1358-1370.

Weir BS (1996) Genetic Data Analysis II, Sinauer Associates, Sunderland, Massachusetts.

Won Y, Young CR, Lutz RA, Vrijenhoek RC (2003) Dispersal barriers and isolation among deep-sea mussel populations (Mytilidae: Bathymodiolus) from eastern Pacific hydrothermal vents. Molecular Ecology, 12, 169-184.

Wood AR, Gardner JPA (2007) Small spatial scal population genetic structure in two limpet species endemic to the Kermadec Islands, New Zealand. Marine Ecology Progress Series, 349, 159-170.

Wright S (1931) Evolution in Mendelian populations. Genetics, 16, 97-159.

Wright S (1940) Breeding structure of populations in relation to speciation. The American Naturalist, 74, 232-248.

Wright S (1951) The genetical structure of population. Annals of Eugenetics, 15, 323354.

Young CM (2003) Reproduction, development and life history traits. In: P. A. Tyler, editor. Ecosystems of the deep sea, Vol. 28. Rotterdam: Elsevier. pp. 381-426.

Young CR, Fujio S, Vrijenhoek RC (2008) Directional dispersal between mid-ocean ridges: deep-ocean circulation and gene flow in Ridgeia piscesae. Molecular Ecology, 17, 1718-1731. 
Zouros E, Foltz DW (1984) Possible explainations of heterozygote deficiency in bivalve molluscs. Malacologia, 25, 583-591. 


\title{
Chapter 4
}

\section{Intra-ridge segment and temporal population genetic patchiness at hydrothermal vents}

\begin{abstract}
Hydrothermal vent habitats and the populations that depend on them exhibit spatial, temporal, and demographic heterogeneity. This environment is non-continuously distributed at a range of spatial scales, from meters within a vent field to hundreds of kilometers between active vent clusters. Vents are also temporally transient, with fluid chemistry shifts occurring on timescales of less than a year and episodic seafloor eruptions at fast-spreading ridge segments occurring roughly every 10 to 20 years. These characteristics influence the distributions of vent fauna in space and time. The dynamics and patchiness of the vent habitat suggest that studying the ecology of component species may be well suited to a metapopulation approach (cf. Section 1.3). The siboglinid tubeworm Riftia pachyptila presents a well-characterized organism through which to consider the genetic signature of vent populations at fine spatial and temporal scales with respect to their history of colonization and turnover. Here I examine population genetic differentiation at ridge segment spatial scales of 10 s of kilometers $\left(9^{\circ} \mathrm{N} \mathrm{EPR,} 86^{\circ} \mathrm{W}\right.$ GAR) and over multi-year sampling of single populations on two different ridge systems, spanning an eruptive event. Despite variations in vent chemistry and fluid flow and recent local extinctions, I found that Riftia populations remain genetically similar over a period of seven years. Proximity to other populations and the ability to settle as related cohorts through local retention and along-axis dispersal likely allows this high degree of genetic connectivity on ecologically and demographically relevant scales.
\end{abstract}




\subsection{Introduction}

The geographic distribution of a species is often patchy, reflecting the heterogeneity of suitable habitat and the varied historic and contemporary events acting on its populations. Patchiness can occur on a range of spatial scales, even for species with a high dispersal potential. The genetic and demographic structure of populations often reflect the realized degree of movement of individuals among populations, but may represent the cumulative effect of various processes that have occurred over time, such as colonization, extinction, and selection. The microevolutionary consequences of these processes and a species' ability to cope with changing conditions play an important role in establishing future populations. Although traditional population genetic studies have focused on regional spatial patterns that result from many generations of historic gene flow, analysis of fine spatial and temporal genetic variation can establish the processes responsible for contemporary population structure developed over much shorter timescales. Temporal variations may be particularly important to species living in ephemeral environments. Variable genetic markers (e.g., DNA microsatellites) enable investigation into the relative importance of fine-scale and temporal variation in ephemeral and patchy habitats.

Three main challenges in population ecology currently face the marine ecology community (R. Cowen, OSM 2008): determining (1) the explicit processes that create spatial and temporal distribution patterns, (2) the shape and influence of dispersal on those patterns, and (3) the role of rates in population and community dynamics. Moreover, the issue of scale in demographic and genetic processes continues to be important. This chapter investigates potential ecological processes (e.g., self-recruitment, cohort fidelity, local larval retention) responsible for the population genetic patterns observed in Riftia pachyptila (a monospecific genus hereafter be referred to as Riftia) at hydrothermal vents in the eastern Pacific. In order to extend the regional-scale findings presented in Chapter 3, I consider spatial scales of meters to 10s of kilometers, genetic similarity among cohorts, and interannual temporal genetic stability. This approach especially targets the processes of larval dispersal may influence the observed 
distribution of population genetic patterns in this system. Based on my results, future studies may be able to provide further insights into the rates of these processes.

\subsubsection{Fine-scale spatial and temporal population genetic variation}

In marine systems, spatiotemporal genetic variation in larval cohorts has been used to investigate the variation observed in adult populations. Diverse findings of these studies range from consistent along-current settlement patterns of mussel larvae over a two-year period (Gilg \& Hilbish 2003a) to rapid changes in the genetic structure of sea bream populations (Planes \& Lenfant 2002). In cases of small populations with stochastic fluctuations in allele frequencies, observed spatial variation in adults comes as the result of spatial variation in settling larval cohorts (Gilg \& Hilbish 2003b). These transient, non-equilibrium states can result in population divergence over time, though not directly due to temporal variation or selective pressures (Newman \& Squire 2001). Multiple nonexclusive scenarios for the establishment and maintenance of such chaotic genetic patchiness can be posed, including local recruitment with homogenizing selection, local recruitment with low-level long-distance dispersal, and widespread dispersal with sitespecific post-settlement selection (Wood \& Gardner 2007). Temporal habitat variability could alternatively drive fine-scale genetic differentiation in species with sporadic, geographically discontinuous dispersal and limited gene flow, as in the estuarine sea anemone Nematostella vectensis (Darling et al. 2004).

Even on fine spatial scales (10s of meters), populations of highly dispersive terrestrial and marine species — such as rain forest trees, copepods, sea palms, or sea urchins - may become genetically isolated (Born et al. 2008a, Burton \& Lee 1994, Kusumo et al. 2006, Palumbi 1996). In some systems, dispersal may predominantly occur between neighboring demes. However, not all populations in close geographic proximity exchange individuals at contemporary timescale and yet they may still appear to be genetically well connected (Jehle et al. 2005). Episodic long distance transport (gene flow) can be countered by regional genetic drift, as observed in sea urchins from the Indo-West Pacific 
(Palumbi 1996). If demography plays a greater role than habitat suitability, gene flow can also be asymmetric. A new allele may arise and become confined to one population, resulting in high levels of differentiation among populations and low levels of variation within populations (Burton \& Lee 1994). Sampling populations across a spectrum of spatial scales from neighboring sites to those across the species range can elucidate the processes governing their genetic structure. Moreover, highly variable molecular markers (e.g., microsatellites) are expected to be able to provide additional resolution into these population genetic patterns, when previous approaches have hidden subtle ecological processes.

\subsubsection{Sweepstakes reproductive success}

In cases of "sweepstakes" reproductive success, whereby the progeny of a small number of adults successfully recruit despite large reproductive output, individuals of a population do not all uniformly contribute to the next generation (Jehle et al. 2005). Variability in habitat quality or larval transport can create recruit-limited regions, increasing local reproductive success and population retention in other areas (Pringle \& Wares 2007). As a result, partial inbreeding is possible in species with large populations and dispersive planktonic larvae (Hedgecock et al. 2007). Within a species complex, these variable settlement patterns - in combination with post-settlement selection - can also create temporal genetic heterogeneity (Pedersen et al. 2000, Watts et al. 1990), as may be suspected for benthic invertebrates at deep sea hydrothermal vents. Heritably early spawners may create distinct cohorts reproductively isolated from later spawners and result in temporal genetic heterogeneity (Hendry \& Day 2005).

As these types of isolation by time (IBT) patterns can be greater in magnitude than geographic components of genetic differentiation (Maes et al. 2006), considering populations irrespective of time could lead to inappropriate conclusions about their genetic structure. Temporally heterogeneous sampling design may suggest patterns of isolation by distance (IBD) when IBT is more likely. The scale and duration of 
observations are therefore important considerations. For instance, within a spawning season, variable adult reproductive success in European eels might not create an IBT trend, but such genetic sweepstakes over several years can result in isolation (Maes et al. 2006). Improper sampling would either miss the cumulative outcome of variable reproduction or misattribute its cause. These processes can be better understood by sampling multiple cohorts over time at a range of spatial scales, as conducted in the population genetic study presented here.

\subsubsection{Metapopulation processes}

Species in ephemeral habitats can be more sensitive to changes over time and to patch lifespan than to spatial components (Keymer et al. 2000). Temporal habitat variability can control genetic patterns more than spatial heterogeneity especially if genetic divergences are extreme within a site (Darling et al. 2004). In fragmented habitats as found at deep sea hydrothermal vents, rapid colonization and survival at new vent sites has been proposed to have a greater impact on genetic diversity than migration (Vrijenhoek et al. 1998). The effects of extinction/colonization on genetic differentiation of populations, bound as a single unit or alternately with independent trajectories, hinge upon how groups of colonizers to vacant sites are formed and the proportion of migrants (at extant sites) to colonists (Wade \& McCauley 1988). Specifically, for extinction and colonization dynamics to reduce population differentiation (i.e., homogenize a metapopulation), there must be many more colonists than migrants.

While global hydrothermal vent biogeography has been considered (Van Dover 2002) and the emerging faunal distribution hypothesized to be established by the decadal and high frequency variability of the venting source (Christiansen 2000), ridge-scale genetic structure of vent populations has received little attention. Population disturbance and turnover have been well documented at the vent and vent field scale, especially at $9^{\circ} \mathrm{N}$ on the EPR. Between 1989 and 2008, this ridge segment has experienced two major seafloor eruptions and numerous shifts in hydrothermal venting and community composition 
(Shank et al. 1998, Tolstoy et al. 2006). Most recently in 2005-2006, following a period of increased microseismicity, $18 \mathrm{~km}$ of vent communities were paved over by fresh lava (Tolstoy et al. 2006, Cowen et al. 2007, Soule et al. 2007). New communities began to develop in the months thereafter as they did following the 1990-1991 eruptions, with Tevnia jerichonana replacing microbial mats and the subsequent re-settlement of solitary Riftia individuals (Shank et al. 2006). These events and recorded changes in community structure, coupled with extensive cross-disciplinary sampling since the 1991 eruption through to after the 2005-2006 eruption distinguish the $9^{\circ} \mathrm{N}$ EPR hydrothermal region from other less-studied vent fields and afford the opportunity for spatiotemporal studies.

Vent communities at $86^{\circ} \mathrm{W}$ GAR have also experienced significant shifts and eruptions over the past few decades (Shank et al. 2003). Before the discovery of Galápagos vents, there was evidence of a 1972 eruption in the $86^{\circ} \mathrm{W}$ area (Macdonald \& Mudie 1974). The high flow Rose Garden site, thought to have originated in the early 1970s and last visited in 1990, was not found in 2002 (Childress 1988, Shank et al. 2003). Venting at Rose Garden had been active in observations made from 1979 to 1990; however, between 1979 and 1985, tubeworms all but disappeared from this site, a single cluster remaining atop a large mussel bed (Desbruyères 1998). Dives of the submersible Alvin in 2002 on what was once Rose Garden revealed that a recent volcanic eruption (no more than 2.5 years prior) had paved over the populations of tubeworms, mussels, and other vent fauna last seen thriving in a large fissure at that location in 1990 (Shank et al. 2003). While this flow of fresh seafloor eliminated a known, well-established community and changed the venting terrain and subsurface plumbing, a few hundred meters northwest, a new hydrothermal community was observed with juvenile tubeworms, mussels, and clams colonizing a nascent vent field. This new low temperature $\left(24^{\circ} \mathrm{C}\right)$ site, about $60 \mathrm{~m}$ by 50 $\mathrm{m}$ with four main venting areas, was named Rosebud. Rosebud and the surrounding area were visited again in May 2005 in an attempt to document changes to the community structure and water chemistry since its discovery. In three years, mussel and tubeworm communities had grown substantially and continued to inhabit discrete habitat patches 
while additional regions of diffuse flow remained available for colonization (Nevala 2005). Fourteen kilometers east on the GAR, the Garden of Eden vent site supports a robust vent community discovered in 1977 (Corliss et al. 1979) and revisited throughout the 1980s. Extensive Riftia assemblages at Garden of Eden in 2005 contained the largest recorded tubeworms ( $>2 \mathrm{~m}$, pers. obs. T. Shank) in 2005, suggesting the might be part of a long-lived population unaffected by the Rose Garden eruption.

As components of communities dependent on the fleeting existence and disjunct locations of hydrothermal vents as discussed above, vent species should exhibit genetic variability and phenotypic plasticity within local populations, while facilitating gene flow among populations on a ridge scale. Metapopulation processes involving patch-network displacements and transient contact zones may therefore be able to predict genetic structure in this environment (Jollivet et al. 1999). Variation in genetic structure over time and space is likely driven by the interactions of populations coping with a variety of productivity, recruitment, and disturbance regimes. Temporal instability and habitat constraints at hydrothermal vents may provide a more connected network of patches than suggested at any given time when considered in respect to historical venting, explaining the persistence of fauna in these habitats (Chevaldonné et al. 1997). Genomic flexibility could also facilitate vent faunal adaptation to an ever-fluctuating supply of nutrients and temperatures.

\subsubsection{Biological model and objectives for present study}

The siboglinid tubeworm Riftia presents a well-characterized system in which to consider the genetic signature of vent populations at fine spatial and temporal scales with respect to their history of colonization and turnover (see Section 1.6). These tubeworms are early vent colonizers and are dependent on diffuse hydrothermal fluids for survival. Riftia has a trochophore larval stage potentially retained within $100-200 \mathrm{~km}$ of their natal habitat by along-axis currents (Marsh et al. 2001, Mullineaux et al. 2002). However, population genetic homogeneity evidenced by protein and single locus DNA-based analyses suggests 
that gene flow in Riftia is high across much of its range (Black et al. 1994, Hurtado et al. 2004). Recent genomic fingerprinting revealed the potential for greater genetic differentiation among populations on the EPR and for settlement as related larval cohorts (Shank \& Halanych 2007).

High-resolution microsatellite loci have already been developed (Chapter 2) and applied to a regional population genetic investigation at an inter-ridge scale, consistent with local larval retention within some vent fields (Chapter 3). Now, within-ridge segment samples and time-series archival material is available to explore the subtler genetic connections among local populations, allowing for their foundation and persistence. An historical and contemporary view of population structure on these metapopulation scales can provide the context for processes responsible for observed genetic patterns and help make predictions for future scenarios at vents. In this paper, population genetic differentiation is examined at within ridge segment spatial scales $\left(9^{\circ} \mathrm{N}\right.$ EPR, $86^{\circ} \mathrm{W}$ GAR) and over multi-year sampling of single populations on two different ridge systems, spanning an eruptive event.

\subsection{Materials and methods}

\subsubsection{Sample collection}

Riftia individuals were collected using the submersible $D S V$ Alvin operating from the $R / V$ Atlantis on the East Pacific Rise (EPR) and Galápagos Rift (GAR) (Figures 4.1-4.3). In order to maximize temporal genetic variance among samples, month-long field excursions to each ridge segment constrained the fine-scale sampling program.

Tubeworms from specific assemblages within sites along these mid-ocean ridge segments were placed in Alvin's sealed, insulated boxes on the seafloor. Within hours of Alvin recovery, individual specimens were removed from their chitinous tubes and measured 


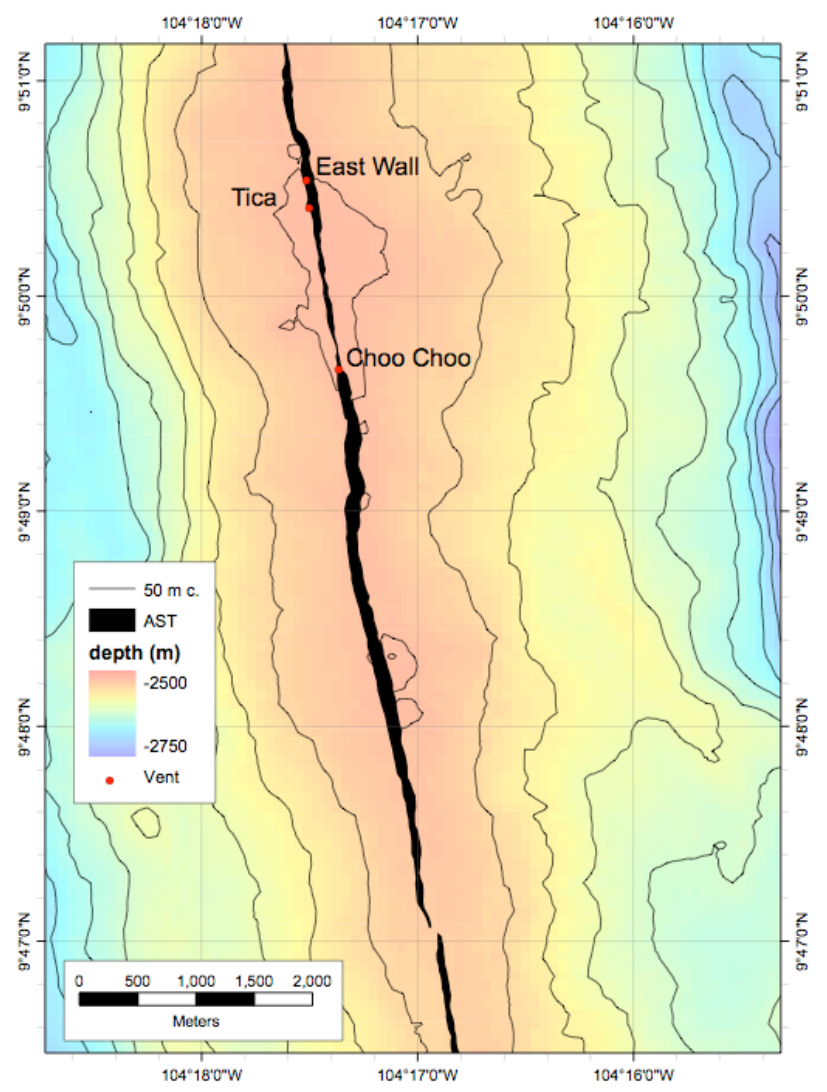

Figure 4.1 Location of 2000 sampling efforts at 9' $\mathrm{N}$ on the East Pacific Rise (East Wall, Tica, Choo Choo).

Figure 4.2 Location of 2005 sampling efforts at $86^{\circ} \mathrm{W}$ on the Galápagos Rift (Rosebud Markers J and N, Garden of Eden Marker Q).

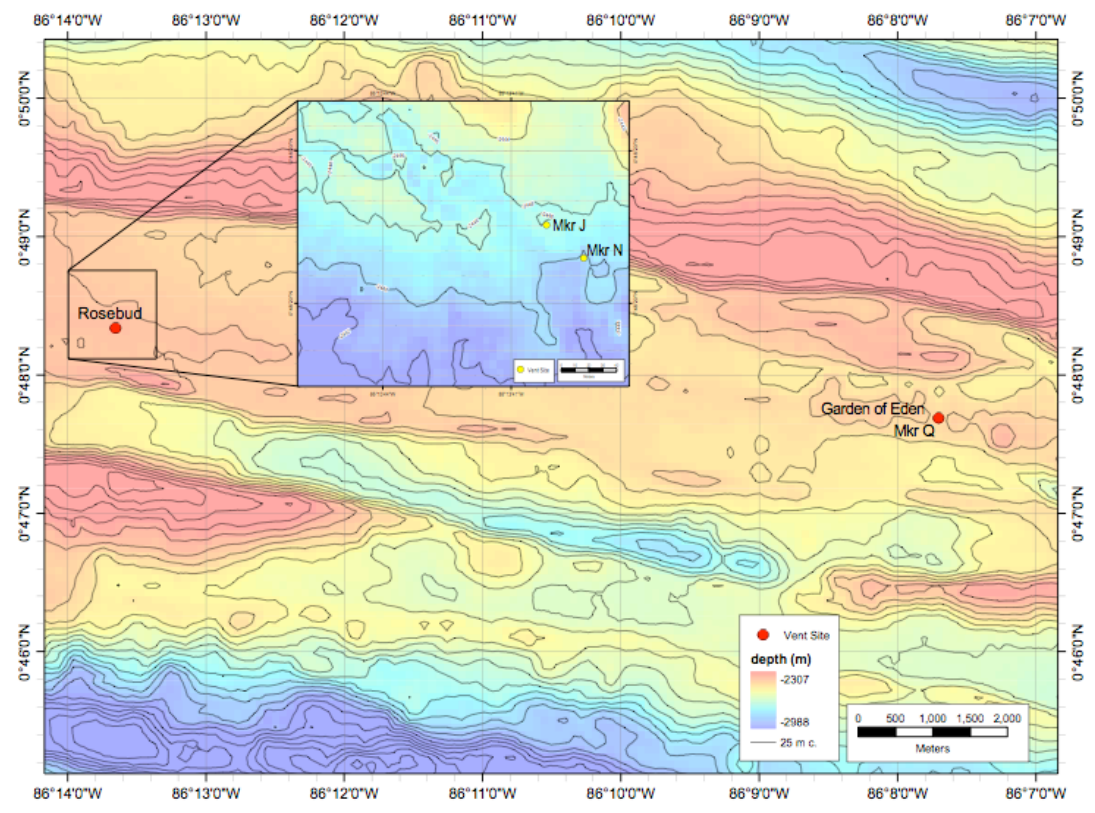




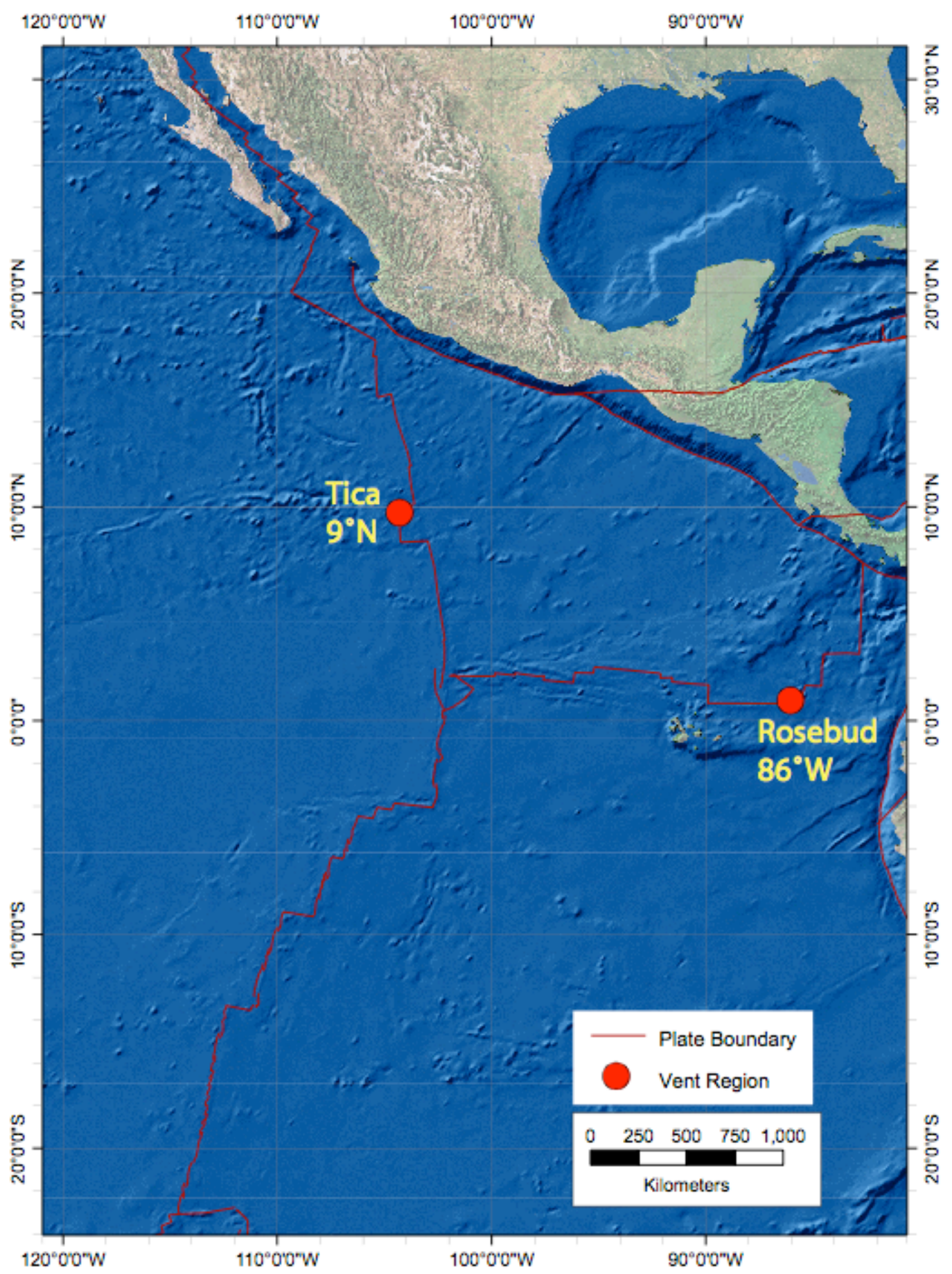

Figure 4.3 Location of temporal efforts on the EPR and GAR (Tica: 2000, 2002, 2004, 2005, 2007; Rosebud: 2002, 2005). 
for total body length (tip of plume to tip of opisthosome) to the nearest $0.5 \mathrm{~cm}$ or estimated (e.g., $>250 \mathrm{~mm},>500 \mathrm{~mm},<5 \mathrm{~mm},<20 \mathrm{~mm}$ ). Worms were categorized and sorted either as "recent colonists" (body length $<30 \mathrm{~mm}$ for intraregional samples, $<45$ $\mathrm{mm}$ for temporal samples) or "resident adults" (body length $>100 \mathrm{~mm}$ for temporal and $9^{\circ} \mathrm{N}$ EPR intraregional samples, $>75 \mathrm{~mm}$ for $86^{\circ} \mathrm{W}$ intraregional samples), ignoring intermediate size classes. Whole animals or individual tissues were frozen at $-80^{\circ} \mathrm{C}$. Further molecular processing was conducted in a shore-based laboratory at Woods Hole Oceanographic Institution.

Recent colonists were inferred to be less than one year old, while resident adults likely represented many years of recruitment (as in Grassle 1985). As in Chapter 3, the chosen body length bins for colonists and residents were selected to maximize differences in age between the two "cohorts" and to avoid "short, fat" morphologies whose relative age would be difficult to assign. Resident adults collected from successive expeditions were binned per site when sample number was low, but colonist samples were limited to those collected on a single research expedition in order to avoid mixing discrete cohorts.

For the first intra-segment, fine-spatial scale component, resident adults were collected in 2000 from three sites along the $9^{\circ} \mathrm{N}$ East Pacific Rise ridge segment on expeditions AT350 and AT3-51: East Wall ( $9^{\circ} 50.53^{\prime} \mathrm{N}, 104^{\circ} 17.51^{\prime} \mathrm{W}, 2505 \mathrm{~m}$ deep), Tica $\left(9^{\circ} 50.41^{\prime} \mathrm{N}\right.$, $104^{\circ} 15.50^{\prime} \mathrm{W}, 2511 \mathrm{~m}$ deep), and Choo Choo ( $9^{\circ} 49.66^{\prime} \mathrm{N}, 104^{\circ} 17.37^{\prime} \mathrm{W}, 2500 \mathrm{~m}$ deep) (Table 4.1). Along the Galápagos Rift, both recent colonists and resident adults were collected in 2005 on expedition AT11-27 from three additional sites: Rosebud Marker F $\left(0^{\circ} 48.36^{\prime} \mathrm{N}, 86^{\circ} 13.67^{\prime} \mathrm{W}, 2451 \mathrm{~m}\right.$ deep), Rosebud Marker N $\left(0^{\circ} 48.35^{\prime} \mathrm{N}, 86^{\circ} 13.65^{\prime} \mathrm{W}\right.$, $2452 \mathrm{~m}$ deep), and Garden of Eden Marker Q ( $0^{\circ} 47.68^{\prime} \mathrm{N}, 86^{\circ} 7.71^{\prime} \mathrm{W}, 2489 \mathrm{~m}$ deep) (Table 4.1).

To examine the stability of genetic diversity at sites over multiple years spanning an eruption on a fast-spreading ridge, the $9^{\circ} \mathrm{N}$ East Pacific Rise Tica site was sampled for 


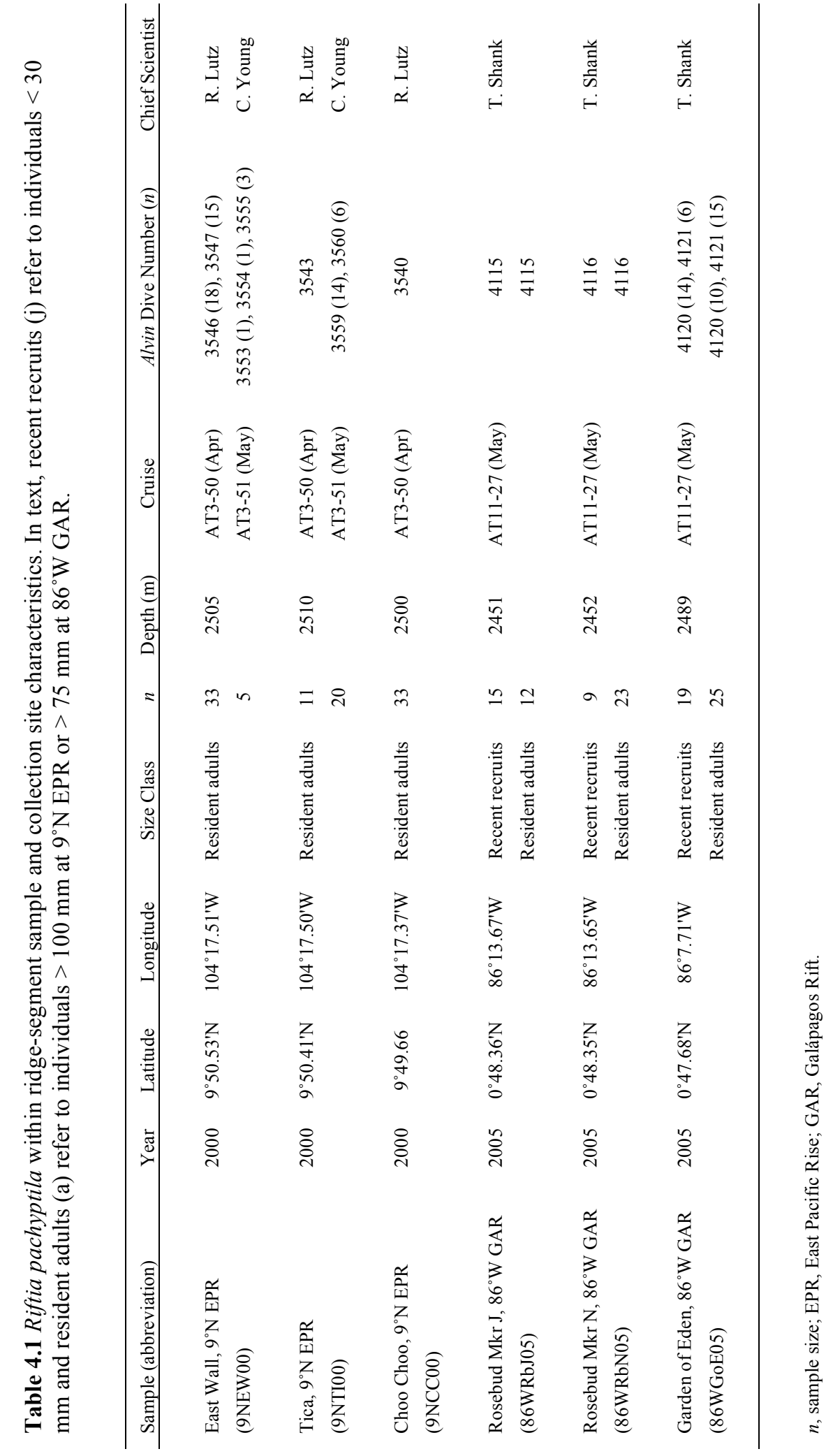




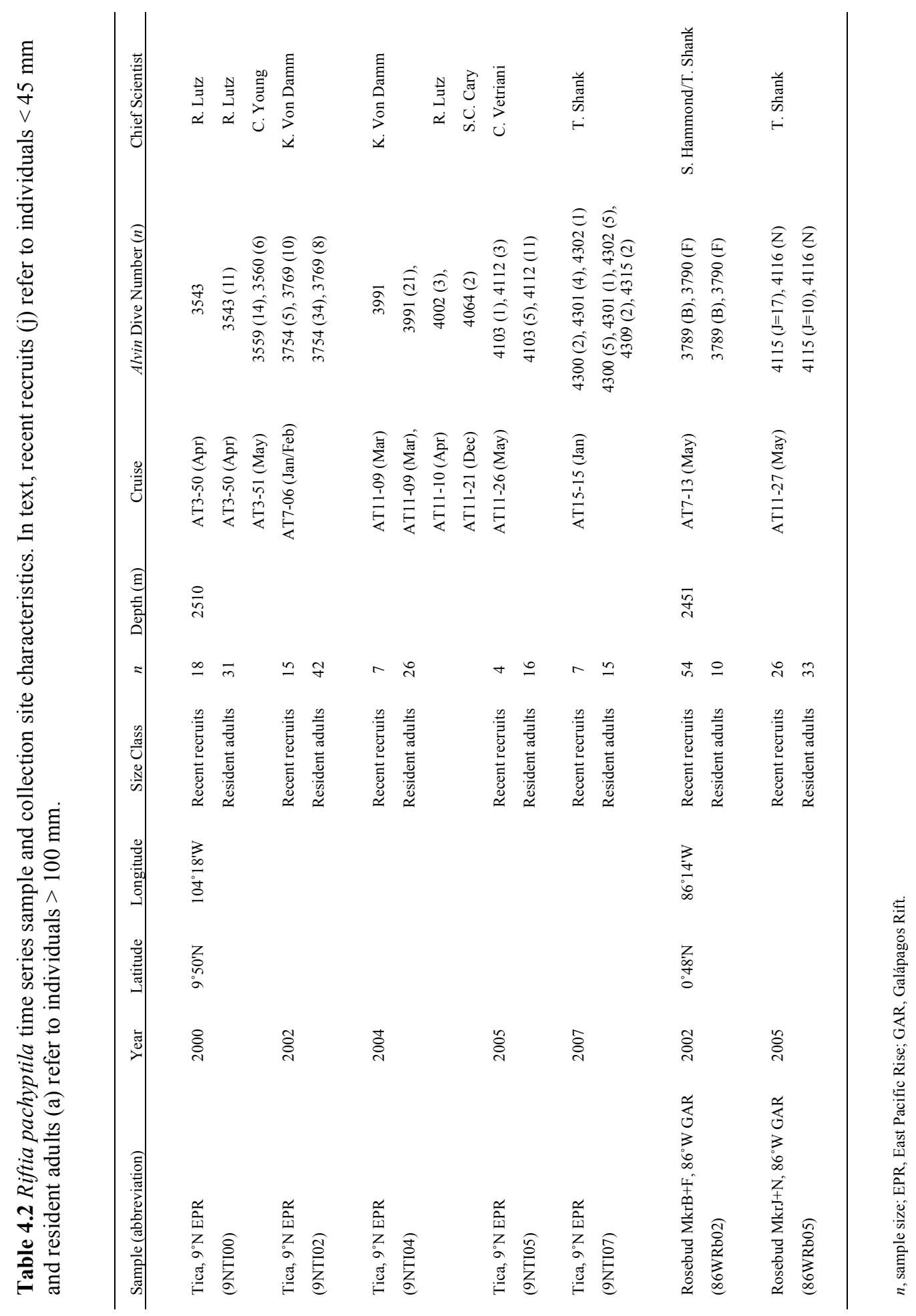


recent colonists and resident adults in 2000 (AT3-50, AT3-51), 2002 (AT7-06), 2004 (AT11-09, AT11-10, AT11-21), 2005 (AT11-26), and 2007 (AT15-15) (Table 4.2). As two Tica resident individuals collected in December 2004 (AT11-21) were considered large enough to have also been residents earlier that year when the remainder of that year's Riftia were collected, they were included in order to increase sample size; exclusion of these individuals did not have a significant effect on subsequent analyses. The Rosebud population at $86^{\circ} \mathrm{W}$ on the intermediate-spreading Galápagos Rift was sampled two and five years following estimated establishment, in 2002 (AT7-13) and 2005 (AT11-27), respectively (Table 4.2). Based on the concurrent results of the $86^{\circ} \mathrm{W}$ GAR intra-segment analyses, samples from two proximate Rosebud Riftia patches were pooled for 2002 (Markers B and F) and 2005 (Markers J and N).

For the duration of this chapter, samples collected from a given site or year are collectively referred to as a pooled population, while the recent colonists and resident adults from each site or year are designated as a subpopulation or cohort.

\subsubsection{DNA extraction, genotyping, and data preparation}

Genomic DNA was isolated from the frozen vestimentum (and from one opisthosome and one body wall) of 421 Riftia individuals using either the DNeasy Tissue (Qiagen) extraction kit or the Chelex 100 procedure (Roy \& Sponer 2002). Samples were amplified at eight highly polymorphic microsatellite loci (R2D12, R2E14, R3B6, R3D3, Rpa10CA02, Rpa10CA06, Rpa10CA07, Rpa10A1101) previously developed for genotyping (Fusaro et al. 2008). Allele fragment length was analyzed on an ABI 3730 DNA Analyzer using the GeneScan 500 LIZ standard and GENEMAPPER version 3.7 (Applied Biosystems) with manual electropherogram inspection. PCR products from a subset of individuals were replicated between separate runs to monitor and control for genotyping inconsistencies. Raw allele sizes were binned into whole number allele

lengths (number of base pairs) using the automated FLEXIBIN (Amos et al. 2007) program 
and manually reviewed for ambiguities. Allele lengths were then translated to number of repeats based on sequenced clones from Fusaro et al. (2008).

Input files for analyses were created from a MS Excel spreadsheet in the 3-digit MICROCHECKER version 2.2.3 (van Oosterhout et al. 2004) and 6-digit GENETIX version 4.05.2 (Belkhir et al. 2004) formats. Data from the latter file-type were pasted into GENETIX to create input files for FSTAT version 2.9.3.2 (Goudet 2001), ARLEQUIN version 3.11 (Excoffier et al. 2005), and GENEPOP ON THE WEB version 3.4 (Raymond \& Rousset 1995). The GENEPOP file format was also implemented in BOTTLENECK version 1.2.02 (Cornuet \& Luikart 1996). The FSTAT file format was used in PCA-GEN version 1.2 (Goudet 1999). These data were formatted for 2-digit allele length (FSTAT, GENEPOP, BOTTLENECK), 3-digit allele length (MICRO-CHECKER, GENETIX), and repeat number (ARLEQUIN). The 3-digit allele length data were manually formatted for analysis in STRUCTURE version 2.2 (Pritchard et al. 2000; Falush et al. 2003, 2007).

\subsubsection{Single locus statistical analyses and conformance to Hardy- Weinberg equilibrium}

The number of alleles, allelic richness (normalized to the smallest subpopulation size; El Mousadik \& Petit 1996), allele size range, and size and frequency of the most common allele(s) were calculated per subpopulation and across all subpopulations in the programs GENETIX and FSTAT. Nonbiased expected and observed heterozygosity values were determined in ARLEQUIN following Nei (1987). MICRO-CHECKER was used to screen loci in each subpopulation for scoring errors - null alleles, large allele dropout, and stuttering - that would result in departure from Hardy-Weinberg equilibrium (HWE) expectations (run at the default 95\% CI, 1000 permutations). The probabilities for observed homozygote size-class frequencies were calculated via a cumulative binomial distribution (Weir 1996), ranking the observed frequency in a distribution of randomized genotypes (van Oosterhout et al. 2004). These $P$ values were then combined to identify deviations from Hardy-Weinberg proportions (van Oosterhout et al. 2004). Fisher-type 
exact tests of HWE comparing $H_{\mathrm{E}}$ and $H_{\mathrm{O}}$ per locus and cohort were also conducted in ARLEQUIN with a recommended Markov chain of 2,000,000 steps and 200,000 dememorization steps for reproducibility (L. Excoffier on the Genetic Software Forum pers. comm.). To examine deviation from HWE expectations due to non-random mating,

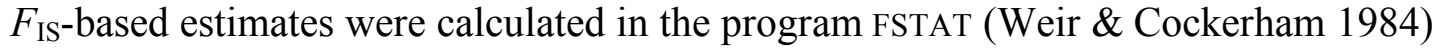
using 2000 permutations (recommended value for $<10$ loci $=1000$ permutations; however, it took 2000 randomizations to allow for little variation in significant values among multiple runs). The data were analyzed for linkage disequilibrium (Weir 1996), using a probability test on all locus-specific contingency tables under the null hypothesis of independence (Cockerham \& Weir 1979). Parameter values in GENEPOP ON THE WEB consisted of 5000 dememorization steps, 500 batches, and 2000 iterations per batch —at which level pairwise significance was consistent among multiple runs. In order to correct for multiple comparisons, all significance tests were run at a nominal alpha level of 0.05 with sequential Bonferroni correction (Rice 1989).

\subsubsection{Estimates of population and cohort structure}

To detect heterogeneity among pooled populations and cohorts, exact tests of differentiation in allele (genic) and genotype (genotypic) distributions between population pairs were conducted in GENEPOP ON THE WEB using 5000 dememorization steps, 500 batches, and 2000 iterations per batch, as described for tests of linkage disequilibrium. Estimates of Weir \& Cockerham's (1984) allele frequency-based $\theta_{\mathrm{WC}}$ (estimates Wright's $1951 F_{\mathrm{ST}}$ ), assuming the infinite alleles model of mutation, and Slatkin's (1995) allele repeat-based $R_{\mathrm{ST}}$, assuming the stepwise model of microsatellite mutation, were calculated between population pairs in ARLEQUIN. Significance was tested using 20,000 permutations - pairwise significance levels were consistent among runs at this number of permutations — with table wide sequential Bonferroni correction for multiple tests. $F_{\mathrm{ST}}$ was also calculated and tested for significance per locus over all populations in FSTAT. 
Population structure was estimated using hierarchical analysis of molecular variance (AMOVA, ARLEQUIN) with 20,000 permutations. These estimates allowed quantification of the magnitude of genetic variation (by partitioning total variance into covariance components) among geographic regions or sampling years $\left(\Phi_{\mathrm{CT}}\right)$ relative to other sources of genetic variation among populations ( $\Phi_{\mathrm{SC}}$, inter-population), within cohorts $\left(\Phi_{\mathrm{IS}}\right.$, interindividual), and within individuals ( $\Phi_{\mathrm{IT}}$, intra-individual). Significant differences (from zero) in Wright's fixation indices at these four levels were tested for departure from HWE by comparing observed values to a null distribution estimated by randomly permuting the populations (or years), individuals, or haplotypes among groups of populations defined by sample site (or year), demes, or individuals, respectively.

All populations were further explored for underlying genetic structure within ridge segments or given years at a single site using an admixture model of ancestry and correlated allele frequencies in STRUCTURE (burnin of 20000, followed by 20000 MCMC replicates; tested for $K=1$ through $K=$ total number of subpopulations). This algorithm assigns individuals to groups assuming that loci are at HWE within each population and estimates the population of origin for each individual from the observed genotypes (Pritchard et al. 2000). The calculated membership coefficient $(Q)$ for each individual displays its estimated affinity to a given population. The posterior probability of the data (PPD) was plotted to determine the best number of populations $(K)$ given the results (Garnier et al. 2004). In order to determine the origin of overall population structure, among-colonist and among-resident subpopulation structure was explored using the same parameters.

A principal components analysis (PCA) was used to identify clusters of subpopulations based on $F_{\mathrm{ST}}$ and was performed on the genotypic data using PCA-GEN. Significance of each axis in the PCA was determined using 10,000 randomizations. 
Genetic isolation by geographical distance and by time was evaluated for significance using the Mantel test implemented in GENEPOP ON THE WEB (500,000 permutations). Slatkin's (1995) linearized $F_{\mathrm{ST}}, F_{\mathrm{ST}} /\left(1-F_{\mathrm{ST}}\right)$ or $R_{\mathrm{ST}} /\left(1-R_{\mathrm{ST}}\right)$, was plotted against geographical distance or time to determine the significance of the relationship (Rousset 1997). The linear distance between sites was calculated as the shortest route between given coordinates of latitude and longitude using a great circle calculator with the WGS84 model (available at http://williams.best.vwh.net/gccalc.htm). Time was calculated as the number of years between sample collections.

\subsubsection{Effective migration, population bottlenecks, and cohort relatedness}

For within-ridge spatial samples, the effective number of migrants among populations $(\mathrm{Nm})$ was estimated using the rare alleles method implemented in GENEPOP ON THE WEB (Slatkin 1985, Barton \& Slatkin 1986). This overall estimate of gene flow is based on the average frequency of alleles found in only one population.

Populations and cohorts were tested for the presence of recent genetic bottlenecks using the program BOTTLENECK with the two-phased mutation model parameters of 30\% variance and 70\% SMM (Di Rienzo et al. 1994), 10000 iterations, and the Wilcoxon sign-test, recommended for suites of greater than 4 loci and any sample size ( $\mathrm{n}=15-40$ has most power).

Relatedness estimates were calculated using a method described originally by Blouin et al. (1996) and extended by Gerlach et al. (2001). In detail, the allele sharing coefficient, $M_{\mathrm{xy}}$, was calculated pairwise between individuals $x$ and $y$ of a subpopulation. To evaluate whether this observed $M_{\mathrm{xy}}$ value was significantly different from an expected value based on the frequency of alleles of the total population, the computer program randomly generated 200 pairs of individuals based on the allele frequency of the total population (combined subpopulations from a specific site). This value was considered the expected 
allele sharing coefficient of unrelated individuals. The expected allele sharing value of full-sibs was generated by randomly generating pairs and calculating the allele sharing coefficient of two of their offspring. The expected allele sharing coefficient of half-sibs was calculated by generating an individual with two potential mating partners and assessing how many alleles two randomly generated half-sibs would share. Using a logistic regression analysis (SAS Institute Inc. 1995), the probability of belonging to each of the three different groups (unrelated, half-sibs or full-sibs) was calculated for each $M_{\mathrm{xy}}$. This resulted in threshold values for full- and half sibs and unrelated individuals. To correct for type I error (unrelated animals which were misclassified as half- or full sibs

and vice versa), the distribution of $M_{\mathrm{xy}}$ of unrelated individuals and full- and half sibs was simulated. This analysis ran 1000 simulations based on the gene frequency of the total population at the same site. A G-test was performed to determine whether the observed number of half- and full-sibs were greater than in a randomly created subpopulation of the same size.

\subsection{Results}

\subsubsection{Genetic variability within ridge segments}

Four-hundred twenty-one Riftia individuals were analyzed from 12 populations (22 subpopulations) at eight polymorphic microsatellite loci. Within subpopulations, the number of individuals genotyped at each locus ranged from 31 to 38 along the $9^{\circ} \mathrm{N} \mathrm{EPR}$ segment and 9 to 25 along the $86^{\circ} \mathrm{W}$ GAR segment, due to sampling effort and habitat occupancy at specific vent sites. A subset of individuals was replicated per plate and between runs. All except two individuals at the Garden of Eden site were genotyped at all loci. Among subpopulations, the number of alleles sampled ranged from 13 (Rpa10CA06) to 30 (Rpa10CA02) and 7 to 20 (same loci) at $9^{\circ} \mathrm{N}$ and $86^{\circ} \mathrm{W}$, respectively, with mean allele counts of 21.9 and 13.5. 
Over all within-EPR and -GAR segment subpopulations, the total number of alleles per locus ranged from 17 (Rpa10CA06) to 42 (Rpa10CA02). Allelic richness normalized to a minimum of 9 individuals per sample ranged from 6.4 (Rpa10CA06, 86WGoE05a) to 14.2 (Rpa10CA02, 9NCC00) per locus and subpopulation (mean =10.8). As was found previously for these two mid-ocean ridges (Chapter 3), allelic richness within the $9^{\circ} \mathrm{N}$ EPR segment was significantly greater than that in the $86^{\circ} \mathrm{W}$ GAR region in an unpaired $t$-test (two-tailed $P<0.0001$ ).

Allele lengths ranged from $143 \mathrm{bp}$ (Rpa10CA02) to $277 \mathrm{bp}$ (R2D12). The most common alleles and their frequencies within subpopulations are provided in Table 4.3. 


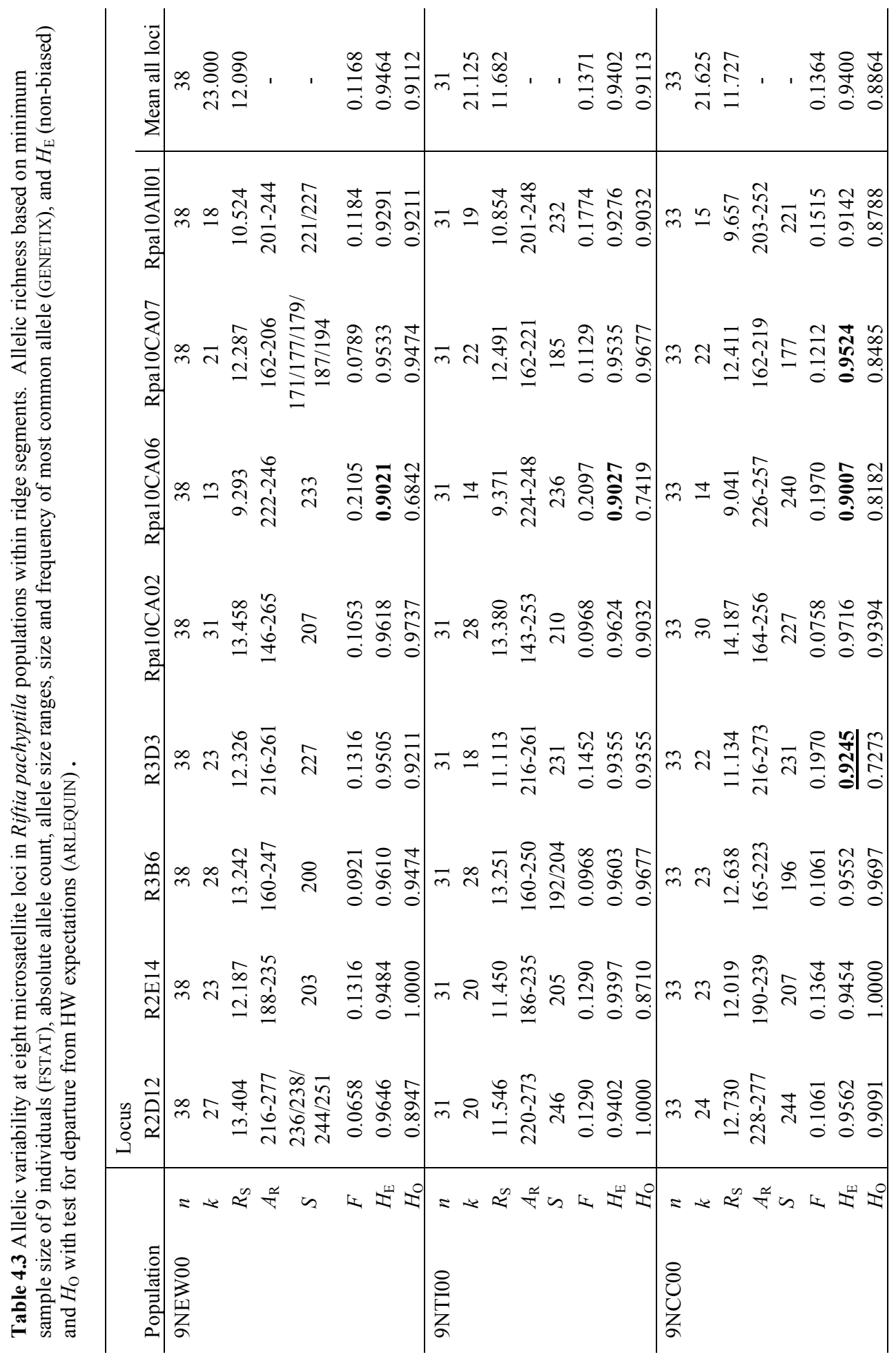




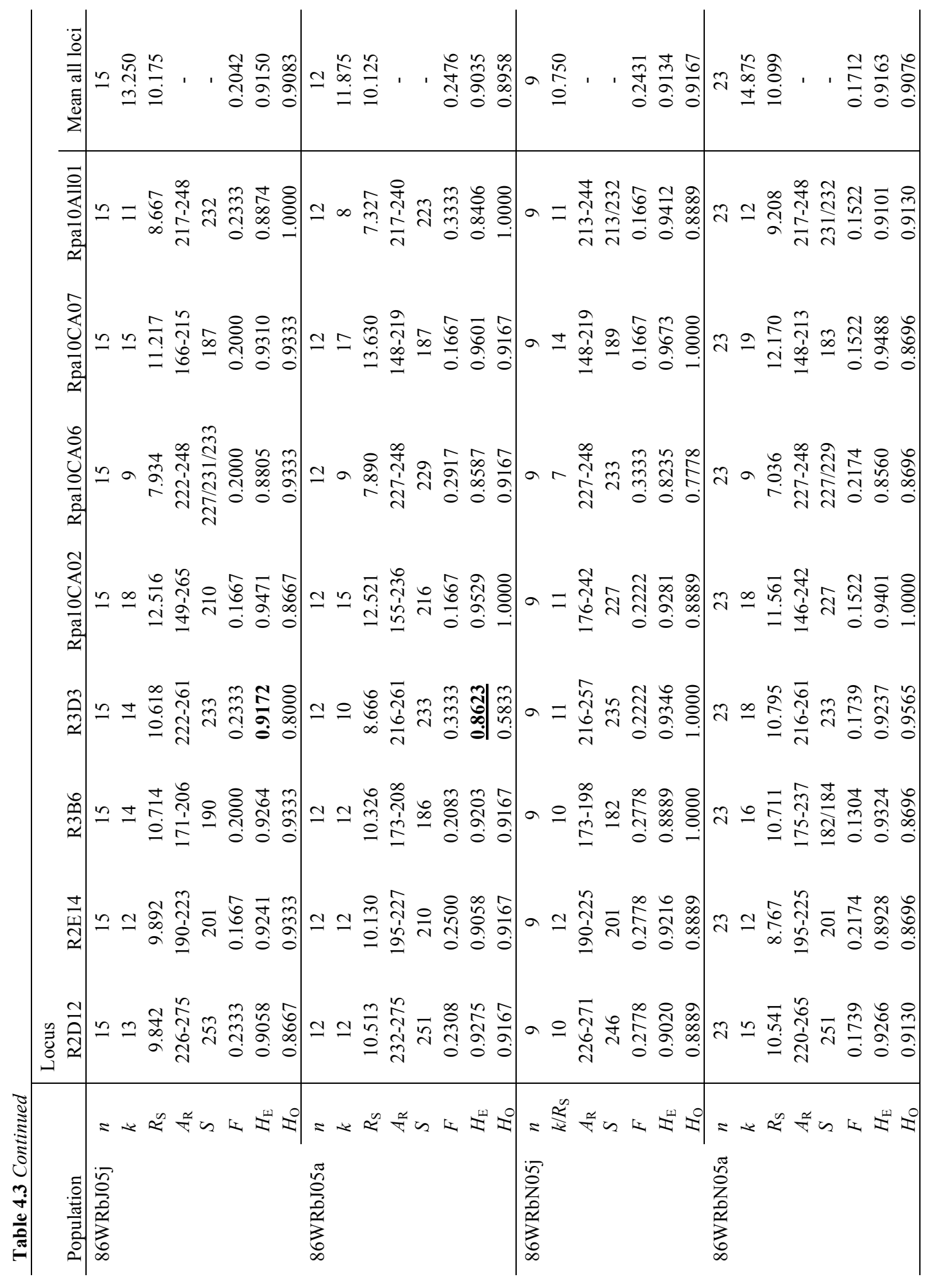




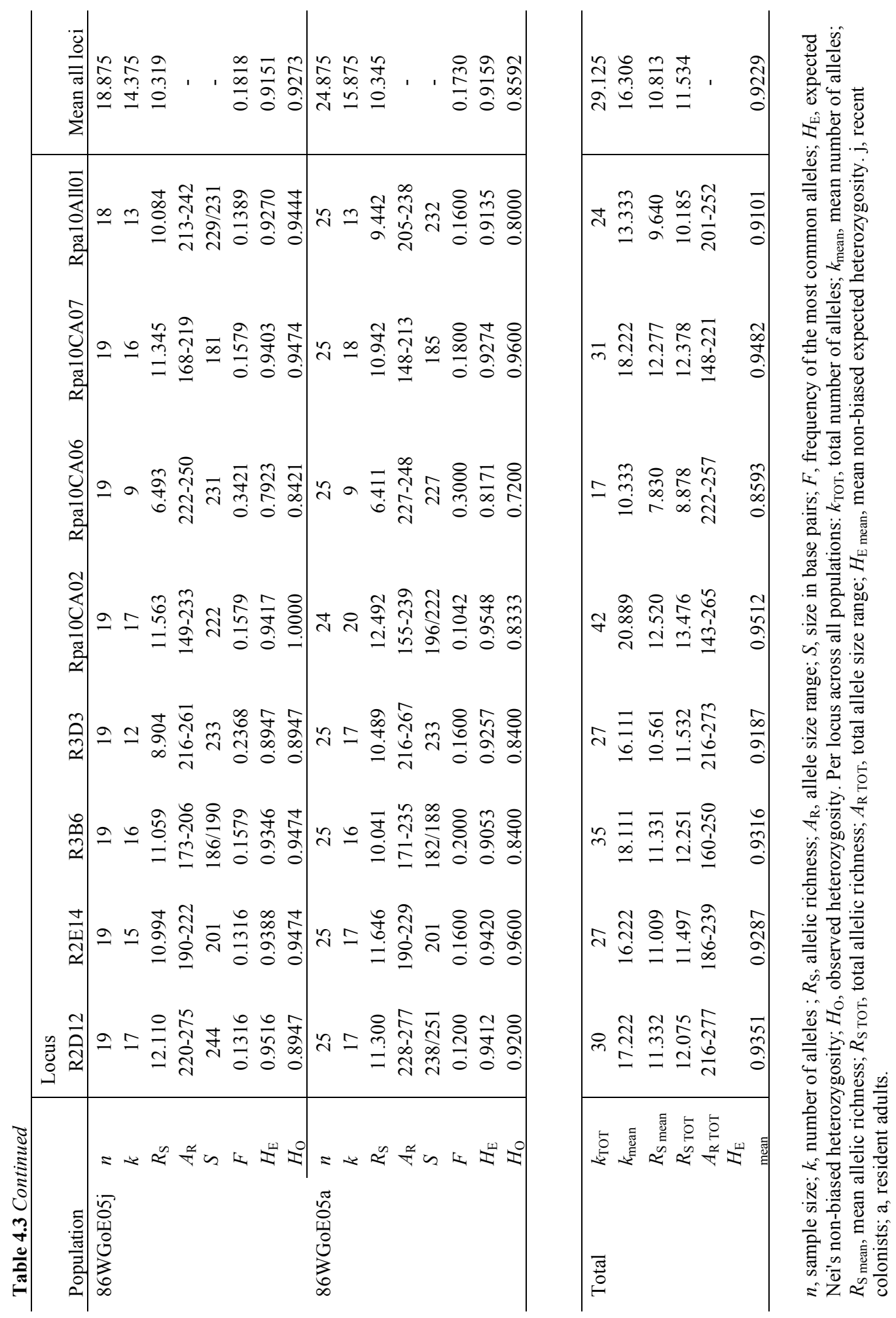




\subsubsection{Temporal genetic variability within sites}

Within subpopulations, the number of individuals genotyped at each locus ranged from 4 to 42 at Tica and from 10 to 54 at Rosebud, due to sampling effort and habitat occupancy in various years. A subset of individuals was replicated per plate and between runs. All except one Tica 2002 individual were genotyped at all loci. Among subpopulations, the number of alleles sampled ranged from 5 (Rpa10CA06) to 28 (R3B6, Rpa10CA02) at Tica and 7 (Rpa10CA06) to 27 (Rpa10CA02, Rpa10CA07) at Rosebud, with mean allele counts of 15.8 and 16.3 , respectively.

Over all cohorts, the total number of alleles per locus ranged from 18 (Rpa10CA06) to 42 (Rpa10CA02) at Tica and 14 to 32 (same loci) at Rosebud. Tica allelic richness normalized to a minimum of 4 individuals per sample ranged from 5 (Rpa10CA06, 9NTI05j) to 8 (Rpa10CA02, 9NTI04j) per locus and subpopulation ( mean $=6.63)$; Rosebud allelic richness normalized to a minimum of 10 individuals per sample ranged from 7 (Rpa10CA06, 86WRb02a) to 15 (Rpa10CA02, 86WRb02a) per locus and subpopulation $($ mean $=10.910)$. Where the most samples were collected over time, mean allelic richness in Tica juveniles tended to be greater in colonists than in residents. Allele lengths ranged from $143 \mathrm{bp}$ (Rpa10CA02) to $277 \mathrm{bp}$ (R2D12). Most common alleles and their frequencies within subpopulations are provided in Table 4.4. 


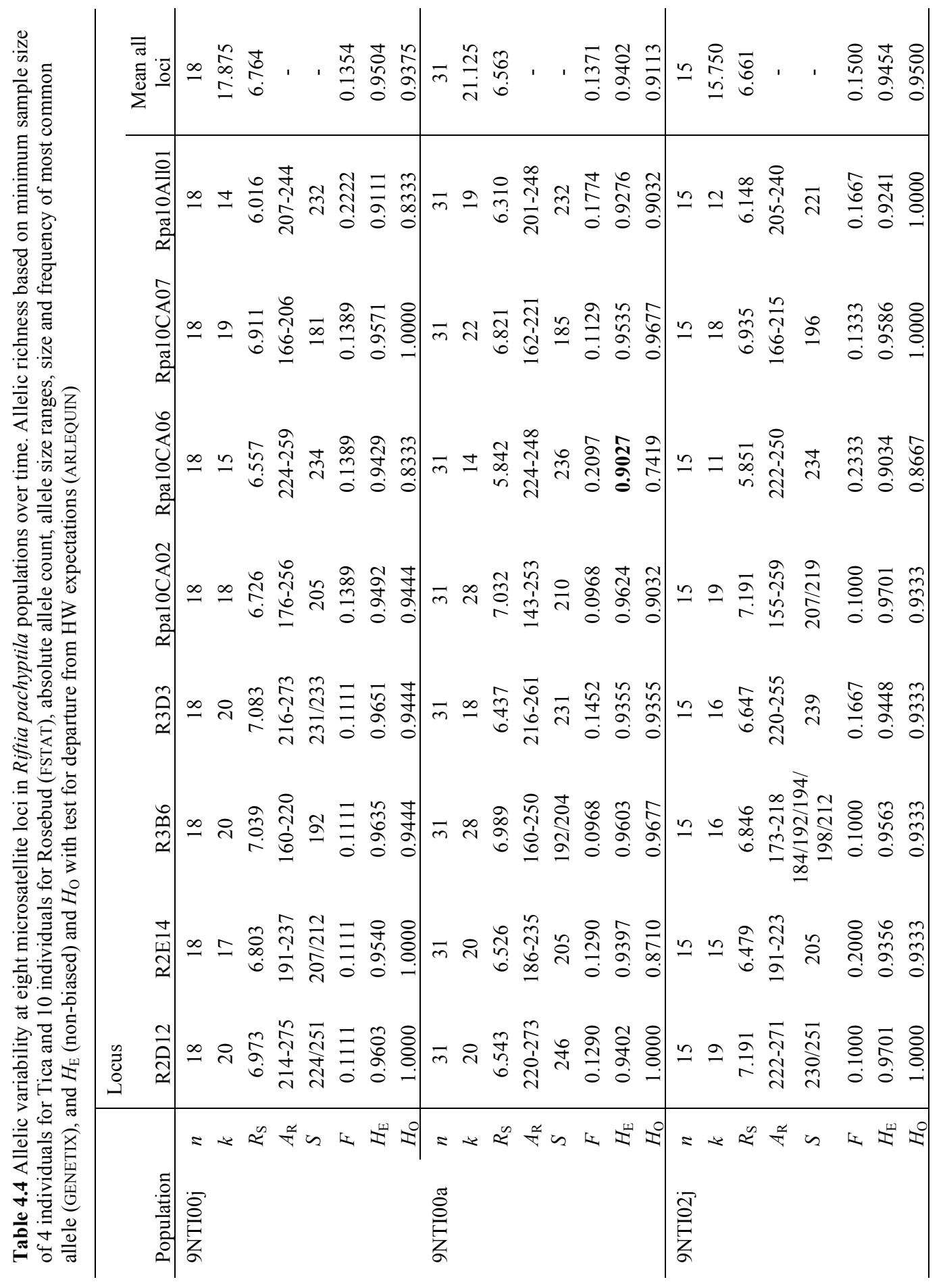




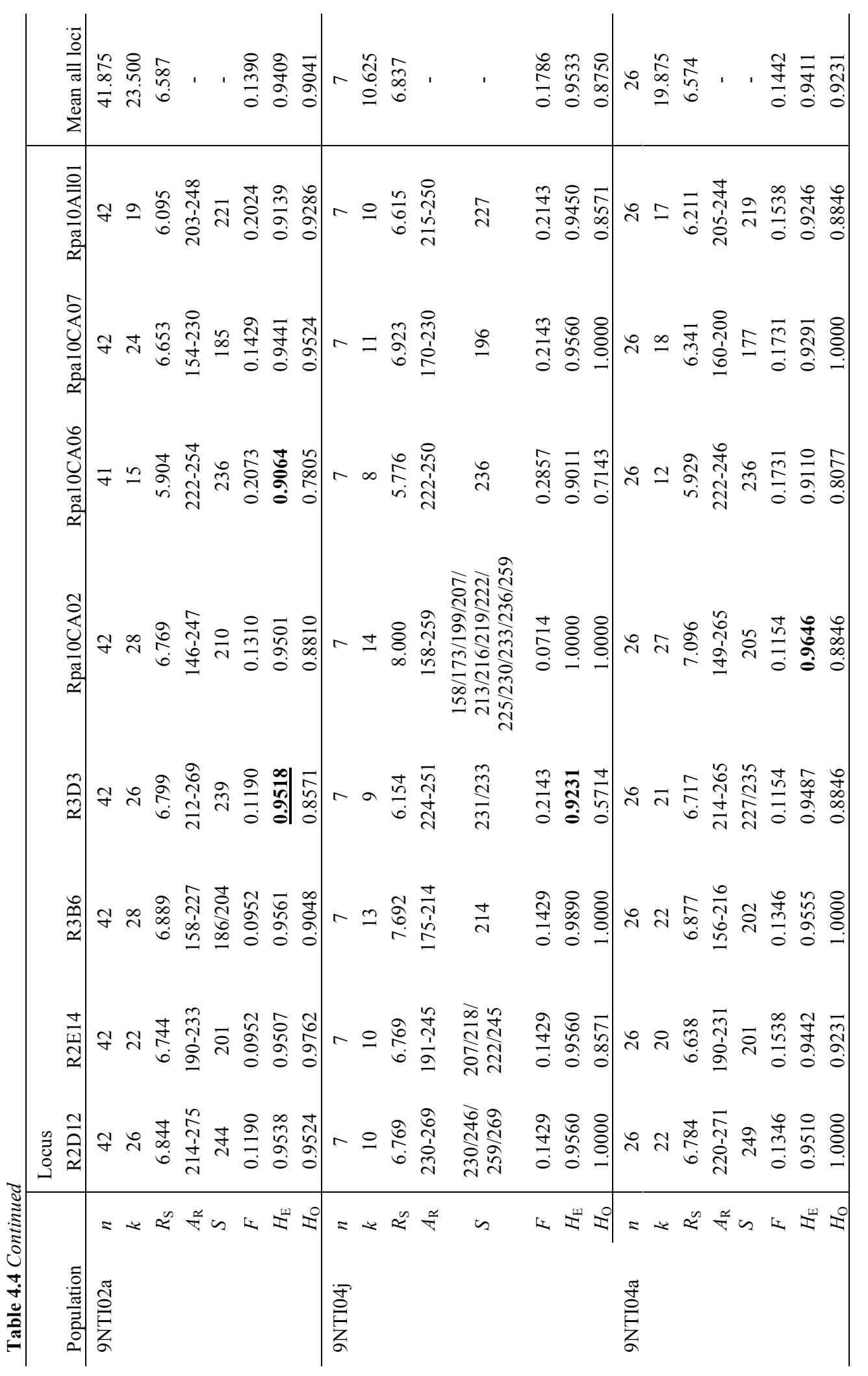




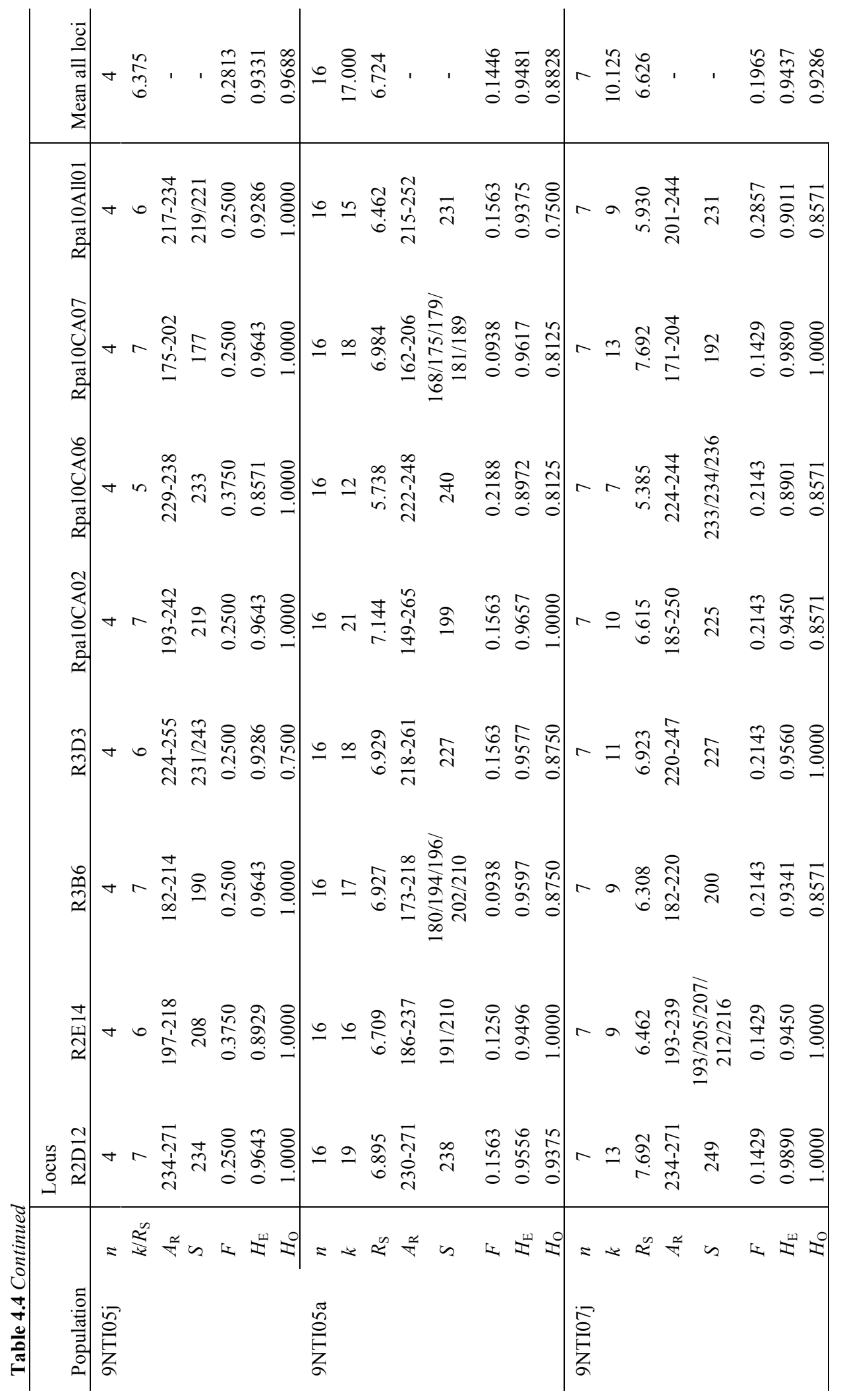




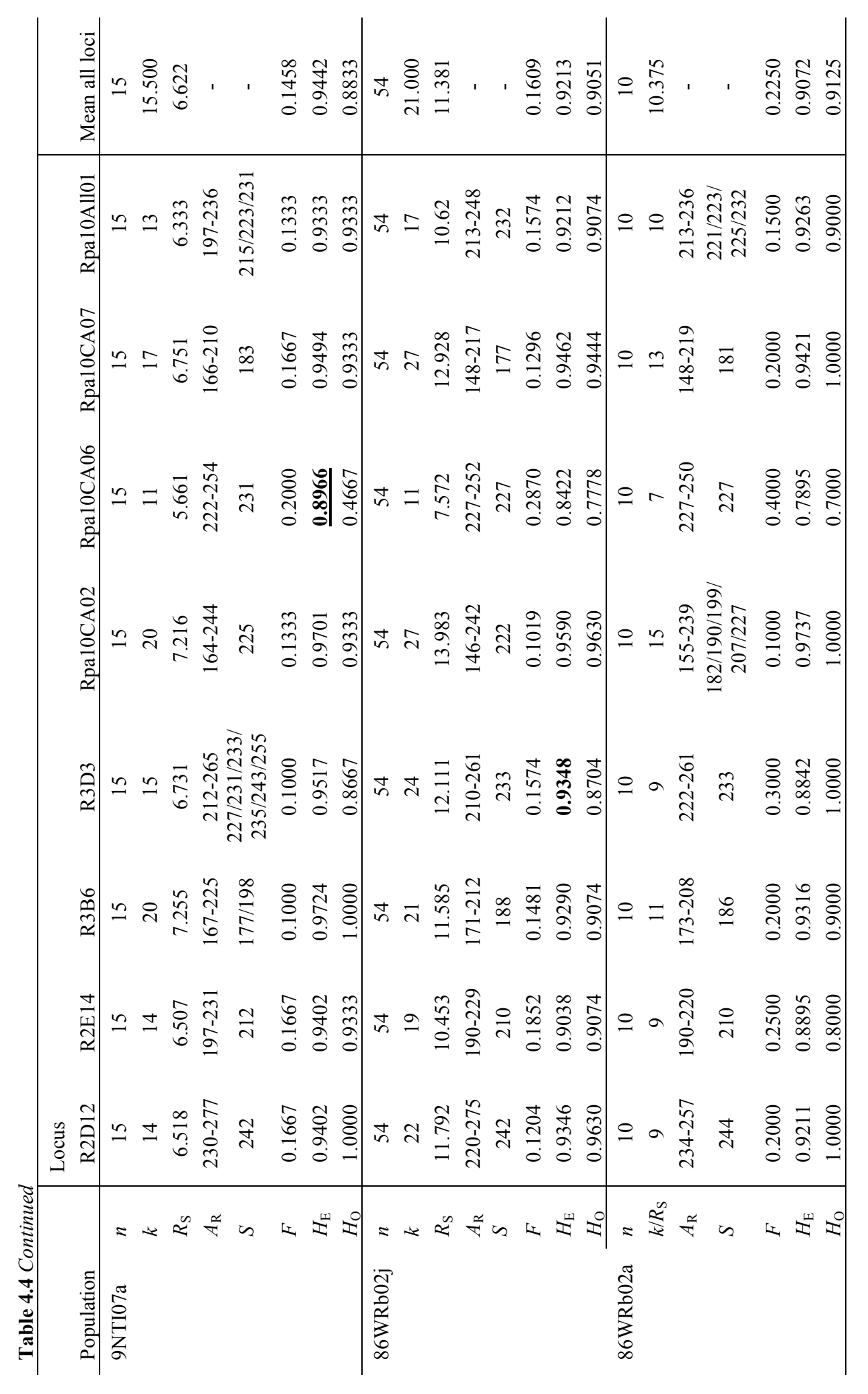




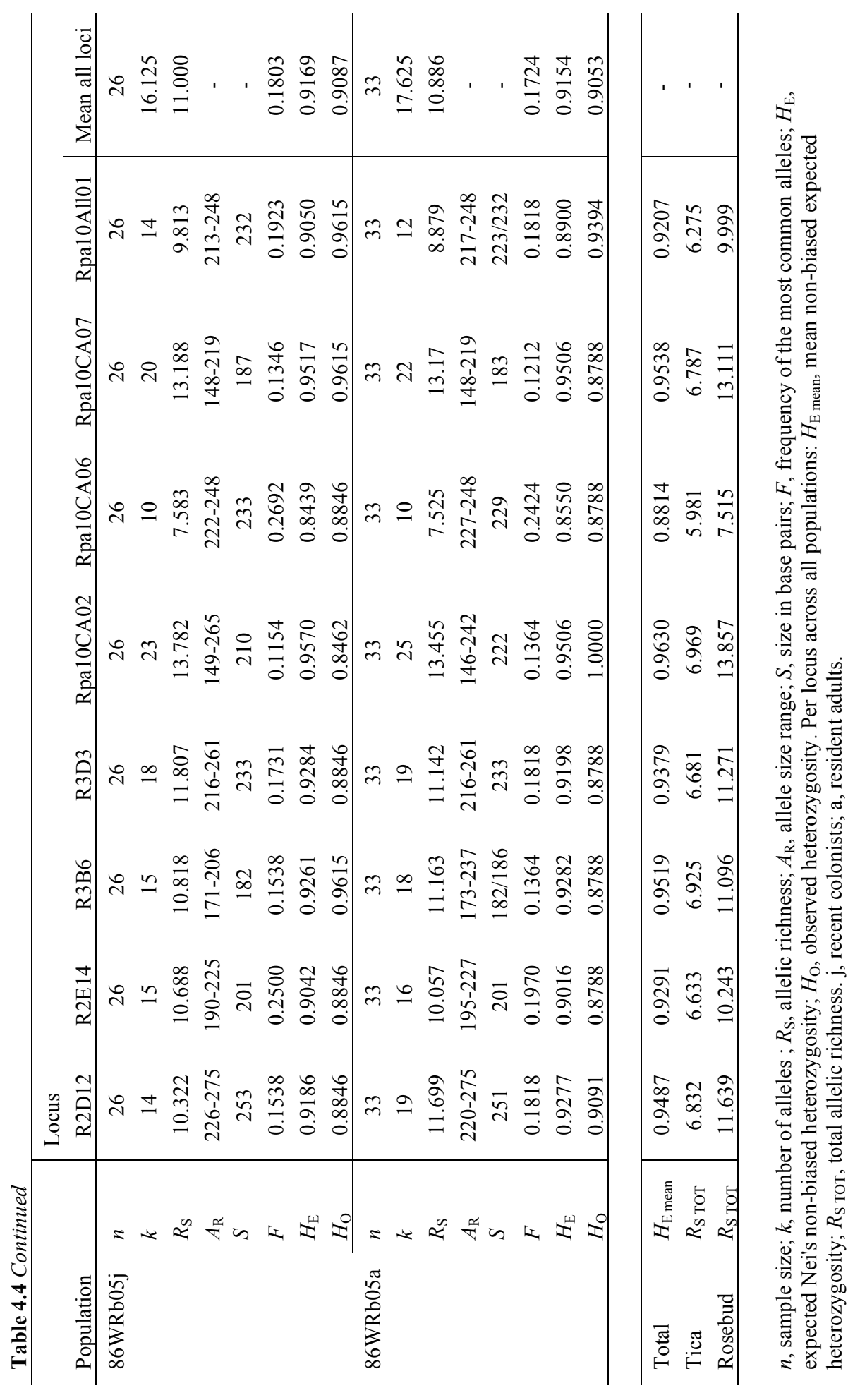




\subsubsection{Hardy-Weinberg equilibrium}

Non-biased expected heterozygosities were high across the intra-EPR segment (range $=$ 0.9007 to 0.9716 , mean $=0.9422$ ) and intra-GAR segment (range $=0.7923$ to 0.9673 , mean $=0.9132)$ subpopulations. Expected heterozygosity was also high across all cohorts at Tica $($ range $=0.8571$ to 1.000 , mean $=0.9440)$ and at Rosebud $($ range $=0.7895$ to 0.9737 , mean $=0.9152)$ in the temporal samples. Observed heterozygosity within the $9^{\circ} \mathrm{N}$ EPR segment subpopulations ranged from 0.6842 to $1.000($ mean $=0.9029)$ and across the $86^{\circ} \mathrm{W}$ GAR segment subpopulations ranged from 0.5833 to 1.000 (mean $\left.=0.9025\right)$. Observed heterozygosity across all temporal cohorts at Tica ranged from 0.4667 to 1.000 (mean $=0.9164)$ and across Rosebud temporal samples ranged from 0.7000 to 1.000 (mean $=0.9079)$. Mean heterozygosities (expected and observed) tended to be greater in colonist than in resident subpopulations (Tables $4.3 \& 4.4$ ).

MICRO-CHECKER suggested the potential excess of homozygotes at four loci (R3D3, Rpa10CA06, Rpa10CA07, Rpa10All01) in some subpopulations (5 of 72 tests in the within ridge segment spatial subpopulations and 7 of 144 tests in the temporal subpopulations suggested the presence of null alleles), but significant departure from HWE in single locus exact tests in ARLEQUIN only supported four heterozygote deficiencies $\left(9^{\circ} \mathrm{N}\right.$ EPR Choo Choo, $86^{\circ} \mathrm{W}$ GAR Rosebud Marker J residents, and $9^{\circ} \mathrm{N}$ EPR Tica 2002 residents at locus R3D3; and 9 ${ }^{\circ} \mathrm{N}$ EPR Tica 2007 residents at locus Rpa10CA06) at a Bonferroni-corrected nominal significance level of 0.05 (Tables 4.3 \& 4.4). In FSTAT, all except three (Rpa10CA06, 9NEW00; R3D3, 9NCC00; Rpa10CA06,

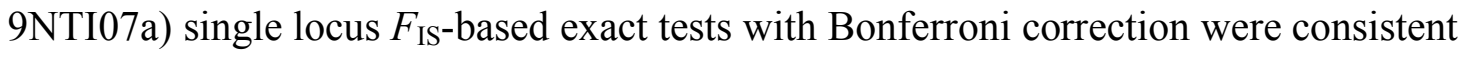
with Hardy-Weinberg equilibrium expectations in the absence of inbreeding (Tables 4.5$4.8)$.

All pairs of loci were found to be in genotypic equilibrium. 


\begin{tabular}{|c|c|}
\hline 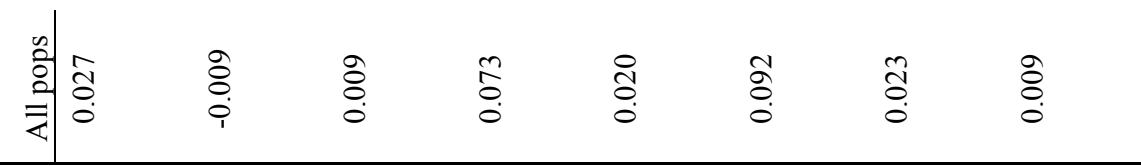 & \\
\hline 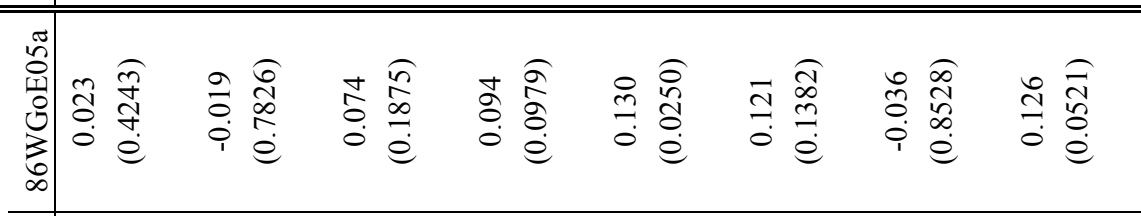 & 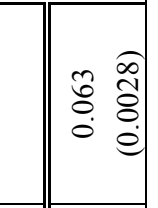 \\
\hline 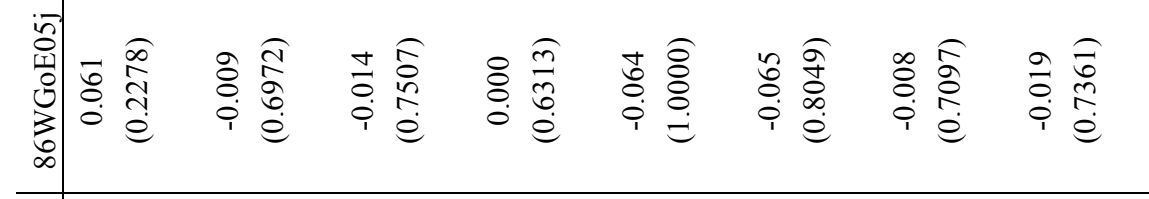 & 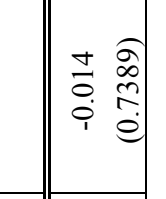 \\
\hline 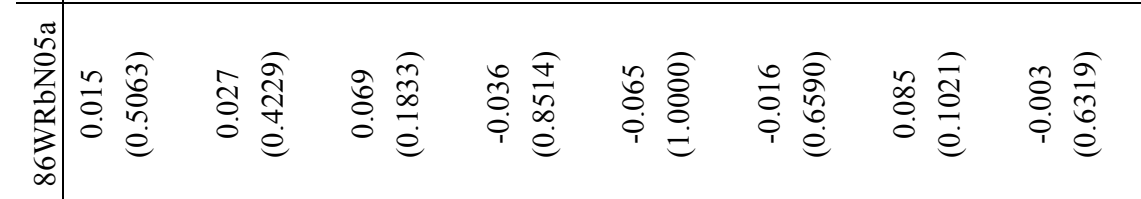 & 彭 \\
\hline 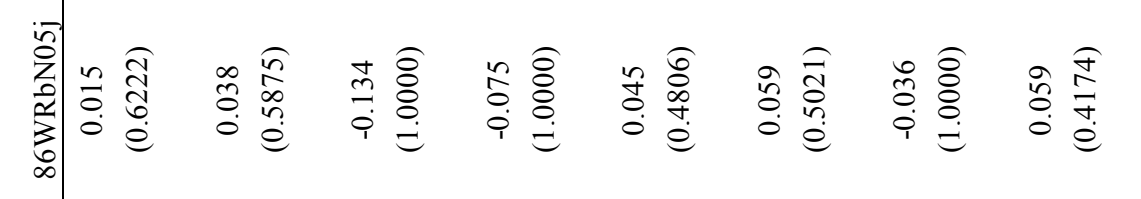 & 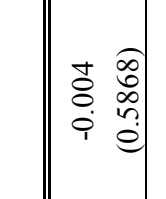 \\
\hline 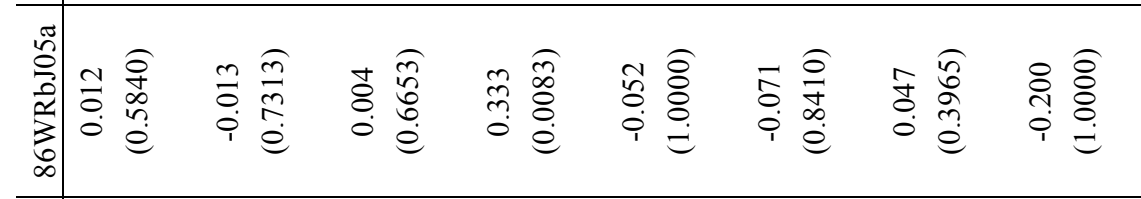 & 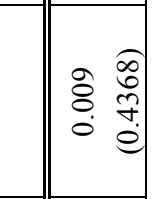 \\
\hline 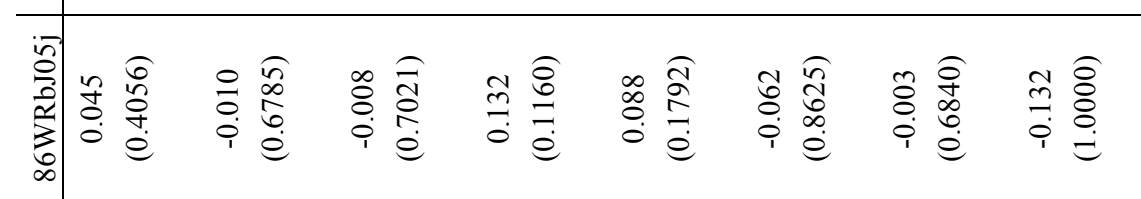 & 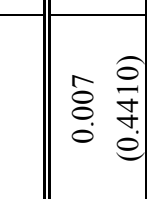 \\
\hline 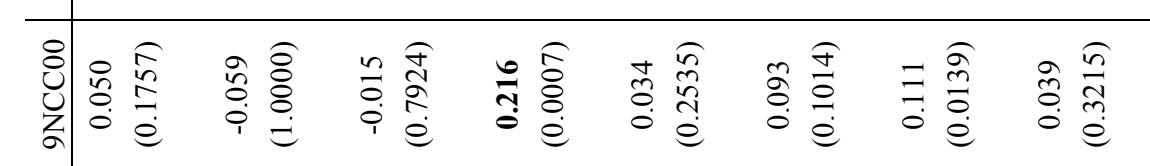 & 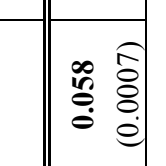 \\
\hline 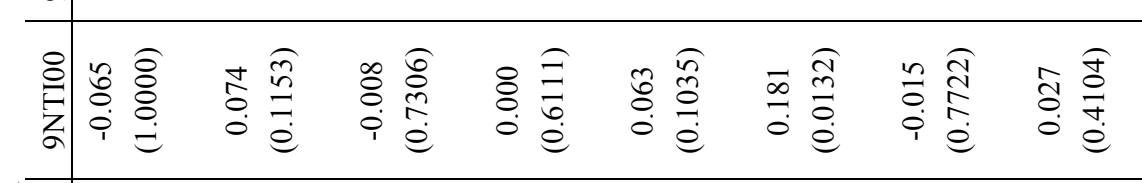 & 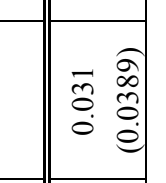 \\
\hline 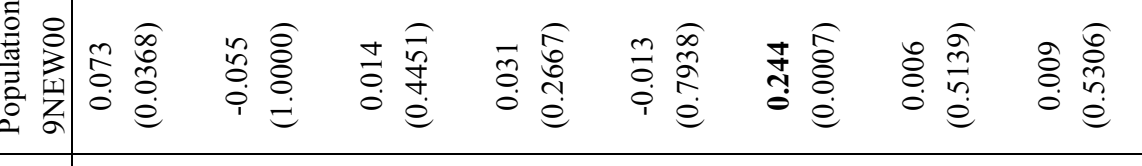 & 善喜 \\
\hline 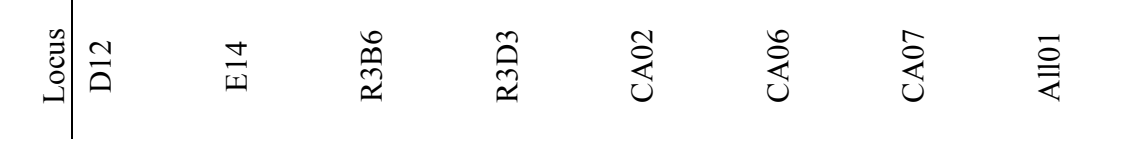 & \\
\hline
\end{tabular}




\begin{tabular}{|c|c|c|c|c|c|c|c|c|c|}
\hline 8 & I & : & 号 & $\begin{array}{l}8 \\
\vdots \\
0\end{array}$ & 㮫 & $\stackrel{n}{0}$ & స̃ & 商 & 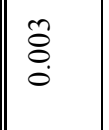 \\
\hline & & 象 & 密 & 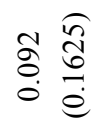 & 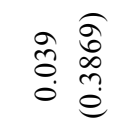 & 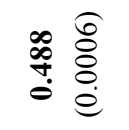 & 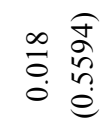 & 总 & 它: \\
\hline है & 产 & 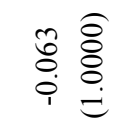 & 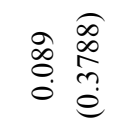 & 㑒 & 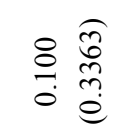 & 嘱高 & 产 & 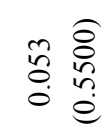 & 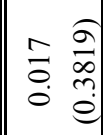 \\
\hline & & 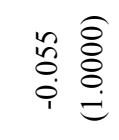 & 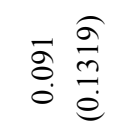 & 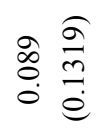 & 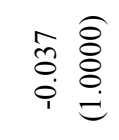 & 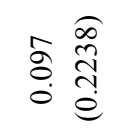 & 官 & 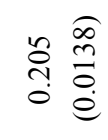 & $\begin{array}{ll}\overrightarrow{5} \\
\overrightarrow{0} \\
0 \\
0\end{array}$ \\
\hline & & 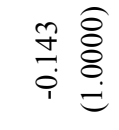 & 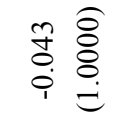 & 동 & 管 & 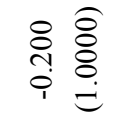 & 管 & 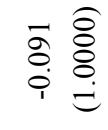 & $\begin{array}{l}\text { 筞動 } \\
\text { i }\end{array}$ \\
\hline & & 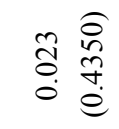 & 亳 & 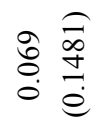 & 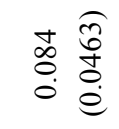 & 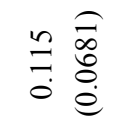 & 童 & 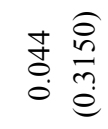 & 高 \\
\hline & & 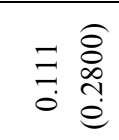 & 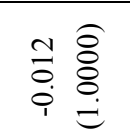 & 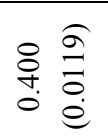 & 客 & तี & 品 & 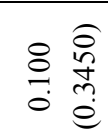 & 离 \\
\hline & 密 & 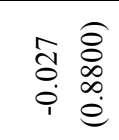 & 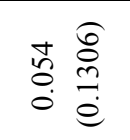 & 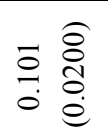 & 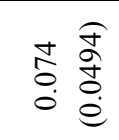 & 导高 & & 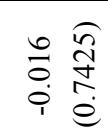 & 导产 \\
\hline & 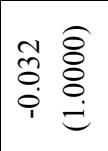 & 兽 & 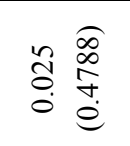 & $\begin{array}{l}m \\
\text { âd } \\
\text { o }\end{array}$ & 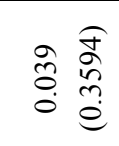 & 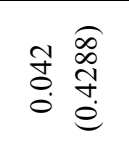 & 话 & 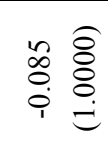 & 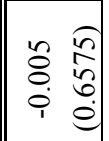 \\
\hline & 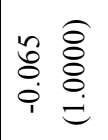 & 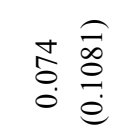 & $\begin{array}{l}\infty \\
\stackrel{0}{0} \\
\dot{i} \\
\dot{i}\end{array}$ & 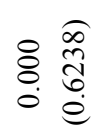 & 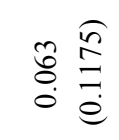 & 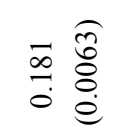 & $\begin{array}{ll}n & \hat{R} \\
0 & 0 \\
i & 0 \\
\dot{e}\end{array}$ & 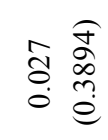 & 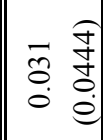 \\
\hline & 旁高 & 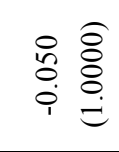 & 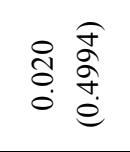 & 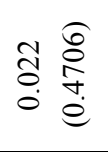 & 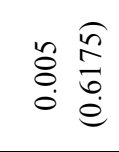 & 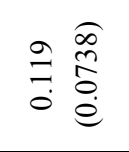 & 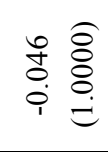 & 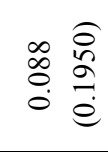 & 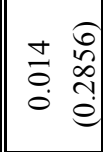 \\
\hline & & $\stackrel{ \pm}{\Psi}$ & $\begin{array}{l}\text { D. } \\
\stackrel{0}{\approx}\end{array}$ & ڤิ & 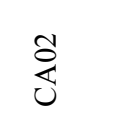 & 过 & 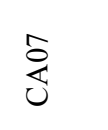 & $\overline{\bar{z}}$ & $\frac{\bar{g}}{\bar{z}}$ \\
\hline
\end{tabular}


Table 4.7 Rosebud temporal $F_{\text {IS }}$ per locus and subpopulation, with cohorts separated by marker B, J=F, and N (FSTAT). $P$ values in parentheses (1280 randomizations).

\begin{tabular}{|c|c|c|c|c|c|c|c|c|c|}
\hline Locus & $\begin{array}{l}\text { Populatio } \\
\text { RbB02j }\end{array}$ & $\mathrm{RbB} 02 \mathrm{a}$ & $\mathrm{RbJ} 02 \mathrm{j}$ & $\mathrm{RbJ} 02 \mathrm{a}$ & $\mathrm{RbF} 05 \mathrm{j}$ & $\mathrm{RbF} 05 \mathrm{a}$ & $\mathrm{RbN} 05 \mathrm{j}$ & $\mathrm{RbN05a}$ & $\begin{array}{c}\text { All } \\
\text { pops }\end{array}$ \\
\hline D12 & $\begin{array}{c}-0.062 \\
(1.0000)\end{array}$ & $\begin{array}{c}-0.091 \\
(1.0000)\end{array}$ & $\begin{array}{c}0.006 \\
(0.5766)\end{array}$ & $\begin{array}{c}-0.063 \\
(1.0000)\end{array}$ & $\begin{array}{c}0.030 \\
(0.4898)\end{array}$ & $\begin{array}{c}0.041 \\
(0.4836)\end{array}$ & $\begin{array}{c}0.015 \\
(0.6344)\end{array}$ & $\begin{array}{c}0.015 \\
(0.5070)\end{array}$ & -0.005 \\
\hline E14 & $\begin{array}{c}0.049 \\
(0.2875)\end{array}$ & $\begin{array}{c}0.200 \\
(0.4563)\end{array}$ & $\begin{array}{c}-0.054 \\
(0.8828)\end{array}$ & $\begin{array}{c}0.014 \\
(0.6922)\end{array}$ & $\begin{array}{c}0.030 \\
(0.4914)\end{array}$ & $\begin{array}{c}0.036 \\
(0.5125)\end{array}$ & $\begin{array}{c}0.038 \\
(0.5766)\end{array}$ & $\begin{array}{c}0.027 \\
(0.4578)\end{array}$ & 0.017 \\
\hline R3B6 & $\begin{array}{c}0.038 \\
(0.3797)\end{array}$ & $\begin{array}{c}0.200 \\
(0.5992)\end{array}$ & $\begin{array}{c}0.007 \\
(0.5586)\end{array}$ & $\begin{array}{c}-0.050 \\
(1.0000)\end{array}$ & $\begin{array}{l}-0.010 \\
(0.7109)\end{array}$ & $\begin{array}{c}0.036 \\
(0.5008)\end{array}$ & $\begin{array}{l}-0.134 \\
(1.0000)\end{array}$ & $\begin{array}{c}0.069 \\
(0.2109)\end{array}$ & 0.016 \\
\hline R3D3 & $\begin{array}{c}0.032 \\
(0.3727)\end{array}$ & $\begin{array}{c}-0.200 \\
(1.0000)\end{array}$ & $\begin{array}{c}0.099 \\
(0.0672)\end{array}$ & $\begin{array}{c}-0.120 \\
(1.0000)\end{array}$ & $\begin{array}{c}0.115 \\
(0.1258)\end{array}$ & $\begin{array}{c}0.246 \\
(0.0391)\end{array}$ & $\begin{array}{c}-0.075 \\
(1.0000)\end{array}$ & $\begin{array}{c}-0.036 \\
(0.8539)\end{array}$ & 0.044 \\
\hline CA02 & $\begin{array}{c}0.038 \\
(0.3070)\end{array}$ & $\begin{array}{c}0.000 \\
(1.0000)\end{array}$ & $\begin{array}{c}-0.038 \\
(1.0000)\end{array}$ & $\begin{array}{c}-0.024 \\
(1.0000)\end{array}$ & $\begin{array}{c}0.130 \\
(0.0602)\end{array}$ & $\begin{array}{c}-0.053 \\
(1.0000)\end{array}$ & $\begin{array}{c}0.045 \\
(0.5016)\end{array}$ & $\begin{array}{c}-0.065 \\
(1.0000)\end{array}$ & 0.002 \\
\hline CA06 & $\begin{array}{c}0.063 \\
(0.3336)\end{array}$ & $\begin{array}{c}0.111 \\
(0.5859)\end{array}$ & $\begin{array}{c}0.084 \\
(0.1852)\end{array}$ & $\begin{array}{c}0.167 \\
(0.2789)\end{array}$ & $\begin{array}{c}-0.080 \\
(0.9203)\end{array}$ & $\begin{array}{c}-0.052 \\
(0.8070)\end{array}$ & $\begin{array}{c}0.059 \\
(0.5219)\end{array}$ & $\begin{array}{c}-0.016 \\
(0.6734)\end{array}$ & 0.030 \\
\hline CA07 & $\begin{array}{c}0.071 \\
(0.1547)\end{array}$ & $\begin{array}{c}-0.091 \\
(1.0000)\end{array}$ & $\begin{array}{c}-0.052 \\
(1.0000)\end{array}$ & $\begin{array}{c}-0.063 \\
(1.0000)\end{array}$ & $\begin{array}{c}0.004 \\
(0.6266)\end{array}$ & $\begin{array}{c}0.047 \\
(0.4563)\end{array}$ & $\begin{array}{c}-0.036 \\
(1.0000)\end{array}$ & $\begin{array}{c}0.085 \\
(0.0984)\end{array}$ & 0.015 \\
\hline All01 & $\begin{array}{c}-0.006 \\
(0.6445)\end{array}$ & $\begin{array}{c}0.000 \\
(1.0000)\end{array}$ & $\begin{array}{c}0.035 \\
(0.3484)\end{array}$ & $\begin{array}{c}0.089 \\
(0.3891)\end{array}$ & $\begin{array}{c}-0.136 \\
(1.0000)\end{array}$ & $\begin{array}{c}-0.233 \\
(1.0000)\end{array}$ & $\begin{array}{c}0.059 \\
(0.4227)\end{array}$ & $\begin{array}{c}-0.003 \\
(0.6359)\end{array}$ & -0.019 \\
\hline All loci & $\begin{array}{c}0.027 \\
(0.1219) \\
\end{array}$ & $\begin{array}{c}0.012 \\
(0.5570)\end{array}$ & $\begin{array}{c}0.010 \\
(0.3398) \\
\end{array}$ & $\begin{array}{c}-0.008 \\
(0.6734)\end{array}$ & $\begin{array}{c}0.012 \\
(0.3570) \\
\end{array}$ & $\begin{array}{c}0.013 \\
(0.4000) \\
\end{array}$ & $\begin{array}{r}-0.004 \\
(0.6242)\end{array}$ & $\begin{array}{c}0.010 \\
(0.3586)\end{array}$ & 0.012 \\
\hline
\end{tabular}


Table 4.8 Rosebud temporal $F_{\text {IS }}$ per locus and subpopulation, with cohorts designated by year and sampling markers combined (FSTAT). $P$ values in parentheses (640 randomizations).

\begin{tabular}{|c|c|c|c|c|c|}
\hline Locus & $\begin{array}{c}\text { Population } \\
\mathrm{Rb} 02 \mathrm{j}\end{array}$ & $\mathrm{Rb} 02 \mathrm{a}$ & $\mathrm{Rb} 05 \mathrm{j}$ & $\mathrm{Rb} 05 \mathrm{a}$ & $\begin{array}{c}\text { All } \\
\text { pops }\end{array}$ \\
\hline D12 & $\begin{array}{c}-0.031 \\
(0.8734)\end{array}$ & $\begin{array}{c}-0.091 \\
(1.0000)\end{array}$ & $\begin{array}{c}0.038 \\
(0.3359)\end{array}$ & $\begin{array}{c}0.020 \\
(0.4734)\end{array}$ & -0.007 \\
\hline E14 & $\begin{array}{c}-0.004 \\
(0.6172)\end{array}$ & $\begin{array}{c}0.106 \\
(0.2938)\end{array}$ & $\begin{array}{c}0.022 \\
(0.4406)\end{array}$ & $\begin{array}{c}0.026 \\
(0.3891)\end{array}$ & 0.018 \\
\hline R3B6 & $\begin{array}{c}0.024 \\
(0.3438)\end{array}$ & $\begin{array}{c}0.036 \\
(0.5016)\end{array}$ & $\begin{array}{c}-0.039 \\
(0.8766)\end{array}$ & $\begin{array}{c}0.054 \\
(0.2281)\end{array}$ & 0.020 \\
\hline R3D3 & $\begin{array}{c}0.069 \\
(0.0656)\end{array}$ & $\begin{array}{c}-0.139 \\
(1.0000)\end{array}$ & $\begin{array}{c}0.048 \\
(0.275)\end{array}$ & $\begin{array}{c}0.045 \\
(0.2844)\end{array}$ & 0.043 \\
\hline CA02 & $\begin{array}{c}-0.004 \\
(0.6594)\end{array}$ & $\begin{array}{c}-0.029 \\
(1.0000)\end{array}$ & $\begin{array}{c}0.118 \\
(0.0203)\end{array}$ & $\begin{array}{c}-0.053 \\
(1.0000)\end{array}$ & 0.007 \\
\hline CA06 & $\begin{array}{c}0.077 \\
(0.1250)\end{array}$ & $\begin{array}{c}0.119 \\
(0.3469)\end{array}$ & $\begin{array}{c}-0.049 \\
(0.8094)\end{array}$ & $\begin{array}{c}-0.028 \\
(0.7125)\end{array}$ & 0.025 \\
\hline CA07 & $\begin{array}{c}0.002 \\
(0.5594)\end{array}$ & $\begin{array}{c}-0.065 \\
(1.0000)\end{array}$ & $\begin{array}{c}-0.011 \\
(0.7297)\end{array}$ & $\begin{array}{c}0.077 \\
(0.0766)\end{array}$ & 0.014 \\
\hline All01 & $\begin{array}{c}0.015 \\
(0.4391)\end{array}$ & $\begin{array}{c}0.030 \\
(0.5719)\end{array}$ & $\begin{array}{c}-0.064 \\
(0.9313)\end{array}$ & $\begin{array}{c}-0.056 \\
(0.8984)\end{array}$ & -0.019 \\
\hline All loci & $\begin{array}{c}0.018 \\
(0.1109)\end{array}$ & $\begin{array}{c}-0.006 \\
(0.6594)\end{array}$ & $\begin{array}{c}0.009 \\
(0.3438)\end{array}$ & $\begin{array}{c}0.011 \\
(0.3250)\end{array}$ & 0.012 \\
\hline
\end{tabular}




\subsubsection{Allelic and genotypic variation}

The three resident subpopulations considered within the $9^{\circ} \mathrm{N}$ EPR ridge segment were homogenous in terms of genic and genotypic variation (Table 4.9a). Among populations within the $86^{\circ} \mathrm{W}$ GAR region, genic differentiation over all loci was significant $(P=0.03$ for pooled populations, $P=0.02$ for subpopulations), with the largest contribution coming from locus Rpa10CA02; the level of genotypic variation over all loci was similar ( $P=0.07$ for pooled populations, $P=0.04$ for subpopulations; Tables $4.9 \mathrm{~b}-\mathrm{c}$ ).

Temporally, only genic differentiation over all loci was significant among Tica pooled populations $(P=0.04)$, with the largest contribution coming from loci Rpa10CA06 and Rpa10Al101 (Tables 4.10a-b). There was no differentiation detected among years at Rosebud, with populations or subpopulations pooled by year or separated as discrete patches by their collection marker and year (Tables $4.10 \mathrm{c}-\mathrm{e})$.

\subsubsection{Pairwise genetic differentiation}

Per locus $F_{\mathrm{ST}}$ estimates over all populations within a ridge segment or over time were very small, ranging from -0.004 to 0.004 on the $9^{\circ} \mathrm{N}$ EPR segment (overall $=-0.001$ ), -0.006 to 0.009 on the $86^{\circ} \mathrm{W}$ GAR segment (overall $=0.002$ ), from -0.005 to 0.004 at Tica (overall $=0$ ), and from -0.008 to 0.005 at Rosebud (overall $=-0.001)$ (Tables 11a-d).

Pairwise $F_{\mathrm{ST}}$ and $R_{\mathrm{ST}}$ values for $86^{\circ} \mathrm{W}$ GAR pooled populations as estimated in ARLEQUIN were as large as 0.004 and 0.03 , respectively — the latter being significantly greater than 0 (between Rosebud Markers J and N).

Pairwise $F_{\text {ST }}$ of resident populations ranged at $9^{\circ} \mathrm{N}$ EPR from -0.00037 to 0.00008 and of pooled populations at $86^{\circ} \mathrm{W}$ GAR from 0.00197 to 0.00420 . Subpopulation pairwise $F_{\text {ST }}$ estimates at $86^{\circ} \mathrm{W}$ GAR ranged from -0.00336 to $0.01277(P=0.05354)$. Between colonists and residents at the same site, genetic differences at $86^{\circ} \mathrm{W}$ were smaller than 
Table 4.9 Spatial differentiation over all populations (GENEPOP ON THE WEB: 5000 dememorization steps, 500 batches, 2000 iterations per batch). Bold $P$ values are significant with sequential Bonferroni correction for 8 tests at a level of $5 \%$.

a. Within the $9^{\circ} \mathrm{N}$ EPR segment

\begin{tabular}{lccccc}
\hline & \multicolumn{2}{c}{ Genic (allelic) } & & \multicolumn{2}{c}{ Genotypic } \\
\cline { 2 - 3 } \cline { 5 - 6 } Locus & $P$ value & S.E. & & $P$ value & S.E. \\
\hline R2D12 & 0.82234 & 0.00427 & & 0.7849 & 0.0051 \\
R2E14 & 0.68636 & 0.00563 & & 0.6953 & 0.0058 \\
R3B6 & 0.83553 & 0.00423 & & 0.9176 & 0.0031 \\
R3D3 & 0.09710 & 0.00356 & & 0.1717 & 0.0044 \\
CA02 & 0.75646 & 0.00534 & & 0.8593 & 0.0042 \\
CA06 & 0.32288 & 0.00505 & & 0.5596 & 0.0057 \\
CA07 & 0.64616 & 0.00563 & & 0.6070 & 0.0063 \\
All01 & 0.64188 & 0.00566 & & 0.7490 & 0.0051 \\
\hline All loci & 0.82485 & & 0.9504 & \\
\hline
\end{tabular}

b. Within the $86^{\circ} \mathrm{W}$ GAR segment, pooled populations

\begin{tabular}{lccccc}
\hline & \multicolumn{2}{c}{ Genic (allelic) } & & \multicolumn{2}{c}{ Genotypic } \\
\cline { 2 - 3 } \cline { 5 - 6 } Locus & $P$ value & S.E. & & $P$ value & S.E. \\
\hline R2D12 & 0.07815 & 0.00335 & & 0.0687 & 0.0029 \\
R2E14 & 0.57583 & 0.00514 & & 0.3874 & 0.0058 \\
R3B6 & 0.82525 & 0.00425 & & 0.8813 & 0.0033 \\
R3D3 & 0.26343 & 0.00574 & & 0.3995 & 0.0064 \\
CA02 & $\mathbf{0 . 0 0 3 8 7}$ & 0.00062 & & 0.0090 & 0.0009 \\
CA06 & 0.46769 & 0.00542 & & 0.5499 & 0.0049 \\
CA07 & 0.16319 & 0.00467 & & 0.3925 & 0.0067 \\
Al101 & 0.24350 & 0.00478 & & 0.2295 & 0.0048 \\
\hline All loci & $\mathbf{0 . 0 2 8 8 3}$ & & 0.0738 & \\
\hline
\end{tabular}

c. Within the $86^{\circ} \mathrm{W}$ GAR segment, separate subpopulations

\begin{tabular}{lccccc}
\hline & \multicolumn{2}{c}{ Genic (allelic) } & & \multicolumn{2}{c}{ Genotypic } \\
\cline { 2 - 3 } \cline { 5 - 6 } Locus & $P$ value & S.E. & & $P$ value & S.E. \\
\hline R2D12 & 0.05146 & 0.00372 & & 0.0345 & 0.0036 \\
R2E14 & 0.83541 & 0.00528 & & 0.7510 & 0.0092 \\
R3B6 & 0.58746 & 0.00915 & & 0.7143 & 0.0099 \\
R3D3 & 0.13824 & 0.00598 & & 0.2017 & 0.0088 \\
CA02 & $\mathbf{0 . 0 0 1 9 9}$ & 0.00049 & & $\mathbf{0 . 0 0 2 8}$ & 0.0011 \\
CA06 & 0.55796 & 0.00735 & & 0.6819 & 0.0079 \\
CA07 & 0.24172 & 0.00802 & & 0.3609 & 0.0118 \\
All01 & 0.42492 & 0.00811 & & 0.4166 & 0.0109 \\
\hline All loci & $\mathbf{0 . 0 2 0 9 6}$ & & $\mathbf{0 . 0 3 6 1}$ \\
\hline
\end{tabular}


Table 4.10 Differentiation over all temporal populations (GENEPOP ON THE WEB: 5000 dememorization steps, 500 batches, 2000 iterations per batch). Bold $P$ values are significant with sequential Bonferroni correction for 8 tests at a level of $5 \%$.

a. Tica pooled populations

\begin{tabular}{l|cc|cc}
\hline & \multicolumn{2}{|l|}{ Genic (allelic) } & Genotypic & \\
Locus & $P$ value & S.E. & $P$ value & S.E. \\
\hline R2D12 & 0.96340 & 0.00258 & 0.9005 & 0.0066 \\
R2E14 & 0.30906 & 0.00883 & 0.2408 & 0.0105 \\
R3B6 & 0.55450 & 0.00967 & 0.6491 & 0.0121 \\
R3D3 & 0.31876 & 0.00888 & 0.5507 & 0.0121 \\
CA02 & 0.26573 & 0.00935 & 0.5977 & 0.0123 \\
CA06 & 0.01595 & 0.00146 & 0.0858 & 0.0052 \\
CA07 & 0.27119 & 0.00859 & 0.3996 & 0.0121 \\
All01 & 0.02367 & 0.00242 & 0.0932 & 0.0061 \\
\hline All loci & $\mathbf{0 . 0 4 2 4 6}$ & & 0.3456 & \\
\hline
\end{tabular}

c. Rosebud pooled populations, sites separate

\begin{tabular}{l|cc|cc}
\hline & \multicolumn{3}{|c|}{ Genic (allelic } & Genotypic \\
Locus & $P$ value & S.E. & $P$ value & S.E. \\
\hline R2D12 & 0.15683 & 0.00506 & 0.1616 & 0.0057 \\
R2E14 & 0.84853 & 0.00435 & 0.8273 & 0.0052 \\
R3B6 & 0.58250 & 0.00764 & 0.6249 & 0.0080 \\
R3D3 & 0.86067 & 0.00441 & 0.9465 & 0.0031 \\
CA02 & 0.08188 & 0.00366 & 0.1394 & 0.0062 \\
CA06 & 0.24274 & 0.00603 & 0.2115 & 0.0052 \\
CA07 & 0.12227 & 0.00478 & 0.2272 & 0.0082 \\
Al101 & 0.21039 & 0.00556 & 0.1544 & 0.0051 \\
\hline All loci & 0.19556 & & 0.2779 & \\
\hline
\end{tabular}

b. Tica subpopulations

\begin{tabular}{l|cc|cc}
\hline & \multicolumn{2}{|c|}{ Genic (allelic) } & Genotypic & \\
Locus & $P$ value & S.E. & $P$ value & S.E. \\
\hline R2D12 & 0.32471 & 0.01177 & 0.3825 & 0.0170 \\
R2E14 & 0.43509 & 0.01316 & 0.3151 & 0.0155 \\
R3B6 & 0.75556 & 0.01122 & 0.8519 & 0.0116 \\
R3D3 & 0.78111 & 0.01024 & 0.9131 & 0.0086 \\
CA02 & 0.59525 & 0.01417 & 0.8431 & 0.0126 \\
CA06 & 0.03798 & 0.00327 & 0.1570 & 0.0106 \\
CA07 & 0.24547 & 0.01090 & 0.3945 & 0.0170 \\
All01 & 0.19514 & 0.01000 & 0.3196 & 0.0155 \\
\hline All loci & 0.28860 & & 0.6785 & \\
\hline
\end{tabular}

d. Rosebud subpopulations, sites separate

\begin{tabular}{l|cc|cc}
\hline & \multicolumn{3}{|c}{ Genic (allelic) } & Genotypic \\
Locus & $P$ value & S.E. & $P$ value & S.E. \\
\hline R2D12 & 0.35420 & 0.01013 & 0.2717 & 0.0124 \\
R2E14 & 0.70262 & 0.00925 & 0.7025 & 0.0115 \\
R3B6 & 0.91745 & 0.00498 & 0.9145 & 0.0075 \\
R3D3 & 0.99165 & 0.00110 & 0.9955 & 0.0013 \\
CA02 & 0.06197 & 0.00515 & 0.0663 & 0.0068 \\
CA06 & 0.70042 & 0.00865 & 0.7410 & 0.0094 \\
CA07 & 0.46013 & 0.01078 & 0.5656 & 0.0148 \\
Al101 & 0.50274 & 0.00979 & 0.4584 & 0.0136 \\
\hline All loci & 0.7320 & & 0.7282 & \\
\hline
\end{tabular}

e. Rosebud subpopulations, by year

\begin{tabular}{l|cc|cc}
\hline & \multicolumn{3}{|c}{ Genic (allelic) } & Genotypic \\
Locus & $P$ value & S.E. & $P$ value & S.E. \\
\hline R2D12 & 0.07884 & 0.00364 & 0.0346 & 0.0025 \\
R2E14 & 0.84381 & 0.00439 & 0.8068 & 0.0058 \\
R3B6 & 0.97988 & 0.00138 & 0.9617 & 0.0025 \\
R3D3 & 0.99990 & 0.00004 & 0.9999 & 0.0001 \\
CA02 & 0.47112 & 0.00851 & 0.4987 & 0.0097 \\
CA06 & 0.25715 & 0.00622 & 0.2096 & 0.0056 \\
CA07 & 0.30901 & 0.00734 & 0.3260 & 0.0090 \\
All01 & 0.56545 & 0.00650 & 0.4809 & 0.0080 \\
\hline All loci & 0.66017 & & 0.4914 & \\
\hline
\end{tabular}


Table 4.11 $F_{\text {ST }}$ per locus over all subpopulations (FSTAT).

a. $9^{\circ} \mathrm{N}$ EPR segment

\begin{tabular}{c|c|c|c|c|c|c|c||c}
\hline R2D12 & R2E14 & R3B6 & R3D3 & CA02 & CA06 & CA07 & Al101 & All loci \\
\hline-0.004 & -0.001 & -0.002 & 0.004 & -0.002 & 0.002 & -0.003 & -0.001 & -0.001 \\
\hline
\end{tabular}

b. $86^{\circ} \mathrm{W}$ GAR segment

\begin{tabular}{c|c|c|c|c|c|c|c||c}
\hline R2D12 & R2E14 & R3B6 & R3D3 & CA02 & CA06 & CA07 & Al101 & All loci \\
\hline 0.008 & -0.006 & 0.002 & 0.001 & 0.009 & 0.000 & 0.002 & -0.001 & 0.002 \\
\hline
\end{tabular}

c. $9^{\circ} \mathrm{N}$ EPR Tica temporal

\begin{tabular}{c|c|c|c|c|c|c|c||c}
\hline R2D12 & R2E14 & R3B6 & R3D3 & CA02 & CA06 & CA07 & Al101 & All loci \\
\hline 0.001 & -0.000 & -0.003 & -0.005 & -0.003 & 0.002 & 0.001 & -0.000 & -0.003 \\
\hline
\end{tabular}

d. $86^{\circ} \mathrm{W}$ GAR Rosebud temporal

\begin{tabular}{c|c|c|c|c|c|c|c||c}
\hline R2D12 & R2E14 & R3B6 & R3D3 & CA02 & CA06 & CA07 & Al101 & All loci \\
\hline 0.002 & -0.003 & -0.001 & -0.008 & 0.005 & -0.001 & 0.001 & -0.002 & -0.001 \\
\hline
\end{tabular}


$0.00447($ mean $=0.00050)($ Tables 4.12a-c).

While there is a suggestion of genetic variation between pooled years at Tica (pairwise $F_{\text {ST }}$ range $=0.00009$ to 0.00596 , mean $=0.00219$ ), no pairwise temporal values were significant (Table 4.13a). When cohorts were treated as separate subpopulations, the largest difference was detected between 2004 and 2007 residents. Between Tica colonists and residents collected in the same year, pairwise genetic differences were smaller than 0.00065 (mean $=-0.00241)$ (Table 4.13b). Moreover, all colonist-to-colonist comparisons were effectively equal to 0 ; while non-significant, nearly all resident-to-resident comparisons possessed $F_{\mathrm{ST}}$ values greater than 0 and tended to grow in magnitude as the time between samples increased.

In spite of a 2005-2006 eruption that paved over $18 \mathrm{~km}$ of vent communities at $9^{\circ} \mathrm{N} \mathrm{EPR}$, including decimation of the Tica Riftia population, the 2005 and 2007 samples displayed no change in genetic composition. A subset of individuals $(\mathrm{n}=7)$ in the Tica 2007 resident subpopulation was identified by their placement around the vent periphery as potential survivors of the 2005 eruption; when they were removed from pairwise analysis, the magnitude of $F_{\mathrm{ST}}$ comparisons with the Tica 2007 residents increased but remained non-significant.

Rosebud pooled populations were similar between years (0.008, Table 4.13c). Between Rosebud colonists and residents collected in the same year, pairwise genetic differences were -0.00773 and -0.00051 in 2002 and 2005, respectively (Table 4.13d). To test the influence of pooling samples from proximate markers for given years, each marker's subpopulation was also considered separately; non-significant pairwise $F_{\mathrm{ST}}$ comparisons ranged from -0.01376 to $0.01003(P=0.10698)$ (Tables $4.13 \mathrm{e}-\mathrm{f})$. 
Table 4.12a Genetic differences between populations at $9^{\circ} \mathrm{N}$ EPR $\left(F_{\mathrm{ST}}\right.$, above diagonal) and respective $P$ values (below diagonal). Sequential Bonferroni corrected significant values are bolded (ARLEQUIN, 20022 permutations).

\begin{tabular}{r|ccc}
\hline & EW00 & TI00 & CC00 \\
\hline EW00 & - & -0.00031 & 0.00008 \\
TI00 & 0.65844 & - & -0.00037 \\
CC00 & 0.59786 & 0.67607 & - \\
\hline
\end{tabular}

Table 4.12b Genetic differences between populations at $86^{\circ} \mathrm{W}$ GAR $\left(F_{\mathrm{ST}}\right.$ or $R_{\mathrm{ST}}$, above diagonal) and respective $P$ values (below diagonal). Sequential Bonferroni corrected significant values are bolded (ARLEQUIN, 20022 permutations).

\begin{tabular}{lr|ccc}
\cline { 2 - 5 } $\mathrm{F}_{\mathrm{ST}}:$ & $\mathrm{RbN05}$ & $\mathrm{RbJ05}$ & GoE05 \\
\cline { 2 - 5 } & $\mathrm{RbN05}$ & - & 0.00420 & 0.00273 \\
& $\mathrm{RbJ05}$ & 0.06158 & - & 0.00197 \\
$\mathrm{GoE05}$ & 0.11522 & 0.21745 & - \\
\cline { 2 - 5 } $\mathrm{R}_{\mathrm{ST}}:$ & $\mathrm{RbN05}$ & $\mathrm{RbJ05}$ & GoE05 \\
\cline { 2 - 5 } & & - & $\mathbf{0 . 0 2 9 9 2}$ & 0.00299 \\
& RbN05 & - & -0.00091 \\
$\mathrm{RbJ05}$ & 0.00874 & 0.48414 & - \\
\hline GoE05 & 0.32203 & &
\end{tabular}

Table 4.12c Genetic differences between subpopulations at $86^{\circ} \mathrm{W}$ GAR $\left(F_{\mathrm{ST}}\right.$, above diagonal) and respective $P$ values (below diagonal). Sequential Bonferroni corrected significant values are bolded (ARLEQUIN, 20022 permutations).

\begin{tabular}{c|cccccc}
\hline & 86WRbJ05j & 86WRbJ05a & 86WRbN05j & 86WRbN05a & 86WGoE05j & 86WGoE05a \\
\hline 86WRbJ05j & - & 0.00447 & 0.00796 & 0.00182 & 0.00363 & 0.00023 \\
86WRbJ05a & 0.22999 & - & 0.01277 & 0.00327 & 0.00340 & 0.00639 \\
86WRbN05j & 0.12476 & 0.05354 & - & -0.00336 & 0.00996 & 0.00191 \\
86WRbN05a & 0.33222 & 0.25006 & 0.71043 & - & 0.00160 & 0.00036 \\
86WGoE05j & 0.17984 & 0.21980 & 0.04859 & 0.29686 & - & 0.00040 \\
86WGoE05a & 0.56090 & 0.14743 & 0.45722 & 0.52000 & 0.49558 & - \\
\hline
\end{tabular}




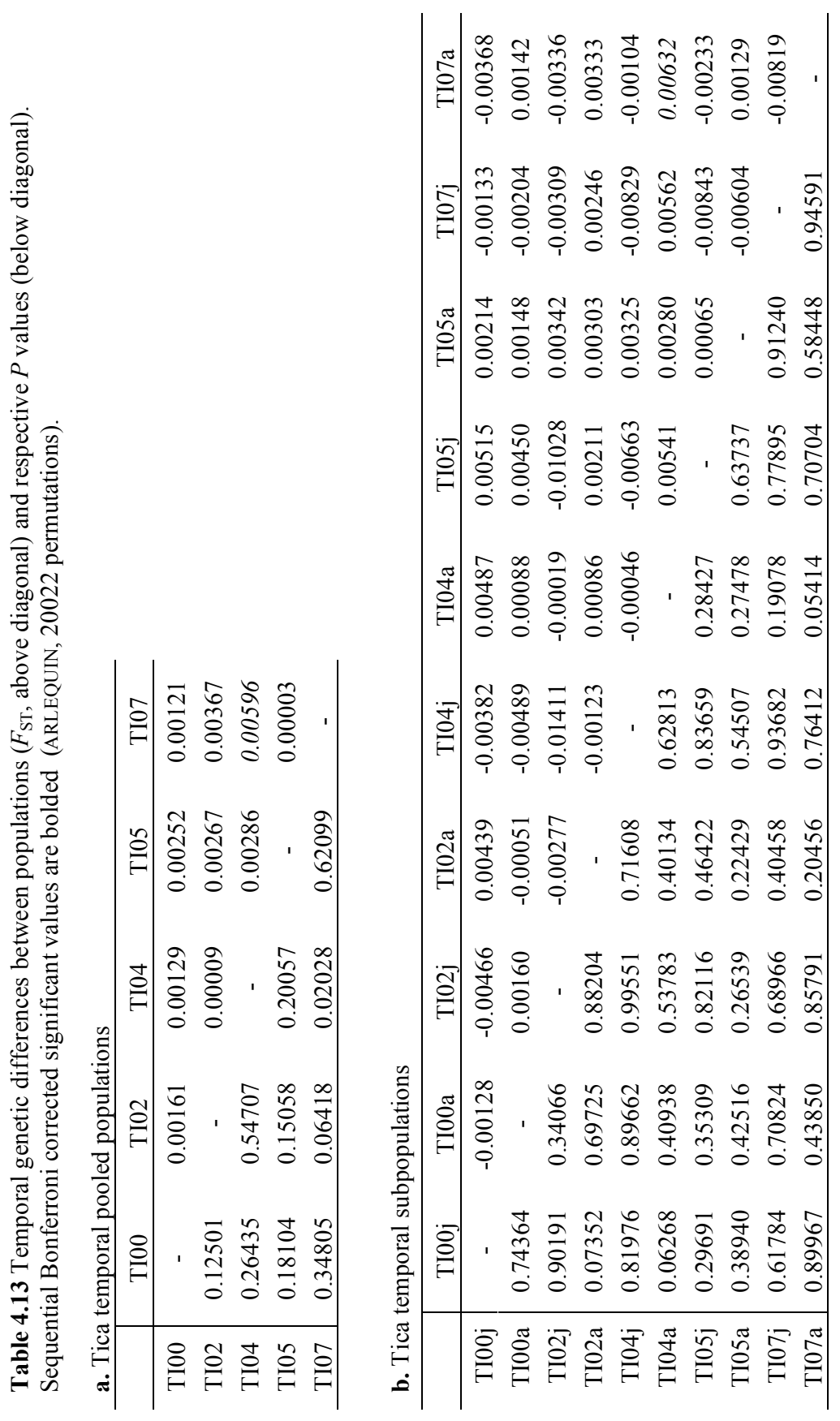


c. Rosebud pooled

\begin{tabular}{c|cc}
\hline & Rb02 & Rb05 \\
\hline Rb02 & - & 0.00083 \\
Rb05 & 0.25146 & - \\
\hline
\end{tabular}

e. Rosebud temporal, pooled by site

\begin{tabular}{r|cccc}
\hline & RbB02 & RbF02 & RbJ05 & RbN05 \\
\hline RbB02 & - & 0.00089 & 0.00082 & 0.00222 \\
RbF02 & 0.35529 & - & 0.00248 & 0.00158 \\
RbJ05 & 0.40334 & 0.14723 & - & 0.00304 \\
RbN05 & 0.10676 & 0.22649 & 0.12935 & - \\
\hline
\end{tabular}

d. Rosebud temporal subpopulations

\begin{tabular}{c|cccc}
\hline & $\mathrm{Rb02j}$ & $\mathrm{Rb02a}$ & $\mathrm{Rb05j}$ & $\mathrm{Rb05a}$ \\
\hline $\mathrm{Rb02j}$ & - & -0.00773 & 0.00055 & -0.00008 \\
$\mathrm{Rb02a}$ & 0.98277 & - & -0.00455 & -0.00169 \\
$\mathrm{Rb05j}$ & 0.40693 & 0.81931 & - & -0.00051 \\
$\mathrm{Rb05a}$ & 0.53633 & 0.63837 & 0.57744 & - \\
\hline
\end{tabular}

f. Rosebud temporal subpopulations, by site

\begin{tabular}{r|cccccccc}
\hline & $R b B 02 j$ & $R b B 02 a$ & $R b F 02 j$ & $R b F 02 a$ & $R b J 05 j$ & $R b J 05 a$ & $R b N 05 j$ & $R b N 05 a$ \\
\hline RbB02j & - & -0.00925 & -0.01190 & -0.00013 & -0.00180 & 0.00413 & 0.00302 & -0.00037 \\
RbB02a & 0.80308 & - & -0.00954 & 0.00172 & 0.00309 & -0.00462 & 0.00166 & 0.00090 \\
RbF02j & 0.98482 & 0.69006 & - & -0.01376 & -0.00930 & 0.00167 & -0.00799 & -0.00725 \\
RbF02a & 0.54273 & 0.44199 & 0.99660 & - & 0.00169 & 0.00306 & 0.00597 & -0.00199 \\
RbJ05j & 0.71887 & 0.43760 & 0.92758 & 0.30580 & - & 0.00194 & 0.00514 & 0.00089 \\
RbJ05a & 0.25226 & 0.65480 & 0.41008 & 0.27149 & 0.38466 & - & 0.01003 & 0.00168 \\
RbN05j & 0.31923 & 0.45013 & 0.77496 & 0.12481 & 0.21460 & 0.10698 & - & -0.00336 \\
RbN05a & 0.57774 & 0.47520 & 0.86955 & 0.77431 & 0.42017 & 0.38591 & 0.70834 & - \\
\hline
\end{tabular}




\subsubsection{Fine spatial and temporal population structure}

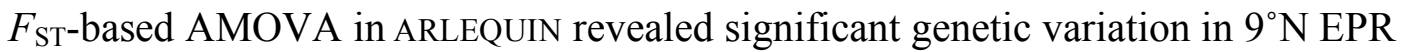
resident populations at the within populations and within individuals levels $\left(\Phi_{\mathrm{IS}}=4.2 \%\right.$, $\Phi_{\mathrm{IT}}=4.1 \%$; Table $\left.4.14 \mathrm{a}\right)$. There was no significant structure at any level of comparison among the $86^{\circ} \mathrm{W}$ GAR populations (Tables $4.14 \mathrm{~b}-\mathrm{c}$ ).

In comparisons among the different years' subpopulations at Tica, significant genetic structure was found among years, within cohorts, and within individuals $\left(\Phi_{\mathrm{CT}}=0.4 \%\right.$, $\Phi_{\mathrm{IS}}=3.3 \%, \Phi_{\mathrm{IT}}=3.3 \%$; Table $\left.4.14 \mathrm{~d}\right)$. When possible survivors of the 2005 eruption were removed from the 2007 Tica resident subpopulation, $F_{\mathrm{ST}}$-based AMOVA variance remained significant ( $\Phi_{\mathrm{CT}}=0.3 \%, \Phi_{\mathrm{IS}}=3.0 \%, \Phi_{\mathrm{IT}}=3.0 \%$ ). There was no significant variance at any level of comparison among different years at the Rosebud population (Tables 4.14e-f).

STRUCTURE was unable to resolve fine spatial samples or temporal samples into distinct populations within a ridge segment or across multiple years at a single site, respectively.

PCA of pairwise $F_{\mathrm{ST}}$ values was used to determine how colonist and resident subpopulations clustered with one another. No population structure was visually apparent, nor was there significant variation along any principal component axis, within ridge segments or among subpopulations through time.

\subsubsection{Isolation, migration, and population bottlenecks}

No isolation by distance pattern was apparent at the within ridge segment spatial scale at $9^{\circ} \mathrm{N}$ EPR or at $86^{\circ} \mathrm{W}$ GAR. There was no isolation by time trend at the Tica site. Because the Rosebud temporal samples only consisted of two time points, the Mantel test was not applied. 
Table 4.14 $F_{\mathrm{ST}}$-based analysis of molecular variance. Bold values are significant at 5\% nominal alpha level (ARLEQUIN: 20022 permutations).

\begin{tabular}{|c|c|c|c|c|}
\hline \multicolumn{5}{|c|}{ a. Group $1=\mathrm{TI} 00$, EW00, CC00 } \\
\hline Source of Variation & $d f$ & Variance & $\%$ & $F$ \\
\hline Among populations & 2 & -0.00309 & -0.08 & $F_{\mathrm{ST}}=-0.00082$ \\
\hline Within populations & 99 & 0.15947 & 4.23 & $F_{\mathrm{IS}}=\mathbf{0 . 0 4 2 2 7}$ \\
\hline Within individuals & 102 & 3.61275 & 95.85 & $F_{\mathrm{IT}}=\mathbf{0 . 0 4 1 4 9}$ \\
\hline Total & 203 & 3.76913 & - & - \\
\hline \multicolumn{5}{|c|}{ b. Group $1=\operatorname{RbJ} 05 j \&$ a, $2=\operatorname{RbJ} 05 j \&$ a, $3=\operatorname{GoE} 05 j \&$ a } \\
\hline Source of Variation & $d f$ & Variance & $\%$ & $F$ \\
\hline Among populations & 2 & 0.00956 & 0.26 & $F_{\mathrm{ST}}=0.00262$ \\
\hline Within populations & 100 & 0.05243 & 1.44 & $F_{\mathrm{IS}}=0.01440$ \\
\hline Within individuals & 103 & 3.58738 & 98.30 & $F_{\text {IT }}=0.01699$ \\
\hline Total & 205 & 3.64937 & - & - \\
\hline \multicolumn{5}{|c|}{ c. Group 1 = RbJ05, RbN05, GoE05 } \\
\hline Source of Variation & $d f$ & Variance & $\%$ & $F$ \\
\hline Among populations & 2 & 0.00942 & 0.26 & $F_{\mathrm{CT}}=0.00258$ \\
\hline $\begin{array}{l}\text { Among "cohorts" } \\
\text { within populations }\end{array}$ & 3 & 0.00027 & 0.01 & $F_{\mathrm{SC}}=0.00007$ \\
\hline Within "cohorts" & 97 & 0.05230 & 1.43 & $F_{\text {IS }}=0.01437$ \\
\hline Within individuals & 103 & 3.58738 & 98.30 & $F_{\mathrm{IT}}=0.01699$ \\
\hline Total & 205 & 3.64937 & - & - \\
\hline
\end{tabular}


d. Group 1= TI00j \& a, $2=$ TI02j \& a, $3=$ TI04j \& a, $4=$ TI05j \& a, $5=$ TI07j \& a

\begin{tabular}{lrcrc}
\multicolumn{1}{c}{ Source of Variation } & $d f$ & Variance & $\%$ & $F$ \\
\hline \hline & 4 & 0.01339 & 0.36 & $F_{\mathrm{CT}}=\mathbf{0 . 0 0 3 5 5}$ \\
Among years & 5 & -0.01313 & -0.35 & $F_{\mathrm{SC}}=-0.00349$ \\
$\begin{array}{l}\text { Among "cohorts" } \\
\text { within years }\end{array}$ & 171 & 0.12299 & 3.26 & $F_{\mathrm{IS}}=\mathbf{0 . 0 3 2 6 0}$ \\
Within "cohorts" & 181 & 3.64917 & 96.73 & $F_{\mathrm{IT}}=\mathbf{0 . 0 3 2 6 7}$ \\
Within individuals & 361 & 3.77242 & - & - \\
Total & & & & \\
\hline
\end{tabular}

e. Group 1= Rb02, Rb05

Source of Variation

$d f \quad$ Variance

$\%$

F

\begin{tabular}{lcccc} 
Among years & 1 & 0.00281 & 0.08 & $F_{\mathrm{ST}}=0.00077$ \\
$\begin{array}{l}\text { Among individuals } \\
\text { within years }\end{array}$ & 121 & 0.04079 & 1.11 & $F_{\mathrm{IS}}=0.01112$ \\
Within individuals & 123 & 3.62602 & 98.81 & $F_{\mathrm{IT}}=0.01188$ \\
Total & 245 & 3.66961 & - & - \\
\hline
\end{tabular}

f. Group 1= Rb02j \& Rb02a, $2=R b 05 j \&$ Rb05a

\begin{tabular}{lrrrr}
\multicolumn{1}{c}{ Source of Variation } & $d f$ & Variance & $\%$ & $F$ \\
\hline \hline & 1 & 0.01053 & 0.29 & $F_{\mathrm{CT}}=0.00287$ \\
Among years & 2 & -0.01255 & -0.34 & $F_{\mathrm{SC}}=-0.00343$ \\
$\begin{array}{l}\text { Among populations } \\
\text { within years }\end{array}$ & 119 & 0.04555 & 1.24 & $F_{\mathrm{IS}}=0.01241$ \\
Within populations & 123 & 3.62602 & 98.81 & $F_{\mathrm{IT}}=0.01186$ \\
Within individuals & 245 & 3.66955 & - & \\
Total & & & & \\
\hline
\end{tabular}


Estimation of the number of migrants per generation $(\mathrm{Nm})$ along the $9^{\circ} \mathrm{N}$ EPR ridge segment using the private allele method implemented by GENEPOP ON THE WEB and corrected for sample size suggested moderate gene flow of approximately 9 migrants per generation among the resident populations. Along the $86^{\circ} \mathrm{W}$ GAR ridge segment, this method also suggested moderate gene flow among populations of approximately 9 migrants per generation. The estimated number of Galápagos colonist migrants exchanged per generation was equivalent to that of the residents $(\sim 4)$.

BOTTLENECK analyses revealed heterozygosity excess across all $9^{\circ} \mathrm{N}$ EPR ridge segment scale populations and within the $86^{\circ} \mathrm{W}$ GAR Rosebud Marker N and Garden of Eden subpopulations but not within the Rosebud Marker J demes. Upon closer examination, heterozygote excess particularly in 3 loci (R2D12, R2E14, and Rpa10CA07) contributed to the overall pattern.

At the temporal scale, each year's sample at Tica and Rosebud had significant heterozygote excess.

\subsubsection{Cohort relatedness}

Pairwise allele sharing coefficients were generated for colonists and residents sampled at the same location and time as the pairwise $F_{\mathrm{ST}}$ values between subpopulations collected at the same location (e.g., Tica, $9^{\circ} \mathrm{N}$ EPR; Rosebud, $86^{\circ} \mathrm{W}$ GAR) showed non-significant differences ranging from (-0.00727 to 0.00134) (Table 4.13). All animals of the same location were used to generate the expected values of the allele sharing coefficient (Table 4.15). For Tica these values were for half-sibs 0.19 for full-sibs 0.43 , for Rosebud halfsibs 0.24 and full sibs 0.47 .

In 4 out of 10 subpopulations at Tica significantly more half-sibs were found than in a randomly generated group of the same size. At Rosebud, all 6 subpopulations showed significantly more half-sibs than in a randomly generated group. The number of full sibs 
Table 4.15 Relatedness within subpopulations. Observed number of pairwise comparisons that exceeded the expected value of $M_{x y} \exp$ of a group of randomly generated half sibs. $M_{x y} \exp$ for $9^{\circ} \mathrm{N} \mathrm{EPR}=0.19$ and for $86^{\circ} \mathrm{W} \mathrm{GAR}=$ 0.24 . The value for full sibs was 0.43 and 0.47 for $9^{\circ} \mathrm{N}$ EPR and $86^{\circ} \mathrm{W}$ GAR.

\begin{tabular}{cccccc}
\hline Subpopulation & $\begin{array}{c}\text { Sampling } \\
\text { period }\end{array}$ & Stage & $n$ & $\begin{array}{c}\text { Observed pairs } \\
\text { of half sibs }\end{array}$ & $P$ \\
\hline 9NTI00j & 2000 & colonists & 18 & 10 & $0.012 *$ \\
9NTI00a & 2000 & residents & 31 & 44 & $0 * * *$ \\
9NT02j & 2002 & colonists & 15 & 33 & $0 * * *$ \\
9NT02a & 2002 & residents & 42 & 94 & 0.357 \\
9NT04j & 2004 & colonists & 7 & 0 & 1 \\
9NT04a & 2004 & residents & 26 & 25 & $0 * * *$ \\
9NT05j & 2005 & colonists & 4 & 0 & 1 \\
9NT05a & 2005 & residents & 16 & 6 & 0.103 \\
9NT07j & 2007 & colonists & 7 & 0 & 1 \\
9NT07a & 2007 & residents & 15 & 6 & 0.069 \\
86WRb02j & 2002 & colonists & 54 & 281 & $0 * * *$ \\
86WRb02a & 2002 & residents & 10 & 14 & $0 * * *$ \\
86WRbJ05j & 2005 & colonists & 17 & 30 & $0 * * *$ \\
86WRbJ05a & 2005 & residents & 10 & 13 & $0.001 * *$ \\
86WRbN05j & 2005 & colonists & 9 & 8 & $0.016 *$ \\
86WRbN05a & 2005 & residents & 23 & 63 & $0 * * *$ \\
\hline
\end{tabular}

Significance at $5 \%(*), 1 \%(* *)$, and $0.1 \%(* * *)$

was not significantly different in any subpopulation at any location. The increased degree of relatedness was not only found in subpopulations consisting of colonists but also in resident adults.

\subsubsection{Summary of results}

In summary, all loci were in HWE for all populations. Greater allelic diversity was present at $9^{\circ} \mathrm{N}$ on the East Pacific Rise than at $86^{\circ} \mathrm{W}$ on the Galápagos Rift, consistent with previous inter-ridge comparisons (Chapter 3). Though non-significant, colonist cohorts tended to be more genetically diverse than were mixed resident cohorts. 
Moreover, cohorts sampled at the same site or in the same year along a ridge segment were undifferentiated.

Variation was minimal among populations within ridge segments in the eastern Pacific and had no isolation by distance signal, suggesting high gene flow at a spatial scale of 10 s to 100 s of meters, though allele frequencies showed subtle variation at $86^{\circ} \mathrm{W}$ GAR. Comparison between the Rosebud Marker N colonists and two other subpopulations were responsible for this signal. Bottlenecks were suggested in all subpopulations at $9^{\circ} \mathrm{N}$ EPR and $86^{\circ} \mathrm{W}$ GAR, with the exception of at Rosebud Marker J.

Temporal variation was also minimal at the Tica $9^{\circ} \mathrm{N}$ EPR and Rosebud $86^{\circ} \mathrm{W}$ GAR vent sites. While allele frequencies may differ among years over all populations at Tica, stemming from small non-significant variation between the 2004 and 2007 residents, there was no differentiation detected between Rosebud samples. Colonists sampled at Tica were more similar to one another regardless of sampling year than were residents collected at different years. Resident populations grew more distinct from each other as time progressed, although comparisons between them were non-significant. There was no genetic signal detected among populations collected before and after the extensive 2005$20069^{\circ} \mathrm{N}$ EPR seafloor eruption, though all subpopulations displayed evidence of recent bottlenecks.

Estimates of relatedness were high among samples at a single site and consistent throughout the sampling period of 2 to 7 years. In particular, there were more half-sibs at Tica and Rosebud than expected by chance in both resident and colonist cohorts. 


\subsection{Discussion}

\subsubsection{Higher genetic diversity on fast-spreading ridge}

As found in Chapter 3, Riftia exhibits high genetic diversity throughout the sampled locations and years. Allelic richness is consistently greater on the $9^{\circ} \mathrm{N}$ East Pacific Rise segment than along the $86^{\circ} \mathrm{W}$ Galápagos Rift segment. Less variation on the GAR could be accounted for by smaller effective population size $\left(N_{\mathrm{e}}\right)$, fewer and less diverse source populations, a more recent founder event, greater selection against alleles that are rare on the EPR, or more infrequent habitat perturbations for which greater genetic diversity would be advantageous to population recovery (Reusch et al. 2005, Hughes et al. 2008). Differences in effective population size and in the frequency of habitat turnover are suspected to be the most reasonable explanations, as venting is less robust and the spreading rate is slower on the GAR, though more work will have to be conducted to test these hypotheses.

\subsubsection{Low level patchiness within ridge segments and among sampling years}

In species with long-distance planktonic dispersal, fine-scale chaotic genetic patchiness (i.e. variation in allele frequencies among populations at scale of tens of meters that is inconsistent among loci, sites, or years) can result from temporal variation in numbers and genotypes of recruits (Johnson \& Black 1982). Levels of temporal habitat variability as found in estuaries can also drive fine-scale genetic differentiation (Darling et al. 2004). Contrary to the expectations of Riftia population subdivision on scales of $410 \mathrm{~m}$ to $19 \mathrm{~km}$ evidenced by Shank and Halanych (2007) on the EPR, there were no significant $F_{\mathrm{ST}}$ differences found among populations at the $86^{\circ} \mathrm{W}$ GAR segment. However, overall genic and genotypic variation suggests that there is an underlying stochastic genetic patchiness to this system, with alleles and genotypes unevenly distributed. Within the $9^{\circ} \mathrm{N}$ EPR segment, genetic variance was greatest within populations and within individuals. If more 
colonists had been sampled from the $9^{\circ} \mathrm{N}$ EPR segment, variation among those populations may have also been recognized.

Shank and Halanych (2007) used very few individuals from their two $9^{\circ} \mathrm{N}$ EPR sites and their primary subpopulation clusters were later recognized to consist of individuals $<10$ $\mathrm{cm}$ in length. This level of genetic variation in arriving cohorts could be accounted for by the fact that each $9^{\circ} \mathrm{N}$ EPR site was sampled a year apart in their study. However, even within the same year's sample at the East Wall site, their four smallest individuals clustered separate from their two individuals $>10 \mathrm{~cm}$, indicating between-cohort structure that should have been detected in the present study. Colonist cohorts from Tica, Choo Choo, and East Wall should be collected for future microsatellite analysis in order to fully compare these results to those of Shank and Halanych (2007).

The absence of isolation by distance at the intra-segment spatial scale reflects the lack of isolation at the ridge scale (see Chapter 3). As observed in other species, detection of IBD in Riftia appears to hinge upon the scale of individual dispersal behavior in concert with other population processes (O. Puebla, OSM 2008; North et al. 2008; also see Denny et al. 2004 for discussion of scale in ecology). The scale of 10 s to 100 s of meters considered here does not appear to be large enough for an IBD pattern to emerge in Riftia.

Chaotic genetic patchiness from large variance in reproductive success (e.g., high fecundity and stochastic oceanographic conditions) can lead to rapid changes in population genetic composition (Planes \& Lenfant 2002), but that was not observed in the present Riftia dataset. In the Tica samples, divergence among subpopulations (genic differentiation) and among sample years (AMOVA) was detected. Rosebud populations were genetically homogeneous on the temporal scale considered. Additional Rosebud sample years would be useful to further test the stability of its population diversity. As in the pre- and post-eruption samples from the Tica site, multiple marine studies found no temporal genetic differentiation between cohorts within a population, despite 
demographic population reduction (Ruzzante et al. 2001, Cassista \& Hart 2007, Derycke et al. 2007, Kusumo et al. 2006). A small but significant difference among years (AMOVA) suggests that cohorts may be differentiated from each other within a region, but specific cases were restricted to a subset of year classes.

Homogeneity in genetic composition can result from high gene flow among populations or from historical patterns of colonization from a common source (if time since separation has not been sufficient for drift or accumulation of novel mutations). However, genetic homogeneity does not necessarily imply that a population is panmictic or is acting as a single demographic unit and can therefore be replenished by individuals from any part of the population; so called "sink" populations are maintained only by immigration from up-current (Pringle \& Wares 2007). It can also be the result of extinction-colonization dynamics — with frequent extinctions and mixed-stock founders or recurrent dispersal from a common source (Newman \& Squire 2001). Non-equilibrium (gene flow-genetic drift) dynamics can set up conditions under which populations appear genetically homogenous but actually have a low migration rate, as in the gag grouper in the tropical Atlantic (E. Sotka, OSM 2008). These non-equilibrium conditions are likely to be highly influential in Riftia.

It is alternately possible that regional-scale genetic homogeneity overwhelmed a weak contribution of among-cohort genetic variation to population structure (Cassista \& Hart 2007). Although the sampling design of colonists restricted collections to the smallest and presumably youngest individuals, it is also possible that spatial and temporal variation was confounded with some degree of uncaptured post-settlement selection (Gilg \& Hilbish 2003b). The high mutation rates in Riftia's microsatellite markers may further limit resolution of weak genetic structure due to increased allele size homoplasy (O'Reilly et al. 2004), as discussed in more detail in the Chapter 5. 


\subsubsection{Influence of seafloor eruptions and metapopulation dynamics}

Given the instability of hydrothermal vent habitats, it is not surprising that bottlenecks can be inferred for all populations. A recent eruption on the GAR in 2000 created the Rosebud community and two eruptions on the EPR in 1991 and 2005 similarly affected the $9^{\circ} \mathrm{N}$ communities. However, a reduction in allele number or elimination of rare alleles was not observed coincident with these events. High levels of disturbance similarly have no impact on the genetic structure of a pioneer rainforest tree, where gene flow was inferred not to be limiting (Born et al. 2008b). Again, mutation-drift disequilibrium can be created by the observed population expansion in Riftia quickly following population reduction (Busch et al. 2007). As a result, populations may have high genetic variation within them and negligible subdivision between them. Specifically, allelic diversity can be maintained by a variety of processes, including single genetically diverse larval influx from multiple source populations, influx from one genetically diverse source population, or multiple introduction events (Holland 2001). Higher reproductive success in smaller populations is another mechanism by which less genetic diversity is lost during population bottlenecks (Jehle et al. 2005). Collections of embryos and larvae will be necessary to evaluate reproductive success directly in the future. Nevertheless, it is predicted that as all sampled Riftia resident populations exhibited high allelic variability, parental diversity is likely to influence the composition of future colonist cohorts, regardless of the particular reproductively successful adults.

An alternative expectation would be that if sites within a ridge segment experienced different rates of turnover, they would exhibit heterogeneity at short spatial scales (Watts et al. 1990). That not being evidenced in Riftia suggests that the metapopulation processes often invoked in hydrothermal vent systems (Jollivet et al. 1999) may not substantially reduce neutral genetic diversity (Jehle et al. 2005). Instead, under a heterogeneous or changing set of selective conditions, a highly variable assortment of genotypes is predicted to be adaptively and evolutionarily stable, increasing the probability of successful establishment (Holland 2001). 
Lastly, if significant divergences had arisen between adult and juvenile cohorts (e.g., Hedgecock et al. 2007), such differences could have been consistent with "sweepstakes" reproductive success. This mechanism of reproductive success by a small number of adults is consistent with the finding of excess heterozygosity, but neither less allelic diversity within nor more heterogeneity among colonist cohorts as compared to resident populations was evident in Riftia. Moreover, loci were in gametic phase equilibrium. In order to investigate this discrepancy with expectations, the proportions of full- and halfsib relationships in recent colonists were next examined.

\subsubsection{Settlement as related larval cohorts}

The elimination of excess homozygotes in a population could result from a temporal Wahlund effect-young settlers originate from only a couple families, while older individuals come from a mix of several families (Planes \& Lenfant 2002). In the system presented here, the combined factors of (1) low $F_{\text {ST }}$ values between colonists and resident adults collected at the same site, (2) modeled currents that transport advective particles (larvae) back to the ridge crest (Jackson et al. in prep), (3) extensive heterozygote excess, (4) strong assignment of colonists to their collection location especially at the $86^{\circ} \mathrm{W}$ GAR site (Chapter 3), and (5) the previous genomic fingerprinting which found unresolved polytomies in the smallest Riftia cohorts (Shank \& Halanych 2007), motivated us to consider the possibility of siblingship within settling cohorts. By analysing the allele sharing coefficient $M_{x y}$, it was revealed that many subpopulations sampled at the same location and time consisted of half sibs. Individuals in 10 out of 16 subpopulations shared significantly more alleles than had they been derived from randomly generated groups. Such a result is consistent with a subset of "clouds" of larvae spawned and released at the same time remaining together as a coherent group during their mobile stage and settling next to each other.

If a high level of relatedness is maintained at vent sites, heterozygote deficiencies and a greater potential for inbreeding would be expected, as is common to species with 
planktonic gametes (Addison \& Hart 2005). In contrast, the heterozygote excess found in the present study leads to the hypothesis that despite the close proximity of relatives and several groups of related cohorts that may be transported together as larvae, mating is still likely to be random.

Low genetic differentiation found within ridge segments, with significant isolation between ridges (Chapter 3), is also consistent with the predominance of local retention and periodic among "island" migration (Rivera et al. 2004). Short-distance dispersal of woody tree seeds has also been reported to result in the presence of half-siblings near their parents (Born et al. 2008b). At $9^{\circ} \mathrm{N}$ EPR, assignment tests had not been as strongly suggestive of retention as at $86^{\circ} \mathrm{W}$ GAR, suggesting that EPR larval cohorts may be more widely dispersed or preserve the genetic signature of more historical mixing events than GAR cohorts. However, both EPR and GAR subpopulations exhibit more relatedness within subpopulations than expected under random conditions. Dispersal and settlement as aggregated sibling cohorts was also suggested in the preliminary genomic fingerprinting study which led to the more spatially and temporally constrained work discussed here (Shank \& Halanych 2007). Allele frequencies among colonist cohorts are remarkably consistent over time, which could indicate a stable source population (Gilg \& Hilbish 2003b). Yet the marked genetic diversity and history of metapopulation dynamics at these vents may make traditional island or stepping-stone models of dispersal obsolete (Hellberg 2006).

\subsection{Conclusions}

Considering local and temporal patterns, subtle genetic variation with underlying homogeneity and high diversity were found among Riftia populations along a ridge segment and through time. The prevalence of larval retention (on scale of $10 \mathrm{~s}$ to $100 \mathrm{~s}$ meters) and dispersal in discrete related cohorts ensures that a network of populations are maintained and ecologically connected in spite of frequent local extinctions and a disjunct habitat (metapopulation dynamics). 
Future work should consider Riftia post-settlement mortality in order to determine its timing and influence on cohorts. On the sampling scales of this study, selective processes that occur soon after settlement may have been missed; if present, these will be important to quantify with respect to the hypothesis of local retention. Coupling high-resolution and dynamic modeling of currents from small to large scales will further inform the delivery mechanisms of larvae to vents. Lastly, the role of non-equilibrium dynamics at vents requires further investigation. The incorporation of historical coalescence and simulation of other non-equilibrium processes may be useful in tracking the emergence of current patterns (E. Sotka, OSM 2008). 


\subsection{References}

Addison JA, Hart MW (2005) Colonization, dispersal, and hybridization influence phylogeography of North Atlantic sea urchins (Strongylocentrotus droebachiensis). Evolution, 59, 532-543.

Amos W, Hoffman JI, Frodsham A et al. (2007) Automated binning of microsatellite alleles: problems and solutions. Molecular Ecology Notes, 7, 10-14.

Barton NH, Slatkin M (1986) A quasi-equilibrium theory of the distribution of rare alleles in a subdivided population. Heredity, 56, 409-416.

Belkhir K, Borsa P, Goudet J, Chikhi L, Bonhomme F (2004) GENETIX 4.05, logiciel sous Windows TM pour la génétique des populations. Laboratoire Génome et Populations, CNRS UPR 5000, Université Montpellier II, Montpellier.

Black MB, Lutz RA, Vrijenhoek RC (1994) Gene flow among vestimentiferan tube worm (Riftia pachyptila) populations from hydrothermal vents of the Eastern Pacific. Marine Biology, 120, 33-39.

Blouin MS, Parsons M, Lacaille V, Lotz S (1996) Use of microsatellite loci to classify individuals by relatedness. Molecular Ecology, 5, 393-401.

Born C, Hardy OJ, Chevallier M-H, et al. (2008a) Small-scale spatial genetic structure in the Central African rainforest tree species Aucoumea klaineana: a stepwise approach to infer the impact of limited gene dispersal, population history and habitat fractionation. Molecular Ecology, 17, 2041-2050.

Born C, Kjellberg F, Chevallier M-H, et al. (2008b) Colonization processes and the maintenance of genetic diversity: insights from a pioneer rainforest tree. Proceedings of the Royal Society B, FirstCite doi:10.1098/rspb.2008.0446.

Burton RS, Lee B-N (1994) Nuclear and mitochondrial gene genealogies and allozyme polymorphism across a major phylogeographic break in the copepod Tigriopus californicus. Proceedings of the National Academy of Sciences of the United States of America, 91, 5197-5201.

Busch JD, Waser PM, DeWoody JA (2007) Recent demographic bottlenecks are not accompanied by a genetic signature in banner-tailed kangaroo rats (Dipodomys spectabilis). Molecular Ecology, 16, 2450-2462.

Cassista MC, Hart MW (2007) Spatial and temporal genetic heterogeneity in the Arctic surfclam (Mactromeris polynyma). Marine Biology, 152, 569-579.

Chevaldonné P, Jollivet D, Vangriesheim A, Debruyères D (1997) Hydrothermal-vent alvinellid polychaete dispersal in the eastern Pacific. 1. Influence of vent site distribution, bottom currents, and biological patterns. Limnology and Oceanography, 42, 67-80. 
Childress JJ (1988) Biology and chemistry of a deep-sea hydrothermal vent on the Galapagos Rift; the Rose Garden in 1985. Introduction. Deep-Sea Research, 35, 1677-1680.

Christiansen S (2000) Lucky Strike: a potential MPA. WWF North-East Atlantic Programme briefing.

Cockerham CC, Weir BS (1979) Estimation of linkage disequilibrium in randomly mating populations. Heredity, 42, 105-111.

Corliss JB, Dymond J, Gordon LI, et al. (1979) Submarine thermal springs on the Galápagos Rift. Science, 203, 1073-1083.

Cornuet JM, Luikart G (1996) Description and power analysis of two tests for detecting recent population bottienecks from allele frequency data. Genetics, 144, 2001-2014.

Cowen JP, Fornari DJ, Shank TM, et al. (2007) Volcanic eruptions at East Pacific Rise Near $9^{\circ} 50 '$ N. Eos, 88, 81, 88.

Cowen RK (2008) Population connectivity in marine systems: progress and promising directions. Ocean Science Meeting, Orlando, Florida.

Darling JA, Reitzel AM, Finnerty JR (2004) Regional population structure of a widely introduced estuarine invertebrate: Nematostella vectensis Stephenson in New England. Molecular Ecology, 13, 2969-2981.

Denny MW, Helmuth B, Leonard GH, Harley CDG, Hunt LJH, Nelson EK (2004) Quantifying scale in ecology: lessons from a wave-swept shore. Ecological Monographs, 74, 513-532.

Derycke S, Backeljau T, Vlaeminck C, et al. (2007) Spatiotemporal analysis of population genetic structure in Geomonhystera disjuncta (Nematoda, Monhysteridae) reveals high levels of molecular diversity. Marine Biology, 151, 1799-1812.

Desbruyères D (1998) Temporal variations in the vent communities on the East Pacific Rise and Galápagos Spreading Centre: a review of present knowledge. Cahiers de Biologie Marine, 39, 241-244.

Di Rienzo A, Peterson AC, Garza JC, Valdes AM, Slatkin M, Freimer NB (1994) Mutational processes of simple-sequence repeat loci in human populations Proceedings of the National Academy of Sciences, 91, 3166-3170.

El Mousadik A, Petit RJ (1996) High level of genetic differentiation for allelic richness among populations of the argan tree [Argania spinosa (L.) Skeels] endemic to Morocco. Theoretical and Applied Genetics, 92, 832-839.

Excoffier L, Laval G, Schneider S (2005) Arlequin (version 3.0): an integrated software package for population genetic analysis. Evolutionary Bioinformatics Online, 1, 4750. 
Falush D, Stephens M, Pritchard JK (2003) Inference of population structure using multilocus genotype data: linked loci and correlated allele frequencies. Genetics, 164, 1567-1587.

Falush D, Stephens M, Pritchard JK (2007) Inference of population structure using multilocus genotype data: dominant markers and null alleles. Molecular Ecology Notes, 7, 574-578.

Fusaro AJ, Baco AR, Gerlach G, Shank TM (2008) Development and characterization of 12 microsatellite markers from the deep-sea hydrothermal vent siboglinid Riftia pachyptila Molecular Ecology Resources, 8, 132-134.

Garnier S, Alibert P, Audiot P, Prieur B, Rasplus J-Y (2004) Isolation by distance and sharp discontinuities in gene frequencies: implications for the phylogeography of an alpine insect species, Carabus solieri. Molecular Ecology, 13, 1883-1897.

Gerlach G, Schardt U, Eckman R, Meyer A (2001) Kin-structured subpopulations in Eurasian perch (Perca fluviatilis L.). Heredity, 86, 213-221.

Gilg MR, Hilbish TJ (2003a) Spatio-temporal patterns in the genetic structure of recently settled blue mussels (Mytilus spp.) across a hybrid zone. Marine Biology, 143, 679690.

Gilg MR, Hilbish TJ (2003b) Patterns of larval dispersal and their effect on the maintenance of a blue mussel hybrid zome in southwestern England. Evolution, 57, 1061-1077.

Goudet J (1999) PCA-GEN for Windows, V. 1.2. Distributed by the author, Institute of Ecology, Univ. of Lausanne.

Goudet J (2001) FSTAT, a program to estimate and test gene diversities and fixation indices (version 2.9.3). Available from http://www2.unil.ch/popgen/softwares/fstat.htm. Updated from Goudet (1995).

Grassle JP (1985) Genetic differentiation in populations of hydrothermal vent mussels (Bathymodiolus thermophilus) from the Galapagos Rift and $13^{\circ} \mathrm{N}$ on the East Pacific Rise. Bulletin of the Biological Society of Washington, 6, 429-442.

Hedgecock D, Launey S, Pudovkin AI, Naciri Y, Lapègue S, Bonhomme F (2007) Small effective number of parents $(\mathrm{Nb})$ inferred for a naturally spawned cohort of juvenile European flat oysters Ostrea edulis. Marine Biology, 150, 1173-1182.

Hellberg ME (2006) Genetic approaches to understanding marine metapopulation dynamics. pp. 431-455 in Marine Metapopulations, J. Kritzer and P. F. Sale (eds.). Academic, San Diego.

Hendry AP, Day T (2005) Population structure attributable to reproductive time: isolation by time and adaptation by time. Molecular Ecology, 14, 901-916. 
Holland BS (2001) Invasion without a bottleneck: microsatellite variation in natural and invasive populations of the brown mussel Perna perna (L). Marine Biotechnology, 3, 407-415.

Hughes AR, Inouye BD, Johnson MT, Underwood N, Vellend M (2008) Ecological consequences of genetic diversity. Ecology Letters, 11, 609-623.

Hurtado LA, Lutz RA, Vrijenhoek RC (2004) Distinct patterns of genetic differentiation among annelids of eastern Pacific hydrothermal vents. Molecular Ecology, 13, 26032615.

Jackson PR, Ledwell JR, Thurnherr AM (in prep) Dispersion of a tracer on the East Pacific Rise $\left(9^{\circ} \mathrm{N}\right.$ to $\left.10^{\circ} \mathrm{N}\right)$, including the influence of hydrothermal plumes.

Jehle R, Wilson GA, Arntzen JW, Burke T (2005) Contemporary gene flow and the spatio-temporal genetic structure of subdivided newt populations (Triturus cristatus, T. marmoratus). Journal of Evolutionary Biology, 18, 619-628.

Johnson MS, Black R (1982) Chaotic genetic patchiness in an intertidal limpet, Siphonaria sp. Marine Biology, 70, 157-164.

Jollivet D, Chavaldonné P, Planque B (1999) Hydrothemal-vent alvinellid polychaete dispersal in the eastern Pacific. 2. A metapopulation model based on habitat shifts. Evolution, 53, 1128-1142.

Keymer JE, Marquet PA, Velasco-Hernández JX, Levin SA (2000) Extinction thresholds and metapopulation persistence in dynamic landscapes. American Naturalist, 156, 478-494.

Kusumo HT, Pfister CA, Wootton JT (2006) Small-scale genetic structure in the sea palm Postelsia palmaeformis Ruprecht (Phaeophyceae). Marine Biology, 149, 731742.

Maes GE, Pujolar JM, Hellemans B, Volckaert FAM (2006) Evidence for isolation by time in the European eel (Anguilla anguilla L.). Molecular Ecology, 15, 2095-2107.

Macdonald KC, Mudie JD (1974) Microearthquakes on the Galapagos Spreading Centre and the seismicity of fast-spreading ridges. Geophysical Journal International, 36, 245-257.

Marsh AG, Mullineaux LM, Young CM, Manahan DT (2001) Larval dispersal potential of the tubeworm Riftia pachyptila at deep-sea hydrothermal vents. Nature, 411, 7780.

Mullineaux LS, Speer KG, Thurnherr AM, Maltrud ME, Vangriesheim A (2002) Implications of cross-axis flow for larval dispersal along mid-ocean ridges. Cahiers de Biologie Marine, 43, 281-284.

Nei M (1987) Molecular Evolutionary Genetics, Columbia University Press, New York. $512 \mathrm{pp}$.

Nevala AE (2005) On the seafloor, a parade of roses. Oceanus 44, 6. 
Newman RA, Squire T (2001) Microsatellite variation and fine-scale population structure in the wood frog (Rana sylvatica). Molecular Ecology, 10, 1087-1100.

North, EW, Schlag Z, Hood RR, Li M, Zhong L, Gross T, Kennedy VS (2008) Vertical swimming behavior influences the dispersal of simulated oyster larvae in a coupled particle-tracking and hydrodynamic model of Chesapeake Bay. Marine Ecology Progress Series, in press.

van Oosterhout C, Hutchinson WF, Wills DPM, Shipley P (2004) MICRO-CHECKER: software for identifying and correcting genotyping errors in microsatellite data. Molecular Ecology Notes, 4, 535-538.

O’Reilly PT, Canino MF, Bailey KM, Bentzen P (2004) Inverse relationship between Fst and microsatellite polymorphism in the marine fish, walleye pollock (Theragra chalcogramma): implications for resolving weak population structure. Molecular Ecology, 13, 1799-1814.

Palumbi SR (1996) Macrospatial genetic structure and speciation in marine taxa with high dispersal abilities. In: Molecular Zoology: Advances, Strategies, and Protocols. Ferraris JD, Palumbi SR (eds.) Wiley-Liss, John Wiley \& Sons, New York.

Pedersen EM, Hunt HL, Scheibling RE (2000) Temporal genetic heterogeneity within a developing mussel (Mytilus trossulus and M. edulis) assemblage. Journal of the Marine Biological Association of the United Kingdom, 80, 843-854.

Planes S, Lenfant P (2002) Temporal change in the genetic structure between and within cohorts of a marine fish, Diplodus sargus, induced by a large variance in individual reproductive success. Molecular Ecology, 11, 1515-1524.

Pringle JM, Wares JP (2007) Going against the flow: maintenance of alongshore variation in allele frequency in a coastal ocean. Marine Ecology Progress Series, 335, 69-84.

Puebla O (2008) Genetic signature of the spatial scale of dispersal mediated by coral reef fish larvae. Ocean Sciences Meeting, Orlando, Florida.

Pritchard JK, Stephens M, Donnelly P (2000) Inference of population structure using multilocus genotype data. Genetics, 155, 945-959.

Raymond M, Rousset F (1995) GENEPOP (version 1.2): population genetics software for exact tests and ecumenicism. Journal of Heredity, 86, 248-249.

Reusch TBH, Ehlers A, Hämmerli A, Worm B (2005) Ecosystem recovery after climatic extremes enhanced by genotypic diversity. Proceedings of the National Academy of Sciences, 102, 2826-2831.

Rice WR (1989) Analyzing tables of statistical tests. Evolution, 43, 223-225.

Rivera MAJ, Kelley CD, Roderick GK (2004) Subtle population genetic structure in the Hawaiian grouper, Epinephelus quernus (Serranidae) as revealed by mitochondian DNA analyses. Biological Journal of the Linnean Society, 81, 449-468. 
Rousset F (1997) Genetic differentiation and estimation of gene flow from F-statistics under isolation by distance. Genetics, 145, 1219-1228.

Roy MS, Sponer R (2002) Evidence of a human-mediated invasion of the tropical western Atlantic by the 'world's most common brittlestar.' Proceedings of the Royal Society London B, 269, 1017-1023.

Ruzzante DE, Taggert CT, Doyle RW, Cook D (2001) Stability in the historical pattern of genetic structure of Newfoundland cod (Gadus morhua) despite the catastrophic decline in population size from 1964-1994. Conservation Genetics, 2, 257-269.

Shank T, Fornari D, Yoerger D, et al. (2003) Deep submergence synergy: Alvin and ABE explore the Galápagos Rift at $86^{\circ} \mathrm{W}$. Eos, 84, 425, 432-433.

Shank TM, Fornari DJ, Von Damm KL, et al. (1998) Temporal and spatial patterns of biological community development at nascent deep-sea hydrothermal vents $\left(9^{\circ} 50^{\prime} \mathrm{N}\right.$, East Pacific Rise). Deep-Sea Research II, 45, 465-515.

Shank T, Govenar B, Buckman K, et al. (2006) Initial biological, chemical, and geological observations after the 2005-6 volcanic eruption on the East Pacific Rise. Eos Transactions, $A G U, \mathbf{8 7}$, Fall Meeting Supplement, Abstract V13C-04.

Shank TM, Halanych KM (2007) Toward a mechanistic understanding of larval dispersal: insights from genomic fingerprinting of the deep-sea hydrothermal vent tubeworm Riftia pachyptila. Marine Ecology, 28, 25-35.

Slatkin M (1985) Rare alleles as indicators of gene flow. Evolution, 39, 53-65.

Slatkin M (1995) A measure of population subdivision based on microsatellite allele frequencies. Genetics, 139, 457-462.

Sotka E, Cushman E, Jue NK (2008) The relative importance of larval and adult dispersal in the economically-important gag grouper Mycteroperca microlepis: a genetic approach. Ocean Science Meeting, Orlando, Florida.

Soule SA, Fornari DJ, Perfit MR, Rubin KH (2007) New insights into mid-ocean ridge volcanic processes from the 2005-2006 eruption of the East Pacific Rise, $9^{\circ} 46^{\prime} \mathrm{N}$ 956’N. Geology, 35, 1079-1082.

Tolstoy M, Cowen JP, Baker ET, et al. (2006) A sea-floor spreading event captured by seismometers. Science, 314, 1920-1922.

Van Dover CL, German CR, Speer KG, Parson LM, Vrijenhoek RC (2002) Evolution and biogeography of deep-sea vent and seep invertebrates. Science, 295, 1253-1257.

Vrijenhoek RC, Shank T, Lutz RA (1998) Gene flow and dispersal in deep-sea hydrothermal vent animals. Cahiers de Biologie Marine, 39, 363-366.

Wade MJ, McCauley DE (1988) Extinction and recolonization: their effect on the genetic differentiation of local populations. Evolution, 42, 995-1005. 
Watts RJ, Johnson MS, Black R (1990) Effects of recruitment on genetic patchiness in the urchin Echinometra mathaei in Western Australia. Marine Biology, 105, 145 151.

Weir BS, Cockerham CC (1984) Estimating F-Statistics for the analysis of population structure. Evolution, 38, 1358-1370.

Weir BS (1996) Genetic Data Analysis II, Sinauer Associates, Sunderland, Massachusetts.

Wood AR, Gardner JPA (2007) Small spatial scal population genetic structure in two limpet species endemic to the Kermadec Islands, New Zealand. Marine Ecology Progress Series, 349, 159-170.

Wright S (1951) The genetical structure of population. Annals of Eugenetics, 15, 323354. 


\section{Chapter 5}

\section{Concluding remarks}

The general goal of this thesis was to analyze spatial and temporal population genetic patterns and the processes governing them at ephemeral and disjunct habitats. To do this, I considered cohorts of a dominant macrofaunal species at deep-sea hydrothermal vents in the equatorial eastern Pacific, the siboglinid tubeworm Riftia pachyptila, for which a time series of samples was available. Samples were also collected on two ridge systems over spatial scales of tens of meters to hundreds of kilometers, enabling examination of the effect of distance on population genetic structure. A significant seafloor eruption during the seven-year sampling period allowed investigation into the role of local extinction in population genetic diversity at the Tica vent site at $9^{\circ} \mathrm{N}$ EPR, while Riftia collections within two and five years of an eruption that created the Rosebud vent field at $86^{\circ} \mathrm{W}$ GAR provided insights into genetic diversity input over population establishment.

\subsection{Summarized findings}

This thesis has developed a suite of 12 hypervariable neutral molecular markers presumed to be representative of Riftia's entire genome and capturing high levels of genetic diversity within the northern portion of its species range (Chapter 2). Eight of these microsatellite loci were applied to a regional scale population genetic study of recent colonist and resident adult cohorts at five sites. For the first time, genetic differences between Riftia populations on the East Pacific Rise and Galápagos Rift could be shown (Chapter 3). More importantly, the separate treatment of colonist and resident subpopulations revealed a high potential for local larval retention at vent sites. This mechanism for recruitment likely sustains disjunct populations and supports the recolonization of locally extinct areas after disturbance events, while episodic longdistance dispersal maintains genetic coherence of the species. Building on the hypothesis 
of local recruitment, population genetic analysis was extended to fine-scale spatial comparisons at three sites within each of the $9^{\circ} \mathrm{N}$ EPR and $86^{\circ} \mathrm{W}$ GAR segments and to temporal comparisons over two to seven years the $9^{\circ} \mathrm{N}$ EPR Tica and $86^{\circ} \mathrm{W}$ GAR Rosebud vent sites (Chapter 4). Temporal population genetic consideration at the Tica site on the East Pacific Rise spanned a 2005-2006 seafloor eruption, which had little to no discernable effect on local population genetic composition. Local populations appear to exhibit a small degree of genetic patchiness, with a high degree of relatedness among a subset of individuals within both colonist and resident cohorts (half-sibs).

\subsection{Barrier to gene flow between the East Pacific Rise and Galápagos Rift}

A potential barrier to gene flow in Riftia (e.g., larval dispersal barrier) exists between the East Pacific Rise and the Galápagos Rift populations considered in this thesis. EPR and GAR Riftia populations consistently fell as two entities, with the resident genetic signal primarily acting to differentiate the two groups. Exact tests of genic and genotypic differentiation, variation along the first principal component axis of a PCA, individual partitioning in STRUCTURE analysis, and multi-locus estimates of $F_{\mathrm{ST}}$ and $R_{\mathrm{ST}}$ revealed significant differences between the two ridge population assemblages. Small (less than $\left.3 \% F_{\mathrm{ST}}\right)$ but significant genetic distance between Riftia populations on the EPR and GAR may indicate that long-distance larvae originating from one ridge may occasionally colonize hydrothermal vent sites along the other ridge, but the preponderance of evidence here suggests that populations on each ridge system are primarily self-seeding on a mesoscale level (as in Johansson et al. 2008) and that gene flow between them is a relict of historic processes.

Within a ridge system, however, low genetic differentiation suggests that cohorts are well mixed and gene flow is extensive. The pooled EPR populations displayed significant overall genic differentiation; yet, this signal disappeared when colonists and residents were considered separately. Non-significant, but roughly $1 \%$, genetic differentiation 
(patchiness), existed between $21^{\circ} \mathrm{N}$ EPR and other EPR populations to the south. Visually apparent from the PCA, but also non-significant, was the more distant arrangement of $13^{\circ} \mathrm{N}$ from $21^{\circ} \mathrm{N}$ EPR subpopulations. The $9^{\circ} \mathrm{N}$ EPR ridge segment populations were homogenous in terms of genic and genotypic variation, but overall significant genic variation was present on the $86^{\circ} \mathrm{W}$ GAR segment. No significant $F_{\mathrm{ST}}$ differences were found among intra-segment populations, nor was IBD apparent on that scale.

I propose the following scenarios for establishing the genetic patterns described above:

- A young population such as Rosebud may be founded by a stochastic dispersal event from an EPR-like population - and perhaps one that was not sampled or was otherwise undetected-leaving that signal of genetic similarity in the original residents; recent colonists will more likely arrive from nearby GAR populations, which have already established a genetic signal distinct from the EPR. Although vents on these two ridge systems provide a similar chemical milieu, focused black smoker flow is not present in the $86^{\circ} \mathrm{W}$ GAR region. As such, the cue for larval settlement may be weaker and more localized at the GAR than at the EPR, favoring recruits from nearby vents.

- Meanwhile, the Garden of Eden population has had time to assemble itself and differentiate from the EPR. In 2005, extensive Riftia assemblages at Garden of Eden contained the largest recorded tubeworms ( $>2 \mathrm{~m}$, pers. obs. T. Shank), suggesting they might be part of a long-lived, robust population, first observed at this site in 1977 (Corliss et al. 1979). At $\sim 20$ years old, this population may be at a stage in development in which it is likely to act as a source population for nearby and nascent sites.

- The $21^{\circ} \mathrm{N}$ ridge segment has been active for at least 300 years with a spreading rate of $60 \mathrm{~mm} / \mathrm{yr}$, but a short shift in activity likely occurred over the past century, followed by several decades of continuous flow (Desbruyères 1998). As such, there has been time to receive limited input from distant vent populations to the 
south, though genetic similarity to other populations on the EPR could also be a relict of historic dispersal processes predating the Rivera Fracture Zone.

- Vents at $13^{\circ} \mathrm{N}$ experienced instabilities in fluid flux between 1982 and 1990 (Fustec et al. 1987, Desbruyères 1998) and a resurgence of hydrothermal activity in the 1990s (Voight et al. 2004), but it is hypothesized that two centuries ago the $13^{\circ} \mathrm{N}$ segment was relatively stable. Less punctuated disturbance could have prevented the settlement of early colonists like Riftia, thus precluding significant gene flow from other areas.

\subsubsection{Influence of larval transport on oceanographic currents}

Coupled with these genetic findings and predictions of population establishment and persistence based on geological observations, the physical oceanographic setting requires consideration in respect to larval transport among vents. Correlations of strong along-axis flow with daily larval supply support the prediction of primary larval supply from local sources (1-2 km) in other hydrothermal vent taxa, while entrainment by mesoscale eddies (apparently generated along distant storm tracks; Palacios \& Bograd 2005) may facilitate transport between vents hundreds of kilometers apart two to three times a year (Adams 2007, Adams \& Mullineaux 2008). Moreover, deep current models on the East Pacific Rise have predicted that along-ridge flow reversals likely retain most larvae within tens of kilometers of their source population, while larvae that remain longer in the water column have a greater likelihood of being swept off-axis and lost to the ridge system (Marsh et al. 2001, Thiébaut et al. 2002, Mullineaux et al. 2002). Larvae that remain near the EPR's ridge axis may be dispersed by tidal reversals on the order of $100 \mathrm{~km}$ (SSE, half as much to NNW) along axis, except for at $13^{\circ} \mathrm{N}$, where sustained SSE flows and a longer larval lifespan could extend Riftia's potential dispersal up to $245 \mathrm{~km}$ (Marsh et al. 2001, Mullineaux et al. 2002). Outside the axial rift valley, larvae are likely transported away from their natal vents by tidal currents, in which mixing could homogenize larval abundance on scale of 100s m (Mullineaux et al. 2005). However, recent tracer experiments have followed plume advection $80 \mathrm{~km}$ off-axis and subsequently returned to 
the ridge crest within $50 \mathrm{~km}$ of the site of origin (Jackson et al. in prep). The combined factors of along-axis flow with periodic reversal and stochastic eddy passage could primarily retain larvae at a local scale while preserving high genetic heterozygosity in the eastern equatorial Pacific, as evidenced in our results.

Plume-level dispersal of vent larvae could be important for initial colonization and the maintenance of species between distant vent habitats, while local recruitment from nearby populations may be more important to the growth of new populations and the maintenance of those already in existence (Kim \& Mullineaux 1998, Mullineaux et al. 2005). As the populations included in the present study were established years before the time of sampling, it is unlikely that larval inputs stemming exclusively from buoyant vent plumes were sampled.

\subsubsection{Moderate migration rates versus non-equilibrium dynamics}

Homogeneity in genetic composition can result from high gene flow among populations or from historical patterns of colonization from a common source (if time since separation has not been sufficient for drift or accumulation of novel mutations). However, genetic homogeneity does not necessarily imply that a population is panmictic or is acting as a single demographic unit and can be the result of extinction-colonization dynamics - with frequent extinctions and mixed-stock founders or recurrent dispersal from a common source (Newman \& Squire 2001).

As the estimated level of Riftia larval migration in this study is moderate $(\sim 10$ migrants/generation), it could be sufficient for gene flow to counter genetic drift at local populations. Yet similar broad spatial homogeneity and significant differentiation at only on the largest geographic scale of a study's consideration has also been found in surf clams (Cassista \& Hart 2007). In that case, the level of migration between populations needed to homogenize allele frequencies between them is much lower than that needed to replenish exploited populations by dispersal. Likewise, Riftia populations that experience 
contraction or local extinction may be able to be recolonized by small larval input and still maintain genetic homogeneity.

This variety of non-equilibrium (gene flow-genetic drift) dynamics can establish conditions under which populations appear genetically homogenous but actually have a low migration rate, as in the gag grouper in the tropical Atlantic (E. Sotka, OSM 2008). Historical population expansion is able to mask low levels of migration and give an upward bias to gene flow estimates. Such non-equilibrium conditions are likely to be highly influential in Riftia given its environmental setting of frequent habitat turnover. Thus, the level of genetic polymorphism and its spatial distribution is predicted to vary over time and blur the signature of past demographic events with present gene flow. The necessary approach to interpreting contemporary genetic structure must include consideration of these complex ecological interactions.

\subsection{Local larval retention and transport with related individuals}

This thesis suggests that local larval retention (10s-100s meter scale) plays a key role in establishing and maintaining Riftia populations, while limited gene flow exists on longer timescales between ridge systems in the eastern Pacific. Colonists were most genetically similar to residents sampled at the same (and next proximate location), as were cohorts sampled in the same year within a ridge segment $\left(F_{\mathrm{ST}}\right.$; nonparametric van der Waerden test comparing mean $F_{\text {ST }}$ of colonists with local versus more distant resident populations; PCA clustering of colonists with residents from the same sampling location). Within a ridge system, colonists are also more similar to other colonists than residents are to other residents $\left(F_{\mathrm{ST}}\right)$. The majority of self-assigned colonists $(53.8 \%$ overall colonist assignment to the resident adult subpopulation at the same location) were found in the GAR population, suggesting particular fidelity at the Rosebud site, while the $21^{\circ} \mathrm{N}$ and $9^{\circ} \mathrm{N}$ EPR assignments were less dramatic, perhaps owing to mesoscale eddy mixing, but suggest that some recruits are nevertheless retained. 
Considered in summation, the consistency of these results with localized genetic heterogeneity might reflect different rates of population turnover and degrees of patchiness, with genetically homogeneous cohorts and recruits encompassing less variation (seen in STRUCTURE's lack of recruit partitioning) than adults among sites (Watts et al. 1990). These processes support the case for local retention, in that larvae tend to settle at their natal population but occasionally travel longer distances, creating the low differentiation observed among adult cohorts. I propose that the larval cohorts lack genetic signatures unique to their site of origin due to the evolutionarily well-mixed genetic composition of standing populations.

Beyond evidence for high genetic similarity between colonists and resident adults at the same site, extensive heterozygote excess, strong assignment of colonists to their collection location especially at the $86^{\circ} \mathrm{W}$ GAR site, previous genomic fingerprinting which found unresolved polytomies in the smallest Riftia cohorts (Shank \& Halanych 2007), and modeled currents that transport advective particles (larvae) back to the ridge crest (Jackson et al. in prep), "clouds" of larvae spawned and released at the same time may remain together as a coherent group during their mobile stage and settle next to each other upon metamorphosis. Estimates of relatedness were high among samples at a single site and consistent throughout the sampling period of 2 to 7 years ( 4 out of 10 Tica subpopulations and all 6 Rosebud subpopulations had significantly more half-sibs were found than in a randomly generated group of the same size), but the number of full sibs was not significantly different in any subpopulation at any location.

Dispersal in discrete larval cohorts that include aggregated siblings ensures that a network of populations are maintained and ecologically connected in spite of frequent local extinctions and a disjunct habitat (metapopulation dynamics). Weak assignment at $9^{\circ} \mathrm{N}$ EPR was not as strongly suggestive of retention as at $86^{\circ} \mathrm{W}$ GAR, suggesting that EPR larval cohorts may be more widely dispersed or preserve the genetic signature of more historical mixing events than GAR cohorts. The heterozygote excess found in the 
present study leads to the hypothesis that despite the close proximity of relatives and larval transport as related cohorts, mating is still likely to be random (contrast with Addison \& Hart 2005). I propose that like pioneer rainforest trees in Africa, a high proportion of Riftia adults contribute to colonist establishment within a vent site or segment, thereby creating stable heterozygosity and allelic richness (Born et al. 2008). Such absence of a founder effect despite metapopulation dynamics can be accomplished through a combination of local retention and aggregated cohort dispersal, coupled with high fecundity and contributions of overlapping generations.

\subsection{Ecological and evolutionary genetic connectivity}

Proximity to other Riftia populations and the ability to settle as related cohorts through local retention and along-axis dispersal likely allows a high degree of genetic connectivity on ecologically and demographically relevant scales. Despite variations in vent chemistry and fluid flow and recent local extinctions, Riftia temporal variation was also minimal at the Tica $9^{\circ} \mathrm{N}$ EPR and Rosebud $86^{\circ} \mathrm{W}$ GAR vent sites over periods of three to seven years. There was no differentiation detected among years at Rosebud, with populations or subpopulations pooled by year or separated as discrete patches by their collection marker and year. However, in the Tica samples, divergence among subpopulations \& pooled years (genic differentiation), and also among sample years (AMOVA), was detected. Pairwise temporal $F_{\mathrm{ST}}$ values were not significant, but the largest difference was detected at Tica between 2004 and 2007 residents. Allele frequencies among colonist cohorts were remarkably consistent over time, which could indicate a stable source population (Gilg \& Hilbish 2003). Stepping-stone dispersal does not seem to be the mechanism for maintaining genetic cohesiveness across northern EPR and GAR Riftia populations over evolutionary time but may be responsible for biologically important genetic differences with ecological significance (as in Purcell et al. 2006). It is more likely that the marked genetic diversity and history of metapopulation dynamics at these vents may make traditional island or stepping-stone models of dispersal obsolete (Hellberg 2006). 


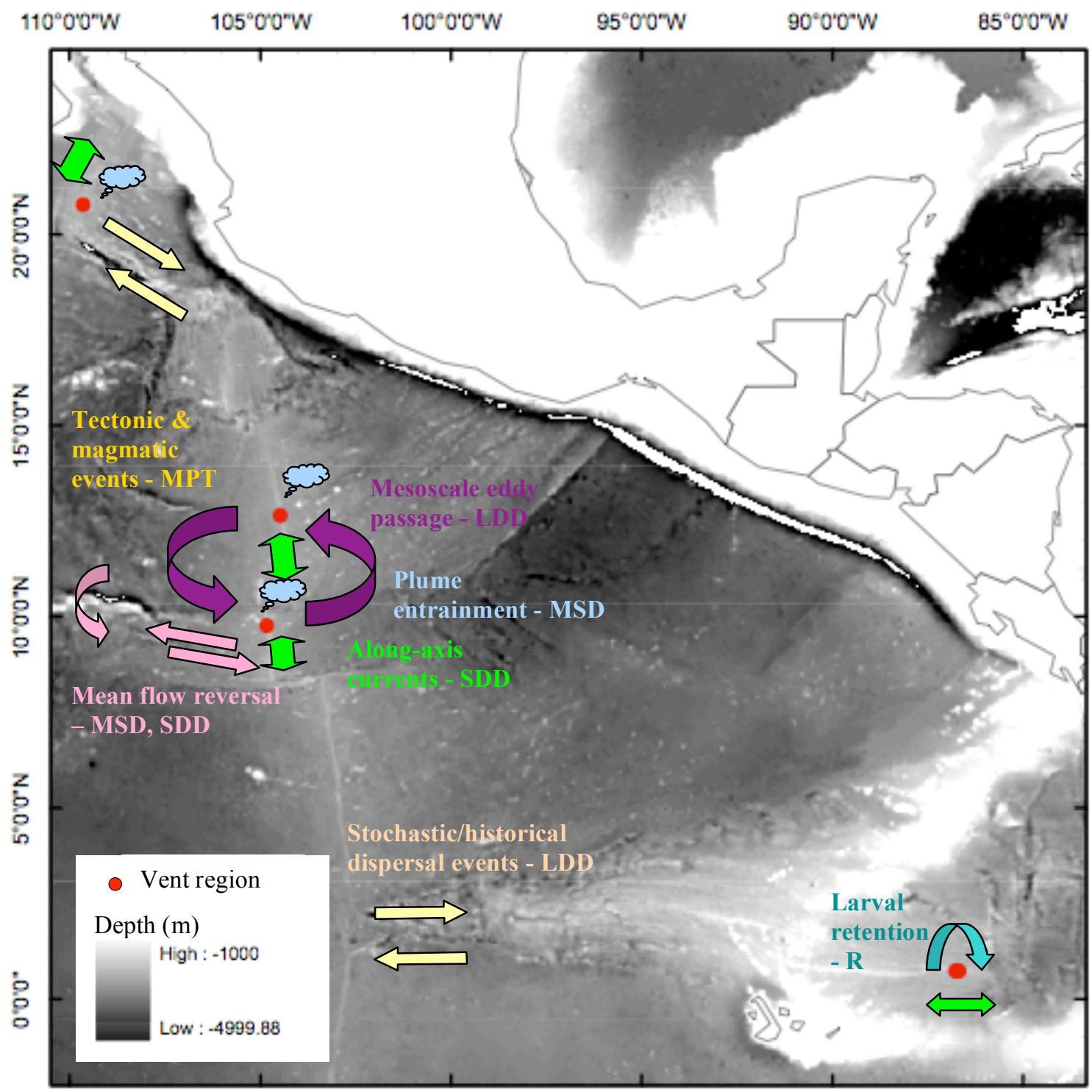

Figure 5.1 Conceptual model of Riftia dispersal and colonization on the East Pacific Rise and Galápagos Rift. Gene flow and population genetic connectivity are proposed to be higher on the EPR due to a higher rate of habitat and population turnover (metapopulation dynamics of extinction and colonization promoting genetic diversity) and longer-range dispersal via periodic mesoscale eddy passage driven by distant storms, and hydrothermal buoyant plume entrainment from more prevalent black smokers. Mean flow reversals and along-axis currents serve to transport larvae short to intermediate distances, sometimes returning related colonists to their populations of origin. Meanwhile, on the GAR, the notable paucity of storm tracks and black smokers, combined with a longer life expectancy of vent fluid sources due to few magmatic and tectonic disturbances, are proposed to favor larval retention. Stochastic or historical long-distance dispersal events preserve species genetic coherence among EPR and GAR populations. MPT, metapopulation turnover, LDD, long-distance dispersal $(>200 \mathrm{~km}), \mathrm{MSD}$, mesoscale dispersal (50-200 km), SDD, short-distance dispersal $(10-50 \mathrm{~km}), \mathrm{R}$, retention $(<10 \mathrm{~km})$. 


\subsection{Conceptual model of Riftia dispersal and colonization}

In order to visualize the complex interplay of processes influencing the population genetic structure of Riftia at vents, I have outlined a conceptual model for dispersal, retention, and colonization (Figure 5.1). This model highlights the proposed dominance of larval retention within the GAR and mechanisms for population genetic connectivity along the EPR. Future studies should investigate the relative importance of each hypothesized process in establishing and maintaining the overall population genetic structure observed within these ridge systems. Additionally, the effect of gamete release and larval behavior at a local scale should be considered in relation to these larger scale processes.

\subsection{Comparisons with historical study design and previous genetic patterns in Riftia}

The traditional markers (allozymes, mtDNA) selected for historical population genetic studies of Riftia exhibited low levels of variability and subsequently concluded high gene flow exists through most of Riftia's species range. Black et al. (1994) observed slight isolation by distance with an intermediate rate of gene flow $(\mathrm{Nm}=10)$, but the greatest genetic distances between populations were not in EPR-GAR comparisons, as found in this dissertation. These previous authors included samples from multiple years and pooled tubeworms both larger and smaller than $30 \mathrm{~cm}$, which may have blurred their results. They found no significant differences between observed and expected heterozygosities resulting from violation of random mating, and observed heterozygosity decreased from north (Guaymas Basin) to south (Galápagos Rift), resulting from higher $F_{\mathrm{IS}}$ in the south and higher gene diversity $\left(H_{\mathrm{E}}\right)$ in the north (Black et al. 1994). In the current work, I found opposite trends, with higher observed heterozygosity and lower $F_{\text {IS }}$ in populations to the south; gene diversity is higher on the EPR than on the GAR, but there was no apparent trend with latitude along the EPR itself. The pattern discrepancy may be due to the markers chosen for each study. Perhaps allozymes tend to be more 
diverse in stable environments, while microsatellite diversity is favored in regions of high population turnover. That said, Black et al. (1994) found few rare alleles $(<10 \%)$ in any population, consistent with frequent population bottlenecks and rapid population growth. However, rare alleles were prevalent my study. Higher mutation rates in microsatellite DNA predispose these loci to greater allele diversity than found in other molecular markers. Rare alleles are more likely to arise on shorter time scales in microsatellites and therefore have the potential to be maintained and dispersed despite demographic contractions.

In a study ten years following Black and colleagues' that also pooled samples collected over a number of years, population subdivision was found only across the Easter Microplate in the southern Pacific Ocean (Hurtado et al. 2004). A third allele was limited to the Galápagos Rift, but because most individuals from the EPR were screened with a restriction enzyme that cuts at a particular assumed diallelic polymorphism, that third sequenced allele may have been missed. Hurtado and colleagues (2004) invoke a strong bottleneck or selective sweep as an explanation for reduced genetic variability. As discussed in more detail in the following section, this thesis found high levels of genetic variation within populations, suggesting that there is another process compensating for demographic bottlenecks in Riftia, potentially local retention and metapopulation dynamics.

Recently, Shank \& Halanych (2007) demonstrated that discrete cohorts of related individuals could be identified in Riftia. These authors hypothesized that previous studies have used genetic markers insensitive to ecological scale processes (e.g., larval dispersal, habitat turnover), thereby under-sampling genetic diversity. Using unique genomic fingerprints, they found significant differences among EPR populations (Shank \& Halanych 2007). However, their non-Mendelian fingerprinting data were unable to distinguish homozygous from heterozygous individuals and cannot be compared directly to my results. Ongoing work with autonomous nuclear loci, nuclear introns, and mtDNA 
by Coykendall and others (2007 IRTI) is consistent with the genetic differences we found between EPR and GAR populations, but also is suggestive of IBD. Microsatellite markers developed for the current study were able to capture the unique genetic composition of individuals but could not differentiate among populations at the ridge-scale. These new loci likely belong to a class of hypervariable loci, whose utility is partially compromised by extreme diversity and high mutation rates.

\subsection{Microsatellite markers and genetic variation}

\subsubsection{Application of hypervariable loci}

A highly variable locus is defined as one with more than 25 alleles, greater than $85 \%$ heterozygosity, greater than $92 \%$ expected heterozygosity, or greater than $84 \%$ mean within population heterozygosity $\left(H_{\mathrm{s}}\right)$ (Selkoe \& Toonen 2006; Beck et al. 2003; Olsen et al. 2004). Low to moderate polymorphism in a locus is defined as less than $60 \%$ mean $H_{\mathrm{s}}$ (Olsen et al. 2004). Highly variable loci have more power to distinguish close relatives and to assign individuals to a source population than less variable loci, but $F_{\mathrm{ST}}$ estimates may likewise be dampened due to a high occurrence of allele homoplasy or higher heterozygosity (Selkoe \& Toonen 2006; Olsen et al. 2004). Loci of similar heterozygosity should be grouped in analyses in order to limit the negative correlation between $F_{\mathrm{ST}}$ and heterozygosity (Selkoe \& Toonen 2006; Olsen et al. 2004). Moreover, it is recommended to use $F_{\mathrm{ST}}$ of binned alleles or $R_{\mathrm{ST}}$ estimates to infer population genetic structure when $F_{\text {ST }}$ appears underestimated by highly polymorphic loci (Olsen et al. 2004; Buonaccorsi et al. 2001). Pairwise estimates of $F_{\mathrm{ST}}$ can also be stratified by spatial scale in comparison to theoretical expectations to avoid incorrect inferences of migration rates (Olsen et al. 2004).

In the present thesis, all or nearly all Riftia loci could be categorized as hypervariable, which likely dampened $F_{\mathrm{ST}}$ estimates across populations. However, analyses of relatedness and assignment were also strengthened by this extreme allelic diversity. There was no need to consider some loci separately, as they were all of similar heterozygosities. 
Binning alleles into larger size ranges was not possible, given the even continuum of Riftia fragment lengths. The artificial division and lumping of certain alleles may not be appropriate in this case. I did however consider $F_{\mathrm{ST}}$ estimates in increments via the design of this study, ranging from long distance comparisons in Chapter 3 to finer increments in Chapter 4. Time was considered separately in Chapter 4, as well.

As for the measure of population differentiation, mutation rates in hypervariable loci may be high enough to violate the assumptions or interpretations of population genetic analyses (Epperson 2005). For instance, when mutation rate is greater than or equal to migration rate, $F_{\mathrm{ST}}$ can be misinterpreted and the effective number of migrants will be overestimated; thus, inferences about the forces structuring populations will be incorrect (Olsen et al. 2004). Estimates of $R_{\mathrm{ST}}$ are mutation-based compared to the frequency-based estimates of $F_{\mathrm{ST}}$, and the former account for the mutational component of microsatellites. Contrary to expectations, estimates of $R_{\mathrm{ST}}$ using these Riftia data did not reveal more genetic structure among population than did estimates of $F_{\text {ST. This may be due to }}$ violation of equilibrium processes in systems exhibiting frequent extinction and recolonization. Although mutation rates were certainly high enough to generate the observed allelic diversity, the frequency of those alleles in populations might better reflect their origins.

When using highly polymorphic microsatellite data, increasing the number of individuals sampled can decrease the coefficient of variance (and increase the precision of the estimate), but only to a certain point; beyond that, the returns for a larger sample size are diminishing, the degree determined by the extent of population differentiation (Kalinowski 2005). Sample size has not, however, been correlated with the proportion of significant comparisons (Buonaccorsi et al. 2001). The coefficient of variance can also be decreased by using loci with high mutation rates, but mutation rate and the level of locus polymorphism are independent of the contribution sample size makes (Kalinowski 2005). All the same, studies that include populations with small genetic divergence will need to 
sample more individuals in order to increase the precision of estimating that differentiation (e.g., using 16 loci with an $F_{\mathrm{ST}}>0.05$ requires sample sizes of $\mathrm{n} \sim 20$ per population, while the same number of loci attempting to differentiate populations with $F_{\mathrm{ST}}<0.01$ will need n 100 per population to have the same precision). Deep-sea biologists are continuously fraught with limited access to sites and samples, but it would appear that there might not have been large enough sample sizes in the current work to routinely detect differences among populations. Finer scale structure might have been more apparent had more individuals been available across all sites.

To make more complete use of the power and precision of these Riftia microsatellites, sample size should be increased to around 50 individuals per subpopulation. Future studies should collect more individuals so that this potential for greater resolution on the ridge scale can be tested. Understandably, given the dynamic nature of demographic bottlenecks and recolonization in vent populations, temporal studies of cohorts may not always have enough individuals to sample, as in case of the 2002 adult subpopulation at Rosebud and of both post-eruption colonists and residents in 2007 at Tica. Nevertheless, efforts should be taken to evenly sample representative cohorts whenever possible.

\subsubsection{Microsatellite variability in polychaetes}

The high proportion of hypervariable loci developed for Riftia led to the question of whether this may be typical of annelids or polychaetes in general. A survey of all published microsatellites located six other polychaete studies for comparison (Table 5.1).

The range of observed heterozygosities in Riftia tended to be similar to that of other polychaetes, but mean subpopulation $H_{\mathrm{O}}$ was greatest in the present study. Riftia expected heterozygosities all fell in the upper range of other polychaetes and its mean $H_{\mathrm{E}}$ was similar to the tube-building, intertidal terebellid Pectinaria koreni (Weinmayr et al. 2000). In addition, microsatellite loci in Riftia had average to above average numbers of 
Table 5.1 Microsatellite markers variability in polychaetes.

\begin{tabular}{lccccccc}
\hline Polychaete species & $n$ & $H_{\mathrm{O}}$ & $H_{\mathrm{O} \text { mean }}$ & $H_{\mathrm{E}}$ & $H_{\mathrm{E} \text { mean }}$ & $k$ & $k_{\text {mean }}$ \\
\hline Capitella capitata $^{1}$ & 30 & $0.10-0.87$ & 0.52 & $0.37-0.98$ & 0.77 & $4-36$ & 15.27 \\
Branchipolynoe seepensis $^{2}$ & 92 & $0.165-0.944$ & 0.565 & $\mathrm{n} / \mathrm{a}$ & $\mathrm{n} / \mathrm{a}$ & $2-54$ & 11.89 \\
${\text { Pectinaria } \text { koreni }^{3}}^{4}$ & 35 & $0.29-0.81$ & 0.57 & $0.84-0.97$ & 0.93 & $16-41$ & 29 \\
Hobsonia florida $^{4}$ & 19 & $0.21-0.92$ & 0.60 & $0.52-0.92$ & 0.78 & $6-11$ & 8.62 \\
Seepiophila jonesi $^{5}$ & 168 & $0.08-1.00$ & 0.70 & $0.31-0.97$ & 0.80 & $4-54$ & 22.12 \\
Lamellibrachia luymesi $^{5}$ & 235 & $0.44-0.96$ & 0.74 & $0.55-0.93$ & 0.85 & $12-30$ & 20.8 \\
Hydroides elegans $^{6}$ & 137 & $0.465-0.893$ & 0.854 & $0.493-0.896$ & 0.821 & $3-24$ & 16.2 \\
Riftia pachyptila $^{5}$ & $\mathbf{4 6 9}$ & $\mathbf{0 . 4 6 6 7 - 1 . 0 0 0 0}$ & $\mathbf{0 . 9 0 4 7}$ & $\mathbf{0 . 7 8 9 5 - 1 . 0 0 0 0}$ & $\mathbf{0 . 9 3 2 6}$ & $\mathbf{1 8 - 4 2}$ & $\mathbf{1 5 . 2 8}$ \\
\hline
\end{tabular}

$n$, number of alleles per locus over all populations, $H_{\mathrm{O}}$ and $H_{\mathrm{E}}$, observed and expected locus heterozygosities per subpopulation, $k$, number of alleles per locus over all populations. ${ }^{1}$ Du et al. $2007^{2}$ Daguin \& Jollivet $2005^{3}$ Weinmayr et al. $2000{ }^{4}$ Olson et al. $2006{ }^{5}$ McMullin et al. $2004{ }^{6}$ Pettengill et al. 2003

alleles. Although the mean per subpopulation allele number was low due to a few subpopulations with small sample sizes, total allele counts per locus were concentrated in the upper range of other species. The absence of low diversity loci in Riftia could have originated in the screening process during locus development, but the same bias for longer and more polymorphic loci could be similar in other studies. If it is assumed that highly polymorphic loci are more available in a given genome, then the likelihood for finding these loci increases. In that case, Riftia's genome may be enriched in hypervariable microsatellite regions. The evolutionary explanation for such variability is unknown, but it may be that like other polychaetes from deep-sea chemosynthetic environments (Branchipolynoe seepensis, Seepiophila jonesi, and Lamellibrachia luymesi) or shallow-water estuaries (Pectinaria koreni), Riftia favors genetic diversity in the form of simple sequence repeats.

\subsubsection{Genetic variation in the survival of species}

High Riftia genetic variation, as evidenced by microsatellites, likely results from, and is a mechanism for, species survival in the ephemeral vent environment. Differences in effective population size and in the frequency of habitat turnover are suspected to be the most reasonable explanations for greater genetic diversity on the EPR. As a result of 
mutation-drift disequilibrium created by population expansion quickly following population reduction (Busch et al. 2007), populations may have high genetic variation within them and negligible subdivision between them. Thus, the metapopulation processes often invoked in hydrothermal vent systems (Jollivet et al. 1999) may not substantially reduce neutral genetic diversity (Jehle et al. 2005). Instead, under a heterogeneous or changing set of selective conditions, a highly variable assortment of genotypes is predicted to be adaptively and evolutionarily stable, increasing the probability of successful establishment (Holland 2001). Moreover, allelic diversity can be maintained by a variety of processes (Holland 2001), but the standing diversity of each population suggests that influx from one genetically diverse source population is sufficient.

\subsection{Broader impacts}

\subsubsection{Consideration of fine spatial and temporal scale patterns}

The work presented in this thesis demonstrates the importance of population genetic marker selection relative to the scale of ecological processes of interest. Moreover, heterogenous habitat landscapes are not necessarily reflected in population genetic structure. Coupling high-resolution and dynamic modeling of currents from small to large scales will likewise inform the delivery mechanisms of larvae to vents. Lastly, the role of non-equilibrium dynamics at vents requires further investigation. In the scale of our sampling, selective processes that occur soon after settlement may have been missed; if present, these will be important to quantify with respect to the hypothesis of local retention. The incorporation of historical coalescence and simulation of other nonequilibrium processes may thus be useful in tracking the emergence of current patterns (E. Sotka, OSM 2008). 


\subsubsection{Multiple cohort perspective in population genetics}

Multiple cohorts are important to consider in population genetic studies, as ecological processes act separately on different life stages. In order for tests of population differentiation to be significant, care should be taken to adequately sample individuals from separate cohorts. Future studies of population genetics at hydrothermal vents will have to consider (larval,) juvenile and adult cohorts in order to understand dispersal and local processes more completely, as focusing only on a particular stage could lead to different inferences about recruitment processes and the extent of contemporary or historic gene flow.

Sampling distinct cohorts of vent populations will ensure that the genetic signal inherent to recent arrivals is not lost by pooling individuals from the larger multigenerational population. The genetic composition of colonist cohorts records important information about their origins and dispersal process. The arrival of colonists from local populations further aids population genetic maintenance. Furthermore, Riftia post-settlement mortality should be considered in order to determine its timing and influence on cohorts.

\subsection{Final remarks and future directions}

In this thesis, I was able to develop highly polymorphic DNA microsatellites for a wellcharacterized deep-sea organism. These loci had the power to distinguish EPR from GAR populations but found primarily intra-ridge population genetic homogeneity. Assignment tests and relatedness analyses revealed the tendency for local retention of Riftia larvae, especially on the GAR, which likely facilitates the existence of this species in an ephemeral and disjunct environment fraught by local population turnover.

The hotspot-influenced region of the Galápagos Spreading Center from $86^{\circ}$ to $95^{\circ} \mathrm{W}$ may be particularly interesting to monitor for future hydrothermal activity. It has been proposed that during waxing periods of interactions with the Galápagos hotspot, 
hydrothermal habitats will be abundant and vent fauna will easily disperse among sites; however, during waning times, populations will become genetically isolated on opposite sides of the hotspot (Haymon et al. 2007). If the region between Rosebud/Rose Bowl and the recently discovered Navidad black smokers $400 \mathrm{~km}$ to the west is chronically deficient in vents, Riftia populations may be more divergent than a similar distance on the East Pacific Rise.

Ongoing development of microsatellite markers for two additional vent species (the vent mussel Bathymodiolus thermophilus and commensal polychaete Branchipolynoe symmytilida, Appendix C) with similar demographic ranges as Riftia will facilitate consideration of fine-scale genetic patterns resulting from different larval life histories. A metapopulation approach may have even greater utility with the tubeworm Tevnia jerichonana. Given the recent 2005-2006 eruption and subsequent colonization and persistence of Tevnia en masse at $9^{\circ} \mathrm{N}$ EPR, it will be interesting to consider the resulting population genetic patterns in this species with temporal sampling and high resolution markers in the future. 


\subsection{References}

Adams DK (2007) Influence of hydrodynamics on the larval supply to hydrothermal vents on the east Pacific Rise. PhD Thesis, MIT/WHOI Joint Program, Massachusetts Institute of Technology/Woods Hole Oceanographic Institution, MA.

Adams DK, Mullineaux LS (2008) Supply of gastropod larvae to hydrothermal vents reflects transport from local larval sources. Limnology and Oceanography, in press.

Addison JA, Hart MW (2005) Colonization, dispersal, and hybridization influence phylogeography of North Atlantic sea urchins (Strongylocentrotus droebachiensis). Evolution, 59, 532-543.

Beck NR, Double MC, Cockburn A (2003) Microsatellite evolution at two hypervariable loci revealed by extensive avian pedigrees. Molecular Biology and Evolution, 20, 54-61.

Black MB, Lutz RA, Vrijenhoek RC (1994) Gene flow among vestimentiferan tube worm (Riftia pachyptila) populations from hydrothermal vents of the eastern Pacific. Marine Biology, 120, 33-39.

Born C, Kjellberg F, Chevallier M-H, et al. (2008) Colonization processes and the maintenance of genetic diversity: insights from a pioneer rainforest tree. Proceedings of the Royal Society B, FirstCite doi:10.1098/rspb.2008.0446.

Buonaccorsi VP, McDowell JR, Graves JE (2001) Reconciling patterns of inter-ocean molecular variance from four classes of molecular markers in blue marlin (Makaira nigricans). Molecular Ecology, 10, 1179-1196.

Busch JD, Waser PM, DeWoody JA (2007) Recent demographic bottlenecks are not accompanied by a genetic signature in banner-tailed kangaroo rats (Dipodomys spectabilis). Molecular Ecology, 16, 2450-2462.

Cassista MC, Hart MW (2007) Spatial and temporal genetic heterogeneity in the Arctic surfclam (Mactromeris polynyma). Marine Biology, 152, 569-579.

Corliss JB, Dymond J, Gordon LI, et al. (1979) Submarine thermal springs on the Galápagos Rift. Science, 203, 1073-1083.

Coykendall DK, Lutz R, Vrijenhoek R (2007) Investigation of gene flow and migration across the global range of Riftia pachyptila using six molecular markers. InterRidge Theoretical Institution, Woods Hole, MA 02571.

Daguin C, Jollivet D (2005) Development and cross-amplification of nine polymorphic microsatellite markers in the deep-sea hydrothermal vent polychaete Branchipolynoe seepensis. Molecular Ecology Notes, 5, 780-783. 
Desbruyères D (1998) Temporal variations in the vent communities on the East Pacific Rise and Galápagos Spreading Centre: a review of present knowledge. Cahiers de Biologie Marine, 39, 241-244.

Du H, Han J, Lin K, Qu X, Wang W (2007) Characterization of 11 microsatellite loci derived from genomic sequences of polychaete Capitella capitata complex. Molecular Ecology Notes, 7, 1144-1146.

Epperson BK (2005) Mutation at high rates reduces spatial structure within populations. Marine Ecology, 14, 703-710.

Fustec A, Desbruyères D, Juniper SK (1987) Deep-sea hydrothermal vent communities at $13^{\circ} \mathrm{N}$ on the East Pacific Rise: microdistribution and temporal variations. Biological Oceanography, 4, 121-161.

Gilg MR, Hilbish TJ (2003) Spatio-temporal patterns in the genetic structure of recently settled blue mussels (Mytilus spp.) across a hybrid zone. Marine Biology, 143, 679690.

Haymon RM, Baker ET, Resing JA, et al. (2007) Hunting for hydrothermal vents along the Galápagos Spreading Center. Oceanography, 20, 100-107.

Hellberg ME (2006) Genetic approaches to understanding marine metapopulation dynamics. pp. 431-455 in Marine Metapopulations, J. Kritzer and P. F. Sale (eds.). Academic, San Diego.

Holland BS (2001) Invasion without a bottleneck: microsatellite variation in natural and invasive populations of the brown mussel Perna perna (L). Marine Biotechnology, 3, 407-415.

Hurtado LA, Lutz RA, Vrijenhoek RC (2004) Distinct patterns of genetic differentiation among annelids of eastern Pacific hydrothermal vents. Molecular Ecology, 13, 26032615.

Jackson PR, Ledwell JR, Thurnherr AM (in prep) Dispersion of a tracer on the East Pacific Rise $\left(9^{\circ} \mathrm{N}\right.$ to $\left.10^{\circ} \mathrm{N}\right)$, including the influence of hydrothermal plumes.

Jehle R, Wilson GA, Arntzen JW, Burke T (2005) Contemporary gene flow and the spatio-temporal genetic structure of subdivided newt populations (Triturus cristatus, T. marmoratus). Journal of Evolutionary Biology, 18, 619-628.

Johansson ML, Banks MA, Glunt KD, Hassel-Finnegan HM, Buonaccorsi VP (2008) Influence of habitat discontinuity, geographical distance, and oceanography on finescale population genetic structure of copper rockfish (Sebastes caurinus). Molecular Ecology, 17, 3051-3061.

Jollivet D, Chevaldonné P, Planque B (1999) Hydrothemal-vent alvinellid polychaete dispersal in the eastern Pacific. 2. A metapopulation model based on habitat shifts. Evolution, 53, 1128-1142. 
Kalinowski ST (2005) Do polymorphic loci require large sample sizes to estimate genetic distances? Heredity, 94, 33-36.

Kim S, Mullineaux LS (1998) Distribution and near-bottom transport of larvae and other plankton at hydrothermal vents. Deep-Sea Research, 45, 423-440.

Marsh AG, Mullineaux LS, Young CM, Manahan DT (2001) Larval dispersal potential of the tubeworm Riftia pachyptila at deep-sea hydrothermal vents. Nature, 411, 7780 .

McMullin ER, Wood J, Hamm S (2004) Twelve microsatellites for two deep sea polychaete tubeworm species, Lamellibrachia luymesi and Seepiophila jonesi, from the Gulf of Mexico. Molecular Ecology Notes, 4, 1-4.

Mullineaux LS, Mills SW, Sweetman AK, et al. (2005) Vertical, lateral and temporal structure in larval distributions at hydrothermal vents. Marine Ecology Progress Series, 293, 1-16.

Mullineaux LS, Speer KG, Thurnherr AM, Maltrud ME, Vangriesheim A (2002) Implications of cross-axis flow for larval dispersal along mid-ocean ridges. Cahiers de Biologie Marine, 43, 281-284.

Newman RA, Squire T (2001) Microsatellite variation and fine-scale population structure in the wood frog (Rana sylvatica). Molecular Ecology, 10, 1087-1100.

Olsen JB, Habicht C, Reynolds J, Seeb JE (2004) Moderately and highly polymorphic microsatellites provide discordant estimates of population divergence in sockeye salmon, Oncorhynchus nerka. Environmental Biology of Fishes, 69, 261-273.

Olson MA, Zajac R, Caccone A, Russello MA (2006) Characterization of polymorphic microsatellite loci for the polychaete tubeworm Hobsonia florida. Molecular Ecology Notes, 6, 390-392.

Palacios DM, Bograd SJ (2005) A census of Tehuantepec and Papagayo eddies in the northeastern tropical Pacific. Geophysical Research Letters, 32, L23606.

Pettengill JB, Hadfield MG, Schug MD, Wendt DE (2003) Characterization of six polymorphic microsatellites for the polychaete tubeworm Hydroides elegans and cross-species amplification in the congener Hydroides hexagonus. Molecular Ecology Notes, 3, 369-371.

Purcell JFH, Cowen RK, Hughes CR, Williams DA (2006) Weak genetic structure indicates strong dispersal limits: a tale of two coral reef fish. Proceedings of the Royal Society of London B, 273, 1483-1490.

Selkoe KA, Toonen RJ (2006) Microsatellites for ecologists: a practical guide to using and evaluating microsatellite markers. Ecology Letters, 9, 615-629.

Shank TM, Halanych KM (2007) Towards a mechanistic understanding of larval dispersal: insights from genomic fingerprinting of the deep-sea hydrothermal vent tubeworm Riftia pachyptila. Marine Ecology, 28, 25-35. 
Sotka E, Cushman E, Jue NK (2008) The relative importance of larval and adult dispersal in the economically-important gag grouper Mycteroperca microlepis: a genetic approach. Ocean Science Meeting, Orlando, Florida.

Thiébaut E, Huther X, Shillito B, Jollivet D, Gaill F (2002) Spatial and temporal variations of recruitment in the tube worm Riftia pachyptila on the East Pacific Rise $\left(9^{\circ} 50^{\prime} \mathrm{N}\right.$ and $\left.13^{\circ} \mathrm{N}\right)$. Marine Ecology Progress Series, 234, 147-157.

Voight J, Zierenberg R, McClain J, and the Science Party (2004) FIELD cruise to the northern EPR: discoveries made during biological investigations from $8^{\circ} 37^{\prime} \mathrm{N}$ to $12^{\circ} 48^{\prime}$ N. In: Ridge 2000 Events.

Watts RJ, Johnson MS, Black R (1990) Effects of recruitment on genetic patchiness in the urchin Echinometra mathaei in Western Australia. Marine Biology, 105, 145151.

Weinmayr G, Vautrin D, Solignac M (2000) Isolation and characterization of highly polymorphic microsatellites from the polychaete Pectinaria koreni. Marine Biotechnology, 2, 92-99. 


\section{Appendix A}

\section{Microsatellite development in Bathymodiolus thermophilus and Branchipolynoe symmytilida}

\section{A.1 Overview}

This thesis originally sought to develop DNA microsatellite markers for three hydrothermal vent species, each with a different life history strategy, in order to test the influence of different larval dispersal potentials upon a species' realized dispersal and population genetic structure. If a dispersive propagule is in the water column longer, then it is expected to be able to disperse further than a propagule with a shorter dispersive stage. It is also expected that spatial genetic structure can reveal the extent of realized dispersal and population connectivity/gene flow. With this comes the assumption that microsatellites provide higher resolution into population genetic structure as compared to previous markers and that this structure will accurately reflect realized dispersal. If cohorts arriving to existing populations are genetically similar through space, then the network of vent sites are interconnected in one large effective population. Furthermore, if genetic variation between local populations is less than that between distant populations, then regional populations are likely to be genetically isolated and local populations are on their way to increased genetic differentiation (Van de Zande et al. 2000).

\section{A.2 Targeted species: distribution and life history strategy}

In addition to the siboglinid tubeworm Riftia pachyptila, which formed the bulk of this thesis research, preliminary microsatellite research was initiated in two other abundant hydrothermal vent species - the mytilid Bathymodiolus thermophilus and its commensal 
polynoid polychaete Branchipolynoe symmytilida. These three species exhibit different life history strategies, proposed to affect their range and population structure (Craddock et al. 1997). However, larval collection, larval lifespan, hydrography, and respiration investigations over the past few decades have led to predictions of dispersal capabilities inconsistent with global and regional distribution patterns and inferred levels of gene flow using traditional population genetic markers. Through the use of highly polymorphic DNA microsatellite markers to reveal fine-scale genetic patterns, insights into these disagreements and underlying processes determining their distribution were sought to be gained. Specifically, my research objectives were:

1) To develop and apply DNA microsatellites to a high-resolution investigation of genetic spatiotemporal variability in mussel-tubeworm assemblages in order to correlate genetic structure with colonization and habitat turnover, infer past processes, and predict future state;

2) To apply DNA microsatellites to explain discrepancies in ridge-scale population genetic structure and dispersal potential inferred from larval mode and current dynamics, and to correlate a variety of known/inferred life-history strategies and estimates of gene flow to understand how populations are sustained in an environment prone to multiple scales of disturbance;

3) To gain insights into the existence of vent fauna exhibiting metapopulation dynamics in order to predict the importance of colonization and habitat ephemerality to species maintenance/persistence.

Bathymodiolus thermophilus and Riftia (a monospecific genus) are dominant macrofaunal members of hydrothermal vent communities in the Eastern Pacific from $27^{\circ} \mathrm{N}$ (Guaymas Basin) to $32^{\circ} \mathrm{S}$ along the East Pacific Rise (EPR), with additional populations along the Galápagos Rift (GAR). Branchipolynoe symmytilida is codistributed with its mussel host along the same range. In contrast to Riftia (discussed in Section 1.6), the mussel B. thermophilus has small oocytes (50 $\mu \mathrm{m})$ and planktotrophic larvae with high larval dispersal and long larval duration. Bathymodiolus thermophilus 
spawns asynchronously as does B. symmytilda and has high fecundity as found in Riftia. Juvenile-biased size distribution of mussel colonists on the GAR is suggestive of continuous recruitment (Van Dover 1988), but age cohorts of its congeneric mussel in the shallow MAR predict sporadic microhabitat-based reproduction (Christiansen 2000). Bathymodiolus thermophilus tends to be a late arriver to a developing vent community, often colonizing after conditions have begun to decline for the tubeworm assemblage (e.g., increased diffuse flow, higher sulfide concentrations, lower temperatures).

In general, the genus Bathymodiolus is one of the most widespread vent or seep genera (Tyler \& Young 2003). Migration rates are high in this mussel, as predicted from their rselected life history strategy, while the extent of genetic connectivity has been shown in different studies (and ocean basins, see allozyme data from Jollivet et al. 1998) to vary and follows an island model of gene flow (Craddock et al. 1995, Tyler \& Young 2003). Vent mussel larvae have been proposed to experience mixed sources prior to settlement, and may have a longer average dispersal time than Riftia (Van Dover et al. 2002). Yet, Mullineaux and colleagues (1998) suggest adult distributions of $B$. thermophilus are controlled by post-settlement processes, as indicated from abundant colonization of settlement blocks placed in warm diffuse flow. Thus, there is no real consensus on what drives the population genetic structure of vent mussels.

The genus Branchipolynoe is known in some species (e.g., B. seepensis) to have lecithotrophic larvae arisen from asynchronous gametogenesis and large, yolky oocytes $(500 \mu \mathrm{m})$. Males and juveniles in this scaleworm tend to be more mobile than females, moving frequently between their mussel hosts (Jollivet et al. 2000). Their colonization of a vent field is though to be tertiary, with the arrival of mussels themselves, as $B$. symmytilida has been found to infest the mantle cavity of even the smallest recovered mussel size classes (Britayev et al. 2003) and has a species range from $13^{\circ} \mathrm{N}$ to $32^{\circ} \mathrm{S}$ on the East Pacific Rise (EPR) and along the Galápagos Rift (GAR) coinciding with that of its host. Host infectivity can be up to $95 \%$ of a mussel population (Christiansen 2000). 
While IBD gene flow is high on the EPR for B. symmytilida as indicated by high mitochondrial DNA (mtDNA) haplotype diversity, gene flow appears low across longer distances, such as between the EPR and GAR (Hurtado et al. 2004). Likewise, the migration rate has been found to be quite variable on different spacial scales (Hurtado et al. 2004). Comparatively, worldwide phylogenies based on the ribosomal DNA (rDNA) second interspacing transcribed subunit (ITS2) revealed generic level divergence to be occur more rapidly in the commensal worm than in its mussel host, yet speciation events do not seem to be as common in Branchipolynoe, perhaps owing to low, episodic levels of propagule exchange (Jollivet et al. 1998).

\section{A.3 Predicted influence of life history strategies on population genetic patterns}

Life history strategies at deep-sea hydrothermal vents are diverse and often inconsistent with global and regional distribution patterns (Chevaldonné et al. 1997). Along the northern and southern EPR, Riftia and B. symmytilida persist in a system of genetic population structure contrary to the limited dispersal expected from their respective life history strategies. Bathymodiolus thermophilus possesses a greater potential for dispersal, yet realizes a distribution similar to these other two vent species. These species' population genetic structures may be influenced by potential barriers to dispersal in the Pacific_-including genetic barriers around the Easter Microplate, between the EPR and GAR, around the Equator, and on either side of the Rivera Fracture Zone - that seem to act differently on each species (Hurtado et al. 2004). Specifically, it was found that:

1) Riftia populations were genetically subdivided across the Easter Microplate, while B. symmytilida population were not;

2) Branchipolynoe symmytilida was fixed with respect to its genetic lineages, while $B$. thermophilus was not;

3) Gene flow in Riftia and B. thermophilus was not restricted across the Equator; and 
4) The Rivera Fracture Zone at $18^{\circ} \mathrm{N}$ on the EPR forms the northern limit to $B$. symmytilida and B. thermophilus, while Riftia's range extends to $27^{\circ} \mathrm{N}$ in the Guaymas Basin.

Variations in the life history strategies exhibited by these organisms also raise questions about their resulting population genetic patterns. Riftia conforms in some studies to a model of steady genetic change between neighboring populations (stepping stone), while the $B$. thermophilus appears to be dispersed by contributing to and sampling from a large, effectively single larval pool (island model) (Tyler \& Young 2003). When observed using fine-scale genetic techniques, these patterns should be able to be viewed in higher resolution than previous studies. It is predicted at deep-sea hydrothermal vents based on differing life histories that Riftia populations are genetically more isolated from one another in space than mussel Bathymodiolus populations, and commensal scaleworm Branchipolynoe populations are genetically connected at a level lower than their host mussels.

Temporal genetic patterns of different species may vary as a result of their larval dispersal strategies. It is expected based on models by Kallismanis and colleagues (2005) that if disturbance (e.g., water chemistry/temperature change) is localized, then larvae retained within aggregated habitats are at a lower risk of extinction than if the disturbance was more pervasive (e.g., eruption, paving of site, fissure network). Therefore, it is predicted that under small environmental changes, genetic diversity is maintained better in Riftia and Branchipolynoe than in mussels, while after a more pervasive seafloor eruption, Bathymodiolus populations retain more genetic diversity than polychaete populations. Moreover, Whitlock and McCauley (1990) purport that when local populations exist on a time scale not allowing gene frequencies to come to equilibrium, their composition instead reflects population history (e.g., founding events, progress 
Table A.1 Summary of microsatellite development and testing status for Branchipolynoe symmytilida and Bathymodiolus thermophilus.

\begin{tabular}{|r|c|c|}
\cline { 2 - 3 } \multicolumn{1}{c|}{} & B. symmytilida & B. thermophlius* \\
\hline Targeted & 11 & 15 \\
Polymorphic/Labeled & 4 & 5 \\
With promise & - & - \\
In need of troubleshooting & - & 1 \\
Unlabeled to test & - & - \\
Abandoned & 5 & 4 \\
Min & 2 & 2 \\
Max & 19 & 15 \\
Median & 3,11 & 4 \\
\hline Number of alleles (polymorphic): & & $11-40$ \\
Genotyped & $28-77$ & $5-8$ \\
For sites & $7-9$ & $9 \mathrm{~N}-21^{\circ} \mathrm{S} ; 89-86^{\circ} \mathrm{W}$ \\
For regions & $9 \mathrm{~N}-21^{\circ} \mathrm{S} ; 86^{\circ} \mathrm{W}$ & 1998 to 2004 \\
For times & 1998 to 2005 & $>35$ \\
\hline Number of individuals: & $>17$ & \\
\hline
\end{tabular}

towards equilibrium, termination by extinction). It is thus expected that vent species at fast-spreading ridges are adapted for vent transience and habitat instability. This assumes that fast-spreading ridges have higher rates of habitat turnover and thus more open space relative to occupied habitat than more slowly spreading ridges. It is predicted that Riftia, which occurs along fast- and medium-spreading ridges, will have increased genetic diversity as compared to Branchipolynoe and Bathymodiolus, which have congeners at slow- and ultra-slow spreading ridges, as well as temporally-stable hydrocarbon seeps.

\section{A.4 Preliminary microsatellite development}

Tables A.1 and A.2 outline the progress made to date in development (as in Fusaro et al. 2008) and characterization of microsatellite loci in B. thermophilus and B. symmytilida. 


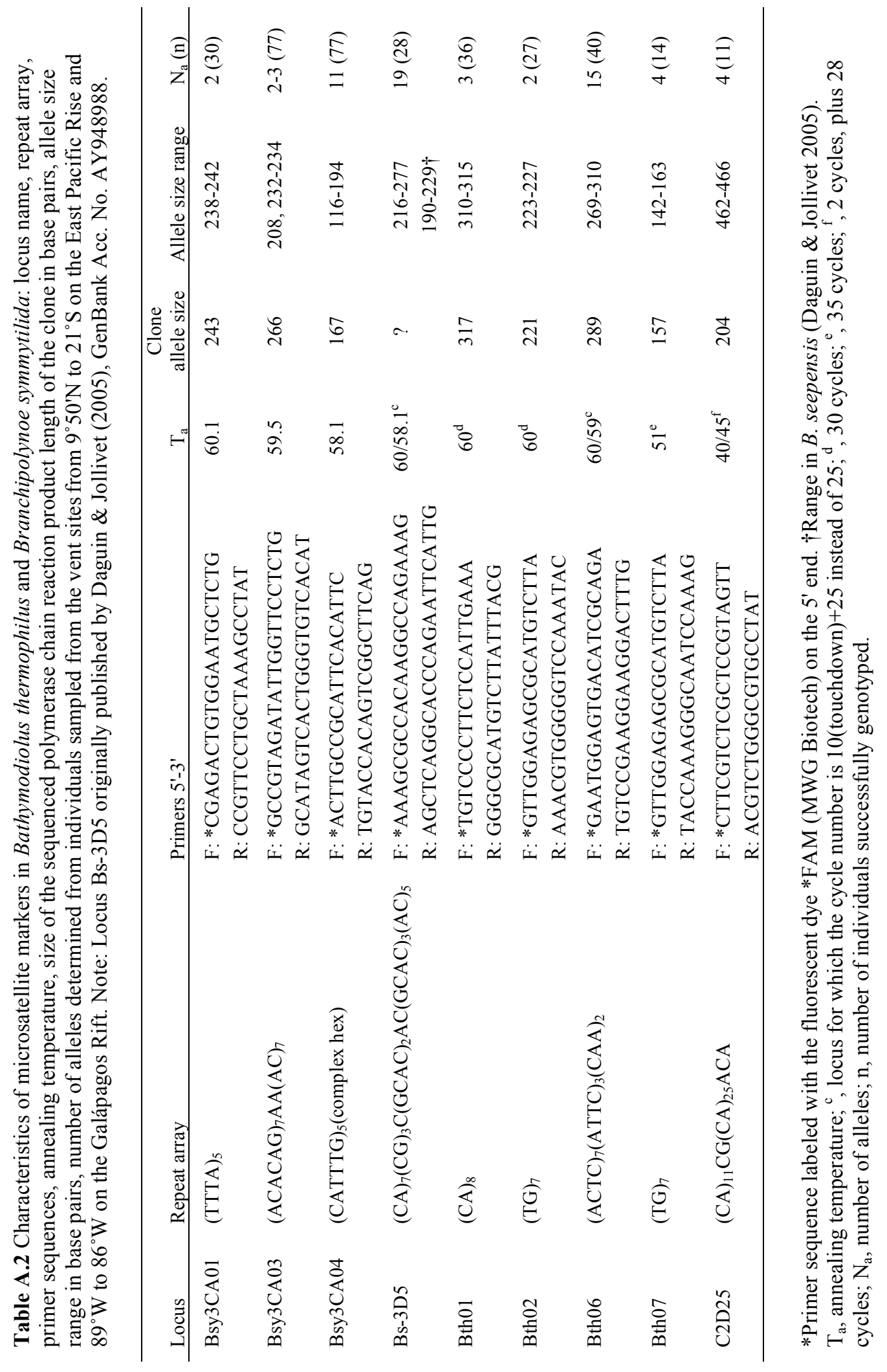




\section{A.5 Microsatellite Clone Sequence Data}

>Bsy3CA01 Clone Bsym3 CA-4-3

GATCGTGCTTTTAGTATTGCTGCCC<CGAGACTGTGGAATGCTCTG>CCAGGATATATT ACAGATTGTAAATATGTTGGTGCTTTTAAAAAAGGTCTTAAGACACATTTGTTTAAATC TGCTTTTAACTAGGTGACATTTATTTTCCTGTATATTTGTTTGTTATGTAAAGCGCCTG AGAACGGCTTGCTGGACAGGGCGCTATATAAATGC . TTTATTTATTTATTTATTTA . TT CCACAAATCTGACCCT<ATAGGCTTTAGCAGGAACGG>GTTCTATTAAATTGCCTCAGT ATTCCCTTCTATGTAGCAACAAATGCTTAATAATAATAAGTACATCAGTATCTAAGTCA GATATGCCAAATCAATTCTAGATAATTGCTATGGCTTTTAAAATGTGATGCTTCGTCAA ACTATGCAGCTTTAATGTTGCATAGCTGAATGGTTTTGAGTTTCTTTAAGTTTCTTTTG TAAATAAATATATTACGTTGATTGTTGTAATCGCTGCTACTTC

$>$ Bsy3CA03 Clone Bsym3 CA-5-5

GATCGGACGAGAACCGGTGATTTCAACGTGATATG<GCCGTAGATATTGGTTCCTCTG> TATAAGCTGCTCAGATAGTCGCCAGCAGAAATTCAGGTGGGAGATTTTATTTTTAATAT GAAAACCTTCAAGATTTATTGGTCGCTTACAATCTGTGGTGATTAGCCAGTT . ACACAG ACACAGACACAGACACAGACACAGACACAGACACAG . AA . ACACACACACACAC . AAAG AGTTCGGGGGGAACAACCGGAGAGACACTGACACAGTGACAGTCCCTAC <ATGTGACAC CCAGTGACTATGC>ATATGATGCATGCAGGAGGGGCGTAGAAACGGGTCATGCTGTGGC TTTTTTAGCCTCTCGTTAGTGTGCATGTAGCAATCTGCTAATTCATGACATGGTATTAG TCACCAACGCCGATGTTGGGTCAGTTTTCGACTTGAAAGTGTTGAAAATCGTCTAGCAT CTTCTGGGCTCGAGACACTCGTCCTGAGCGATAATGCAATTAAACAAGGAACATAGGCA ACGATTT

>Bsy3CA04 Clone Bsym3 CA-7-2

GATGCGGTACCCGGGAAGCTTGGGATGCGGTACCCGGGAAGCTTGGGATGCGGTACCCG GGAAGCTTGGGATGCGGTACCCGGGAAGCTTGGGATGCGGTACCCGGGAAGCTTGGGAT GCGGTACCCGGGAAGCTTGGATGCGGTACCCGGGGAGCTTGGGATGCGGTACCCGGGAA GCTTGGGATGCGGTACCCGGGAAGCTTGGGATGCGGTACCCGGGAAGCTTGGGATGCGG TACCCGGGAAGCTTGGGATGCGGTACCCGGGAAGCTTGGGATCC <ACTTGCCGCATTCA CATTC >ACA . TTTGCATTTGCATTTGCATTTGCATTTGCA . TTCACATTTGCATTCGCA TTTGCATTTGCATTCGCATTCACATTCGCATTCACATTCGCATTCGCGTAACTCATACA GCGTATATGGAATCTCAG<CTGAAGCCGACTGTGGTACA>CCCAGTCACGTGATTACAC TTCCGGTACGGTCTATGACGCGAATAAAGCCGGTGATATATGACTGTCTTTGTTCTGTA GGCGGCTACCTCGGCTTCCCGCACGGAGGCGGCACGGAGACTGACAGCTCCATG

$>$ Bth01 Clone M31 ALL A12

CCAGAAAAGAATTATAAGGATCTAAATTGATCCTCTCTAAATGCATGCTCGAGGCGGGC GCCAGTGTGATGGATATCTGCAGCAATTCTGCCCTTGAGGTACCCGGGAAGCTTGGGAT CTATAATGATAAA <TGTCCCCTTCTCCATTGAAA > TTAGTAGTCACTGTGTTGAAATGA AATAACATTATGCTGGTATGTCAAACAACGCTGGCAAGATTATTATGTTTGGTTGAAAA 
CGTGGGGGTCCAAATACAACTTGGGAAAACAGTCAGTCTTCTATAACTAAACGTTAGAG AATACCAAAGGGCAACCCAAAAATGACAATCTAGAGAAGCTGACAACTTGGGGTACACA AGACGAAACAAAACAAAGCAAAAACACAACACAATGTATGTTCGATACCACTATG . CAC ACACACACACACA . GTTAA <CGTAAATAAGACATGCGCCC >TCCAACAAACAACTGATA AAACAGGAACCAAACATAGGCTCTCTGAGATTGATGTAAACATTACAAATGGTGTGGTT TTCTTTACACATCACGAACAATATTACATCGAAATACATGTGCAAATCTAACCTTTGCA GTATTCATGGCTTACACAATATCAATTCATATTATAACAACATAAGCTTTGTGAATTTC CAATATGTCTTTGTTTAAATTTCGTCCTTATTGATGACTATGCCTTTGTTTACCTGTTT TTAATGATCCCAAGCTT

>Bth02 Clone M31 CA C36 .

TGTTT< <TTGGAGAGCGCATGTCTTA>TTTACGTTAAT . TGTGTGTGTGTGTG . CATAG TGGTGTCCTGCATACATTGTGTTGTGTTTTTGCTTTGCTTTATCTCGTATTGTGTATCC TAAGTGTCAGGTTCTCTAAATTGTCATTTTTGGATTGCCCTTTGGTATTCTCTAACGTT TAGTTATAGAAGACTGACTTTTTTCCCAAATT<GTATTTGGACCCCCACGTTT>TCAGC CAAACATAA

$\ldots$

>Bth06 Clone M31 CA D5

$\ldots$

<GAATGGAGTGACATCGCAGA>CTGTTGTTTTCAGTGAGCAAGCACTATAAAAATCCAA CTAAGCCTGTTGGTCTAGTACAAAGAGGACACCAGCATTATCTCATTGACAATTAAATT GTTCTTGCCATAATATAGCTAAAATTTGATGAGTTGGTGTTAAACAACAATCACTCAAT TACTCAATT . ACTCACTCACTCACTCACTCACTCACTCATTCATTCATT . CAACAATGA TATCGATATGAACAGAACGAGCAAACACCTTGGAAAT<CAAAGTCCTTCCTTCGGACA> AGCACATTAAT

. .

>Bth07 Clone M31 CA F21

...

CATAGCCTATGTTTGGTTCCTGTTTTATCAGTTGTTT<GTTGGAGAGCGCATGTCTTA> TTTACGTTAAT . TGTGTGTGTGTGTG . CATAGTGGTGTCCAACATACATTGTGTTGTGT TTTTGCTTTGTTTTATTTCATCTTGTGTACCCTAAGTTGTCAGCTTCTCTAGATTGTCA T<CTTTGGATTGCCCTTTGGTA>TTCTCTAACGTTTAGTTATAGAAGACTGACGTTTTT CCCAAATTGT

$\ldots$

$>\mathrm{C} 2 \mathrm{D} 25$ Clone $\mathrm{C} 2 \mathrm{D} 25$

TACTCCAATCATACAGCATTGCAATTGACTTNTTTCGAAAATAATGTTGTT <CTTCGTC TCGCTCCGTAGTT >CACACAACGTGGCGAGGAAATATAAACAGTCACAGTCACACTACT GCACACATTACAGGTCAGCGGTTACACCAAAACGTTAACCC . ACACACACACACACACA CACACGCACACACACACACACACACACACACACACACACACACACACACACACAC . AAC AGACG $<$ ATAGGCACGCCCAGACGT>GCATGTATCTACTGCGTTAATGCCTACTGT 


\section{A.6 References}

Britayev TA, Krylova EM, Martin D, von Cosel R, Aksiuk TS (2003) Symbiont-host interraction in the association of the scaleworm Branchipolynoe aff. seepensis (Polychaeta: Polynoidae) with the hydrothermal vent mussel, Bathymodiolus spp. (Bivalvia: Mytilidae). InterRidge News, 12, 13-16.

Christiansen S (2000) Lucky Strike: a potential MPA. WWF North-East Atlantic Programme briefing.

Chevaldonné P, Jollivet D, Vangriesheim A, Debruyères D (1997) Hydrothermal-vent alvinellid polychaete dispersal in the eastern Pacific. 1. Influence of vent site distribution, bottom currents, and biological patterns. Limnology and Oceanography, 42, 67-80.

Craddock C, Hoeh WR, Lutz RA, Vrijenhoek RC (1995) Extensive gene flow among mytilid (Bathymodiolus thermophilus) populations from hydrothermal vents of the Eastern Pacific. Marine Biology, 124, 137-146.

Craddock C, Lutz RA, Vrijenhoek RC (1997) Patterns of dispersal and larval development of archaeogastropod limpets at hydrothermal vents in the eastern Pacific. Journal of Experimental Marine Biology and Evolution, 210, 37-51.

Daguin C, Jollivet D (2005) Development and cross-amplification of nine polymorphic microsatellite markers in the deep-sea hydrothermal vent polychaete Branchipolynoe seepensis. Molecular Ecology Notes, 5, 780-783.

Fusaro AJ, Baco AR, Gerlach G, Shank TM (2008) Development and characterization of 12 microsatellite markers from the deep-sea hydrothermal vent siboglinid Riftia pachyptila. Molecular Ecology Resources, 8, 132-134.

Hurtado LA, Lutz RA, Vrijenhoek RC (2004) Distinct patterns of genetic differentiation among annelids of eastern Pacific hydrothermal vents. Molecular Ecology, 13, 26032615.

Jollivet D, Empis A, Baker MC, et al. (2000) Reproductive biology, sexual dimorphism, and population structure of the deep sea hydrothermal vent scale-worm, Branchipolynoe seepensis (Polychaeta: Polynoidae). Journal of the Marine Biological Association of the UK, 80, 55-68.

Jollivet D, Comtet T, Chevaldonné P, Hourdez S, Desbruyères D, Dixon DR (1998) Unexpected relationship between dispersal strategies and speciation with the association Bathymodiolus (Bivalvia) - Branchipolynoe (Polychaeta) inferred from the rDNA neutral ITS2 marker. Cahiers de Biologie Marine, 39, 359-362.

Kallimanis AS, Kunin WE, Halley JM, Sgardelis SP (2005) Metapopulation extinction risk under spatially autocorrelated disturbance. Conservation Biology, 19, 534-546. 
Mullineaux LS, Mills SW, Goldman E (1998) Recruitment variation during a pilot colonization study of hydrothermal vents ( $9^{\circ} 50^{\prime} \mathrm{N}$, East Pacific Rise). Deep-Sea Research II, 45, 441-464.

Tyler PA, Young CM (2003) Dispersal at hydrothermal vents: a summary of recent progress. Hydrobiologia, 503, 9-19.

Van de Zande L, Van Apeldoorn RC, Blijdenstein AF, De Jong D, Van Delden W, Bijlsma R (2000) Microsatellite analysis of population structure and genetic differentiation within and between populations of the root vole Microtus oeconomus in The Netherlands. Molecular Ecology, 9, 1651-1656.

Van Dover CL, Berg C, Turner RD (1988) Recruitment at deep-sea hydrothermal vents. Eos, 69.

Van Dover CL, German CR, Speer KG, Parson LM, Vrijenhoek RC (2002) Evolution and biogeography of deep-sea vent and seep invertebrates. Science, 295, 1253-1257.

Whitlock MC, McCauley DE (1990) Some population genetic consequences of colony formation and extinction: genetic correlations within founding groups. Evolution, 44, 1717-1724. 
Appendix B

Microsatellite locus profiles 


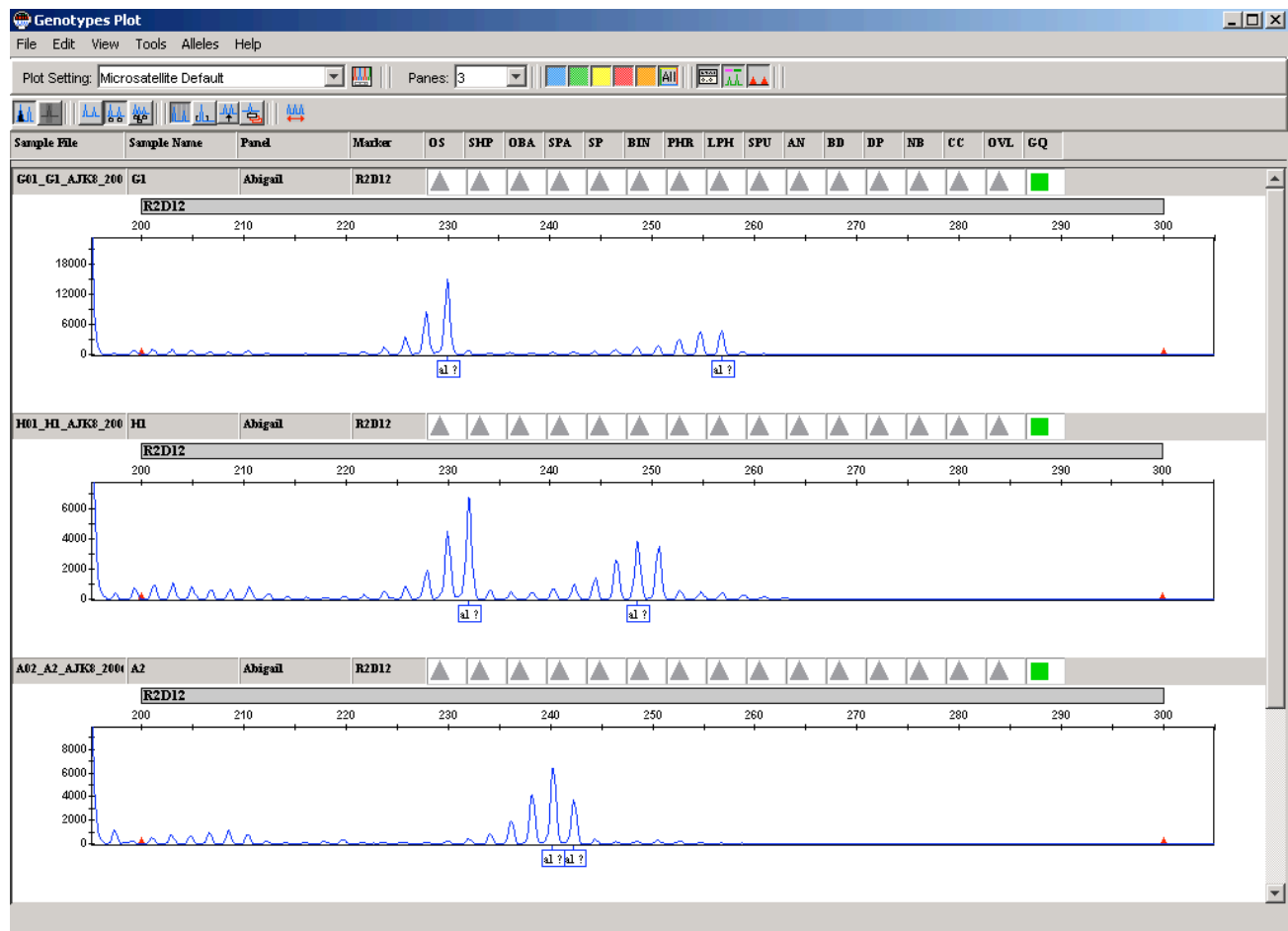

Figure B.1 Microsatellite electropherogram profile for locus R2D12.

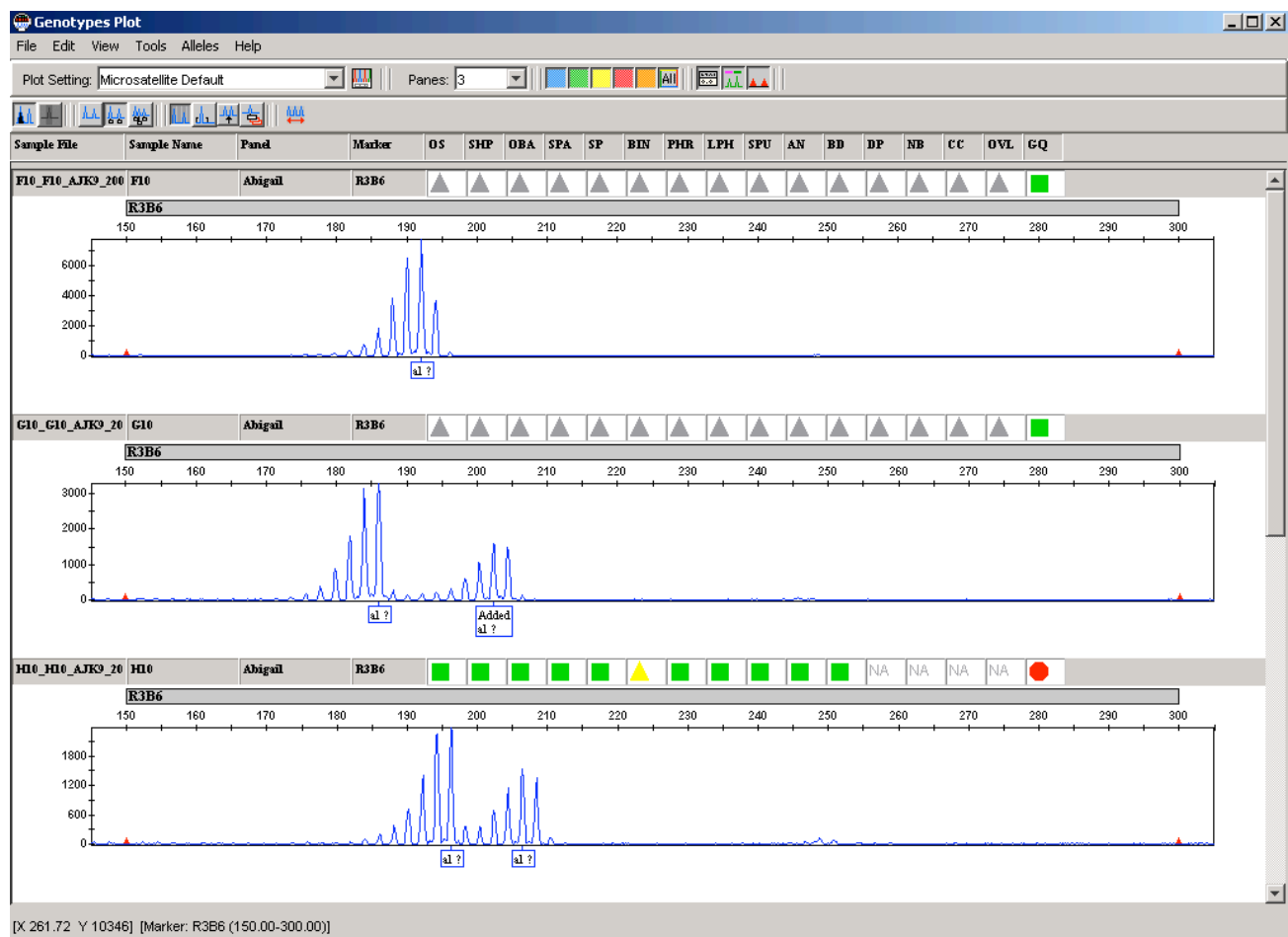

Figure B.2 Microsatellite electropherogram profile for locus R3B6. 


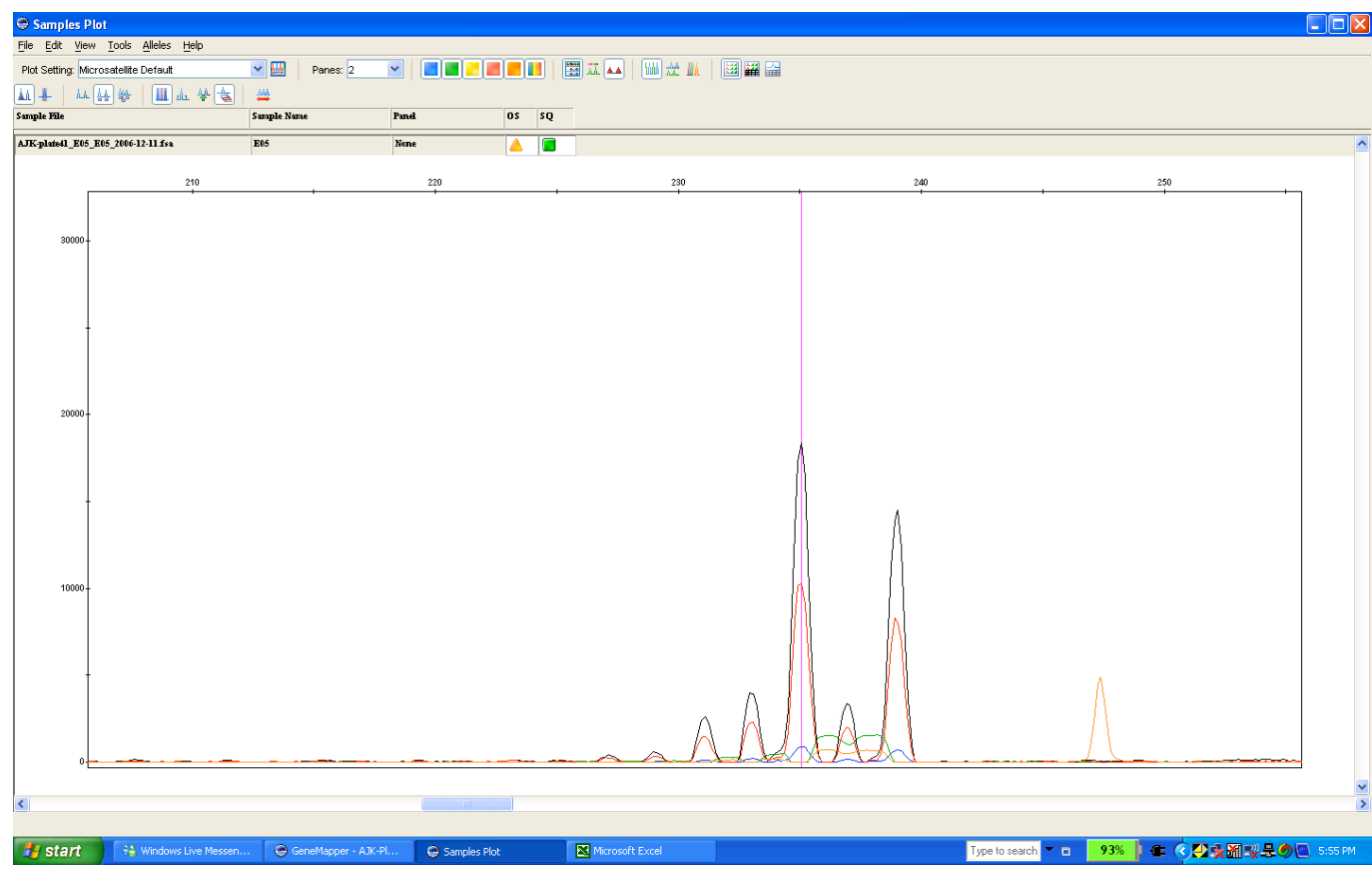

Figure B.3 Microsatellite electropherogram profile for locus R3D3.

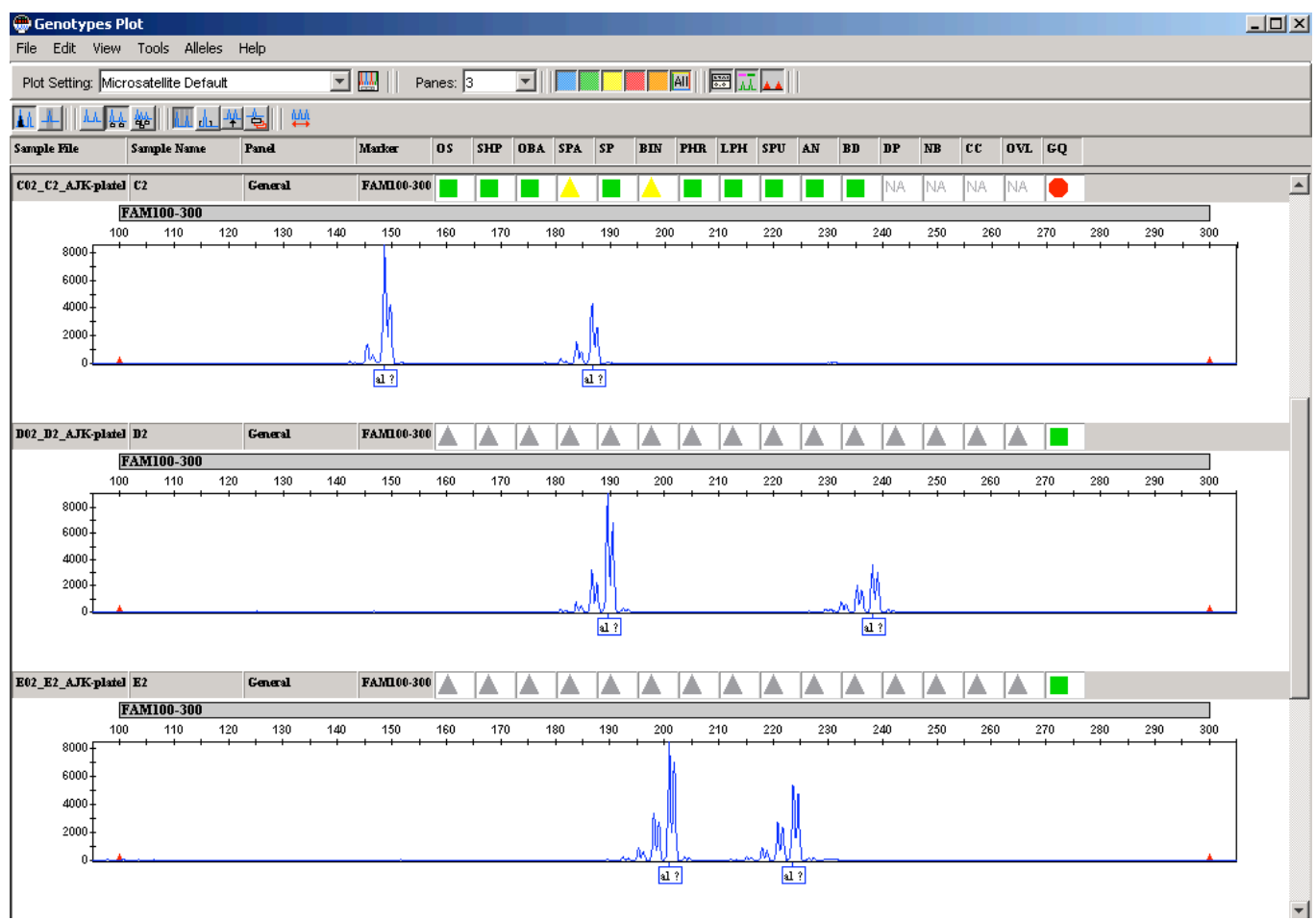

Figure B.4 Microsatellite electropherogram profile for locus Rpa10CA02. 


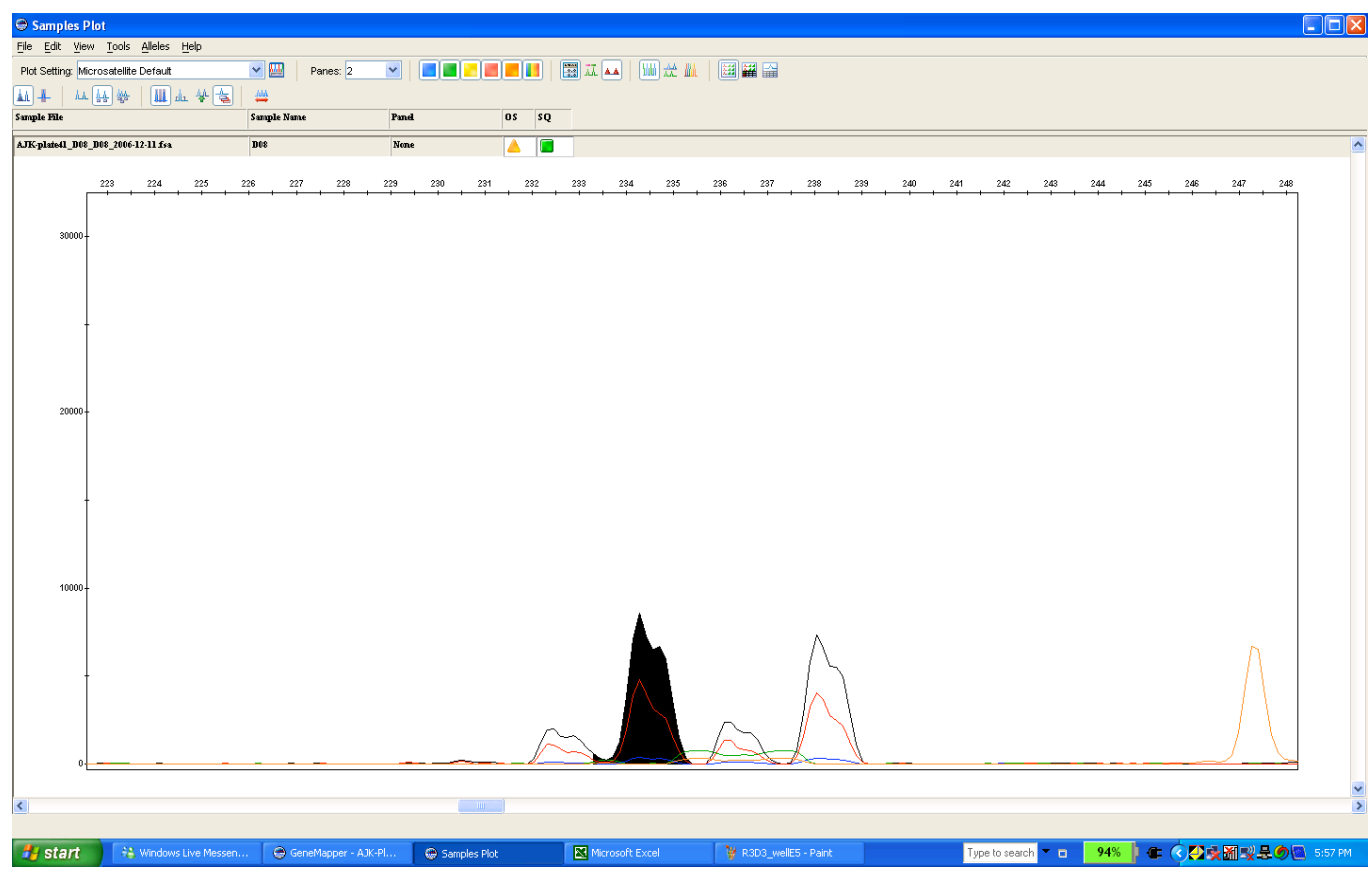

Figure B.5 Microsatellite electropherogram profile for locus Rpa10CA06.

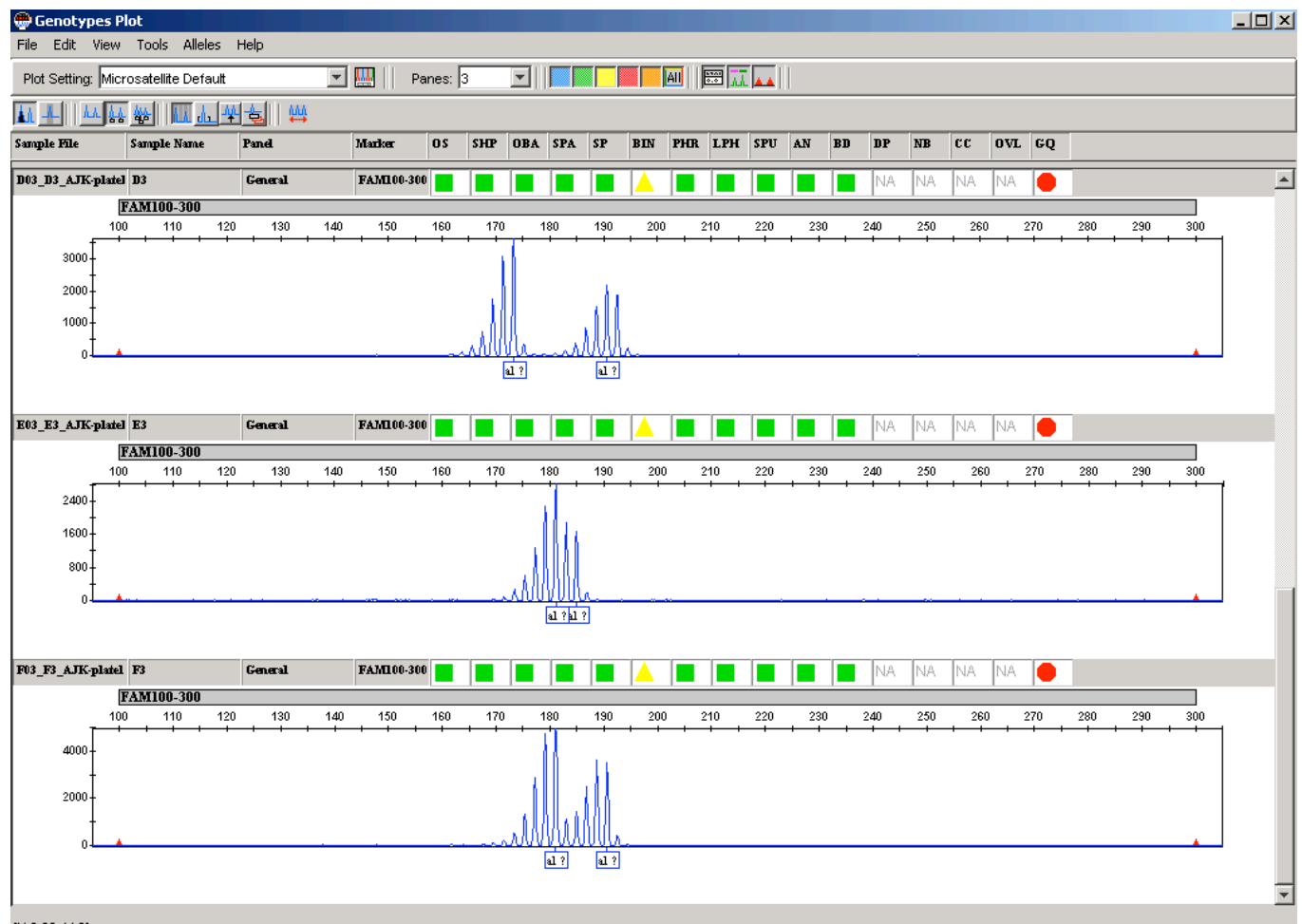

Figure B.6 Microsatellite electropherogram profile for locus Rpa10CA07. 


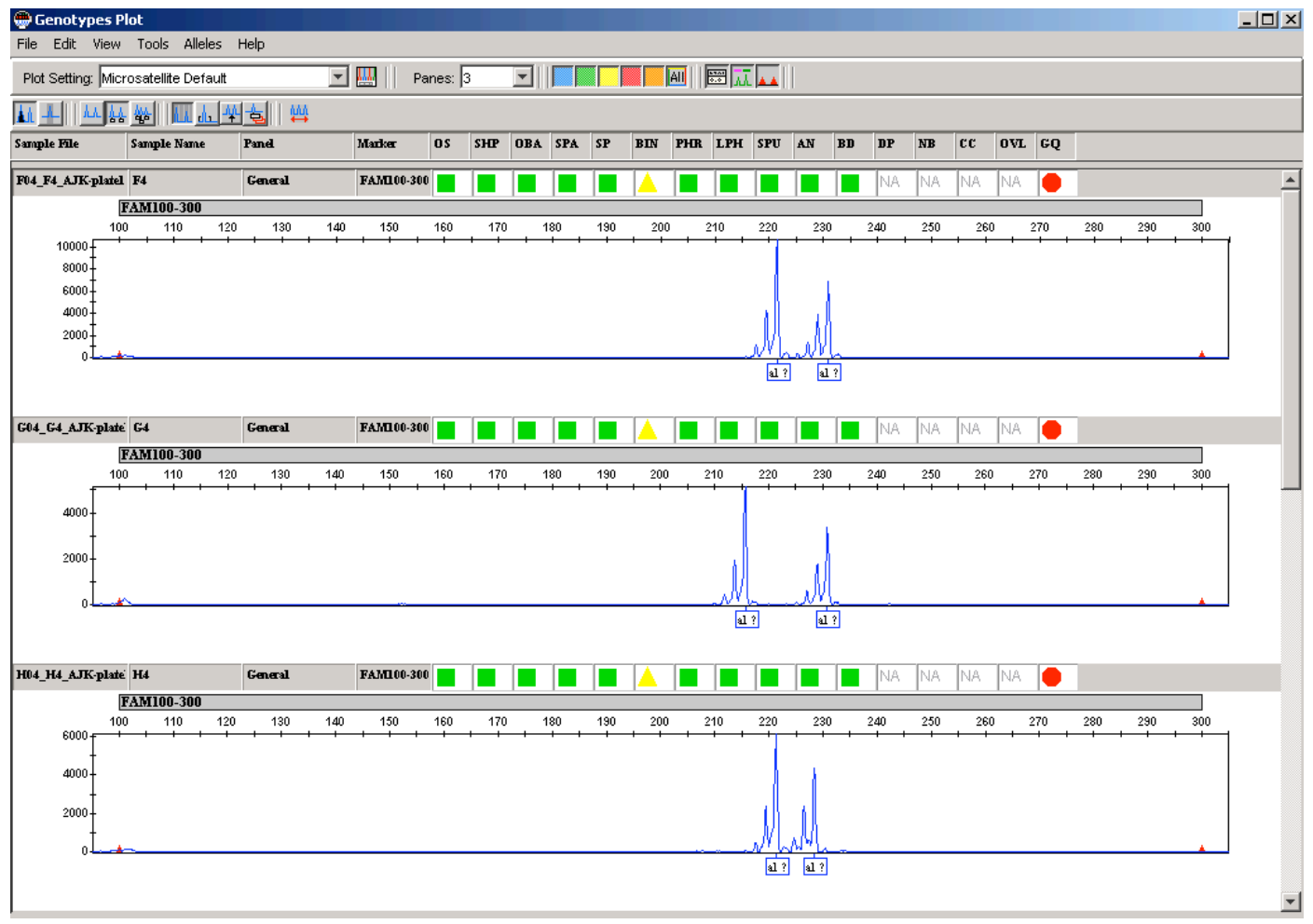

Figure B.7 Microsatellite electropherogram profile for locus Rpa10All01.

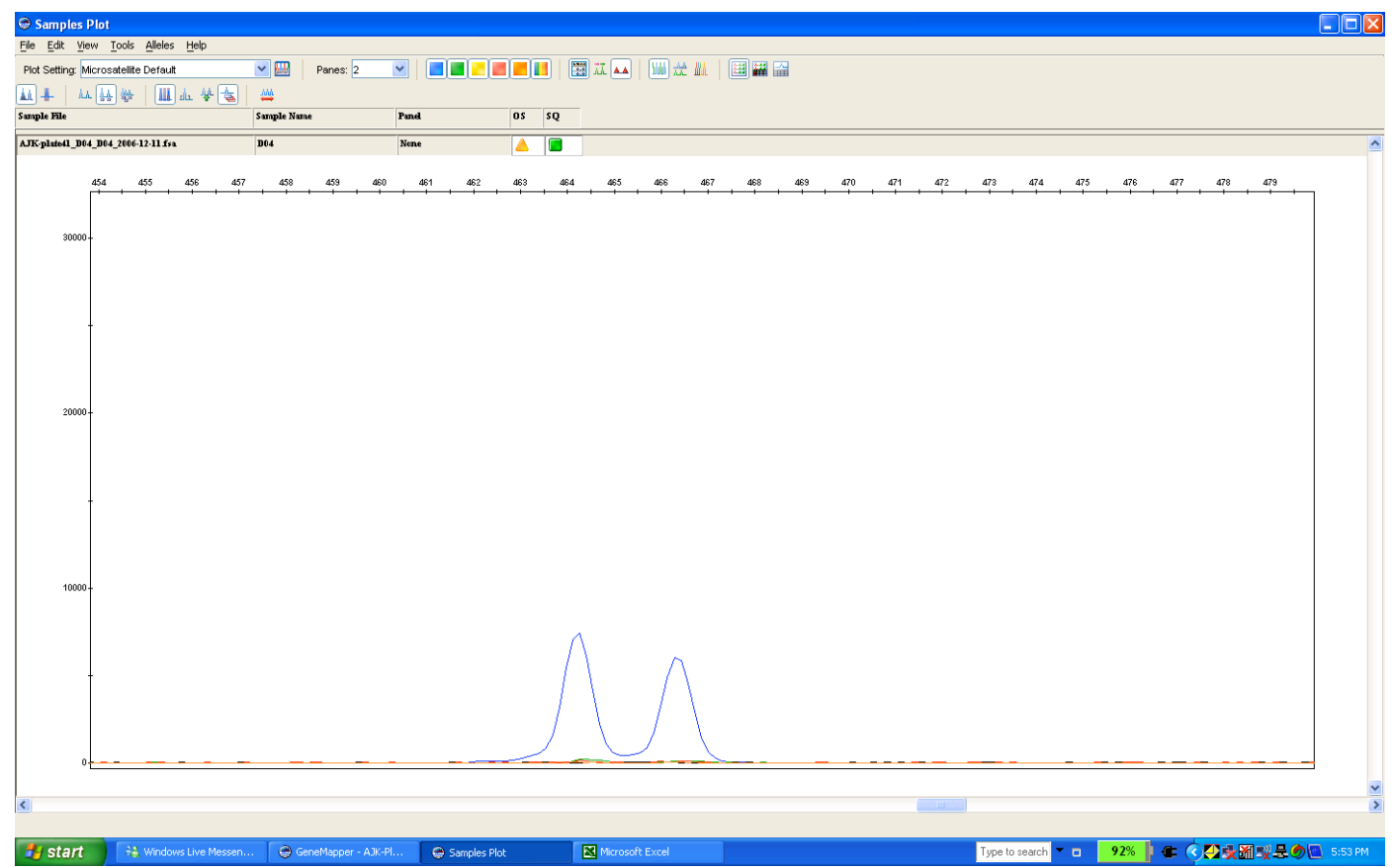

Figure B.8 Microsatellite electropherogram profile for locus C2D25. 


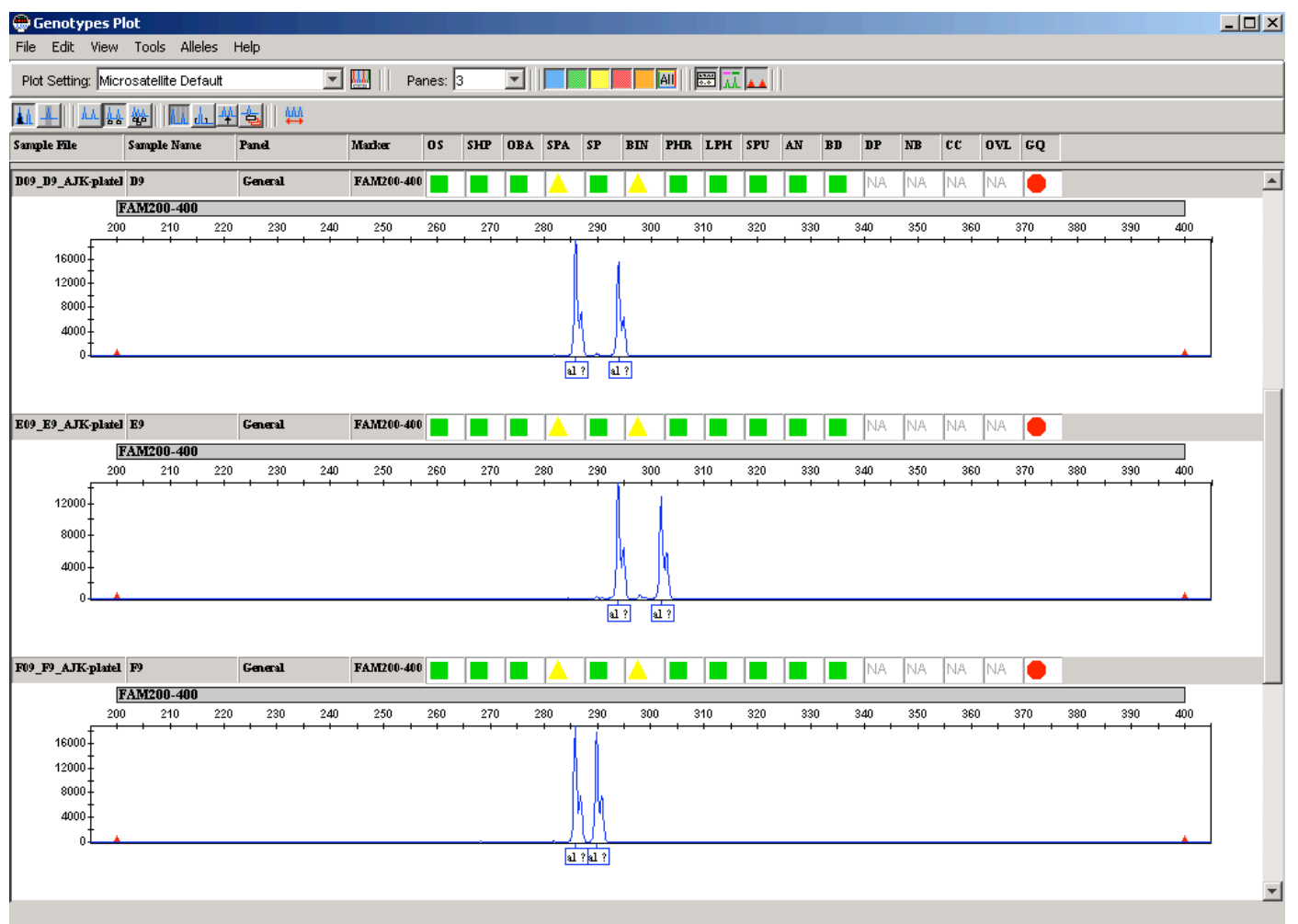

Figure B.9 Microsatellite electropherogram profile for locus Bth06.

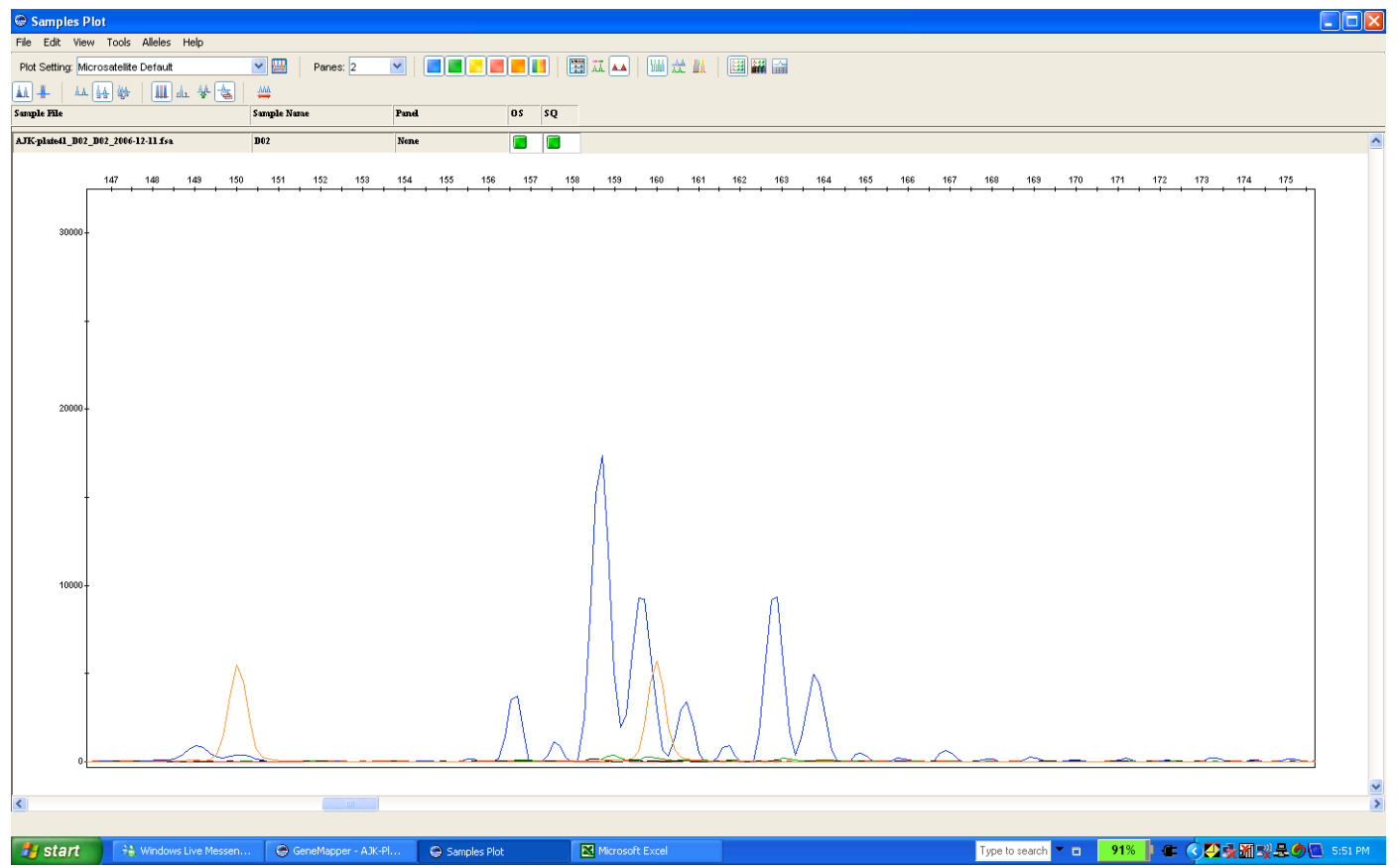

Figure B.10 Microsatellite electropherogram profile for locus Bth07. 